UNIVERSIDADE DE SÃO PAULO

FFCLRP - DEPARTAMENTO DE BIOLOGIA

PROGRAMA DE PÓS-GRADUAÇÃO EM BIOLOGIA COMPARADA

\title{
"Canais e poros do sistema látero-sensorial cefálico de Characiformes (Ostariophysi): anatomia e seu significado filogenético".
}

Murilo Nogueira de Lima Pastana

Dissertação apresentada à Faculdade de Filosofia, Ciências e Letras de Ribeirão Preto da USP, como parte das exigências para a obtenção do título de Mestre em Ciências, Área: BIOLOGIA COMPARADA

RIBEIRÃO PRETO -SP 

UNIVERSIDADE DE SÃO PAULO

FFCLRP - DEPARTAMENTO DE BIOLOGIA

PROGRAMA DE PÓS-GRADUAÇÃO EM BIOLOGIA COMPARADA

\section{"Canais e poros do sistema látero-sensorial cefálico de Characiformes (Ostariophysi): anatomia e seu significado filogenético".}

Murilo Nogueira de Lima Pastana

Orientador: Flávio Alicino Bockmann

Dissertação apresentada à Faculdade de Filosofia, Ciências e Letras de Ribeirão Preto da USP, como parte das exigências para a obtenção do título de Mestre em Ciências, Área: BIOLOGIA COMPARADA

RIBEIRÃO PRETO -SP 

Pastana, Murilo Nogueira de Lima

Canais e poros do sistema látero-sensorial cefálico de Characiformes (Ostariophysi): anatomia e seu significado filogenético. Ribeirão Preto, 2014.

192 p.; 28 il.; $30 \mathrm{~cm}$

Dissertação de Mestrado, apresentada à Faculdade de Filosofia, Ciências e Letras de Ribeirão Preto/USP. Departamento de Biologia.

Orientador: Bockmann, Flávio Alicino.

1. Ordem Characiformes. 2. Canais e poros. 3. Sistemática. 4. Otophysi 5. Anatomia. 



\section{Advertência.}

Este trabalho é apresentado como parte dos requerimentos para obtenção do título de Mestre em Biologia Comparada pela Faculdade de Filosofia, Ciências e Letras de Ribeirão Preto, e não é pretendido ser uma publicação científica. Os dados presentes neste volume, bem como os resultados aqui expressos, não estão disponíveis na literatura zoológica. Os leitores devem estar cientes de que referências públicas ao conteúdo deste estudo, na forma em que são expressos, somente devem ser feitas após aprovação prévia do autor. 



\section{Resumo}

O sistema látero-sensorial dos peixes é responsável, dentre outras funções, pela percepção de vibrações e de movimentos na água. A unidade funcional desse sistema é denominada neuromasto, o qual pode estar presente na superfície ou em ranhuras da pele, ou também em canais que percorrem ossos dérmicos, alcançando a superfície externa da pele por intermédio de poros. O padrão de ossificação dos canais sensoriais cefálicos é conservado em diversas linhagens de peixes de tal forma que esse complexo morfológico representa uma rica fonte de informações filogenéticas, sendo amplamente utilizado em análises cladísticas de vários grupos de Ostariophysi, como, por exemplo, em Siluriformes. No entanto, o sistema láterosensorial cefálico de Characiformes, uma das mais diversificadas ordens de teleósteos e também um membro de Ostariophysi, nunca havia sido descrito em detalhes, sendo suas implicações filogenéticas pouco investigadas. $O$ presente trabalho teve como objetivo realizar uma análise exploratória da homologia dos diversos elementos que compõem o sistema látero-sensorial em Characiformes, especificamente de: 1) levantar informações sobre os padrões de ramificação e de ossificação dos canais sensoriais cefálicos de todas as suas principais linhagens; 2) mapear as terminações destes ramos, os poros sensoriais, que se abrem na superfície da pele; e 3) identificar as principais implicações filogenéticas relacionadas a este sistema dentre os Characiformes e demais Ostariophysi. Para tal, foram analisados um total de trinta e seis táxons da ordem Characiformes, englobando representantes de todas as suas famílias e principais subfamílias. Além destes, outros treze componentes da ordem Ostariophysi, bem como sete demais Teleostei foram incluidos na análise como representantes do grupo-externo. Um dos principais resultados do presente estudo foi a constatação de que a disposição dos canais do sistema látero-sensorial cefálico, e o número de poros associados a cada um destes canais pouco variou dentre as diferentes famílias de Characiformes, mantendo-se também relativamente contantes nos demais Ostariophysi, e apresentando-se altamente informativas em um contexto filogenético. A complexidade morfológica desse sistema deixa implícito que o mesmo pode representar uma grande fonte de informações anatômicas combinando-os com demais caracteres morfológicos. Os resultados apresentados no presente trabalho indicam que os canais e poros da linha látero-sensorial cefálica constituem mais uma evidência de que novas fontes de caracteres morfológicos, apesar de não tradicionais, têm muito a contribuir com o entendimento das relações de parentesco entre peixes. 


\section{Abstract}

The laterosensory system of fishes is responsible, among other functions, for the perception of water movement and vibration. The functional unit of this system is the neuromast, which can be present on the skin surface or in grooves on it, or also in canals that are distributed along dermic bones, reaching the skin surface by pores. The ossification pattern related to the laterosensory canals is conserved among distinct fish lineages so that this morphological complex may represent a rich source of phylogenetic information. This system has been extensively used in cladistics analysis on several Ostariophysans, such as in Siluriformes and Cypriniformes. However, the laterosensory system of Characiformes, one of the most diverse order of teleost and also a member of the superorder Ostariophysi, has not been described in details yet, and its phylogenetic implications are poorly investigated. The present study aimed on performing an investigation on the laterosensory system components of Characiformes, having as its main goals: 1) a description of the cephalic laterosensory canals and branches for all main lineages of the order; 2 ) a characterization the canals ending points, i.e. the pores that open on the skin surface; and 3) a interpretation of the main philogenetical implications related to the laterosensory system among Characiformes and Ostariophysi. In order to accomplish these goals, a total of thirty-six Characiformes taxa were analysed, encompassing all families and main subfamilies of this order. Added to that, another thirteen representatives of other Ostariophysans, as well as seven taxa of other Teleostei were included to the comparative analysis as out-group material. As one of the main results of this survey is the acknowledgement that the distribution of the canals os the laterosensory system, as well as the number of branches and pores in association to this complex show little variation between the different lineages of Characiformes, keeping relatively stable among other Ostariophysi. This is interpreted as evidence that morphological traits in relation to this system may be very informative on a phylogenetical context when combined to other sources of characters. Therefore, these results indicate that features of the canals and pores of the laterosensory system may be one more source of anatomical characters, that even not traditionally used, are potentially informative on what regards the the relationship of fishes. 


\section{Agradecimentos.}

Expresso aqui meus sinceros agradecimentos a todos aqueles que, de uma maneira ou de outra, colaboraram com a conclusão deste trabalho.

Primeiramente deixo aqui registrado meu agradecimento e admiração ao Flávio Alicino Bockmann, não apenas pela orientação, mas também pela liberdade e confiança que depositou em mim ao longo dos anos de desenvolvimento desse projeto. O Flávio exerceu não só o papel de orientador acadêmico, mas também foi um grande amigo e conselheiro dos mais variados assuntos ao longo desses anos.

Ao professor Ricardo M. C. Castro, por um dia ter aberto as portas do seu laboratório, e consequentemente possibilitado meu ingresso na carreira acadêmica e ictiologia. Aos colegas do Laboratório de Ictiologia de Ribeirão Preto (LIRP), funcionários ou estudantes, Fernando Apone, Osmar Santos, William Ruiz, Thiago Pereira, Gustavo Vaz, Dahyes Félix, João Pedro Trevisan, Vanessa Roma, André Esguícero, Hertz Santos, D. Cláudia, Ana Carla Aquino e à recém-chegada Renata Stopiglia, todos estes que sempre tornaram o ambiente de trabalho um local bastante prazeroso. Dentre os colegas LIRPianos, reservo um agradecimento particular à Veronica Slobodian, hoje aluna do MZUSP, que me ajudou de inúmeras maneiras enquanto esteve na mesa ao lado da minha.

Pelo auxílio em processos de empréstimos ou durante visitas à coleção, sou bastante grato aos colegas do Museu de Zoologia da Universidade de São Paulo. Agradeço a ajuda do Michel Gianetti e Osvaldo Oyakawa pela curadoria e empréstimo de materiais utilizados no projeto. Durante minha estadia em São Paulo sempre estive na companhia agradável dos colegas William Ohara, Túlio Franco Teixeira, Priscilla Camelier, Manoela Marinho, Marina Loeb, Henrique Varella e llana Fichberg. Do time de ictiólogos do MZUSP dedico meus agradecimentos em especial ao Fernando Dagosta, grande amigo desde seus tempos de LIRP, sempre um grande entusiasta de empreitadas ictiológicas e/ou ornitológicas. Agradeço ao Fernando também por sempre ter-me hospedado em sua casa em período de visitas a São Paulo, e ainda por ter mantido este convite mesmo após eu levar suas chaves embora para Ribeirão Preto. Sou grato aos professores Mario de Pinna e Aléssio Datovo, também do MZUSP, por terem colaborarado com comentários pertinentes em relação à morfologia da linha lateral cefálica de diferentes grupos de peixes. O Mário também permitiu gentilmente a análise de exemplares de espécimes de Denticeps clupeoides e do táxon Erythrinoidea sp. nov., incluidos no presente estudo. Já o Aléssio sempre figurou como um importante incentivador 
de trabalhos morfológicos explorando diferentes complexos anatômicos, além ter sempre mostrado interesse em discutir comigo os resultados encontrados ao longo deste estudo.

Ao Laboratório de Estudos Subterrâneos da Universidade Federal de São Carlos, liderado pela professora Maria Elina Bichuette, que gentilmente cedeu espécimes de Stygichthys typhlops utilizados neste trabalho, e que também sempre se mostrou interessada nos resultados desta pesquisa. Também do time do $\mathrm{LESCI}$, agradeço ao Pedro Rizzato, amigo e grande entusiasta de aventuras ictiológicas, que acompanhou de perto o desenvolvimento desse trabalho e sempre discutiu comigo os resultados encontrados. Hoje oficialmente membro do LIRP e companheiro de república nossas discussões sobre peixes tem se tornado bem mais frequentes.

O tempo total dedicado à execução deste projeto de mestrado contou com uma experiência de estágio de dois meses no laboratório do professor Richard P. Vari, na divisão de peixes do National Museum of Natural History (Smithsonian Institution). Esta oportunidade só se concretizou devido à enorme disposição e hospitalidade do Richard, pessoa que colaborou em muito, tanto nos processos burocráticos, quanto em importantes comentários acerca das relações filogenéticas de Characiformes. Por este motivo sou bastante grato à sua pessoa. 0 ambiente de trabalho em Washington - DC foi bastante acolhedor também por causa da companhia de laboratório de David de Santana e de Casey Dillman. Ambos os colegas, além de tornarem meu período nos Estados Unidos uma experiência mais divertida, me ajudaram de maneira imensuravel ao longo desses dois meses. Pude apreciar também comentários e palavras de incentivo de Stanley e Marilyn Weitzman, David Johnson, Bruce Colette, Thomas Munroe, Lynne Parenti, Roy McDiarmid, Kevin De Queiroz em momentos de POETS e de pausa para cafezinhos. Destes, reservo um parêntese especial ao professor David Johnson, que gentilmente permitiu uso de seu equipamento de captura de imagens, ouviu e opinou sobre diversos problemas de homologia envolvendo canais sensoriais dos Ostariophysi. Expresso meus agradecimentos ao trabalho de curadoria de Jeff Clayton, Sandra Raredom, Kris Murphy, Diane Pitassy e Ai Nonaka. Agradeço ao Chad Walter pela hospedagem em DC. Agradeço a companhia de toda máfia latino-americana do NMNH, fiéis colegas de almoço, café, POETS, Karaokes e empanadas, que mesmo em períodos de contraturno do laboratório, apreciaram um bom papo de biólogo. Deixo aqui meu sincero "gracias" aos colegas Rodolpho Menezes, Daniela Yepes Gaurisas, Eliéces Gutierrez, Lucas Antonietto, Alejandro Zuluaga e Stella Rodrigues. Por fim, sou bastante grato ao grande incentivador desse meu estágio no exterior, Guilherme Dutra, colega que me auxiliou bastante com informações de hospedagem, logística e me apresentou para a máfia latino-americana. 
Agradeço ao professor John Lundberg por ter me recebido em seu laboratório na Academia de Ciências da Drexel University, na Filadélfia, e também ao auxílio de Mark Sabaj Perez ao acesso ao acervo biológico. Durante meu período na Filadélfia, agradeço também pela hospitalidade dos colegas Tiago Carvalho e Mariangeles Hernandez, que além de me receberem muito bem, foram meu guia turístico nos finais de semana naquela cidade.

Sou grato também a todos aqueles que, em algum momento, reservaram um minuto para me ouvir falar de canais e poros de peixes. Dentre eles estão Murilo de Carvalho, Aléssio Datovo, George Mattox, Cristiano Moreira, Guilherme Dutra e André Netto-Ferreira. Essas discussões, sempre que possíveis, foram feitas on-line, demonstrando uma real inclusão das redes sociais no ambiente acadêmico. Além destes citados acima, todos os integrantes do grupo online BBBritzkers também devem ser lembrados, pois sempre que puderam, me ajudaram a encontrar as referências citadas neste trabalho.

Agradeço à Vera, funcionária da pós-graduação, que me ajudou bastantes com seus lembretes e lembretes dos prazos e compromissos que surgiram ao longo desses dois anos. Agradeço também ao coordenador do programa e a todos os outros docentes, funcionários e pós-graduandos que ajudam a carregar o nome e manter a excelência do programa da Biologia Comparada da Faculdade de Filosofia, Ciências e Letras de Ribeirão Preto.

Aos meus grandes amigos de república Danilo Benette, Rafael Teixeira, Diego Sasso, Vitor Zanchetta, Paulo Ricardo, e mais recentemente ao novo integrante Pedro Rizzato. Agradeço pelas inúmeras experiências vivenciadas ao longo desse tempo. Esta fusão entre ictiólogos, entomólogos, educadores, paleontólogos, neurocientistas e médicos certamente resultou em muitas risadas e grandes ideias. Vou sempre levar estes bons momentos comigo.

Aos amigos da USP Ribeirão Preto, companheiros desta, ou de outra pós-graduação, que sempre tiveram paciência em ouvir, e por vezes a coragem de arriscar alguns palpites sobre os resultados desse projeto. Agradeço em especial aos amigos Pedro Lorena Godoy, Matheus Rossignoli, Danilo Ament, Thiago Loboda e Flávia Petean pelos momentos dedicados ao papo sobre peixes e também aqueles destinados à descontração.

Aos meus familiares, em especial aos meus pais Firmo e Eliana Pastana, por sempre ter me dado apoio e incentivo frente a todas as minhas decisões. Meu irmão Marcelo também sempre companheiro de aventuras em busca de peixes, em praias, várzeas, riachos e costões, por vezes ouvindo pacientemente "histórias de ictiólogo". Aos meus avós, maternos e paternos, que também transmitiram um pouco desse fascínio por peixes, me levando a pescarias ou me encantando com contos de pescador desde minha infância. 
Agradeço especialmente ao meu grande amor, Paula Thaísa Galdini Carvalho. Sua ajuda na realização do presente trabalho é imensurável. Agradeço por toda a paciência e tolerância pelos (não raros) momentos em que estive ausente. Mantenho minhas palavras de anos atrás, reafirmando que você sempre esteve presente, apesar da distância. Porém, espero muito estar ao seu lado nessa próxima etapa que está por começar. Muito obrigado por ser esta pessoa incrível, sempre ao meu lado.

Este estudo foi financiado em seu início pela CAPES, bolsa de Demanda Social, e majoritariamente pela Fundação de Amparo à Pesquisa do Estado de São Paulo, com a bolsa regular de mestrado (\#2012/22685-2) e com a Bolsa Ensino e Pesquisa no Exterior (\#2013/26548-2). 


\section{Conteúdo.}

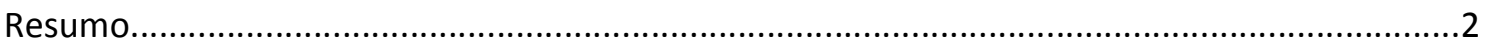

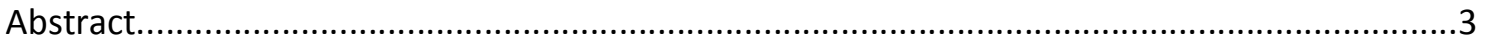

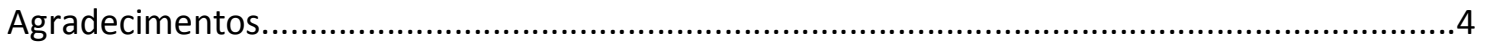

Índice de Figuras............................................................................................... 11

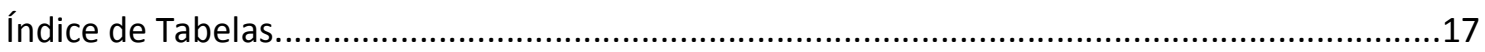

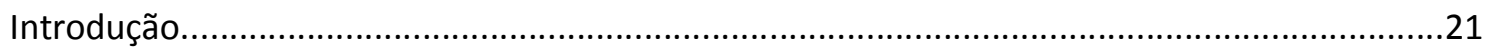

1. Considerações gerais sobre a linha lateral cefálica................................................21

2. Histórico dos estudos do sistema látero-sensorial cefálico em Ostariophysi.................27

3. Estudos do sistema látero-sensorial cefálico em Characiformes...................................30

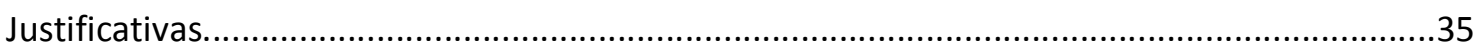

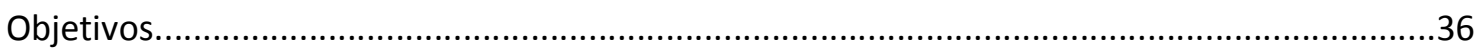

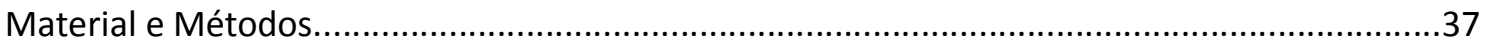

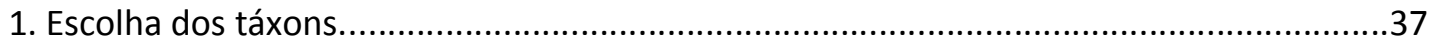

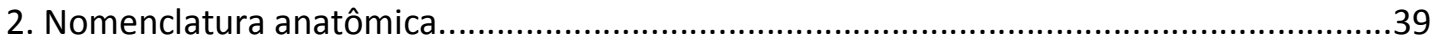

3. Preparação do material e confecção das imagens...................................................4 41

4. Acrônimos institucionais............................................................................42

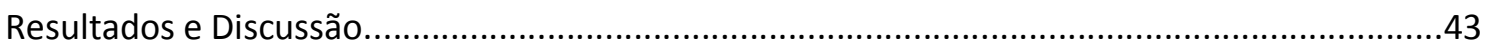

1. Canais látero- sensoriais cefálicos de Characiformes...........................................43

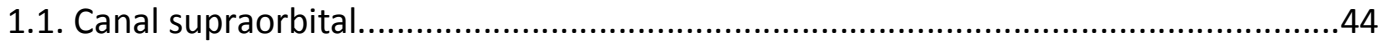

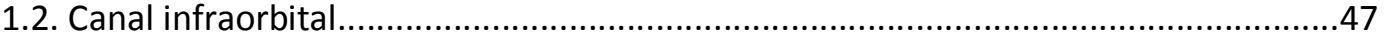

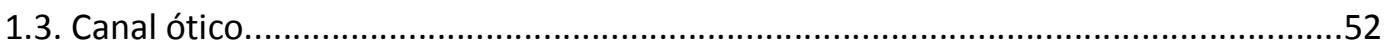

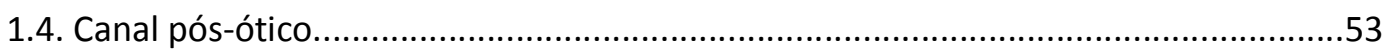

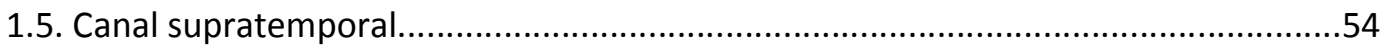

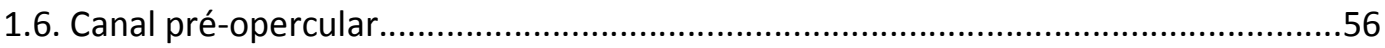

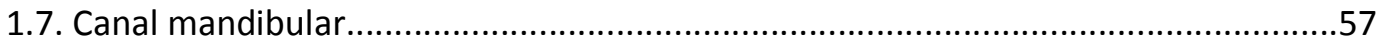

1.8. Desenvolvimento dos canais látero-sensoriais cefálicos em Characiformes.............59 
1.9. Demais considerações acerca dos canais látero-sensoriais cefálicos - comparações

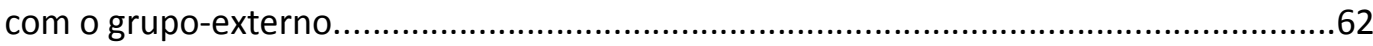

2. Ramos acessórios (e poros) ao longo da linha lateral cefálica.........................................68

2.1. Ramos acessórios ao longo da linha lateral cefálica de Characiformes.....................68

2.1.1. Ramos acessórios ao longo do canal supraorbital de Characiformes................69

2.1.2. Ramos acessórios ao longo do canal infraorbital de Characiformes..................74

2.1.3. Ramos acessórios ao longo do canal ótico em Characiformes...........................80

2.1.4. Ramos acessórios ao longo do canal pós-ótico em Characiformes......................81

2.1.5. Ramos acessórios ao longo do canal supratemporal em Characiformes............84

2.1.6. Ramos acessórios ao longo do canal pré-opercular de Characiformes...............86

2.1.7. Ramos acessórios ao longo do canal mandibular de Characiformes..................88

2.2. Demais considerações acerca dos ramos acessórios ao longo dos canais láterosensoriais cefálicos - comparações com o grupo-externo.........................................90

2.2.1. Ramos acessórios ao longo do canal supraorbital em grupo-externo................91

2.2.2. Ramos acessórios ao longo do canal infraorbital de grupo-externo..................93

2.2.3. Ramos acessórios ao longo do canal ótico de grupo-externo.............................96

2.2.4. Ramos acessórios ao longo do canal pós-ótico de grupo-externo......................97

2.2.5. Ramos acessórios ao longo do canal supratemporal de grupo-externo...........100

2.2.6. Ramos acessórios ao longo do canal pré-opercular de grupo-externo.............102

2.2.7. Ramos acessórios ao longo do canal mandibular de grupo-externo................103

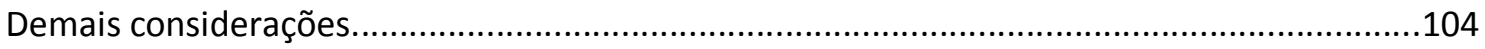

1. Homologia dos ossos dérmicos portadores de canais látero-sensoriais cefálicos...........104

1.1. Homologia dos ossos infraorbitais de Ostariophysi..........................................105

1.2. Homologia do supra-pré-opérculo em Ostariophysi.........................................109

1.3. Homologia dos neuromastos temporais em Ostariophysi...................................112

1.3.1. Neuromastos temporais e suas implicações na morfologia e homologia do osso extraescapular

1.3.2. Neuromastos temporais e homologia do ramo pterótico do canal pósotico. 


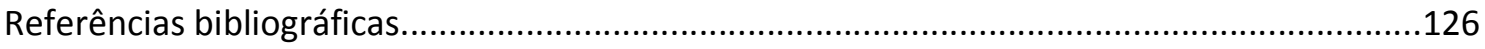

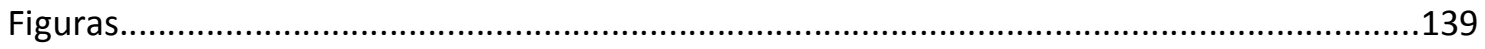

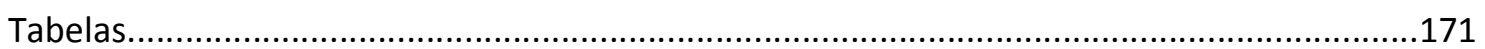

Anexo - Material Examinado...........................................................................186

Material incluido na análise - Characiformes.........................................................187

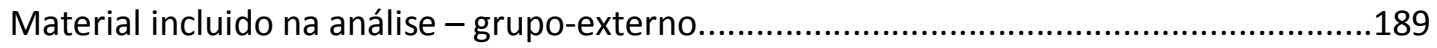

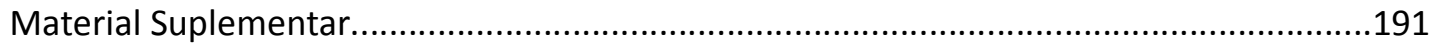




\section{Índice de Figuras.}

Figura 1. Vista lateral esquerda do crânio de um exemplar de Brycon nattereri (LIRP 3590), indicando canais e poros do sistema látero-sensorial cefálico. S1-S8 indicam poros do canal supraorbital; i1-i10 indicam poros do canal infraorbital; PR1-PR7 indicam poros do canal préopercular; M1-M5 indicam poros do canal mandibular; P01-PO5 indicam poros do canal pósótico; ST1 e ST2 indicam poros do canal supratemporal. Asteriscos representam poros supranumerários. 140

Figura 2. Vista lateral esquerdado crânio de um exemplar de Acestrorhynchus cf. microlepis (LIRP 7534), indicando canais e poros do sistema látero-sensorial cefálico. S1-S8 indicam poros do canal supraorbital; i1-i9 indicam poros do canal infraorbital; PR1-PR7 indicam poros do canal pré-opercular; M1-M5 indicam poros do canal mandibular; PO1-PO5 indicam poros do canal pós-ótico; ST1 e ST2 indicam poros do canal supratemporal. Asteriscos representam poros supranumerários.

Figura 3. Vista lateral esquerda do crânio de um exemplar de Astyanax altiparanae (LIRP 11163), indicando canais e poros do sistema látero-sensorial cefálico. S1-S8 indicam poros do canal supraorbital; i1-i9 indicam poros do canal infraorbital; PR1-PR7 indicam poros do canal préopercular; M1-M5 indicam poros do canal mandibular; PO1-PO5 indicam poros do canal pósótico; ST1 e ST2 indicam poros do canal supratemporal. Asteriscos representam poros supranumerários. 144

Figura 4. Vista lateral esquerda do crânio de um exemplar de Characidium cf. xanthopterum (LIRP 4470), indicando canais e poros do sistema látero-sensorial cefálico. S1-S7 indicam poros do canal supraorbital; i1-i9 indicam poros do canal infraorbital; PR1-PR7 indicam poros do canal pré-opercular; M2-M5 indicam poros do canal mandibular; 01 indica poro do canal ótico; PO1-PO5 indicam poros do canal pós-ótico; ST2 indica poro do canal supratemporal..........146

Figura 5. Vista lateral esquerda do crânio de um exemplar de Pyrrhulina cf. australis (LIRP 8590), indicando canais e poros do sistema látero-sensorial cefálico. S1-S8 indicam poros do canal supraorbital; i1-i9 indicam poros do canal infraorbital; PR1-PR7 indicam poros do canal préopercular. Canais mandibular, pós-ótico e supratemporal estão ausentes nesse táxon.

Figura 6. Vista lateral esquerda do crânio de um exemplar de Neolebias unifasciatus (MZUSP 84531), indicando canais e poros do sistema látero-sensorial cefálico. S1-S8 indicam poros do 
canal supraorbital; i1-i9 indicam poros do canal infraorbital; PR1-PR7 indicam poros do canal pré-opercular; M2-M5 indicam poros do canal mandibular; PO1-PO5 indicam poros do canal pós-ótico; ST2 indica poro do canal supratemporal 148

Figura 7. Vista lateral esquerda ilustrando ossos dérmicos cranianos em associação com canais e poros do sistema látero-sensorial cefálico de um exemplar de Leporellus vittatus (LIRP 8857). S1-S8 indicam poros do canal supraorbital; i1-i10 indicam poros do canal infraorbital; PR1 indica primeiro poro pré-opercular; P01-PO5 indicam poros do canal pós-ótico; ST1 e ST2 indicam poros do canal supratemporal. Demais poros pré-operculares, bem como poros do canal mandibular não foram ilustrados. Asteriscos representam poros supranumerários....149

Figura 8. Vista dorsal do crânio de um exemplar de Leporellus vittatus (LIRP 8857), indicando canais e poros do sistema látero-sensorial cefálico. S1-S8 indicam poros do canal supraorbital; PO1 e PO2 indicam poros do canal pós-ótico; ST1 e ST2 indicam poros do canal supratemporal. Poros do canal infraorbital, pré-opercular e mandibular, bem como demais poros do canal pós-ótico e supratemporal não observados em vista dorsal. Asteriscos representam poros supranumerários. 150

Figura 9. Vista dorsal do crânio de um exemplar de Characidium gomesi (LIRP 8239), indicando canais e poros do sistema látero-sensorial cefálico. S1-S8 indicam poros do canal supraorbital; i9 indica último poro do canal infraorbital; PO1 e PO2 indicam os dois primeiros poros do canal pós-ótico; ST2 indica poro do canal supratemporal. Demais poros infraorbitais e pré-operculares, bem como poros mandibulares não observados em vista dorsal. Demais poros do canal pós-ótico não ilustrados. 151

Figura 10. Vista dorsal do crânio de um exemplar de Hoplias aimara (LIRP 9108), indicando canais e poros do sistema látero-sensorial cefálico. S1-S8 indicam poros do canal supraorbital; PO1 e PO2 indicam os dois primeiros poros do canal pós-ótico; ST2 indica poro do canal supratemporal. Poros pré-operculares, infraorbitais e mandibulares não observados em vista dorsal. Demais poros do canal pós-ótico não ilustrados.

Figura 11. Vista dorsal do crânio de um exemplar de Stygichthys typhlops (LESCI 000230/ 002), indicando canais e poros do sistema látero-sensorial cefálico. S1-S7 indicam poros do canal supraorbital. Canais mandibular, pós-ótico e supratemporal ausentes nesse táxon. Demais canais não observados em vista dorsal. 
Figura 12. Poros do canal infraorbital e ossos dérmicos associados de um exemplar de Hoplias aimara (LIRP 9108) em vista lateral esquerda. A1 indica poro do trecho antorbital do canal infraorbital; i1-i9 indicam poros ao longo do canal infraorbital. 154

Figura 13. Região temporal do crânio de um exemplar de Prochilodus brevis (LIRP 3781) ilustrado em vista lateral esquerda, indicando canais e poros do sistema látero-sensorial cefálico. S5S8 indicam poros do canal supraorbital; i8-i10 indicam poros do canal infraorbital; PR1+PO1 indica anastomose entre o primeiro poro pós-ótico com o primeiro poro do canal préopercular; PO2-PO5 indicam poros do canal pós-ótico; ST1 e ST2 indicam poros do canal supratemporal. Asteriscos indicam poros supranumerários. Detalhe para as ramificações sobre a placa dermoesfenótica, característica sinapomórfica para o gênero Prochilodus (sensu Castro \& Vari, 2004). Asteriscos representam poros supranumerários. 155

Figura 14. Região temporal do crânio de um exemplar de Caenotropus schizodon (LIRP 8333) ilustrado em vista lateral esquerda, indicando canais e poros do sistema látero-sensorial cefálico. S6-S8 indicam poros do canal supraorbital; i8-i10 indicam poros do canal infraorbital; PR1+PO1 indica anastomose entre o primeiro poro pós-ótico com o primeiro poro do canal pré-opercular; PO2-PO5 indicam poros do canal pós-ótico; ST1 e ST2 indicam poros do canal supratemporal 156

Figura 15. Região temporal do crânio de um exemplar de Chalceus epakros (LIRP 7538) ilustrado em vista lateral esquerda, indicando canais e poros do sistema látero-sensorial cefálico. S7 e S8 indicam poros do canal supraorbital; i8-i10 indicam poros do canal infraorbital; PR1+PO1 indica anastomose entre o primeiro poro pós-ótico com o primeiro poro do canal préopercular; PO2-PO4 indicam poros do canal pós-ótico; ST1 e ST2 indicam poros do canal supratemporal. 157

Figura 16. Região temporal do crânio de um exemplar de Eugnatichthys sp. (USNM 326206) ilustrado em vista lateral esquerda, indicando canais e poros do sistema látero-sensorial cefálico. S5-S8 indicam poros do canal supraorbital; i7-i9 indicam poros do canal infraorbital; PR1+PO1 indica anastomose entre o primeiro poro pós-ótico com o primeiro poro do canal pré-opercular; PO2-PO5 indicam poros do canal pós-ótico; ST1 indica primeiro poro supratemporal. Asteriscos representam poros supranumerários. .158

Figura 17. Crânio de Xenocharax spilurus em vista lateral direita. Linha pontilhada representa o sistema látero-sensorial cefálico, circulos brancos indicam poros associados a esse sistema, e números apontam ossos superficiais do crânio. Detalhe para a seta sobre o osso de número 
7, indicando o início do canal ótico, que nos Distichodontidae parte de uma ramificação lateral sobre o dermoesfenótico. Imagem adaptada de Daget (1960). 159

Figura 18. Vista dorsal do crânio de um exemplar de Gymnotus cf. carapo (LIRP 10129), indicando canais e poros do sistema látero-sensorial cefálico. S1-S7 indicam poros do canal supraorbital; A1 indica poro do trecho antorbital do canal infraorbital; i1-i9 indicam poros do canal infraorbital; PO1-PO3 indicam poros do canal pós-ótico; ST2 indica poro do canal supratemporal. Poros do canal pré-opercular e mandibular não observados em vista dorsal 160

Figura 19. Vista lateral esquerda da cabeça de um exemplar de Electrophorus sp. (MPEG 25442), indicando canais e poros do sistema látero-sensorial cefálico. S1-S8 indicam poros do canal supraorbital; $\mathbf{A} 1$ indica poro associado à porção antorbital do canal infraorbital; i1-i9 indicam poros do canal infraorbital; PR1-PR7 indicam poros do canal pré-opercular; M1-M5 indicam poros do canal mandibular; PO1-PO5 indicam poros do canal pós-ótico; ST1 indica primeiro poro do canal supratemporal. Asteriscos, quando presentes, indicam poro supranumerário. .161

Figura 20. Poros do canal infraorbital e ossos dérmicos associados de um exemplar de Kneria sp. (USNM 290762) em vista lateral esquerda. i1-i9 indicam poros ao longo do canal infraorbital, $\mathbf{O 1}$ indica poro ao longo do canal ótico. .162

Figura 21. Vista lateral direita dos poros do canal infraorbital e ossos dérmicos associados de um exemplar de Campostoma anomalum (USNM 200731). i1-i9 indicam poros ao longo do canal infraorbital, 01 indica poro ao longo do canal ótico, asteriscos indicam poros supranumerários em relação ao canal infraorbital dos Characiformes.

Figura 22. Poros do canal infraorbital e ossos dérmicos associados de um exemplar de Salmo trutta (USNM 373790). i1-i9 indicam poros ao longo do canal infraorbital, 01 indica poro ao longo do canal ótico, asteriscos indicam poros supranumerários em relação ao canal infraorbital dos Characiformes. 164

Figura 23. Região temporal do crânio de um exemplar de Kneria auriculata (BMNH 1976.10.20.142-160) ilustrado em vista lateral esquerda. Fr indica osso frontal; Pto indica o osso pterótico; Epo indica o osso epioccipital; Soc indica o osso supraoccipital; Ppt indica o osso pós-temporal; Scl indica o osso supracleitro. Detalhe para a seta indicando um elemento ósseo dérmico associado à porção lateral do canal supratemporal, aqui identificado como 
porção medial extraescapular associada ao neuromasto formador do poro ST1. Imagem adaptada de Britz \& Moritz ( 2007). 165

Figura 24. Diagramas representando variações morfológicas apresentadas por Characiformes ao longo do trecho nasal do canal supraorbital. O padrão com três poros látero-sensoriais, apresentados nas ilustrações de cima, foi considerado primitivo em Characiformes, apresentando um poro anterior (S1), um poro ao longo (S2), e outro poro posterior (S3) ao osso nasal, este último localizado entre o nasal e o osso frontal. Redução para uma condição com apenas dois poros sensoriais, (ilustrações de baixo), foi considerada derivada para a ordem Characiformes, apresentando três possíveis identificações dos poros tubulares explicando esta condição. A hipótese apresentada em A considera a perda do poro intermediário ao osso nasal (S2), preservando os poros anterior (S1) e posterior (S3) a este osso. Esta proposta leva em conta a localização dos poros S1 e S3 no estado primitivo (superior), mantendo a identificação destes mesmos poros em uma condição derivada (inferior). Os esquemas B e C apresentam identificações alternativas dos poros tubulares ao longo do trecho nasal do canal supraorbital, considerando reduções de neuromastos de canal na identificação dos poros em um estado derivado. Em uma primitiva há dois neuromastos de canal (indicados como NR1 e NR2) entre três poros tubulares (S1, S2 e S3). Uma perda do neuromasto NR1, apresentada na hipótese B, acarreta na supressão da formação do primeiro poro tubular, bem como de toda a metade anterior do osso nasal, conservando apenas os poros S2 e S3 e a porção do osso nasal. Já a condição C considera a perda do segundo neuromasto do canal supraorbital (NR2), refletindo na supressão da formação metade posterior do osso nasal e na formação do terceiro poro supraorbital (S3). 166

Figura 25. Região temporal do crânio de um exemplar de Opsariichthys uncirostris (USNM 86470) ilustrado em vista lateral esquerda, indicando canais e poros do sistema látero-sensorial cefálico. i7-i9 indicam poros do canal infraorbital; PR1 indica primeiro poro do canal préopercular; PO1-PO5 indicam poros do canal pós-ótico; ST1 e ST2 indicam poros do canal supratemporal. 167

Figura 26. Diagramas representando a morfologia dos canais, poros, neuromastos e ossos dérmicos encontrados na região temporal de diferentes Ostariophysi. A indica a condição típica de um exemplar da ordem Characiformes, ilustrada em vista lateral esquerda. Neste, o pterótico possui dois neuromastos temporais (NT1 e NT2), ao longo dos canais ótico e pósótico, separados entre si pela confluência do canal pré-opercular com o canal ótico 
(PO1+PR1). Entre o pterótico e a extraescápula surge um poro tubular, aqui identificado como segundo poro do canal pós-ótico (PO2). Um terceiro neuromasto temporal (NT3) é encontrado sobre a extraescápula, osso que também porta o primeiro neuromasto do canal supratemporal (NST1). Mais adiante, outros dois neuromastos são encontrados ao longo da cintura escapular (NT4 e NT5), dispostos sobre o pós-temporal e o supracleitro, respectivamente. Ao longo do canal ótico associado à extraescápula, pós-temporal e supracleitro, outros três poros são encontrados, identificados por PO3, PO4 e PO5. Já ao longo do canal supratemporal, poros estão presentes sobre a extraescápula (ST1) e na margem medial do osso parietal (ST2), porção que também porta o segundo neuromasto supratemporal (NST2). Em B é ilustrada a condição típica de um Cypriniformes, em vista lateral direita. Esta difere-se de Characiformes principalmente por apresentar o poro ST1 entre a extraescápula e o parietal, consequência do deslocamento medial do neuromasto NST1. Isto parece refletir na morfologia da extraescápula, reduzida apenas aos trechos dos canais pós-ótico e supratemporal nesses táxons .168

Figura 27. Diagramas representando a morfologia dos canais, poros, neuromastos e ossos dérmicos encontrados na região temporal de Siluriformes. A condição apresentada em $\mathbf{A}$ ilustra a morfologia temporal de um representante Siluriformes típico em vista lateral esquerda. Esta se difere dos Characiformes e Cypriniformes (Figura 26, A e B) principalmente por não possuir um canal supratemporal e possuir três neuromastos temporais sobre o osso pterótico (NT1, NT2 e NT3). Aparentemente esta disposição de neuromastos acarreta na presença do ramo PO2 ainda sobre o osso pterótico, além da supressão da formação de um osso extraescapular. Entretanto, nos Siluriformes apresentando extraescápula (C, em vista lateral direita), o terceiro neuromasto temporal (NT3) encontra-se posterior aos limites do osso pterótico, o que parece resultar na reaquisição de uma ossificação extraescapular de maneira homoplástica aos demais Teleostei 169

Figura 28. Vista lateral esquerda do crânio de um exemplar de Denticeps clupeoides (MZUSP 84776), indicando canais e poros do sistema látero-sensorial cefálico. Detalhe para o ramo ptrc, emergindo da região entre o recessus lateralis e a extraescápula, sugerido por Di Dario \& de Pinna (2006) como uma sinapomorfia para Clupeomorpha. Imagem adaptada de Di Dario \& de Pinna (2006) 170 


\section{Índice de tabelas.}

Tabela 1. Poros compartilhados entre canais sensoriais da linha lateral cefálica de Characiformes. Números indicam a abertura individual (zero) ou o compartilhamento de uma única abertura (um) entre poros de diferentes canais. A condição expressa por "in." indica que a característica foi inaplicável para determinado táxon, que no caso de Characiformes, foi relacionada à ausência da formação de canais. .172

Tabela 2. Poros compartilhados entre canais sensoriais da linha lateral cefálica dos grupos externos à ordem Characiformes. Números indicam a abertura individual (zero) ou o compartilhamento de uma única abertura (um) entre poros de diferentes canais. A condição expressa por "in." indica que a característica foi inaplicável para determinado táxon, que esta relacionada à ausência da formação de canais ou modificações estruturais dos mesmos

Tabela 3. Poros do canal supraorbital da linha lateral cefálica de Characiformes. S1 a S8 indicam poros ao longo do canal supraorbital. Números indicam a ausência (zero) ou presença (um) de determinado poro ao longo do canal. Asteriscos $(*)$ indicam poros supranumerários, de modo que cada asterisco represente um poro extra relacionado a determinada posição. A condição expressa por "in." demonstra característica inaplicável para determinado táxon, que no caso de Characiformes esteve relacionada à ausência da formação de canais 174

Tabela 4. Poros do canal infraorbital da linha lateral cefálica do material examinado de Characiformes. i1 a i10 indicam poros ao longo do canal infraorbital, A1 indica poro abrindose sobre o trecho antorbital do canal infraorbital. Números indicam a ausência (zero) ou presença (um) de determinado poro ao longo do canal. Asteriscos (*) indicam poros supranumerários, de modo que cada asterisco represente um poro extra relacionado a determinada posição. A condição expressa por "in." demonstra característica inaplicável para determinado táxon, que no caso de Characiformes esteve relacionada à ausência da formação de canais 175

Tabela 5. Poros do canal temporal (ótico e pós-ótico) da linha lateral cefálica do material examinado de Characiformes. PO1 a PO5 indicam poros ao longo do canal pós-ótico, 01 indica poro abrindo-se ainda sobre o trecho ótico do canal temporal, LL1 indica o primeiro poro da linha lateral corporal. Números indicam a ausência (zero) ou presença (um) de determinado poro ao longo do canal. Asteriscos $\left({ }^{*}\right)$ indicam poros supranumerários, de modo 
que cada asterisco represente um poro extra relacionado a determinada posição. A condição expressa por "in." demonstra característica inaplicável para determinado táxon, que no caso de Characiformes esteve relacionada à ausência da formação de canais 176

Tabela 6. Poros do canal supratemporal da linha lateral cefálica do material examinado de Characiformes. ST1 e ST2 indicam poros ao longo do canal supratemporal. Números indicam a ausência (zero) ou presença (um) de determinado poro ao longo do canal. Asteriscos (*) indicam poros supranumerários, de modo que cada asterisco represente um poro extra relacionado a determinada posição. A condição expressa por "in." demonstra característica inaplicável para determinado táxon, que no caso de Characiformes esteve relacionada à ausência da formação de canais. 177

Tabela 7. Poros do canal pré-opercular da linha lateral cefálica do material examinado de Characiformes. PR1 a PR7 indicam poros ao longo do canal pré-opercular. Números indicam a ausência (zero) ou presença (um) de determinado poro ao longo do canal. Asteriscos (*) indicam poros supranumerários, de modo que cada asterisco represente um poro extra relacionado a determinada posição. A condição expressa por "in." demonstra característica inaplicável para determinado táxon, que no caso de Characiformes esteve relacionada à ausência da formação de canais. 178

Tabela 8. Poros do canal mandibular da linha lateral cefálica do material examinado de Characiformes. M1 a M5 indicam poros ao longo do canal mandibular. Números indicam a ausência (zero) ou presença (um) de determinado poro ao longo do canal. Asteriscos (*) indicam poros supranumerários, Total indica o número total de poros encontrados ao longo do canal mandibular. A condição expressa por "in." demonstra característica inaplicável para determinado táxon, que pode estar relacionada à ausência do canal ou a modificações estruturais do mesmo. .179

Tabela 9. Poros do canal supraorbital da linha lateral cefálica dos grupos externos à ordem Characiformes. S1 a $\mathbf{S 8}$ indicam poros ao longo do canal supraorbital. Números indicam a ausência (zero) ou presença (um) de determinado poro ao longo do canal. Total indica a somatória de poros ao longo do canal. Asteriscos $(*)$ indicam poros supranumerários, de modo que cada asterisco represente um poro extra relacionado a determinada posição. A condição expressa por "in." demonstra característica inaplicável para determinado táxon, que pode estar relacionada à ausência do canal ou a modificações estruturais do mesmo 180 
Tabela 10. Poros do canal infraorbital da linha lateral cefálica do material examinado como grupo externo à ordem Characiformes. i1 a i10 indicam poros ao longo do canal infraorbital, A1 indica poro abrindo-se sobre o trecho antorbital do canal infraorbital. Números indicam a ausência (zero) ou presença (um) de determinado poro ao longo do canal. Total indica a somatória de poros ao longo do canal. Asteriscos $(*)$ indicam poros supranumerários, de modo que cada asterisco represente um poro extra relacionado a determinada posição. A condição expressa por "in." demonstra característica inaplicável para determinado táxon, que pode estar relacionada à ausência do canal ou a modificações estruturais do mesmo.

Tabela 11. Poros do canal temporal (ótico e pós-ótico) da linha lateral cefálica do material examinado como grupo externo à ordem Characiformes. PO1 a PO5 indicam poros ao longo do canal pós-ótico,01 indica poro abrindo-se ainda sobre o trecho ótico do canal temporal, LL1 indica o primeiro poro da linha lateral corporal. Números indicam a ausência (zero) ou presença (um) de determinado poro ao longo do canal. Total indica a somatória de poros ao longo do canal. Asteriscos $(*)$ indicam poros supranumerários, de modo que cada asterisco represente um poro extra relacionado a determinada posição. A condição expressa por "in." demonstra característica inaplicável para determinado táxon, que pode estar relacionada à ausência do canal ou a modificações estruturais do mesmo. .182

Tabela 12. Poros do canal supratemporal da linha lateral cefálica do material examinado como grupo externo à ordem Characiformes. ST1 e ST2 indicam poros ao longo do supratemporal. Números indicam a ausência (zero) ou presença (um) de determinado poro ao longo do canal. Asteriscos $(*)$ indicam poros supranumerários, de modo que cada asterisco represente um poro extra relacionado a determinada posição. A condição expressa por "in." demonstra característica inaplicável para determinado táxon, que pode estar relacionada à ausência do canal ou a modificações estruturais do mesmo. .183

Tabela 13. Poros do canal pré-opercular da linha lateral cefálica do material examinado como grupo externo à ordem Characiformes. PR1 a PR7 indicam poros ao longo do canal préopercular. Números indicam a ausência (zero) ou presença (um) de determinado poro ao longo do canal. Total indica a somatória de poros ao longo do canal. Asteriscos (*) indicam poros supranumerários, de modo que cada asterisco represente um poro extra relacionado a determinada posição. A condição expressa por "in." demonstra característica inaplicável para determinado táxon, que pode estar relacionada à ausência do canal ou a modificações estruturais do mesmo 
Tabela 14. Poros ao longo do canal mandibular do material examinado como grupo externo à ordem Characiformes. M1 a M5 indicam poros ao longo do canal mandibular. Números indicam a ausência (zero) ou presença (um) de determinado poro ao longo do canal. Total indica a somatória de poros ao longo do canal. Asteriscos (*) indicam poros supranumerários, de modo que cada asterisco represente um poro extra relacionado a determinada posição. $\mathrm{A}$ condição expressa por "in." demonstra característica inaplicável para determinado táxon, que pode estar relacionada à ausência do canal ou a modificações estruturais do mesmo .185 


\section{Introdução.}

\section{Considerações gerais sobre a linha lateral cefálica}

O sistema látero-sensorial cefálico é um complexo sensorial generalizado presente em vertebrados, inervado por pares de nervos cranianos e arranjado em linhas de órgãos mecanorreceptores cuja unidade funcional é denominada neuromasto. Cada neuromasto consiste de um grupo de diferentes células, ciliares e de suporte, protegido por uma cúpula gelatinosa, a qual é responsável pela conexão mecânica entre o meio externo e as células ciliares (Dijkgraaf, 1963; Montgomery et al., 2001). Tais órgãos podem estar localizados superficialmente, em fossas ou em ranhuras epidérmicas, ou internamente, em canais que percorrem a superfície de ossos dérmicos, alcançando o meio externo através de ramificações tubulares que se abrem em poros na superfície da pele (Northcutt, 1989; Arratia \& Huaquín, 1995). Esse sistema é de grande importância sensorial para os peixes em seus diferentes estágios de vida, bem como para os anfíbios aquáticos, que o utilizam na percepção de vibrações e de movimentos na água. Além disso, estudos apontam para a importância desse sistema para o comportamento social, como a organização de cardumes e na desova de diferentes grupos de peixes (McHenry \& van Nettel, 2007; Ristovska et al., 2004; Adriaens et al., 1997).

O padrão geral de disposição dos canais sensoriais cefálicos é conservado na grande maioria dos peixes, muitas vezes ocorrendo em associação com os ossos dérmicos que formam a superfície dorsal e lateral da cabeça, em ossos acima e abaixo dos olhos, ao longo do préopérculo, seguindo para o dentário, e ao longo da cintura escapular, seguindo lateralmente pelo tronco do peixe (cf. Allis, 1889; Pehrson 1940, 1944; Lekander, 1949; Webb 1989; Montgomery et al., 2001). Os canais látero-sensoriais cefálicos dos peixes são geralmente arranjados em sete grupos cefálicos, dispostos em pares e denominados supraorbital, infraorbital, ótico, pós-ótico, pré-opércular, mandibular e supratemporal. Algumas de suas ramificações amplamente citadas na literatura anatômica, tais como o ramo parietal e ramo epifiseano, do canal supraorbital, e ramo pterótico do canal pós-ótico (Northcutt, 1989; Arratia \& Huaquín, 1995; Schaefer \& Aquino, 2000). Além dos sete pares de canais cefálicos, o sistema sensorial continua de ambos os lados do tronco como uma linha lateral.

Estudos anatômicos descrevendo o sistema látero-sensorial cefálico vêm sendo realizados há tempos com diversos grupos de peixes, tanto em Chondrichthyes (e.g. Allis, 
1923; Maruska, 2001), como em Osteichthyes (e.g. Allis, 1889, 1903, 1904; Guitel, 1891; Herrick, 1899; Clapp, 1899; Pehrson, 1944; Saxena, 1966; Nelson, 1972; Gardiner, 1984; Asaoka, 2011). Além disso, caracteres relacionados ao sistema látero-sensorial também têm sido amplamente utilizados como fonte de informações cladísticas em grupos distintos de peixes (Nelson, 1972; Lundberg, 1975; Fink \& Fink, 1981; Arratia \& Huaquín, 1995; Webb, 1998; Di Dario, 2004; Di Dario \& de Pinna, 2006; Sidlauskas \& Vari, 2008; Stephens, 2010).

A formação dos canais sensoriais ao longo do desenvolvimento já foi objeto de diferentes estudos utilizando peixes como modelo, os quais tiveram início no final do século XIX (Allis, 1889) e início do século XX (Allis, 1903, 1904; Kindred, 1919; de Beer, 1937; Pehrson, 1944; Lekander, 1949). Ao longo da segunda metade do século XX e início do século XXI, diversos trabalhos também descreveram com variável grau de detalhamento 0 desenvolvimento dos canais e poros da linha lateral cefálica de diferentes grupos de peixes (Graham-Smith, 1979; Webb, 1989; Webb, 1990; Webb \& Northcutt, 1997; Northcutt et al., 2000), por vezes enfatizando sua inervação e relação com o desenvolvimento do esqueleto craniano dérmico.

Comum entre todos estes trabalhos foi a importância destinada ao papel dos neuromastos de canal (neuromastos primários sensu Lekander, 1949) no processo de formação dos canais sensoriais. Já descrita por Allis (1889; 1904), Lekander (1949) e mais recentemente por Webb \& Northcutt (1997), a formação dos canais sensoriais tem início nas primeiras horas após eclosão da larva dos peixes. De maneira simplificada, a formação dos canais da linha lateral cefálica tem início nas primeiras etapas do desenvolvimento, quando aglomerados celulares dispostos sobre a região temporal craniana dão origem às primeiras linhas de neuromastos. Estas séries são formadas por migração celular que partem dos aglomerados celulares (=placódeos) e se organizam linearmente ao longo de determinadas regiões da cabeça, locais onde posteriormente se formarão os canais sensoriais cefálicos. Os primeiros neuromastos a migrarem e se alinharem são denominados neuromastos de canal, estes que, no decorrer da ontogenia, sofrem invaginação epitelial e se tornam totalmente envoltos pelo tegumento superficial da cabeça do peixe em um processo de formação do canal sensorial cefálico. Ao fim dessa etapa, cada um dos neuromastos de canal se encontra localizado dentro de um túbulo preenchido por muco. Este processo ocorre individualmente para cada um dos neuromastos de canal, de modo que a sequência de neuromastos primários formará uma série de pequenos túbulos alinhados que se conectam uns aos outros, que se abrem na superfície externa por meio de poros. Após completamente formado, um canal sensorial apresentará uma sequência de túbulos, cada qual portando um neuromasto, 
intercalados por uma sequência de poros comunicando-os com o meio externo, formando um padrão denominado poro-neuromasto-poro, de modo que o número de poros tubulares é superior em uma unidade ao número de neuromastos ao longo deste canal.

O desenvolvimento de cada um dos pares de canal do sistema látero-sensorial cefálico foi descrito de maneira bem detalhada por Lekander (1949). Utilizando-se de Leuciscus rutilus (=Rutilus rutilus), um representante da ordem Cypriniformes, o autor apresentou toda a sequência de migração dos neuromastos de canal, e também da invaginação dos diferentes canais componentes desse sistema. Lekander (1949) cita a formação dos primeiros componentes da linha lateral cefálica logo após as primeiras 100 horas de vida. Deste momento até $o$ indivíduo atingir aproximadamente $8 \mathrm{~mm}$ de comprimento padrão, os placódios que dão origem à linha lateral cefálica já se desenvolveram por completo, e os neuromastos de canal já migraram formando as linhas de neuromstos primários. Por volta de $18 \mathrm{~mm}$ de comprimento padrão, o padrão geral de formação e ossificação dos canais sensoriais cefálicos já havia se iniciado sobre determinados ossos dérmicos.

A relação da formação dos canais sensoriais cefálicos com as ossificações dérmicas cranianas já foi tópico de discussão de diversos trabalhos descrevendo o desenvolvimento do sistema sensorial cefálico. As primeiras informações a este respeito foram publicadas em meados do século XIX. Estes trabalhos tratavam ossos dérmicos cranianos como placas ósseas que desempenhavam principalmente a função de proteger os componentes da linha lateral da cabeça. Este foi o ponto de vista defendido por Vrolik (1873), que afirmava que não via outra explicação para a ossificação da porção dorsal do crânio (i.e. a existência do osso frontal) senão a proteção dos canais sensoriais. Essa ideia de Vrolik foi, pouco tempo depois, rejeitada por Walther (1883), autor que mencionou que os ossos frontais já estavam quase completamente formados enquanto o canal supraorbital ainda não havia se fechado, de modo que seria improvável assumir a presença de um osso frontal apenas para proteger os elementos da linha lateral.

No que diz respeito à relação entre os elementos do sistema látero-sensorial cefálico com a ossificação de placas dérmicas cranianas, discussões mais detalhadas sobre o assunto podem ser encontradas na monografia publicada por Kindred (1919). Neste trabalho, o autor descreveu o desenvolvimento de ossos cranianos do bagre Amiurus catus (=Ameiurus catus; Ictaluridae), e discutiu a homologia de diferentes complexos ósseos. Kindred (1919) discorreu sobre a sequência de ossificações observada ao longo dos ossos dorsais do crânio e afirmou que, apesar do canal supraorbital e o osso frontal estarem sempre em associação nos indivíduos adultos, seria claramente notável a ossificação do canal supraorbital espacialmente 
separada daquela que forma a lâmina frontal em estágios precoces do desenvolvimento. Kindred (1919) também apresentou uma discussão a respeito da homologia e do desenvolvimento envolvendo ossos dérmicos e canais ossificados da série de ossos ao redor da órbita ocular de Ameiurus catus (Ictaluridae). O autor reportou que os primeiros núcleos de ossificação desses ossos infraorbitais seriam observados abaixo de cada um dos neuromastos do canal infraorbital, e que em um grau mais avançado de desenvolvimento, estas ossificações dariam a impressão de estar envolvendo todo o canal infraorbital, formando uma série de ossos tubulares. Tais ossos, de acordo com Kindred (1919), já teriam recebido o nome de suborbitalia ou infraorbitalia por outros anatomistas, e seriam distintas das placas infraorbitais de outros peixes ósseos.

O célebre anatomista Gavin de Beer também colaborou com o conhecimento a respeito da origem e relação entre canais sensoriais e ossos dérmicos em seu livro intitulado The Development of Vertebrate Skull (1937). Neste, o autor levantou uma série de argumentos que visavam propor a independência completa entre o desenvolvimento de canais sensoriais e ossos dérmicos cranianos. Entre os argumentos elencados por Beer (1937) estavam considerações questionando que se de fato houvesse dependência entre esses dois sistemas, teria que haver outra explicação para a presença desses mesmos ossos em vertebrados terrestres (que não possuem a linha lateral cefálica), ou de ossos dérmicos de peixes que não possuem associação com linha lateral. O autor ainda comentou em seu livro que Walther (1883), quando notou o surgimento temporalmente dissociado dos ossos frontais e do canal supraorbital, não se deu conta da relevância de sua descoberta. De acordo com Gavin de Beer (1937), a partir das observações de Walther (1883) seria possível explicar a presença de canais sensoriais em ossos que usualmente não possuíam qualquer associação com tal sistema apenas assumindo uma movimentação topológica de um desses dois sistemas, desassociando as influências de um na formação do outro. Todavia, os argumentos de Gavin de Beer, apesar de parecerem bastante robustos, seriam ainda rebatidos poucos anos depois por outro importante pesquisador da área.

Próximo à metade do século $\mathrm{XX}$, Pehrson publicou uma série de trabalhos tratando da descrição morfológica e do desenvolvimento dos ossos da superfície craniana de Amia calva (Pehrson, 1922, 1940) e de Esox lucius (Pehrson, 1944). Tais trabalhos visavam elucidar a relação dos canais da linha lateral cefálica com desenvolvimento dos ossos dérmicos cranianos nesses táxons. Em suas descrições, mais especificamente a respeito da formação do par de ossos frontais, Pehrson (1944) afirmou que tais ossos se desenvolviam anteriormente à ossificação completa dos canais sensoriais, dissociando em certo nível a dependência entre 
tais sistemas. Entretanto, segundo Pehrson, isso não significaria independência completa da formação de um sistema em relação ao outro. Em seu trabalho de 1944, o autor registrou que os primeiros focos de ossificação craniana se davam nos arredores dos canais sensoriais ainda não ossificados, e apesar de não haver uma sincronia na formação do par de frontais e dos canais supraorbitais, o autor afirmou que os "sense organs" (neuromastos) seriam de alguma forma os responsáveis pelo início da ossificação dérmica craniana. Desse modo as lâminas ósseas do osso frontal se constituiam em projeções de um precursor sensorial (neuromasto), sendo a formação do canal ao redor do neuromasto apenas um estágio posterior do desenvolvimento craniano. Nas palavras do autor "The forming of the canal itself, or of the bone tubes surrounding it, is only a later stage in the development, and quite irrelevant from the point of view of the origin of the frontal".

Neste mesmo trabalho, Pehrson (1944) ainda rebateu as críticas levantadas por de Beer (1937) a respeito da independência da formação da linha lateral cefálica e dos ossos dérmicos se limitando a dizer que: 1) o único registro de focos distintos de ossificação da linha lateral cefálica e um osso dérmico até então teria sido o de Kindred (1919), e que tais informações não seriam o suficiente para romper com o paradigma vigente da origem conjunta dos dois sistemas; e que 2) as informações obtidas por estudos da anatomia de peixes ainda seriam preliminares, e só deveriam ser aplicadas ao desenvolvimento de peixes. Quanto à sua aplicação no desenvolvimento de ossos cranianos de vertebrados terrestres, este paralelo só poderia ser feito após propostas de homologia robustas entre ossos cranianos destes dois grupos. Dessa maneira, Pehrson (1944) colocava em cheque as afirmações de de Beer (1937), deixando a questão sobre a origem e relação desses dois sistemas ainda um assunto a ser esclarecido.

O desenvolvimento dos elementos da linha lateral cefálica foi posteriormente objeto de uma grande monografia de autoria de Lekander (1949). Em seu trabalho acerca da morfologia desse sistema em Ostariophysi, Lekander forneceu descrições bastante completas sobre o desenvolvimento dessas estruturas em diferentes espécies de Cypriniformes, além de também incluir um representante de Siluriformes. A principal contribuição de Lekander (1949) foi a descrição deste complexo em seus diferentes estágios do desenvolvimento, comparandoos entre as várias espécies analisadas. Em relação ao desenvolvimento do sistema sensorial e sua relação com ossos dérmicos, este autor pareceu inclinado a aceitar os argumentos de de Beer (1949). Em meio à suas descrições, Lekander observou que a origem dos componentes do sistema sensorial da linha lateral (composant dermo - sensu de Devillers, 1947) se dava nos primeiros estágios do desenvolvimento, e de maneira independente daquela dos ossos 
dérmicos (composant membrano) com os quais estes canais se associavam ao fim do desenvolvimento completo.

Uma das últimas contribuições sobre a identidade canal-osso dérmico foi dada por Graham-Smith (1979), que ao explorar a homologia dos ossos e linha lateral da região parietal de Crossopterygii e Dipnoi, apresentou um histórico bastante completo sobre estudos tratando da origem dos ossos dérmicos e canais sensoriais, oferecendo também sua contribuição pessoal. De forma simplificada, este autor defendeu um ponto de vista que, de certo modo, compatibilizaria as afirmações de Pehrson (1944) com as de Kindred (1919) e de Beer (1937). O autor citou que as influências do sistema sensorial cefálico sobre as ossificações dérmicas dependeriam principalmente da sequência de formação destes elementos em determinada região do crânio. Se, por exemplo, o canal sensorial supraorbital fosse o primeiro componente a surgir sobre a região dorsal craniana, isto poderia influenciar modificações celulares dos osteoblastos dérmicos, gerando os primeiros focos de ossificação das placas dérmicas nessa região em específico. Se, por outro lado, o canal sensorial tardasse em se formar, a membrana dérmica poderia se ossificar independentemente desse sistema, sendo o desenvolvimento do canal um estágio posterior do desenvolvimento dérmico craniano. Este surgimento desconexo de elementos dos dois sistemas poderia até resultar em distintos focos de ossificação ocorrendo sobre uma mesma região do crânio, já que o início da formação do canal poderia influenciar em um segundo foco de ossificação dérmica. O canal sensorial serviria portanto como uma espécie de "catalizador" que acarretaria na formação de placas ósseas ao seu redor. Esta mesma perturbação poderia ser causada pela presença de neuromastos em fossas ou ranhuras epidérmicas, explicando a presença de algumas pequenas ossificações de linhas de neuromastos encontradas na superfície craniana de determinados peixes (e.g. Salmoniformes). Em suma, Graham-Smith concluiu que "small bony ossicles that ensheath the canals provide sites at which the formation of the bones proper by ordinary membranogenic processes becomes initially focused. The laterosensory structures thus merely determine the precise positions, and perhaps also influence the timing, of membranogenic ossifications that would in any case develop". O autor, no entanto, baseia sua hipótese principalmente em especulações que tentam explicar a morfologia observada em seu grupo de interesse (Crossopterigyii e Dipnoi), sendo importante esclarecer que estas obsrvações carecem ainda de estudos genético ou ontogenético.

Uma abordagem mais moderna acerca desse complexo morfológico foi expressa por Bockmann (1998), em sua tese de doutoramento. Neste trabalho, ao justificar sua opção por nomear os elementos ósseos ao redor da órbita dos Siluriformes como túbulos suborbitais 
(versus infraorbitais sensu Fink \& Fink, 1981), Bockman (1998) argumenta a favor da origem desassociada dessas estruturas, reservando o termo "infraorbitais" às placas dérmicas cobrindo a lateral da cabeça dos Characiformes e dos Cypriniformes. Bockmann (1998) ainda afirma que seria um equívoco traçar a homologia entre os túbulos suborbitais dos Siluriformes e Gymnotiformes com as placas infraorbitais dos Characiformes, Cypriniformes e Gonorynchiformes, já que estes elementos são originários de complexos morfológicos distintos, mesmo recorrentemente encontrados em associação nos indivíduos adultos,.

\section{Histórico dos estudos do sistema látero-sensorial cefálico em Ostariophysi.}

O maior grupo de peixes de águas continentais da atualidade, com cerca de 7.900 espécies, é a Superodem Ostariophysi (Fink \& Fink, 1981, 1996), a qual inclui entre seus representantes os "milkfishes", "beaked sandfishes" e "snake mudheads" (Gonorynchiformes); carpas, "loaches" e "minnows" (Cypriniformes); curimbatás, dourados, lambaris, piaus e piranhas (Characiformes); cascudos, bagres, mandis e surubins (Siluriformes); e poraquês, sarapós e tuviras (Gymnotiformes). Com relação ao sistema látero-sensorial dos peixes ostariofisários, as ordens mais amplamente estudadas foram os Cypriniformes (Collinge, 1895; Allis, 1904; Lekander, 1949) e Siluriformes (Pollard, 1892; Herrick, 1901; Schaefer, 1990; de Pinna, 1993; Arratia \& Huaquín, 1995; Bockmann, 1998; Schaefer \& Aquino, 2000; Apone, 2008; Bockmann \& Miquelarena, 2010).

Os primeiros estudos envolvendo o sistema látero-sensorial de Ostariophysi datam da segunda metade do século XIX. Wright (1884) e McMurrich (1884) possivelmente apresentaram os primeiros relatos acerca desse sistema em um volume da revista "Proceedings of the Canadian Institute" dedicada a publicações focalizando diferentes complexos anatômicos da espécie Ameiurus catus (Ictaluridae). Wright (1884) descreveu o sistema sensorial do referido táxon, fornecendo as primeiras ilustrações desse sistema de um representante da ordem Siluriformes. Posteriormente, Pollard (1892) e Collinge (1895) descreveram e ilustraram tal sistema de diferentes espécies de Siluriformes, fornecendo informações também dos pares de nervos cranianos associados a tal sistema, comentando suas variações de maneira comparativa. Pollard (1892) tratou do sistema da linha lateral cefálica de representantes das famílias Clariidae, Claroteidae, Callichthyidae, Trichomycteridae e Loricariidae, e comparou seus resultados entre representantes dessas famílias e com demais Teleostei. Collinge (1895) forneceu mais informações sobre o sistema sensorial para os Siluriformes, atentando-se para a invariabilidade dos canais e dos poros da linha lateral cefálica. O autor ainda apresentou uma breve descrição dos poros tubulares e linhas de 
neuromastos de Labeo dussumieri (Cyprinidae), um representante da ordem Cypriniformes, além de fornecer informações inéditas sobre o sistema látero-sensorial cefálico de representantes das famílias Esocidae, Salmonidae e Muraenidae. Os trabalhos de Wright (1884), Collinge (1895) e Pollard (1892) foram os primeiros a ilustrar e reconhecer a homologia entre os canais e poros de diferentes famílias de Siluriformes, comparando-os de maneira superficial com alguns outros grupos de Teleostei.

Destaque especial deve ser dado à extensa monografia publicada por Herrick (1901). Esta se sobressai a qualquer outro trabalho da época por apresentar uma extensa descrição anatômica do sistema látero-sensorial cefálico e nervos envolvidos nesse sistema. Novamente o táxon utilizado como modelo para estas descrições foi um bagre, Ameiurus catus representante da família Ictaluridae. Na ocasião, Herrick (1901) justificou a escolha do táxon dizendo que nenhum outro grupo de peixes apresentaria tantas vantagens como os bagres, pois estes apresentavam grande diversidade, abundância e ampla distribuição de órgãos sensoriais, somado ao fato de não apresentarem escamas.

Seguindo a publicação de Herrick (1901), os outros trabalhos subsequentes tratando do sistema látero-sensorial cefálico dos Ostariophysi seriam os de Kindred (1919) e Lekander (1949). Enquanto Kindred se preocupou mais em descrever o desenvolvimento de todos os ossos cranianos de Ameiurus (Siluriformes, Ictaluridae), o objetivo de Lekander (1949) foi trabalhar especificamente na morfologia do sistema da linha lateral cefálica, reportanto variações deste sistema em diferentes táxons da ordem Cypriniformes, além de comentar brevemente sobre a morfologia dos canais em Plotosus anguillaris (=Plotosus lineatus), bagre escolhido especificamente por ser um exemplar marinho da ordem Siluriformes (Plotosidae).

Um dos mais importantes trabalhos abordando o sistema látero-sensorial de Ostariophysi publicados recentemente é o de Arratia \& Huaquín (1995). Neste trabalho, as autoras realizaram uma investigação detalhada sobre os padrões de distribuição de canais e poros desse sistema em diferentes integrantes da ordem Siluriformes (principalmente da família Diplomystidae e representantes da superordem Loricarioidea), comparando tais configurações com outros membros da Superordem. Como resultado, as autoras notaram que determinados canais sensoriais, como por exemplo, os supraorbitais apresentavam certa constância no que se refere à presença de ramos e poros, surgindo sempre em determinados limites entre ossos (e.g. extremidade anterior e posterior do osso nasal, extremidades laterais do osso frontal), o que possibilitou a proposta de hipóteses de homologia independente para cada um desses poros ao longo dos canais supraorbital, infraorbital, ótico e pós-ótico. Também, Arratia \& Huaquín (1995) listaram características exclusivas encontradas no sistema 
látero-sensorial cefálico de certos grupos de bagres (i.e. sinapomorfias). As autoras propuseram, por exemplo, que o ramo pterótico do canal pós-ótico, estrutura até então considerada sinapomórfica para todos os Siluriformes (Fink \& Fink, 1981), estivesse ausente em Loricarioidea, sendo esta perda uma reversão sinapomórfica para tal grupo (hipótese posteriormente refutada por Schaefer \& Aquino, 2000).

Ainda em relação ao sistema látero-sensorial dos Siluriformes, outros trabalhos de cunho anatômico-comparativo vieram a apresentar informações sobre esse complexo morfológico, desta vez explorando com mais detalhamento as variações deste sistema em um contexto cladístico. Como exemplo, destaca-se o trabalho de Bockmann \& Miquelarena (2008), estudo em que os autores trouxeram contribuições para o conhecimento do sistema láterosensorial cefálico de representantes de Heptapteridae, fornecendo ilustrações e descrições detalhadas dos poros e canais presentes de uma nova espécie de Rhamdella, e utilizando dessas informações para posicionar filogeneticamente o gênero dentre outros representantes da família. Outro exemplo é o trabalho de Apone (2008), que em uma dissertação ainda não publicada, apresentou resultados de uma investigação comparativa e filogenética do sistema látero-sensorial da família Pimelodidae.

Informações publicadas acerca do sistema da linha lateral cefálica de representantes de Gymnotiformes só se tornaram acessíveis muito recentemente. Diferentemente do panorama encontrado com relação aos outros Otophysi tratados acima, a morfologia do sistema sensorial cefálico de representantes de Gymnotiformes sequer havia sido estudada em um maior nível de detalhe até o fim do século XX. As primeiras informações desse sistema surgem como aplicações de algumas variações em um contexto cladístico, publicadas por Alberts apenas em 2001, em um trabalho abordando as relações filogenéticas entre exemplares da ordem Gymnotiformes. Contudo, as referências de Albert (2001) aos canais e poros do sistema láter-sensorial cefálico parecem ter seguido uma proposta de nomenclatura exclusiva de descrições de Gymnotiformes (Albert \& Fink, 1996; Albert et al., 1998), e que ainda carecem de uma descrição mais completa, o que pode ter impossibilitado qualquer tentativa de comparação dessas descrições com as disponíveis para os demais Ostariophysi.

Em relação à Gonorynchiformes, informações acerca da linha lateral cefálica dessa ordem ainda são extremamente raras. Apesar de haver uma publicação dedicada quase que exclusivamente à morfologia e relações filogenética dos peixes dessa ordem, informações acerca da linha lateral cefálica destes peixes foram negligenciadas. 0 pouco que pode ser resgatado acerca deste sistema parece figurar apenas em trabalhos de enfoque cladístico, 
detalhado em descrições de alguns caracteres em específico (Grande \& Poyato-Ariza, 1998; Britz \& Moritz, 2007; Grande et al., 2010).

\section{Estudos do sistema látero-sensorial cefálico em Characiformes.}

A ordem Characiformes é monofilética (Buckup, 1998; Moreira, 2007; Oliveira, 2011), sendo hoje composta por mais de 1.900 espécies válidas, das quais aproximadamente 1.750 são descritas da região Neotropical (Eschmeyer \& Fong, 2014). De acordo com Buckup (1998) e Nelson (2006), dezoito famílias compõem esta ordem (Citharinidae, Distichodontidae, Alestidae, Hepsetidae, Hemiodontidae, Parodontidae, Curimatidae, Prochilodontidae, Anostomidae, Chilodontidae, Erythrinidae, Lebiasinidae, Gasteropelecidae, Ctenoluciidae, Crenuchidae, Cynodontidae, Characidae, Acestrorhynchidae). Já Eschmeyer \& Fong (2014) reconhecem um total de vinte e três famílias (adotando Serrasalmidae, Bryconidae, Triportheidae, Iguanodectidae e Chalceidae neste nível taxonômico), com dezenove destas restritas às Américas, e outras quatro ocorrendo no continente africano. Dentre todas as famílias de Characiformes, a maior riqueza de espécies é encontrada em Characidae. Tal família abriga mais de 160 gêneros e por volta 1.100 espécies descritas (Eschmeyer \& Fong, 2014), sendo que aproximadamente 600 dessas espécies são registradas em território nacional (Buckup et al., 2007).

Apesar de sua diversidade morfológica e taxonômica, são poucos os trabalhos abordando especificamente, ou mesmo com algum grau maior de detalhe a anatomia do sistema látero-sensorial cefálico. Mais raros ainda são trabalhos que descrevem os poros que se projetam dos canais sensoriais de peixes da ordem Characiformes. Os primeiros trabalhos realizados sobre o tema foram publicações ainda no século XIX, tratando de abordagens descritivas dos canais e ossos dérmicos desses peixes. Uma das primeiras publicações encontradas tratando, mesmo que brevemente, dos canais sensoriais de Characiformes foi um trabalho do anatomista alemão Sagemehl, publicado em 1884. Este trabalho apresentou alguns trechos discorrendo sobre os canais cefálicos desses peixes, mas apenas anotando que estes eram variáveis entre os indivíduos por ele examinados.

De caráter descritivo, o maior destaque ainda é o clássico trabalho de Allis (1904). Neste, o autor apresentou o que talvez seja as primeiras ilustrações detalhadas das estruturas componentes do sistema látero-sensorial cefálico de representantes da ordem Characiformes, dedicando algumas páginas de seu trabalho a descrever detalhadamente o percurso dos canais sensoriais, os poros tubulares, e os neuromastos de canal (aos quais Allis denominou de sense 
organs) de Macrodon trahira (=Hoplias malabaricus, Erythrinidae), Hydrocyon brevis (=Hydrocinus brevis, Alestidae) e Alestes nurse (=Brycinus nurse, Alestidae). Entretanto, o principal objetivo desta publicação foi descrever o padrão geral dos canais sensoriais e ossos dérmicos de peixes como um todo, relatando suas variações em diversos outros táxons, incluindo representantes Chondrichthyes (Triakidae, Rajidae, Torpedinidae, Dalatiidae e Chimaeridae), e de diversos outros Osteichthyes (Acipenseridae, Polyodontidae, Gymnarchidae, Arapaimidae, Muraenidae, Esocidae, Salmonidae, Clupeidae, Gadidae, Pleuronectidae, Scombridae, Batrachoididae, Cottidae, Lophiidae). O autor também apresentou um breve comentário sobre as informações de canais látero-sensoriais obtidas em em fósseis.

Após as descrições de Allis (1904), mais de meio século se passou até que outro autor desse a devida atenção aos canais e poros da linha lateral cefálica de Characiformes. Somente na década de 1960, em uma descrição osteológica de Brycon meeki, Weitzman (1962) veio a fornecer ilustrações e comentários sobre os canais sensoriais cefálicos de um representante da ordem. Em seu trabalho, que tinha como objetivo principal descrever o esqueleto de um exemplar de Characiformes, comparando-o com informações disponíveis sobre outros representantes da ordem, Weitzman dedicou uma das pranchas de sua publicação somente aos ossos dérmicos portadores de canal (Weitzman, 1962: Fig. 9). Todavia, o autor reconheceu que a ilustração e as descrições desse sistema eram simplificadas, como se depreende da passagem "branches of the main laterosensory canals on the head of Brycon meeki are far more extensive than the bony distrbution here given", justificando o motivo pelo qual as ramificações e poros do sistema látero-sensorial (ou seja, qualquer porção que não deixava impressão ossificada) permaneceram fora de seu trabalho. Uma abordagem similar foi apresentada por Roberts (1969), que em um trabalho acerca das relações filogenéticas entre determinados grupos de Characiformes, ilustrou crânios de representantes de Hepsetus odoe, Ctenolucius hujeta, Hoplias malabaricus e Salminus brasiliensis. Neste trabalho, Roberts (1969) apresentou uma extensa descrição osteológica dos indivíduos analisados, incluindo nas descrições os detalhes dos canais da linha lateral cefálica, mas novamente preocupando-se apenas com as porções ossificadas desse canal, sem se aventurar em descrever os ramos e túbulos da linha lateral craniana.

Mais recentemente, algumas descrições contendo maior nível de detalhe sobre o sistema látero-sensorial cefálico de Characiformes podem ser encontradas, porém estas estão contidas principalmente em teses de doutoramento, e ainda não disponíveis em material publicado. Um exemplo é foi encontrado nas informações apresentadas por Oyakawa (1998) 
em sua tese tratando sobre as relações filogenéticas de Pyrrhulinidae, Lebiasinidae e Erythrinidae. Neste trabalho o autor levantou informações sobre o padrão de ramificações dos canais sensoriais e poros nos táxons incluidos em sua análise, utilizando-os como caracteres em sua filogenia. Tais caracteres acabaram se mostrando de grande valia em um contexto filogenético, pois sustentaram um clado composto pelos táxons "Gênero novo 1" e "Gênero novo $2^{\prime \prime}$, os quais compartilharam o padrão dendritico de ramificações, abrindo-se em inúmeros poros, da linha lateral cefálica.

Outros trabalhos mais recentes também trataram com maior detalhe do sistema látero-sensorial cefálico de representantes de Characiformes, porém estes sempre estiveram relacionados a animais troglóbios (e.g. Teyke, 1990; Montgomery et al., 2001), e sem qualquer interpretação comparativa mais ampla. Cabe ressaltar também que descrições anatômicas dos nervos cranianos relacionados aos canais e poros sensoriais dessa ordem, diferentemente do que é encontrado em outros Ostariophysi, nunca foram realizadas em representantes de Characiformes. Dados anatômicos sobre o sistema látero-sensorial cefálico, quando figuram na lista de caracteres examinados de análises filogenéticas, aparecem geralmente fazendo alusões ao reflexo dessas estruturas sobre o esqueleto, e muito raramente codificando variações dos ramos e poros tubulares relacionados a este sistema.

Atualmente, há três principais propostas de interrelações filogenéticas de Characiformes baseadas em caracteres morfológicos: a de Buckup (1998), a de Moreira (2007), e a de Mirande (2010). Buckup (1998), cujo objetivo principal foi definir as relações filogenéticas de Crenuchidae, propôs uma filogenia gerada de oitenta caracteres observados em 27 representantes de 16 famílias da ordem Characiformes (membros das famílias Serrasalmidae, Cynodontidae e Gasteropelecidae não foram incluídos em sua análise). Moreira (2007), em sua tese de doutorado versando sobre as relações filogenéticas de Characiformes, analisou 409 caracteres de 97 terminais, representando todas as 19 famílias da ordem. Já Mirande (2010) em um trabalho publicado de cunho filogenético, objetivando testar o monofiletismo da família Characidae, utilizou-se de 161 terminais e 365 caracteres em sua análise, que apesar de compor a mais ampla análise cladística já publicada envolvendo representantes de Characiformes, amostrou apenas 13 das 23 famílias reconhecidas na ordem.

Estes três trabalhos, apesar de detalhados, expressam de forma inequívoca o quanto informações sobre o sistema látero-sensorial cefálico são pouco exploradas em propostas filogenéticas de Characiformes. Dos oitenta caracteres listados por Buckup (1998), apenas quatro ( $5 \%$ do total) são diretamente ligados às variações observadas do sistema láterosensorial da cabeça, registrando apenas a presença ou ausência de canais sensoriais (canal 
supratemporal) ou de ramificações destes canais (ramo parietal do canal supraorbital), sem explorar qualquer variação observada nos poros presentes ao longo dos canais da linha lateral cefálica. De maneira similar, dos 409 caracteres propostos por Moreira (2007), apenas 24 estiveram relacionados à linha lateral cefálica, representando $5,8 \%$ de todos os caracteres incluidos na análise. Em Mirande (2010) apenas 18 dos 365 caracteres, ou seja, 4,9\% se referem à homologias do sistema da linha lateral cefálica.

Dos poucos trabalhos de cunho filogenético que se preocuparam em explorar elementos da linha lateral cefálica a fim de obter caracteres morfológicos, a publicação de Sidlauskas \& Vari (2008) merece maior destaque. Este trabalho acerca das relações filogenéticas de representantes da família Anostomidae representa um dos raros exemplos em que variações envolvendo não só os canais sensoriais, mas também a morfologia e número de poros da linha lateral cefálica foram utilizados como fonte de informação filogenética. Neste, os autores notaram, por exemplo, uma extensão ântero-dorsal do canal infraorbital em exemplares da subfamília Anostominae que porta um número de poros superior a qualquer outro Anostomidae ou Characiformes examinados como grupo-externo no referido trabalho. Este prolongamento do canal infraorbital foi considerado como uma das sinapomorfias a suportanto o monofiletismo da subfamília (sensu Winterbottom, 1980).

Entretanto, o exemplo acima citado representa uma exceção ao panorama atualmente observado em relação ao uso de caracteres de linha lateral em trabalhos de cunho filogenético de Characiformes. Na verdade a homologia e o número de ramificações de cada canal em Characiformes, bem como a localização desses poros ao deixar os canais ossificados e se abrir sobre a superfície da pele ainda são amplamente desconhecidos no grupo. Mesmo em análises filogenéticas de grupos taxonômicos de menor abrangência na ordem, a escolha dos caracteres, quando relacionadas aos canais sensoriais, se restringem ao padrão de ramificações desses canais (Vari et al., 1995; Castro \& Vari, 2004; Zanata \& Vari, 2005; ToledoPiza, 2007), sem dar atenção ao número e padrão de abertura dos poros presente ao longo dos mesmos. Uma explicação para tal panorama é, sem dúvidas, a falta de informação primária, descritiva sobre esse complexo de caracteres, de tal forma que seu potencial filogenético se mantenha desconhecido.

Constata-se, portanto, que estudos comparativos sobre o arranjo dos poros da linha lateral cefálica, abordando a diversidade filogenética de Characiformes, não foram realizados até o momento. Tendo em vista que em outros grandes grupos de peixes os atributos relacionados ao sistema látero-sensorial cefálico são muito diversificados e, por outro lado, altamente conservados em cada linhagem, é de se supor que uma ampla diversidade deste 
complexo anatômico será encontrada nas famílias de Characiformes e em seus subgrupos menos inclusivos, levando-se em consideração a notável diversidade taxonômica da ordem. Por esta razão, foi aqui realizada uma investigação sobre o padrão de ramificação e da disposição dos canais sensoriais cefálicos e poros de Characiformes. Tal estudo teve como maior objetivo apresentar uma descrição do padrão geral das ramificações dos canais sensoriais presentes na cabeça de representantes da ordem, e de apresentar também junto a essa, informações a respeito da presença e variação individual dos poros encontrados ao longo dos canais sensoriais, propondo uma hipótese de homologia para cada um deles. Para cumprir com tal meta, não só exemplares de Characiformes foram examinados, mas também um extenso grupo-externo foi incorporado na análise para melhor se compreender as variações de cada um dos componentes do sistema da linha lateral cefálica.

A partir da descrição desse complexo morfológico, unida com o levantamento de características do sistema látero-sensorial cefálico, foram aqui apresentadas informações inéditas que, se incorporadas em análises filogenéticas, auxiliarão no melhor entendimento das relações de parentesco entre os diferentes táxons componentes da ordem Characiformes. Houve ainda a preocupação de se apresentar hipóteses de homologia primária sobre seções particulare do sistema látero-sensorial cefálico, resgatando informações há tempos descritas sobre o padrão de desenvolvimento das estruturas componentes do referido sistema, bem como seu papel na formação e associação com estruturas ósseas cranianas. 


\section{Justificativas.}

O sistema látero-sensorial cefálico possui forte potencial para a identificação e estabelecimento de homologias entre ossos dérmicos do crânio. Poucas análises descritivas sobre a estrutura e desenvolvimento desse complexo sensorial foram realizadas em Characiformes. Informações sobre esse sistema têm sido incluídas em trabalhos de cunho filogenético, porém quase sempre envolvendo caracteres restritos às ossificações e ramificações dos canais sensoriais, utilizando pouca ou nenhuma informação sobre a distribuição dos poros desses canais sensoriais (e.g. Vari, 1983; Vari et al. 1995; Zanata \& Vari, 2005; Toledo-Piza, 2007).

Frente a estes argumentos, julgou-se necessário a realização de um estudo comparativo aprofundado dos canais látero-sensoriais cefálicos de representantes de Characiformes, bem como a descrição formal do padrão de ramificação dos poros, atentandose à sua relação com as ossificações dérmicas cranianas. Particularidades do arranjo geral e da distribuição de poros são muito conservadas nas diferentes linhagens e, portanto, altamente informativas para análises filogenéticas (F. A. Bockmann, com. pess.). A complexidade morfológica desse sistema deixa implícito que o mesmo pode representar uma grande fonte de informações anatômicas, se tornando importante ferramenta para futuras propostas filogenéticas com relação ao grupo. 


\section{Objetivos.}

1. Descrever e ilustrar os canais látero-sensoriais cefálicos (incluindo seus ramos acessórios e padrões de distribuição de poros na pele), bem como de ossos dérmicos associados, de representantes de todas as famílias e de subgrupos relevantes da ordem Characiformes, estabecendo assim hipóteses de homologias primárias (sensu de Pinna, 1991) entre suas partes constituintes.

2. Indicar novos atributos envolvendo este complexo sensorial que sejam potencialmente informativos para elucidas relações filogenéticas e revisar aqueles que foram previamente propostos.

3. Comparar a anatomia do sistema látero-sensorial cefálico de Characiformes com àquela apresentada pelos demais Ostariophysi e Teleostei, na tentativa de se mapear possíveis sinapomorfias de Characiformes quanto de outros grupos monofiléticos dentro da Superodem Ostariophysi. 


\section{Material e Métodos.}

\section{Escolha dos táxons.}

A lista de material examinado é apresentada em Anexo. O material examinado se encontra preservado em álcool 70\% (Alc.) ou em Glicerol (C\&S), caso dos exemplares diafanizados. Um total de 36 representantes da ordem Characiformes foram escolhidos, incluindo no mínimo um representante de cada uma das 19 famílias reconhecidas da ordem (sensu Buckup, 1998; Nelson 2006; Oliveira et al., 2011) além de uma família nova monotípica, possivelmente relacionada à Erythrinoidea (sensu Oyakawa, 1998), atualmente em processo de descrição formal (de Pinna, com. pess). O gênero neotropical Chalceus, tradicionalmente tratado em sua própria família, Chalceidae, e atualmente assinalado à família Alestidae (sensu Zanata \& Vari, 2005), também foi incluido. Em relação à classificação taxonômica de subfamílias dentro de Characidae, foram adotadas Iguanodectinae, Characinae e Bryconinae, propostas por Moreira (2003), Lucena \& Menezes (2003) e Lima (2003), respectivamente, e publicadas no Check List of Freshwater Fishes of South and Central America (Reis et al., 2003). Entretanto, duas principais modificações foram adotadas em relação às demais subfamílias de Characiformes: Triportheinae foi considerada uma subfamília de Characidae (sensu Buckup et al., 2007) e Serrasalmidae uma família de Characiformes (sensu Ortí et al. 2008; Mirande, 2010; Oliveira et al., 2011). Demais subfamílias de Characiformes reconhecidas neste trabalho, além das propostas apresentadas em Reis et al. (2003) foram: Anostominae (sensu Winterbottom, 1980), e Crenuchinae e Characidiinae (sensu Buckup, 1993). Apesar de o presente trabalho reconhecer apenas vinte famílias em Characiformes, todos os vinte e três táxons reconhecidos por Oliveira et al. (2011) ou Eschmeyer \& Fong (2014) foram amostrados neste estudo. As espécies Brycon nattereri, Iguanodectes variatus e Triportheus angulatus, aqui incluídas em Characidae, poderiam ser alternativamente tratadas como representantes das famílias Briconidae, Iguanodectidae e Triportheidae (sensu Eschmeyer \& Fong, 2014). Das vinte famílias de Characiformes amostradas, sete destas (i.e. Alestidae, Characidae e Anostomidae, Crenuchidae, Lebiasinidae, Distichodontidae e Serrasalmidae) foram representadas por mais de uma espécie (Anexo - Material incluido na análise: Characiformes). Tal escolha se deu tanto pela disponibilidade do material, quanto pelo fato de alguma dessas famílias serem reconhecidamente detentoras das maiores diversidades morfológica e taxonômica dentro da ordem Characiformes. Para as demais famílias da ordem, a amostra incluiu uma espécie apenas. 
Outros vinte táxons foram selecionados para compor o grupo-externo da análise comparativa (Anexo - Material incluido na análise: Grupo-externo). Destes, foram incluidos treze exemplares da superordem Ostariophysi, amostrando no mínimo dois táxons de cada uma das outras ordens. Opções foram feitas por táxons já tratados em outros trabalhos descritivos de linha lateral cefálica (e.g. Arratia \& Huaquín, 1995; Arratia \& Gayet, 1995), ou táxons já apontados como detentores de uma morfologia generalizada (primitiva) e recorrentemente utilizados em análises filogenéticas da superordem (sensu Fink \& Fink, 1981, 1996). Além destes, sete outros táxons componentes de Teleostei não-Ostariophysi, foram incluídos na análise de grupo-externo, de modo a facilitar o mapeamento de características mais conservadas dentre os Ostariophysi e melhorar a compreensão das variações do sistema látero-sensorial cefálico como um todo. No total, cinquenta-e-seis táxons foram utilizados na análise comparativa dos canais e poros do sistema da linha lateral cefálica.

Somados ao material comparativo listado acima, outros vinte-e-sete táxons foram examinados para o presente trabalho (Anexo - Lista de Material Suplementar) com o propósito de embasar as discussões a respeito de problemas específicos de homologia de canais, poros ou ossos dérmicos. A opção de não incluí-los na análise comparativa junto ao material acima listado se deu pela impossibilidade de visualização de todos os canais e poros da linha lateral cefálica (em material dissecado, por exemplo), ou eventual escassez desses materiais em coleções ictiológicas, impossibilitando a sua utilização em procedimentos destrutivos (diafanização e dissecção). Dos táxons incluidos como material suplementar, quatorze são representantes da ordem Characiformes, quatro outros eram componentes das ordens Cypriniformes e Siluriformes (Ostariophysi), além de nove representantes de grupos não ostariofisianos. 


\section{Nomenclatura anatômica.}

A nomenclatura osteológica seguiu Weitzman (1962), adotando modificações propostas por Castro \& Vari (2004), e a nomenclatura em português de Castro \& Castro (1987). Exceções foram ossos infraorbitais 1 a 6 , que aqui foram denominados de placas infraorbitais 1 a 5 somadas a uma placa dermoesfenótica (infraorbital 6 sensu Castro \& Castro, 1987), de modo a evitar confusões dessas com os termos aplicados aos canais e poros infraorbitais. Para a nomenclatura dos canais do sistema látero-sensorial cefálico, foram utilizados como base os trabalhos de Webb (1989), Arratia \& Huaquín (1995) e Bockmann \& Miquelarena (2008). Para a denominação dos ramos ou poros dos canais supraorbital e infraorbital, a terminologia aqui adotada seguiu a nomenclatura adotada por Arratia \& Huaquín (1995), que enumeraram os poros ântero-posteriormente, indicando com uma letra "s" aqueles encontrados ao longo do canal supraorbital, e uma letra " $\mathrm{i}$ " os que ramificam do canal infraorbital. A mesma proposta nomenclatural foi adotada para denominar os poros dos canais ótico, pós-ótico, supratemporal, pré-opercular e mandibular (abreviados por um $\mathbf{O}, \mathbf{P O}, \mathbf{S T}, \mathbf{P R}$ e $\mathbf{M}$, respectivamente). Exceção foi feita em relação à denominação do ramo encontrado ânterodorsalmente ao canal infraorbital dos Siluriformes (i2 sensu Arratia \& Huaquín, 1995). Este ramo e poro foi aqui indicado precedido da letra $\mathbf{A}$, e a porção de canal referida como porção antorbital do canal infraorbital. Tal decisão foi tomada de modo a adequar a nomenclatura dos poros dessa região às informações acerca de seu desenvolvimento, já que há evidências de que este trecho de canal apresente uma origem ontogenética independente do restante do canal infraorbital (Lekander, 1949). Por vezes, a contagem de poros ao longo de determinado canal sensorial revelou um número elevado destas estruturas partindo do canal principal quando comparados ao número regularmente encontrado nos demais táxons examinados. Estes poros foram considerados supranumerários em relação aos seus poros adjacentes, e sua identificação acompanhou um símbolo de asterisco (*).

Os termos ramo (ou ramo acessório) e poro receberam denominações por vezes intercambiáveis ao longo do texto, uma vez que, na maior parte dos táxons examinados, cada ramificação do canal látero-sensorial principal se abriu na superfície epitelial por meio de um único poro (exceção observada em Hoplias aimara). O termo ramo é definido aqui como o prolongamento tubular, por vezes ossificado, que leva à abertura dos poros na supertície epitelial (e.g. ramo parietal, ramo epifiseano, ramo pterótico do canal pós-ótico). Por outro lado, o termo poro foi aplicado apenas às terminações dos ramos do canal látero-sensorial, onde estes se abriam na superfície tegumentar. Por vezes foram notadas aberturas de poros diretamente sobre o canal látero-sensorial, uma condição em que a abertura de poro não 
esteve associada à uma ramificação tubular. Estes casos, quando presentes, são citados ao longo do texto.

Demais termos anatômicos utilizados no presente trabalho referem-se às abreviações presentes nas listas de Materal Examinado e de Material Suplementar. Estas foram CP para comprimento padrão, tomado da ponta do focinho até extremidade posterior da placa hipural; CT para comprimento total, tomado da ponta do focinho até a extremidade posterior dos últimos raios da nadadeira anal ou caudal; ou CC para comprimento da cabeça, tomado da ponta do focinho até a margem óssea posterior do osso opercular. 


\section{Preparação do material e confecção das imagens.}

A maior parte das observações de ossificações dos canais látero-sensoriais, bem como de túbulos e poros presentes na superfície da pele, foram realizadas em espécimes diafanizados de acordo com Taylor \& van Dyke (1985). A análise do material se deu com o auxílio de estereomicroscópios Zeiss SV-11, Leica M50 e Leica MZ16. Imagens das regiões do crânio contendo canais sensoriais foram obtidas com uma câmera microscópica digital Leica DFC420 acoplada ao estereomicroscópio Leica MZ16 (no Laboratório de Ictiologia de Ribeirão Preto) e um sistema de captura digital de imagens Zeiss AxioCam acoplado a um estereomicroscópio Zeiss Discovery V12 (no National Museum of Natural History, Smithsonian Institution). As imagens foram trabalhadas de modo a evidenciar os elementos da linha lateral cefálica com o auxílio do software Adobe Photoshop e Adobe Illustrator, ambos na versão CS5, e serviram de base para as ilustrações, estas apresentadas ao final do texto. As Ilustrações foram realizadas em papel vegetal com tinta preta, baseando-se tanto nas imagens capturadas quanto em observações feitas em lupa dos exemplares diafanizados. As ilustrações foram posteriormente digitalizadas com o auxílio de um scanner modelo Samsung SCX-4200 e editadas no software Adobe Illustrator CS5, e visam auxiliar o acompanhamento das descrições e discussões apresentadas ao longo do texto. 
4. Acrônimos institucionais.

O material utilizado no presente trabalho teve sua origem em diferentes instituições e/ou centros de pesquisa. Grande parte dos táxons utilizados foi obtida na coleção do Laboratório de Ictiologia de Ribeirão Preto (LIRP), instituição sede e onde foi desenvolvida a maior parte do projeto. Demais instituições brasileiras que contribuíram com empréstimo de material foram: Laboratório de Biologia e Genética de Peixes, Universidade Estadual Júlio de Mesquita Filho (LBP); Museu de Zoologia da Universidade de São Paulo (MZUSP); Laboratório de Estudos Subterrâneos e Coleção Ictiológica, Universidade Federal de São Carlos (LESCI); e Museu Paraense Emílio Goeldi (MPEG). Instituições estrangeiras que contribuíram com material foram a Academy of Natural Sciences of Drexel University (ANSP); e National Museum of Natural History (NMNH), ambas sediadas nos Estados Unidos da América. 


\section{Resultados e Discussões.}

\section{Canais sensoriais cefálicos de Characiformes.}

O sistema da linha lateral dos Characiformes apresentou-se bastante conservado dentre os exemplares das diferentes famílias analisadas. O padrão básico de ramificação desse sistema nos Characiformes, que é de certa maneira bastante semelhante ao padrão descrito da maioria dos Teleostei, consistindo de um par de canais da linha lateral (trunk canals) e sete pares de canais principais com inervação distinta entre si (sensu Webb 1989): supraorbital, infraorbital, pré-opércular, mandibular, ótico, pós-ótico e supratemporal. Sub-ramificações desse sistema, quando encontradas, consistiram-se na verdade em porções ossificadas de determinados segmentos acessórios, comumente encontrados ao longo do canal supraorbital (ramo epifiseano e ramo parietal), nas placas infaorbitais (ramos S2, S7 e S10; Weitzman, 1962 - Fig.9; Mirande, 2010 - Figs. 38, 39 e 41), sobre o osso pré-opercular (ramos PR3 a PR5), sobre a extraescápula (ramo ST1), e sobre o supracleitro (ramo PO5).

Os resultados apresentados abaixo acompanham uma descrição do padrão básico de distribuição dos canais sensoriais cefálicos de Characiformes, que tomou como base o padrão observado em um exemplar do gênero Brycon nattereri, táxon escolhido propositalmente para esse objetivo por ter sido objeto de estudo de um vasto trabalho de descrição anatômica (Weitzman, 1962) e por ser recorrentemente citado como detentor de um padrão generalizado em relação às características desse sistema (Lundberg, 1975; Arratia \& Gayet, 1995). Variações do padrão básico de distribuição dos canais sensoriais de Characiformes (ex. ausência ou contato entre canais) são descritas ao longo do texto quando observadas, indicadas nas ilustrações e codificadas em tabelas, ambas apresentadas ao final do texto. Comparações com a anatomia apresentada por táxons incluidos no grupo-externo são apresentadas em um item independente, tratado abaixo no tópico Demais considerações acerca dos canais sensoriais cefálicos - comparações com o grupo-externo. 


\subsection{Canal supraorbital (Figuras 1 a 11).}

O canal supraorbital de Brycon nattereri encontra-se ao longo da superfície dorsal da cabeça, prolongando-se desde sua região anterior até a posterior, observado em associação aos ossos nasal, frontal e parietal. Ao longo do canal supraorbital observaram-se duas principais ramificações majoritariamente ossificadas sobre os ossos dorsais do crânio: o ramo epifiseano e o ramo parietal (Fig. 1 - ramos $\mathrm{S} 6$ e S8, respectivamente). A mais anterior delas, comumente denominada ramo epifiseano, projeta-se medialmente do canal supraorbital e segue em direção à fontanela craniana. Ao longo da extensão do ramo epifiseano foi possível observar sua impressão ossificada sobre o osso frontal, iniciando-se no ponto de ramificação deste em relação ao canal supraorbital principal, e seguindo até sua porção mais distal, atingindo a margem medial do osso frontal (Fig. 1 - S6; Weitzman, 1962 - Fig. 9). Outra ramificação do canal supraorbital, o ramo parietal, também foi facilmente observada em Brycon nattereri. Este ramo projeta-se do canal principal supraorbital em direção ao osso parietal, e nesse ponto, segue como túbulo não ossificado na pele, abrindo-se em um poro próximo ao limite posterior do crânio (Fig. 1-S8).

Algumas variações relacionadas à morfologia do canal supraorbital puderam ser notadas durante análise de grupo-interno, compreendendo exemplares das diferentes famílias analisadas de Characiformes. A mais notável dessas modificações talvez tenha sido encontrada em espécies da família Acestrorhynchidae (Fig. 2). Nestes táxons, a porção anterior do canal supraorbital, que normalmente encontra-se disposta sobre o osso nasal, apresentou um prolongamento anterior e associação com o osso pré-maxilar, característica considerada sinapomórfica para esta família (Menezes, 1969; Toledo-Piza \& Menezes, 1996; Toledo-Piza, 2007 - Car. \#98). Interessantemente, este prolongamento parece ter sido resultado de um deslocamento anterior de um dos neuromastos do canal supraorbital, e não de ganho de neuromastos nesse trecho, já que o número de poros visualizados ao longo da porção anterior do canal supraorbital dos Acestrorhynchidae se manteve no padrão observado em outros Characiformes.

Outros ramos do canal supraorbital dos Characiformes apresentaram variações. 0 ramo 55 , por exemplo, por vezes se prolonga lateralmente, abrindo próximo à margem do osso frontal posteriormente à porção posterior da órbita. A condição mais comum foi a de este ramo apresentar uma pequena porção ossificada, seguida de um túbulo epitelial que se abre em poro na superfície tegumentar (Fig. 7). Todavia, em alguns táxons o ramo S5 está completamente ossificado sobre osso frontal (Fig. 10 ), enquanto outros apresentaram apenas uma abertura no canal principal, por onde a porção tubular abria diretamente para a superfície 
externa, sem qualquer prolongação, seja ossificada ou não (e.g. representantes da família Lebiasinidae e Ctenoluciidae - Fig. 5).

Ainda com relação ao ramo S5, uma característica interessante foi notada sobre o local em que este se ramificava em relação ao sexto ramo supraorbital (ramo epifiseano). Na grande maioria dos representantes analisados da ordem Characiformes que possuíam ambos os ramos, a origem do ramo S5 é alinhada ou posterior à origem do ramo S6 (Figs. 3, 6, 7 e 8). Esta inversão na sequência de ramificação desses poros, todavia, não acarretou em dificuldades em se estabelecer a homologia desses dois ramos, já que o poro S6 foi frequentemente encontrado orientado medialmente, enquanto o ramo e poro S5 sempre se projetava lateralmente. A decisão de se utilizar tal nomenclatura, denominando S5 um poro que se abre posterior ao 56 , justifica-se por seguir uma proposta de identificação de poros supraorbitais já utilizada por Arratia \& Huaquín (1995: Fig. 3C) aplicada a um exemplar de Xenocharax spilurus, caraciforme da família Distichodontidae.

Variações também foram notadas na anatomia do ramo epifiseano (S6) dentre os diferentes exemplares de Characiformes. Este ramo pode tanto projetar medialmente em direção à fontanela craniana, deixando uma impressão ossificada ao longo de sua extensão (Figs. 8 e 10), ou apenas se abrir diretamente sobre a superfície do canal supraorbital, sem se prolongar medialmente (Fig. 11). Esta característica se mostrou bastante variável dentre os Characiformes analisados, mesmo que a condição de apresentar ramificações curtas ou sem projeções do ramo epifiseano pareceu ser conservada ao menos para representantes da família Lebiasinidae. Estes táxons apresentavam não só o ramo epifiseano, mas todas as aberturas de poros supraorbitais localizadas imediatamente sobre o canal principal, apresentando porções tubulares bastante curtas (Figs. 5 e 11; Weitzman, 1964: figs. 2 e 3).

O ramo parietal (S8) também apresentou variações relacionadas à sua presença e sua extensão ossificada ou não. Este variou de ausente (Fig. 4), a uma abertura próxima à porção posterior do canal supraorbital, totalmente contida no osso frontal (e.g. Iguanodectes variatus, Lebiasina melanoguttata, Pyrrhulina cf. australis; Fig. 5; Weitzman 1964, figs 2 e 3), ou até um longo ramo projetado posteriormente, apresentando-se ossificado até próximo à margem posterior do osso parietal (Figs. 1, 2, 3, 6, 7, 8, 9 e 10). A presença do ramo parietal esteve relacionada à presença do poro $\mathrm{S} 8$, e sua frequência nos Characiformes será discutida no item Poros ao longo do canal supraorbital de Characiformes.

Por fim, uma característica notável encontrada ao longo do canal supraorbital foi a morfologia distinta apresentada por Toracocharax stellatus (Gasteropelecidae). A porção de canal sobre os ossos frontal e parietal desse táxon não se encontravam fechadas em um 
túbulo típico, como os vistos em outros Characiformes. Diferindo-se de qualquer outra condição observada, as margens laterais do osso frontal desse táxon são elevadas, de modo que toda a superfície craniana fica separada da superfície tegumentar e coberta por uma membrana de pele. Por não se fechar em um canal tubular, não foi possível averiguar a presença de ramos e poros sobre o canal supraorbital desse táxon. Todavia, postula-se que os neuromastos de canal ainda estejam presentes sob a membrana que recobre a superfície dorsal do crânio mesmo sem uma formação de canal. A natação com a porção dorsal do crânio muito próxima à superfície da água é um comportamento comum dos táxons integrantes da família Gasteropelecidae, este que possivelmente esteja ligado ao fato deste táxon utilizar das modificações estruturais do canal supraorbital na percepção de vibrações na superfície da água (Cristiano Moreira, Com. pess.). 


\subsection{Canal infraorbital (Figuras 1 a 7; Figuras 12 a 17).}

De maneira geral nos Characiformes, o canal infraorbital foi encontrado associado às placas ósseas que circundam a órbita ocular, geralmente situado ao longo da margem interna dessas, prolongando-se desde a região anterodorsal da primeira placa infraorbital até a extremidade dorsal da placa dermoesfenótica (infraorbital 6; Figs. 1 a 7, Fig. 12). Das ramificações encontradas ao longo do canal infraorbital, três delas merecem maiores comentários por se apresentarem recorrentemente ossificadas, associadas às placas infraorbitais. O primeiro destes ramos foi observado logo sobre a primeira placa infraorbital (Fig. 2 -i2; Weitzman, 1962 - Figs. 8 e 9, infraorbital 1), responsável pela abertura do poro i2, sendo ossificado ao longo de sua extensão na maior parte dos caraciformes (Figs. 2 e 7). Outro ramo frequentemente ossificado sobre as placas infraorbitais de Characiformes foi o S7 (Figs. 2, 3 e 7 - i7; Weitzman, 1962 - Figs. 8 e 9, infraorbital 4). Novamente esta condição foi bastante comum à ordem, sendo a sua porção ossificada sobre a placa infraorbital 4 utilizada como fonte de caracteres para análises cladísticas (Mirande, 2010 - Car. \#74). Por fim, uma última ramificação notável ao longo do canal infraorbital de Characiformes, está localizada ao longo do seu trecho mais distal, estendendo-se ântero-doresalmente sobre a placa dermoesfenótica onde se abre em um poro (i10) (Figs. 1, 7, 13, 14 e 15; Weitzman, 1962: Figs. 8 e 9, infraorbital 6). Este ramo também esteve presente em boa parte dos exemplares examinados, presente tanto em uma condição ossificada, associado à placa dermoesfenótica, quanto em uma condição livre da placa, prolongando-se por um túbulo epitelial antes de se abrir no poro i10 (Fig. 7). O padrão de ossificação deste ramo sobre a placa dermoesfenótica já foi utilizada em análises cladísticas (e.g. Vari, 1995 - Car. \#15; Mirande, 2010 - Car. \#76).

O representante da família Erythrinidae (i.e. Hoplias aimara) apresenta uma condição bastante peculiar no canal infraorbital, exibindo um prolongamento ântero-dorsal do canal infraorbital, que se dispõe sobre a ossificação antorbital, e aqui tratado como trecho antorbital do canal infraorbital (A1). Devido à inexistência de um osso antorbital independente, e a presença de uma bifurcação do canal e da primeira placa infraorbital Erythrinidae (Fig. 12), Weitzman (1964) supôs que o osso antorbital e o primeiro infraorbital estivessem coossificados, ou que o osso antorbital estivesse ausente, com o primeiro infraorbital se extendendo sobre a região primitivamente ocupada pelo antorbital, (Weitzman, 1964). Trabalhos posteriores acusaram a ausência do osso antorbital (Vari, 1995; Oyakawa, 1998), argumentando não terem observado qualquer resquício de sutura entre ambos os ossos, ou a condição dos desassociada dos mesmos em exemplares juvenis. Weitzman (1964), e também Nelson (1969: fig. 4B) parecem ter se baseado em duas peculiaridades para proporem a 
condição fundida entre a placa antorbital e infraorbital 1: a existência nesse táxon de um trecho antorbital do canal sensorial, que nas palavras de Weitzman (1964), se assemelhavam em muito à condição observada nos Siluriformes ou Cyprinodintiformes; e a existência de uma bifurcação na porção ântero-dorsal desta ossificação. Especificamente a respeito da bifurcação na porção anterior do primeiro osso infraorbital, sua existência parece ser uma possível consequência da proximidade entre a narina posterior e a ossificação da primeira placa infraorbital. Ao longo do desenvolvimento desses indivíduos, a ossificação antorbital parece expandir-se anteriormente e dorsalmente, envolvendo a porção ventral da narina posterior e adquirindo um aspecto furcado em sua porção mais dorsal. Dessa maneira, apesar da existência de um ramo antorbital do canal infraorbital ser uma característica exclusiva dos Erythrinidae, estes o apresentam sem que exista de fato uma ossificação da placa antorbital. Já a ausência de tal placa parece ser uma característica compartilhada entre os Erythrinidae e os Ctenoluciidae (sensu Vari, 1995; Oyakawa, 1998).

Apesar de alguns trabalhos reportarem uma condição similar da porção anterior do canal infraorbital de integrantes do gênero Boulengerella (Vari, 1995 - Fig. 2), a condição presente em Hoplias aimara foi aqui considerada distinta daquela apresentada pelos Ctenoluciidae. Vari (1995), em seu trabalho de revisão taxonômica e filogenia de Ctenoluciidae, listou como sinapomorfia do gênero Boulengerella a presença de uma série de canais sobre a placa supraorbital, que, em sua opinião, poderiam estar conectados ao canal sensorial infraorbital. O exame do mesmo material utilizado no trabalho de Vari (1995) (Lista de material suplementar - USNM 319783; USNM 319782; USNM 293169; USNM 121334), descartou a hipótese de que o complexo de canais presente sobre a ossificação supraorbital em Boulengerella fosse uma ramificação do canal sensorial infraorbital. Ao que pode ser notado, tais canais ilustrados por Vari (1995) sobre o antorbital de Boulengerella não apresentaram qualquer conexão com o trecho percorrendo a primeira placa infraorbital, e tampouco apresentaram abertura de poros tubulares típicos, como visto ao longo do supraorbital em Erythrinidae. Todavia, a morfologia da superfície externa da placa supraorbital de Boulengerella de fato é distinta daquela observada em exemplares do gênero Ctenolucius, ou em qualquer outro caraciforme, o que justificaria sua condição sinapomórfica em Boulengerella (Vari, 1995 - Car. \#69) embora sua homologia primária seja distinta, não a relacionada aos canais sensoriais infraorbitais. Acerca da homologia do trecho antorbital do canal infraorbital, apesar de exclusivo em Erythrinidae, este foi observado em diferentes representantes do grupo-externo. 
Ainda acerca da morfologia do canal infraorbital de Characiformes, foram encontrados alguns trabalhos de cunho taxonômico/anatômico reportando a presença de elementos do canal sensorial infraorbital em associação com a porção anterodorsal do osso maxilar nos Acestrorhynchidae (Menezes, 1969). No presente trabalho, tal condição não foi encontrada em nenhum dos exemplares examinados. Todavia, encontrou-se de fato um canal percorrendo o osso maxilar de diferentes táxons analisados (Figs. 4 e 6). Entretanto, tal canal é um forâmen no osso maxilar relacionado à passagem de nervos e vasos sanguíneos, e não ao sistema látero-sensorial cefálico. Notou-se também que este forâmen era mais evidente em exemplares da família Acestrorhynchidae, ou da subfamília Characinae (Menezes, 1976), os mesmos táxons a apresentarem sobreposição da primeira e segunda placa infraorbital sobre boa parte do osso maxilar (Fig. 2), o que pode ter originado alguma confusão sobre a identificação deste, relacionando-o com elementos dos canais infraorbitais.

Na porção posterior do canal infraorbital, pode existir uma ramificação sobre a placa dermoesfenótica (placa infraorbital 6), que se projeta ântero-dorsalmente, próxima ao contato entre o dermoesfenótico com o osso frontal (Figs. 1, 7, 13, e 15). Na extremidade dessa bifurcação, que é encontrada em 14 dos 36 Characiformes, se abre o poro i10. Diversos estudos de cunho filogenético já utilizaram de tal ramificação como caráter em suas matrizes (e.g. Zanata \& Vari, 2005 - Car. \#153; Sidlauskas \& Vari, 2008, - Car. \#12; Mattox \& ToledoPiza, 2012 - Car. \#62). Entretanto, a hipótese de homologia de tal ramo que é defendida no presente trabalho se difere daquelas apresentadas nos trabalho acima por se basear no número e distribuição de poros do canal infraorbital, e não apenas nas ossificações deste canal sobre a placa dermoesfenótica.

Antes de se discorrer sobre tal hipótese, cabe uma descrição mais especifica da morfologia dos canais e poros dispostos sobre o osso dermoesfenótico de Xenocharax spilurus, um táxon da família Distichodontidae, costumeiramente utilizado como grupo-externo, ou táxon basal, em análises filogenéticas envolvendo Characiformes (e.g. Fink \& Fink, 1981; Zanata \& Vari, 2005; Sidlauskas \& Vari, 2008; Mattox \& Toledo-Piza, 2012). Este táxon, que também apresenta uma ramificação dos canais sobre o dermoesfenótico, apresenta o canal infraorbital ligando-se posteriormente ao canal supraorbital, em um ponto de contato entre a placa dermoesfenótica e o osso frontal, e lateralmente ramificando-se e dando início ao canal ótico, com grande parte desse canal disposto sobre o dermoesfenótico, e uma pequena fração sobre o pterótico (Fig. 17; Vari, 1979: fig. 20). Apesar da configuração observada em Xenocharax spilurus (Fig. 17) se assemelhar bastante àquela de outros Characiformes (Figs. 7, 15), principalmente pelo fato dos canais ossificados sobre essa placa apresentarem um padrão 
tripartido, este táxon apresentou modificações no arranjo dos canais dessa região que levaram a crer que sua condição não seja homóloga àquelas observadas em outros táxons, e sim uma sinapomorfia exclusiva à Distichodontidae.

A hipótese aqui defendida é a de que a condição tripartida dos canais sobre o dermosfenótico de Xenocharax spilurus ou dos demais Distichodontidae (Figs. 6, 16, 17) seja resultante de uma ossificação do canal ótico sobre o dermosfenótico, e não da presença de um ramo infraorbital sobre esta placa (ramo e poro i10 do presente trabalho). A condição mais comumente encontrada em Characiformes é o contato direto entre o canal infraorbital com o osso frontal, e o início do canal ótico partindo da região de contato entre os ossos dermoesfenótico, frontal, e pterótico (Figs. 13 a 15). Exemplares da família Distichodontidae, por sua vez, apresentaram o canal ótico iniciando diretamente sobre o dermoesfenótico, sem que este canal apresente qualquer associação com o osso frontal ou pterótico (Figs. 6, 16, 17), resultando em um padrão tripartido de canais sobre o dermoesfenótico semelhante àquele observado nos demais Characiformes. Uma possível explicação para este arranjo distinto é que o contato entre canal infraorbital e ótico, em Distichodontidae, seja deslocado ventralmente, de modo que se dispõe lateralmente na cabeça desses animais, enquanto em outros Characiformes o contato entre canais infraorbital e ótico é mais dorsal, muitas vezes envolvendo a participação do osso frontal e pterótico (Figs. 1 a 3). Condição aparentemente ainda mais derivada desse caráter dentre os Distichodontidae foi observada no táxon Eugnatichthys sp. (Fig. 16). Notável neste exemplar foi a presença de uma extensa placa dermoesfenótica cobrindo ampla porção da região temporal craniana, e suprimindo quase que totalmente a porção exposta do osso pterótico sobre essa região. Este táxon apresentou não só o canal ótico totalmente associado à placa dermoesfenótica, mas também porções do canal supraorbital, pré-opercular e pós-ótico. Maiores detalhes acerca da morfologia da região temporal dos canais sensoriais dos Distichodontidae são encontrados em Vari (1979).

Também foram notadas variações na região de contato entre o canal infraorbital e o supraorbital dentre os diferentes caraciformes analisados. Esta variação foi notada principalmente na presença ou ausência de contato entre estes canais (indicado pelo poro complexo S7+i9), quanto no local de contato entre os mesmos, quando presente. O contato entre os canais supraorbital e infraorbital já foi utilizado como característica em análises filogenéticas para a ordem Characiformes (e.g. Buckup, 1998; Mirande, 2010), com sua ausência reportada para diferentes famílias da ordem (e.g. Erythrinidae, Lebiasinidae, Chilodontidae). Quando presente, a comunicação entre o canal supraorbital e infraorbital envolveu diferentes ossos dérmicos. O panorama mais comum foi apresentar esse contato 
entre os ossos dermosfenótico, frontal e pterótico, conforme ilustrado em Brycon nattereri neste trabalho (Fig. 1) e também por diferentes autores (Toledo-Piza, 2007: fig. 9; Sidlauskas \& Vari, 2008: figs. 14 e 15). Entretanto, ao longo deste trabalho notou-se que variações em relação a esse contato foram bastante comuns, podendo envolver apenas o dermosfenótico e o frontal, com o canal ótico adentrando posteriormente o osso pterótico (e.g. Fig. 17; Creagrutus meridionalis; Boulengerella cuvieri, Xenocharax spilurus; Vari, 1995: fig. 5); ou totalmente situado no dermosfenótico, caso extremo de alguns Distichodontidae (Fig. 16; Daget, 1967: fig. 8). O encontro desses dois canais foi aqui considerado um importante marcador topográfico, pois a partir desse ponto, por definição, inicia o canal ótico. 


\subsection{Canal ótico (Figuras 1 a 4; Figuras 6 a 10; Figuras 13 a 17).}

O canal ótico de Brycon nattereri tem início no ponto de contato entre os limites posteriores dos canais supraorbital e infraorbital, localizado na região de contato entre os ossos dermosfenótico, frontal e pterótico (Fig. 1). Em B. nattereri ocanal ótico está majoritariamente associado ao osso pterótico, disposto ao longo de toda a porção anterior deste osso até o entroncamento do canal pré-opercular. Neste táxon não foi observado qualquer ramo ou poro associado ao canal ótico.

Dentre os Characiformes analisados, o canal ótico está ausente apenas em Stygichthys typhlops (Fig. 11), Pyrrhulina cf. australis (Fig. 5) e em Erythrinoidea sp. nov. Variações do canal ótico se relacionam principalmente a o contato dos canais supraorbital e infraorbital, os quais foram tratados acima. Dessa maneira, porções do canal ótico estão tanto associadas ao dermosfenótico (e.g. Distichodontidae; Figs. 6, 16, 17), ao frontal (e.g. Creagrutus meridionalis; Boulengerella cuvieri), à quinta placa infraorbital (e.g. Boulengerella xyrekes - Vari, 1995: fig. 2B), ou ao osso esfenótico (e.g. Characidiinae sensu Buckup, 1998: figs. 4 e 9). 


\subsection{Canal pós-ótico (Figuras 1 a 4; Figuras 6 a 10; Figuras 13 a 17).}

Em Brycon nattereri o canal pós-ótico foi definido como a porção contínua à comunicação do canal pré-opercular com o canal ótico, que segue posteriormente em direção à cintura escapular, atravessando, na sequência, os ossos pterótico, extraescapular, póstemporal e supracleitro, emergindo na região ventral deste último e dando início à linha lateral corpórea (Fig. 1, 13-16).

Variações observadas em Characiformes consistiram-se principalmente na presença ou ausência do canal pós-ótico e associações desse canal com os diferentes ossos da cintura escapular. O canal pós-ótico é totalmente ausente nos táxons Erythrinoidea sp. nov., Stygichthys typhlops e Pyrrhulina cf. australis. Outros táxons, como por exemplo, Caenotropus schizodon, Hoplias aimara e Hepsetus odoe, apesar de apresentarem o canal pós-ótico contínuo, exibiram redução da área exposta do osso pós-temporal na superfície do crânio (Vari et al., 1995: fig. 5; Oyakawa, 1998: car. \#79). Nestes casos, o canal pós-ótico segue direto da extraescápula ao supracleitro, sem associar-se com o osso pós-temporal, e apresentando também reduções no número de poros (Fig. 14). Oyakawa (1998), em sua tese de doutoramento acerca das relações filogenéticas entre Erythrinidae, Pyrrhulinidae e Lebiasinidae, utilizou desse caráter (car. \#79) para quantificar a porção do canal pós-ótico associada à superfície do osso pós-temporal. Considerando como primitivo a presença de um trecho de canal ossificado sob tal osso, o autor obteve como resultado a redução deste trecho sobre o pós-temporal homoplástica para Hepsetus e espécies do gênero Hoplias. De acordo com Oyakawa (1988), os gêneros Erythrinus e Hoplerythrinus, ao que parece, portavam a condição primitiva de associação do osso pós-temporal com o canal pós-ótico. 


\subsection{Canal supratemporal (Figuras 1 a 4; Figuras 6 a 10; Figuras 13 a 17).}

Em Characiformes, canal supratemporal foi o único canal cefálico principal disposto transversalmente sobre o crânio. Em Brycon nattereri, e também em todos os outros Characiformes examinados que apresentam esse canal, este se origina como uma ramificação medial do canal pós-ótico no osso extraescapular, adentrando o osso parietal e se estendendo até a porção posterior da fontanela craniana. Em Brycon nattereri, o canal supratemporal, em sua porção medial, apresentou uma comissura parietal, unindo-se ao canal supratemporal contralateral e emitindo um poro complexo sobre a fontanela parietal (Fig. 1; Tab. 1 $\mathrm{ST} 2+\mathrm{ST} 2)$.

O canal supratemporal se mostrou variavelmente presente nos Characiformes. Notouse que os mesmos táxons que não apresentaram canal ótico e pós-ótico, também careciam do canal supratemporal (e.g. Erythrinoidea fam. nov., Stygichthys typhlops e Pyrrhulina cf. australis). Acompanhando a ausência do canal supratemporal, esses táxons também não apresentaram um osso extraescapular (Fig. 11). A aparente co-dependência entre o osso extraescapular e o canal supratemporal já foi demonstrada, apesar de não discutida, por Buckup (1998). Em seu trabalho acerca do monofiletismo de Crenuchidae, o autor utilizou de dois diferentes caracteres, um relacionado à presença ou ausência do canal supratemporal (Car. \#17), e outra da presença ou ausência do osso extraescapular (Car. \#52). A ausência apomórfica de ambos os caracteres sustentou o clado 25, composto Pyrrhulina + Nannostomus, mas é provável que o suporte tenha sido artificialmente inflacionado devido à possível co-dependência entre estes dois caracteres. A morfologia do osso extraescapular dos Characiformes pode variar bastante, apresentando-se desde apenas uma ossificação de canal (porções do canal pós-ótico e supratemporal; Figs. 4, 6, 14), até uma ampla placa dérmica associada aos ramos do canal pós-ótico e supratemporal (Figs. 1, 2, 3, 7 e 16). Dada esta possível relação entre os canais temporais e o osso extraescapular, uma discussão mais ampla acerca da homologia da extraescápula foi elaborada e apresentada abaixo no item Neuromastos temporais e suas implicações na morfologia e homologia do osso extraescapular.

A formação de uma comissura parietal na porção medial do crânio também variou dentre os Characiformes analisados. Quando esta comissura esteve ausente, os poros do canal supratemporal abriram-se independentes um do outro, geralmente dispostos na extremidade medial de cada um dos ossos parietais. Já em táxons apresentando uma comissura parietal, os canais supratemporais de cada lado da cabeça se encontravam abertos sobre a porção posterior da fontanela craniana. Exceção dessa condição foi observada em Hoplias aimara, que não possui fontanelas cranianas quando adulto, estando o par de ossos parietais em contato 
ao longo de toda a porção posterior do crânio, cobrindo totalmente o osso supraoccipital. Nesse táxon, os canais estiveram ossificados ao longo de todo o parietal até o ponto da comissura supratemporal (Fig. 10). 


\subsection{Canal pré-opercular (Figuras 1 a 7; Figura 17).}

Em Brycon nattereri, o limite dorsal, o canal pré-opercular apresenta uma conexão direta com o canal ótico, localizada sobre o osso pterótico. O contato entre o osso pterótico e o canal pré-opercular foi também um importante marcador topográfico, delimitando o fim do canal ótico e o início do canal pós-ótico, representado pela presença do poro PO1+PR1. Seguindo ventral e anteriormente, o canal pré-opercular localiza-se imediatamente posterior ao canal mandibular, usualmente estando fundido com a região mais posterior do canal mandibular, com o qual compartilha um poro complexo (Tab. 1: PR7+M5). O limite anterior do canal pré-opercular situa-se entre o anguloarticular e a borda ântero-ventral do pré-opérculo (Fig. 1).

Em B. nattereri, o trecho de canal localizado póstero-dorsalmente ao osso préopércular apresentou-se ossificado em grande parte de sua extensão. Este trecho de canal ossificado tem recebido o nome de supra-pré-opérculo (e.g. Moreira, 2007; Mirande, 2010; Mattox \& Toledo-Piza, 2012), apesar de sua homologia com uma placa óssea encontrada na mesma região mas desprovida de canal, que recebe o mesmo nome (sensu Vari, 1995; Oyakawa, 1998), ainda permanecer incerta. Uma discussão mais detalhada a respeito da homologia desses elementos foi será mais apresentada adiante, no item $\underline{\text { Homologia do supra- }}$ pré-opérculo em Ostariophysi.

Assim como em Brycon nattereri, a maioria dos táxons analisados apresentou comunicação direta entre o canal pré-opercular com o canal ótico por intermédio do poro complexo PR1+PO1. Entretanto, outros caraciformes não apresentaram tal contato entre os referidos canais, sendo esta interrupção uma característica bastante consistente em algumas famílias analisadas (e.g. Erythrinidae, Lebiasinidae, Crenuchidae, Ctenoluciidae). Nesses casos, o marcador topográfico utilizado para determinar o fim do canal ótico e início do canal pósótico foi a presença do ramo PO1, enquanto o início do canal pré-opercular apresentava um poro independente, denominado PR1 (Figs. 4, 5 e 6). Em sua região Antero-ventral, o canal pré-opercular apresentou contato direto com o canal mandibular em todos os táxons examinados da ordem Characiformes (exceto em táxons cujo canal mandibular estava ausente). A conexão entre canais pré-opercular e mandibular foi feita por meio de um trecho de canal disposto sobre o osso angularticular. De acordo com Lekander (1949), este trecho de canal é derivado de apenas um neuromasto que, quando presente, realiza a comunicação entre o trecho de canal mandibular com a extremidade anterior do canal pré-opercular. 


\subsection{Canal mandibular (Figuras 1 a 4; Figuras 6 e 7; Figura 17).}

Em Brycon nattereri, o canal mandibular corre ao longo dos ossos dentário e ânguloarticular, iniciando em um poro frontal sobre o mento do animal e terminando em contato com o canal pré-opercular em sua extremidade mais posterior (Fig. 1).

Variações observadas entre os Characiformes foram principalmente relacionadas à presença ou ausência do canal mandibular, e também à sua extensão ao longo do osso dentário. O canal mandibular está ausente em Erythrinoidea sp. nov., Stygichthys typhlops, Sartor sp. e Pyrrhulina cf. australis (Fig. 5). A ausência do canal no dentário de Sartor já havia sido relatada previamente por Winterbottom (1980) e Sidlauskas \& Vari (2008). A ausência desse canal foi utilizada como um caráter na filogenia da família Anostomidae (Sidlauskas \& Vari, 2008: car. \#61), sendo sinapomórfica do clado formado por Gnathodolus e Sartor. No mesmo trabalho, Sidlauskas \& Vari (2008) ainda comentaram que uma redução do comprimento do canal mandibular (Car. \#62) estaria presente em todos os membros da família Anostomidae, compondo uma sinapomorfia ao grupo, e também possivelmente homoplástica à condição presente nos Prochilodontidae. Essas observações foram corroboradas no presente trabalho: a ausência completa do canal mandibular em Sartor sp., e da redução parcial do canal mandibular Leporellus vittatus e Prochilodus brevis.

Ainda a respeito das reduções do canal mandibular presente nos Anostomidae e Prochilodontidae, cabe aqui um comentário mais detalhado sobre sua morfologia. Durante análise do suspensorium desses táxons, notou-se que alguns ossos componentes dessa região, principalmente o osso quadrado, se apresentavam bastante alongados ântero-posteriormente, condição excepcionalmente acentuada em Sartor sp. (Pastana, 2012: fig. 9; Sidlauskas \& Vari, 2008: fig. 37). Reflexo desse alongamento dos ossos do suspensorium foi visto no grande espaçamento entre a porção mais anterior do osso pré-opérculo e ângulo-articular, e também no aparente deslocamento anterior da porção mandibular. Apesar de haver tal separação espacial entre pré-opérculo e mandíbula, o canal pré-opercular não apresentou interrupções nesses táxons, sendo observado contínuo e ossificado ao longo de toda essa região. Frente a tal observação, a hipótese aqui sugerida é de que o trecho de canal que primitivamente estaria disposto sobre boa parte do dentário de Characiformes, em Anostomidae e Prochilodontidae, se dispões parcialmente sobre o hiato entre pré-opérculo e mandíbula dos Anostomidae. Dessa maneira, a aparente redução da porção de canal mandibular é, na verdade, um efeito do um alongamento dos ossos do suspensorium, que consequentemente deslocam os ossos articular e dentário pra frente, diminuindo a sobreposição do canal mandibular com os ossos da mandíbula (Sidlauskas \& Vari, 2008: figs. 34 a 37). Estes autores corretamente anotaram 
que tanto Anostomidae quanto Prochilodontidae apresentavam reduções da porção de canal sobre o mandibular. Entretanto, os mesmos falharam em identificar as porções ossificadas do canal pré-percular como trechos desse canal, nomeando-os de fragmentos do pré-opérculo (sensu Vari, 1983).

As homologias das ossificações do canal pré-opercular dispostas entre o pré-opérculo e a mandíbula já foram objeto de discussão de diferentes trabalhos, ora sendo apontadas como fragmentos do pré-opérculo, não relacionadas ao sistema látero-sensorial cefálico (Winterbottom, 1980; Vari, 1983; Sidlauskas \& Vari, 2008: fig. 37, 45), ora identificadas como o canal pré-opercular e denominadas sub-pré-opérculo (Roberts, 1973: figs. 10-13). O presente trabalho rejeita a hipótese de que tais ossificações sejam fragmentações do osso préopercular, reafirmando sua identificação como elementos ossificados do canal sensorial préopercular e mandibular (sensu Roberts, 1973). 


\subsection{Desenvolvimento dos canais sensoriais cefálicos em Characiformes.}

Em diversos caraciformes foram observadas interrupções ou ausências completas de determinados canais sensoriais da cabeça (e.g. Pyrrhulina cf. australis, Toracocharax stellatus, Stygichthys typhlops). Ao que parece, estes táxons apresentaram truncamento na formação dos canais sensoriais cefálicos. De acordo com Lekander (1949), mesmo apresentando um sistema látero-sensorial completo e diferenciado em neuromastos de canal e pitlines, alguns táxons nunca chegam a formar os canais sensoriais sobre os ossos dérmicos cranianos, processo que parece ser interrompido ao longo da ontogenia desses animais. Nos estudos de Lekander (1949), este fenômeno foi reportado da espécie Cobitis taenia (Cobitidae, Cypriniformes), cuja morfologia também foi reexaminada no presente trabalho.

A combinação de informações sobre o desenvolvimento (e.g. Kindred, 1919; Lekander, 1949) e sobre anatomia comparada dos canais látero-sensoriais de diferentes táxons poderia ser aplicada para se estimar o grau de truncamento do desenvolvimento dos referidos segmentos. Como descrito de maneira bastante completa por Lekander (1949), o desenvolvimento da linha lateral cefálica segue uma ordem relativamente conservada em Ostariophysi: primeiro formam-se os canais supraorbital e preopercular, seguidos do canal mandibular e porção pré e pós-orbital do canal infraorbital, sucedidos dos canais temporais e supratemporais, e por último a porção sub-orbital do canal infraorbital e ramo parietal do canal supraorbital.

Por meio de informações sobre o desenvolvimento, foi possível compreender as variações de presença/ausência de canais, tanto dos caraciformes examinados, quanto de outros táxons descritos na literatura. Foi possível verificar que o truncamento no desenvolvimento dos canais da linha lateral cefálica ocorre em etapas distintas do desenvolvimento nos diferentes táxons. Os trechos do canal látero-sensorial que se originam mais tardiamente foram, recorrentemente, os primeiros a serem perdidos (porção sub-orbital do canal infraorbital e ramo parietal do supraorbital). Em seguida, as perdas abrangiam também os canais com formação um pouco mais recente, chegando ao ponto de acarretar a total ausência de canais sensoriais, em algumas espécies.

Dos táxons examinados, Crenuchus spilurus, Neolebias unifasciatus e Toracocharax stellatus, apresentaram ausência da formação da porção sub-orbital do canal infraorbital, ao passo que todos os outros canais apresentatam-se fechados e delimitados por ramos acessórios terminados em poros. Uma condição similar parece ocorrer no caracídeo Erythrocharax altipinnis, que foi diagnosticado dos demais gêneros de Characidae justamente por apresentar reduções na formação do canal infraorbital (Netto-Ferreira et al., 2013). Este 
trecho de canal seria justamente aquele descrito por Lekander (1949) apresentando um desenvolvimento mais tardio.

Um grau mais acentuado de interrupção do desenvolvimento dos canais láterosensoriais cefálicos afetaria a formação dos canais localizados na região posterior da órbita (e.g. ótico, pós-ótico e supratemporal) e canal mandibular, além dos segmentos listados acima. Dos exemplares de Characiformes analisados, estas reduções foram características em Pyrrhulina cf. australis (Fig. 5), e em um grau mais severo em Stygichthys typhlops (Fig. 11). Além desses, a análise bibliográfica apontou um truncamento nesta etapa do desenvolvimento em diversos outros Characiformes de pequeno porte, tais como em representantes dos gêneros Xenurobrycon (Weitzman \& Fink, 1985; Moreira, 2005), Paracheirodon (Weitzman \& Fink, 1983), Spintherobolus (Weitzman \& Malabarba, 1999), Nannostomus (Weitzman, 1964) e Tricuspidalestes (Zanata \& Vari, 2005).

Um grau extremo de redução da linha lateral cefálica, consequentemente, resultaria na ausência de quase todos, ou todos os canais látero-sensoriais cefálicos. Nesses casos, apenas os neuromastos de canal permaneceriam arranjados em linhas sobre o local de formação dos canais sensoriais. Dentre o material examinado, apenas o táxon Erythrinoidea sp. nov. apresentou tamanho grau de redução dos canais sensoriais, exibindo apenas a porção nasal do canal supraorbital na forma de um tubo fechado. A porção mandibular sobre o osso dentário e a porção mais anterior do pré-operculo exibiram certo grau de diferenciação epitelial, mas sem resultar em qualquer canal ou poro do sistema sensorial. De acordo com a literatura, estes seriam justamente os primeiros elementos de canal a serem formados (Lekander, 1949). Dos caraciformes apresentando equivalente truncamento do sistema láterosensorial há o gênero miniatura Priocharax (Weitzman \& Vari, 1987; Toledo-Piza et al. 2014), cujos canais látero-sensoriais estão ausentes por completo.

De acordo com de Pinna (com. pess) o táxon Erythrinoidea sp. nov. habita folhiços às margens de certos trechos do Rio Negro. Reduções drásticas dos canais do sistema láterosensorial cefálica, são, de certo modo, comuns a táxons habitando ambientes confinados (Bockmann, com. pess.), fato que explicaria a redução dos canais observada em Erythrinoidea sp. nov. Com exceção deste táxon, todos os outros indivíduos acima listados apresentam em comum um pequeno porte corpóreo (inferior a 10 centimetros CP). De modo geral, os canais da linha lateral cefálica tendem a ser reduzidos ou ausentes em táxons de pequeno porte ou miniatura (Weitzman \& Vari, 1988). Em Characiformes, perdas de trechos ou ausência total de canais sensoriais já haviam sido reportadas de diversos gêneros da família Characidae (e.g. Priocharax, Spintherobolus, Xenurobrycon, Paracheirodon, Erythrocharax), Crenuchidae (e.g. 
Crenuchus, Elacocharax), Distichodontidae (e.g. Nannaethiops, Neolebias), Alestidae (e.g. Tricuspidalestes) ou Lebiasinidae (e.g. Pyrrhulina, Nannostomus), sendo que todos são táxons de porte pequeno (Weitzman, 1964; Weitzman \& Fink, 1983; Weitzman \& Fink, 1985; Weitzman \& Vari, 1987; Weitzman \& Vari, 1988; Weitzman \& Malabarba, 1999; Moreira, 2005; Zanata \& Vari, 2005; Toledo-Piza et al. 2014; Netto-Ferreira et al., 2013). Contudo, existem algumas exceções a este paralelo entre miniaturização e redução dos canais da linha lateral cefálica. Recentemente descrito por Mattox et al. (2013), Cyanogaster noctivaga, apesar de ser considerado um caracídeo miniatura, apresenta formação quase que completa dos canais sensoriais cefálicos, demonstrando que processos de miniaturização não necessariamente acarretam na redução dos canais sensoriais. O oposto também parece ser verdadeiro, ou seja, indivíduos de maior porte (> $10 \mathrm{~cm} \mathrm{CP}$ ) podem por sua vez apresentar redução severa dos canais látero-sensoriais, caso presente em Erythrinoidea sp. nov., táxon que habita ambiente confinado (i.e. folhiços).

É importante notar que esta sequência de truncamentos ocorre não só em Characiformes ou Cypriniformes, mas também em diversos outros Ostariophysi e mesmo em Teleostei. No presente trabalho, reduções de canais foram notadas no grupo-externo em Galaxias vulgaris (Galaxidae, Osmeriformes), Fundulus heteroclitus (Fundulidae, Cyprinodontiformes), Cobitis taenia (Cobitidae, Cypriniformes) e Catostomus commersonii (Catostomidae, Cypriniformes), ocorrendo geralmente na porção suborbital do canal infraorbital e na região temporal (ótica e pós-ótica). Nos demais casos registrados em literatura anatômica, chama atenção a morfologia dos bagres da família Trichomycteridae. Descritos de forma satisfatória em relação aos canais sensoriais (Arratia \& Huaquín, 1995), representantes dessa família são conhecidos por frequentemente apresentarem reduções de trechos do canal supraorbital, infraorbital e mandibular (Arratia \& Huaquín, 1995: figs. 8-9). Combinando estas características com propostas filogenéticas para a família, nota-se os seus gêneros mais basais (Copionodon e Trichogenes) apresentam estes canais completamente formados, característica considerada como primitiva da família (de Pinna, 1992 - Fig. 17). Por outro lado, formas mais derivadas dessa família apresentam reduções severas dos canais sensoriais (Arratia \& Huaquín, 1995: fig. 9C). 


\subsection{Demais considerações acerca dos canais látero-sensoriais cefálicos -}

comparações com o grupo-externo (Figuras 18 a 23; Tabelas 1 e 2).

O sistema de canais da linha lateral é uma estrutura bastante conservada em peixes como um todo, apresentando um padrão básico de sete segmentos pares cefálicos somados a um par de canais percorrendo o tronco do peixe formando a linha lateral corpórea (Webb, 1989). Como esperado, essa configuração foi presente também nos táxons incluidos como grupo-externo. Por sua vez variações deste padrão básico foram bastante informativas em um contexto comparativo, auxiliando no mapeamento das diferentes variações de caracteres observados nos Characiformes. Estes exemplos são listados abaixo, acompanhando uma breve descrição de sua morfologia, e também comentários de como estas observações auxiliaram na compreensão da anatomia dos canais sensoriais cefálicos dos Characiformes. Informações sobre a presença, ausência ou contato entre canais sensoriais dentre os representantes do grupo-externo são indicados na Tabela 2.

Um primeiro exemplo se faz sobre o prolongamento anterior deste canal, se estendendo sobre o osso pré-maxilar. Esta morfologia, da maneira como citado acima, é comum aos representantes da família Acestrorhynchidaes da ordem Characiformes, já sugerida como sinapomorfia para os representantes do gênero (Menezes, 1969; Toledo-Piza, 2007). De fato, essa característica é incomum nos táxons incluidos no grupo-externo. Entretanto, a revisão bibliográfica apontou para a ocorrência da mesma característica em peixes das famílias Belonidae e Scomberesocidae (Scomberesocoidea sensu Parin \& Astakhov, 1982: fig. 2-3), certamente uma aquisição homoplástica, considerando-se a posição filogenética de ambos os táxons em que tal característica é presente.

Ao longo do canal supraorbital, foi notável nos caraciformes o fato do ramo epifiseano (S6) ser orientado medialmente e anteceder a origem do ramo S5, cujo poro está orientado lateralmente sobre o osso frontal (Figs. 1, 3, 4, 6, 7). Tal característica foi comum à grande maioria dos exemplares examinados em Characiformes, sendo portanto potencialmente informativa para esta ordem em um contexto evolutivo. Os táxons componentes do grupoexterno, por sua vez, apresentaram a ramificação do poro $\$ 5$ sempre anterior àquela do ramo epifiseano, característica presente também nos demais Ostariophysi (Figs. 18 e 19; Arratia \& Huaquín, 1995: fig. 3), e nos demais Teleostei examinados.

No que diz respeito à morfologia do ramo parietal do canal supraorbital, especial atenção deve ser dada às informações acerca de seu desenvolvimento. De acordo com Lekander (1949), esse segmento de canal aloja um único neuromasto de canal, o qual é um dos primeiros a migrar para sua posição final, na porção posterior do crânio, geralmente sobre o 
osso parietal. Apesar de ser um dos primeiros neuromastos a migrar, localizando-se sobre o osso parietal, a formação desse trecho de canal se dá bastante tardamente quando comparado ao restante do canal supraorbital. Por vezes, este trecho de canal deixa de se formar, sendo substituído por uma linha de neuromastos neuromastos superficiais (neuromastos segundários sensu Lekander, 1949). A formação tardia ou completa ausência do trecho parietal parece estar relacionada à grande variação morfológica observada nessa região. Em Brachyhypopomus pinnicaudatus (Gymnotiformes, Hipopomidae), por exemplo, observou-se a existência de um poro supranumerário na região do ramo parietal. Este poro abria-se na porção mais anterior do ramo parietal, ainda sobre o osso frontal, enquanto o poro S8 foi encontrado em sua porção posterior, sobre o osso parietal. A análise morfológica do ramo parietal do canal supraorbital de $B$. pinnicaudatus revelou que este trecho estava completamente separado do canal supraorbital, indicando que sua formação se dava sobre o neuromasto sobre o osso parietal, avançando anteriormente. 0 truncamento do desenvolvimento completo do ramo parietal nesse estágio provavelmente causou a separação do ramo parietal do restante do canal supraorbital desse táxon, ocasionando o surgimento de um poro supranumerário ( $\left(\mathbf{S} 8^{*}\right)$. Apesar de exclusiva a este táxon dentre o material comparativo, a mesma condição também parece estar presente em Scomberesocoidea, sendo descrita e ilustrada para táxons das famílias Belonidae e Scomberesocidae (Parin \& Astakhov, 1982: fig. 4), mostrando que tal característica possa ser homoplástica em diferentes níveis taxonômicos.

Variações ao longo do canal infraorbital foram abundantes no material examinado, a começar pela sua associação com diferentes ossos cranianos. Em um padrão generalizado, o canal infraorbital foi encontrado associado aos ossos antorbital, às placas infraorbitais e ao osso dermoesfenótico. Entretantos, membros examinados da ordem Elopiformes (e.g. Elops smithi, Elops saurus, Megalops atlanticus) apresentaram um prolongamento anterior do canal infraorbital, o qual está associado ao osso maxilar, lateralmente, e mesetmóide, medialmente. Tal característica, apesar de única dentre o material examinado, já era conhecida também de linhagens basais de Actinopterygii, tais como os gêneros Polypterus (Polypteriformes, Polypteridae) (Allis, 1922), e Amia (Amiiformes, Amiidae) (Allis, 1889: fig. 42; Grande \& Bemis, 1998: fig. 11), o que sugere que se trate de uma característica primitiva retida pelos Elopiformes, posteriormente perdida nos demais Teleostei.

Em relação à associação do canal infraorbital com o osso antorbital esta característica foi somente observada em Hoplias aimara dentre os Characiformes (Fig. 12). Conforme descrito acima, o canal infraorbital, neste táxon, apresentou um prolongamento anterodorsal 
(i.e. trecho antorbital do canal infraorbital), dispondo-se sobre o osso antorbital $\mathrm{e}$ apresentando um poro (A1) localizado entre a narina posterior e a órbita ocular. Apesar de única em Erythrinidae, essa característica foi comum a todos os Siluriformes e Gymnotiformes examinados, e presente também em Osteoglossum bicirrhosum (Osteoglossidae, Osteoglossomorpha), Elops saurus (Elopidae, Elopiformes) e Anguilla rostrata (Anguillidae, Anguilliformes). Alguns táxons apresentaram inclusive o contato direto entre a porção anterior do canal infraorbital com o canal supraorbital, formando um poro complexo (S3+A1; Tab. 2). Apesar de esse trecho ser recorrentemente tratado como pertencente ao canal infraorbital (Arratia \& Huaquín, 1995: fig. 4, porção entre poro i1 e i2), evidências apontam para o surgimento independente desta porção de canal antorbital em relação ao restante do canal infraorbital. Análises feitas em Platyurosternarchus macrostoma (Apteronotidae, Gymnotiformes) sugeriram que o trecho antorbital do canal infraorbital apresentasse origem e desenvolvimento independente do restante do canal infraorbital. A espécie $P$. macrostoma é notável pela morfologia de seu focinho, extremamente longo quando comparado aos demais Gymnotiformes (Santana \& Vari, 2009: fig. 5). Nesse táxon, a abertura nasal posterior é localizada próxima à órbita ocular, ao passo que a abertura nasal anterior abre-se apenas próximo à ponta do focinho, sendo aparentemente deslocada anteriormente. Observou-se que o canal infraorbital de P. macrostoma acompanhava o prolongamento de seu focinho, iniciando-se também na porção anterior do rostro e percorrendo ininterruptamente toda a extensão do focinho, e posteriormente se dispondo ao redor da órbita ocular. Todavia, o trecho antorbital do canal infraorbital foi encontrado entre a abertura nasal posterior e a órbita ocular, completamente separado do canal infraorbital e se disposto apenas como um pequeno trecho de canal portando dois poros (um anterior e outro posterior), parecendo não acompanhar o deslocamento anterior do canal infraorbital. Esta separação entre a porção antorbital do restante do canal infraorbital em Platyurosternarchus macrostoma sugeriu uma possível independência deste trecho de canal (compreendido como a porção disposta entre a narina posterior e porção anterior da órbita ocular) em relação ao restante do canal infraorbital (iniciando-se abaixo das narinas e disposto ao redor da órbita ocular). Além do fato de poderem ocorrer dissociados neste táxon, outra evidência que aponta a favor da independência desses trechos de canal vem de descrições do desenvolvimento do sistema sensorial cefálico. Lekander (1949), em meio a suas descrições acerca do desenvolvimento do canal infraorbital, acrescentou que, em um estágio bastante inicial do desenvolvimento dos canais, a região anterior do infraorbital receberia neuromastos de dois centros de migração distintos, indicando uma origem complexa desse canal. Além disso, o autor citou que em Leuciscus rutilus (=Rutilus rutilus; Cyprinidae, Cypriniformes), a região antorbital deste táxon, 
apesar de possuir neuromastos de canal (neuromastos primários), não se fecham um canal típico, enquanto o restante do canal infraorbital propriamente dito se fecha (Lekander, 1949: fig. 11, a.o.l.). Frente a tais evidências, decidiu-se tratar o pequeno segmento anterior de canal como sendo independente do canal infraorbital, tratando-o como uma porção independedo restante do canal infraorbital, considerando também o poro resultante desse trecho como um poro antorbital (A1).

Ainda a respeito do canal infraorbital, a porção mais anterior desse canal, disposta sobre a primeira placa infraorbital, apresentou dentre os diferentes caraciformes um número variando de dois a quatro ramos, cada qual com um poro em sua extremidade (Figs. 1, 3, 6; S1S3). A análise dos táxons do grupo-externo, no entanto, revelou grandes variações em relação ao número de ramificações sobre a primeira placa infraorbital, desde apenas duas (Fig. 20) até cinco ou sete ramificações resultantes em poros (Figs. 21 e 22, respectivamente). Nos táxons apresentando um número elevado de poros sobre a primeira placa orbital, notou-se também uma flexão dorsal do canal infraorbital em sua região mais anterior onde estes ramos se concentravam. Tal curvatura do canal infraorbital está ausente em todos os Characiformes examinados, exceto Sartor (Anostominae). A mesma curvatura já havia sido descrita para exemplares desse gênero (Winterbottom, 1980), e também utilizada como caráter na análise cladística de Sidlauskas \& Vari (2008). De acordo com Sidlauskas \& Vari (2008), a curvatura dorsal da porção anterior do canal infraorbital é uma sinapomorfia não ambígua para todos os Anostominae. Entretanto, sua presença nos representantes do grupo-externo (Cypriniformes, Gonorynchiformes, Salmoniformes) sugerem uma interpretação desta como uma característica plesiomórfica, ausentes nos Characiformes, mas possivelmente revertida em Sartor sp. Por fim, cabe ressaltar que esta flexão do canal infraorbital não deve ser confundida com a presença de um trecho antorbital do canal infraorbital. Enquanto a curvatura anterior do canal infraorbital sempre está restrita à primeira placa dérmica e sempre ventral à abertura das narinas, o trecho antorbital do canal é encontrado deslocado dorsalmente, entre a narina posterior e a órbita ocular, muitas vezes ligando o canal infraorbital ao supraorbital (Tab.2; Fig. $19-\mathrm{S} 3+\mathrm{A} 1)$.

Outro aspecto variável do canal infraorbital se dá na região de contato entre este canal e o supraorbital. O contato desses canais, que resulta na formação de um poro complexo S7+i9 ocorre tanto em Characiformes quanto no grupo-externo. As Tabelas 1 e 2 expressam a distribuição desta característica, que dentre os Characiformes foi bastante variável, possivelmente informativa em análises morfológica em níveis taxonômicos mais exclusivos. Interrupções ao longo do canal infraorbital também foram variáveis, tanto em Ostariophysi 
quanto nos demais Teleostei. Tais interrupções, quando presentes, ocorreram sempre na porção sub-orbital do canal infraorbital (Fig. 5), separando a porção mais anterior desse canal de sua porção pós-orbital (i.e. porção associada às placas infraorbiais 5 e dermoesfenótica). Dos táxons examinados como grupo externo, reduções desse trecho de canal foram observadas em Fundulus heteroclitus (Fundulidae, Cyprinodontiformes) (Gosline 1949 - Fig. 2) e Galaxias vulgaris (Galaxiidae, Osmeriformes). Ademais, reduções da porção sub-orbital do canal infraorbital já foram registradas também de espécies dos gêneros Trichomycterus e Ituglanis (Siluriformes, Trichomycteridae; Bockmann \& Sazima, 2004: fig. 5).

A respeito do canal supratemporal, assim como em Characiformes, este canal é variavelmente presente no grupo-externo, sendo tipicamente associado aos ossos extraescapular e parietal, e disposto transversalmente sobre a porção psoterior do crânio. Entretanto, uma morfologia distinta foi observada no crânio do táxon Kneria sp. (Kneriidae, Gonorynchiformes). Neste táxon, o início do canal supratemporal foi observado ainda sobre o osso pterótico (Fig. 23), enquanto que em todos os outros táxons examinados este canal se inicia posteriormente ao pterótico, apenas sobre a extraescápula (Figs. 1 a 4, 13 a 16). Curiosamente, o canal supratemporal de Kneria sp. ainda assim foi encontrado associado a um osso extraescapular. Este osso foi encontrado medialmente ao osso pterótico (Fig. 23), acompanhando o percurso do canal supratemporal, enquanto demais táxons a apresentaram posteriormente ao pterótico, na porção póstero-lateral do crânio. Tal morfologia sugere, mais uma vez, uma relação de co-dependência entre o canal supratemporal e o osso extraescapular, assunto que será abordado em maior detalhe mais adiante.

Demais alterações na morfologia dos canais látero-sensoriais em Characiformes foram vistas principalmente em Toracocharax stellatus. A morfologia do canal supraorbital desse táxon foi distinta da apresentada por qualquer outro caraciforme por apresenta-lo aberto e disposto sob uma membrana de pele que revestia toda a porção dorsal do crânio, possivelmente relacionada ao seu hábito de forragear o estrato superficial da coluna d'água. Dentre os exemplares examinados como material suplementar, uma condição bastante semelhante foi vista em Notopterus notopterus (Notopteridae, Osteoglossiformes). Este táxon apresentou não só o canal supraorbital, mas todos os canais sensoriais cefálicos em uma condição semelhante àquela de Toracocharax stellatus (i.e. sem formar um tubo, cobertos apenas por uma membrana de pele). Tal característica já havia sido descrita e ilustrada por Sharma (1964: fig. 1), porém o autor limitou-se apenas a descrições morfológicas bastante superficiais, sem apresentar também maiores detalhes acerca de implicações ecológicas. Alterações na morfologia dos canais sensoriais também foram encontradas em Sternopygus 
macrurus (Sternopygidae, Gymnotiformes). Nesta espécie, ramos mais anteriores da cabeça, associados aos canais supraorbital, infraorbital e pré-opercular, se diferenciaram dos de qualquer outro táxon examinado, apresentando-se como grandes poros situados sobre estes canais. Tal morfologia pareceu implicar até em modificações estruturais dos ossos dérmicos associados a estes canais, conforme ilustrado por Mago-Leccia (1978: fig. 25). Interessantemente, este fenômeno pareceu não ser exclusividade dos Sternopygidae, ou tampouco de Ostariophysi. Uma condição bastante similar foi detalhada em um trabalho recente de Webb et al. (2014) acerca da morfologia de canais de duas diferentes espécies da família Cichlidae. Entre suas principais conclusões, os autores afirmam que: 1) estas modificações nos canais e poros do sistema sensorial cefálico parecem ser consequência de processos de heterocronia; 2) apesar de estruturalmente bastante distinto, não há diferença no número de neuromastos de canais de peixes que apresentam tal característica; 3) modificações de canais podem ocorrer independentemente em diferentes canais, acarretando em alterações morfológicas em diferentes ossos dérmicos. 


\section{Ramos acessórios dos canais da linha lateral cefálica.}

\subsection{Ramos acessórios (e poros) dos canais da linha lateral cefálica de Characiformes}

(Tabelas 3 a 8).

A localização e distribuição dos ramos da linha látero-sensorial cefálica de Characiformes nunca foram estudados em um contexto anatômico-comparativo, e mesmo raramente foram descritas com maior grau de detalhe e precisão. As informações anatômicas sobre o sistema látero-sensorial da cabeça de peixes dessa ordem encontrados atualmente são basicamente fruto do levantamento de caracteres para estudos filogenéticos, sendo estes quase sempre restritos às informações de canais ossificados em placas dérmicas, tornando raras as inclusões de caracteres que dizem respeito aos ramos que se projetam de tais canais. Trabalhos morfológicos visando a distribuição dos poros dos canais sensoriais, ou propondo algum tipo de homologia para estes túbulos inexistem para qualquer exemplar de Characiformes na literatura atual, de modo que as descrições de Allis (1904) ainda sejam os resultados mais completos acerca desse sistema para representantes da ordem. Frente à tal contexto, os resultados apresentados no presente trabalho são inéditos para Characiformes, estes baseados exclusivamente nas observações realizadas durante o presente projeto.

A descrição dos poros da linha lateral cefálica para os Characiformes seguiu o mesmo modelo empregado para a descrição dos canais sensoriais cefálicos, apresentando primeiro uma descrição do padrão observado em um exemplar diafanizado de Brycon nattereri, e depois complementando com discussõs de variações observadas nos outros Characiformes incluidos na lista de material analisado. Poros foram enumerados ântero-posteriormente para todos os canais cefálicos, exceto para o canal pré-opercular e canal supratemporal. O primeiro teve seus poros numerados da porção mais dorsal do pré-opérculo, seguindo ventral e anteriormente. Já poros do canal supratemporal foram enumerados iniciando-se em sua porção lateral, seguindo medialmente até a região da fontanela craniana. Presença ou ausência de cada um dos poros da linha látero-sensorial cefálica dos táxons são apresentadas nas tabelas 3 a 8 . Conforme explicitado no item Materiais e Métodos, asteriscos $\left({ }^{*}\right)$ indicam poro supranumerário, e (in.) aponta para ramos cuja hipótese de homologia foi inaplicável, seja por causa da ausência dos canais, seja pela impossibilidade de identificação do mesmo. 


\subsubsection{Ramos acessórios ao longo do canal supraorbital de Characiformes (Figuras 1 a}

11; Tabela 3).

O canal supraorbital de Brycon nattereri, apresenta onze poros ao longo de sua extensão, dispostos desde sua porção mais anterior, ramificando-se do osso nasal, até a porção posterior craniana, associado ao osso parietal. Esses poros foram numerados de 1 a 8 e precedidos de uma letra $\mathbf{S}$, indicando-os como pertencentes ao canal supraorbital (S1-S8). Apesar de possuir onze poros supraorbitais ao longo de sua extensão, apenas oito desses poros puderam ter sua homologia reconhecida com base em partir de análises dos outros Characiformes e do grupo-externo. Dessa maneira, decidiu-se por identificar três desses poros como ramos supranumerários, indicados em B. nattereri por um asterisco (Fig 1: S2*, S4* e S6*)

O primeiro ramo supraorbital de Brycon nattereri (S1) é encontrado na porção mais anterior do canal supraorbital, emergindo da extremidade anterior da porção tubular do osso nasal. Neste mesmo local também se encontra o primeiro ramo supraorbital de outros Characiformes analisados, sendo a única exceção encontrada no táxon Acestrorhynchus cf. microlepis. Conforme reportado por Menezes (1969), Menezes \& Géry (1983) e Toledo-Piza (2007), exemplares do gênero Acestrorhynchus (fam. Acestrorhynchidae) apresentam associação do canal supraorbital com osso pré-maxilar. Nestes, nota-se o primeiro ramo supraorbital (S1), abrindo-se na porção anterodorsal do osso pré-maxilar (Fig. 2; Toledo-Piza, 2007: fig. 17), e não na porção anterior do osso nasal. A decisão de identificar este ramo de S1 partiu da observação de que, em Acestrorhynchidae, não há qualquer ramo emergindo entre o contato do osso nasal com pré-maxila (Fig. 2), levando a crer que o ramo e poro S1 desse táxon esteja deslocado anteriormente, disposto sobre o pré-maxilar.

Ao longo do trecho nasal do canal supraorbital, Brycon nattereri apresenta um segundo ramo, este denominado de $\mathrm{S} 2$, e variavelmente presente nos demais Characiformes. Além do S2, Brycon nattereri ainda apresenta outra ramificação ao longo do nasal, localizada antes do contato do nasal com o osso frontal. Tal poro é aqui considerado supranumerário (S2*) dada sua ausência na maioria dos Characiformes examinados (Tab. 3: S2*). As principais variações observadas sobre o ramo S2 em Characiformes estiveram relacionadas à ausência completa desse, ou à presença de ramos supranumerários S2* ao longo do nasal. O trecho de canal ao longo deste osso foi um dos de maior variabilidade em relação ao número de ramos supraorbitais em Characiformes. O ramo S2 foi ausente em todos os exemplares examinados das famílias Crenuchidae, Lebiasinidae, Erythrinidae, Gasteropelecidae, Parodontidae, Acestrorhynchidae e Erythrinoidea fam. nov (Tab. 3). Na família Characidae, este foi variou de 
zero a dois ramos ao longo do nasal, e em Distichodontidae de zero a três (Tab. 3). Ramos supranumerários também foram encontrados em Anostomidae (e.g. Leporellus vittatus e Sartor sp.), bem como em Chilodontidae (e.g.Caenotropus schizodon), Citharinidae (e.g. Citharinus latus), e Ctenoluciidae (e.g. Boulengerella cuvieri). Os táxons Prochilodus brevis (Prochilodontidae) e Eugnatichthys sp. (Distichodontidae) apresentaram, além do S2, dois ramos supranumerários ao longo do trecho nasal do canal supraorbital (indicados na tabela 3 como S2**). Apesar de se mostrar bastante variável, aumentos ou reduções do número de ramos ao longo do nasal podem ser informativas na tentativa de sustentar algumas relações de parentesco já propostas para famílias de Characiformes. As famílias Erythrinidae e Lebiasinidae, por exemplo, recorrentemente recobradas como grupo-irmão (Buckup, 1998; Mirande, 2010), compartilharam a ausência do ramo S2 ao longo da porção nasal do canal supraorbital. O mesmo poderia ser informativo para sustentar o monofiletismo de Crenuchidae, já que todos apresentaram ausência do ramo S2 desse trecho de canal. Por outro lado, o ganho de um poro supranumerário $\left(\mathrm{S} 2^{*}\right)$ poderia ser característico para os Anostomidae (ambos os táxons apresentaram um ramo supranumerário).

O terceiro ramo do canal supraorbital é encontrado em Brycon nattereri na extremidade posterior do osso nasal, disposto entre este e o osso frontal. Este mesmo poro é encontrado em todos os caraciformes, aqui denominado de S3. A hipótese de homologia estabelecida para a identificação desse ramo apoia-se principalmente em sua topologia, de modo a identificar como S3 o ramo disposto entre o osso nasal e o frontal. Entretanto, identificações alternativas para este ramo são possíveis em casos de táxons que apresentam reduções do número de ramos supraorbitais na porção nasal (e.g. Chrenuchidae, Erythrinidae). Estas identificações consideram o número de neuromastos dispostos sobre o trecho de canal que percorre o osso nasal, utilizando-os para a identificação dos ramos supraorbitais. Tais hipóteses são apresentadas abaixo, precedidas de uma breve descrição acerca da formação dos canais sensoriais e disposição dos neuromastos ao longo dos mesmos.

Assim como descrito item Introdução, e também detalhado por diversos autores (Allis, 1889; Pehrson, 1944; Lekander, 1949; Webb \& Northcutt, 1997), a formação dos canais e poros do sistema sensorial cefálico envolvem o neuromasto como unidader básica. No decorrer do desenvolvimento, os neuromastos de canal (i.e. os primeiros neuromastos a diferenciarem e migrarem do placódeo temporal) passam a ser envoltos pelo tegumento ao seu redor e a formar túbulos, unidades constituintes do canal sensorial. As extremidades anterior e posterior desse trecho de canal fornecem contato entre a superfície e o lúmen do túbulo através de projeções (i.e. ramos) terminando em poros. Cada um dos neuromastos de 
canal dá origem a um trecho tubular, delimitando anteriormente e posteriormente por poros. Em determinada situação onde há três ramos dispostos linearmente, intercalados por dois fragmentos de canal, nota-se que o ramo intermediário é, na verdade, um ramo complexo entre a projeção posterior do primeiro túbulo, e a projeção anterior do segundo túbulo, que se unem ao longo do desenvolvimento (Allis, 1889: pg. 467, A-D).O trecho nasal do canal supraorbital de Characiformes constitui um exemplo muito semelhante ao exposto acima (Allis, 1904). Este possui dois neuromastos de canal e três ramos supraorbitais, aqui denominados S1, S2 e S3. Reduções de três para dois ramos seriam consequência da redução de um neuromastos de canal, condição descrita por Allis (1904) para Macrodon trahira (=Hoplias malabaricus).

O critério aqui adotado assumiu a ausência do ramo S2 em casos de redução do número de poros ao longo do osso nasal (Fig. 24 A), mantendo a identificação dos ramos S1 e S3 àqueles dispostos anterior e posteriormente ao osso nasal. Entretanto, este mesmo critério é conflitante com a homologia dos neuromastos responsáveis pela formação desses mesmos ramos. Nota-se que, em uma condição primitiva de Characiformes, o primeiro neuromasto supraorbital (Fig. 24 B-C, NR1) é responsável pela formação dos ramos S1 e S2, e o segundo neuromasto (NR2) pelos ramos S2 e S3. Neste cenário, o poro S2 seria um poro complexo entre a projeção tubular posterior do primeiro neuromasto e projeção anterior do segundo neuromasto, e em qualquer uma das situações onde há reduções de neuromasto, o ramo S2 seria conservado, restando como possíveis alternativas apenas perdas do ramo S1 (Fig. 24 B) ou S3 (Fig. 24 C). Uma condição similar parece ocorrer também em eventos de redução do número de poros infraorbitais (e.g. ausência do i2 em Neolebias unifasciatus; Fig. 6) ou ao longo do dentário, sobre o canal mandibular. Em casos como esse, apesar de haver diferentes hipóteses explicando uma mesma morfologia, as variações anatômicas ainda são possíveis de ser observadas, o que não impediria a aplicação das mesmas em análises cladísticas.

Ademais, observações tomadas no grupo-externo também apontaram reduções de ramos ao longo do trecho nasal dos gêneros Fundulus (Cyprinodontiformes, Cyprinodontidae) ou Trichomycterus (Siluriformes, Trichomycteridae). A identificação dos ramos supraorbitais desses táxons também parecem resultar em três possíveis alternativas. Ao menos para Trichomycteridae, a literatura anatômica revela que a identificação dos primeiros ramos supraorbitais já seguiu duas identificações distintas. Enquanto Bockmann \& Sazima (2004: figs. 4-5) ou Datovo (2014: fig. 2) parecem ter adotado a perda do poro S2 do trecho nasal para a identificação dos ramos supraorbitais dos Trichomycteridae (i.e. o mesmo critério aqui adotado para os Characiformes), Arratia \& Huaquín (1995) optaram por assumir a perda do 
segundo neuromasto supraorbital na identificação desses mesmos ramos (Arratia \& Huaquín, 1995: fig. 8 D, fig. 9 D-F).

Ao longo do canal supraorbital, o ramo S4 é o primeiro observado sobre o osso frontal de Brycon nattereri. Poucas são as variações notadas relacionadas à presença desse ramo, que esteve ausente apenas em Hemiodus argenteus. Já em Toracocharax stellatus, não foi possível averiguar a presença deste (ou de qualquer outro) ramo supraorbital localizado após o osso nasal, pois a partir desse ponto o canal supraorbital em $T$. stellatus já não se apresentava fechado em um túbulo típico, impossibilitando a identificação dessas estruturas. Ramos supranumerários relacionados ao S4 foram encontrados apenas em Brycon nattereri. Variações morfológicas foram observadas principalmente em relação à extensão de sua porção tubular, notavelmente mais longas em Anostomidae, ou ausentes, sendo o poro aberto sobre o canala supraorbital em Boulengerella cuvieri (Ctenoluciidae) ou Hepsetus odoe (Hepsetidae).

Já próximo à porção média do osso frontal, nota-se outra ramificação sobre o crânio de Brycon nattereri, aqui identificada como S5. Este ramo foi encontrado lateralmente ao canal supraorbital, abrindo-se próximo à região de contato entre o osso frontal e o osso dermoesfenótico (Fig. 1: S5). Este poro foi variavelmente presente nos diferentes Characiformes examinados (Tab. 3), e apresentou variações relacionadas à sua orientação, se seguindo lateralmente ou medialmente sobre o frontal. Enquando a maior parte dos Characiformes apresentaram o ramo S5 prolongando-se lateralmente (Figs. 3, 4, 6, 7, 10), outros apresentaram-no prolongando em direção à porção medial do crânio, paralelamente ao ramo epifiseano (e.g. Xenocharax spilurus, Lebiasina melanoguttata, Hepsetus odoe, Hydrolychus tatauaia; Arratia \& Huaquín, 1995: fig. 1C).

Ramificando-se medialmente sobre o crânio de Brycon nattereri observa-se o ramo S6, também nomeado ramo epifiseano pela literatura anatômica (Arratia \& Huaquín, 1995; Mirande 2010). Excepcionalmente no exemplar examinado de Brycon nattereri, é encontrada uma subdivisão deste ramo, resultando na abertura do ramo supranumerário S6* (Fig. 1). Este ramo esteve presente em todos os Characiformes, com exceção de Erythrinoidea sp. nov. e de Toracocharax stellatus (Tab. 3). Variações observadas esteviveram ligadas principalmente à extensão da projeção desse ramo e formação de uma comissura com o ramo $\$ 6$ contralateral sobre a fontanela craniana (Tab. 1). Em determinados táxons (e.g. Lebiasinidae e Stygichthys typhlops; Fig. 11), o poro S6 foi observado apenas como uma abertura sobre o canal supraorbital, sem prolongar-se pro um ramo. Todavia, a condição mais comumente observada foi a de um longo ramo, ossificado em sua porção proximal, partindo do canal supraorbital e seguindo em direção à fontanela craniana (Figs. 8-10). 
Na porção posterior do osso frontal, o canal supraorbital apresenta uma curvatura lateral, seguindo de encontro com os ossos pterótico e dermoestenótico (Figs. 1, 2, 3, 7). Nessa região, em Brycon nattereri, é possível observar a abertura de outro ramo supraorbital, identificado aqui como S7, compartilhando uma abertura de poro com o último ramo infraorbital (i9). O ramo $\mathrm{S7}$ foi encontrado na grande maioria dos táxons examinados, ausente somente no exemplar fossorial Erythrinoidea fam. nov. e em uma condição não reconhecível em Toracocharax stellatus. Variações ligadas a este ramo já foram abordadas no item Canais látero-sensoriais cefálicos de Characiformes, subitem, Canal infraorbital, relacionadas principalmente à formação de um ramo complexo com o ramo infraorbital i9 (Tab. 1). Outras variações, também já abordadas, tiveram relação com ao local de abertura desse poro, se sobre o frontal, comum na maioria dos Characiformes (Fig. 1), sobre o pterótico (Fig. 3) ou sobre o dermoesfenótico (Fig. 16).

O último ramo supraorbital de Brycon nattereri, aqui denominado de $\mathrm{S8}$, é encontrado partindo do osso frontal, seguindo em direção à porção posterior do crânio. Este ramo, muitas vezes referido como ramo parietal pela literatura anatômica (Arratia \& Huaquín, 1995; Mirande 2010), foi observado em associação ao osso parietal, se abrindo em um poro próximo ao limite ósseo craniano (Figs. 1, 2, 3, 6 e 7: S8). A frequência (Tab. 3) e a extensão de prolongamento do ramo ossificado sobre o frontal e parietal foram as principais variações morfológicas notadas em relação ao $\mathrm{S} 8$. Em relação à sua morfologia, nota-se que os táxons da família Lebiasinidae o apresentam consideravelmente mais curto, abrindo-se em um poro diretamente do canal supraorbital principal, sem apresentarem ramificações longas (Fig. 5; Weitzman, 1964: figs. 3 e 6). Uma condição similar foi vista no táxon Iguanodectes variatus, cujo ramo parietal prolongou-se por uma curta extensão, abrindo-se ainda sobre o osso frontal. A condição mais comum, no entanto, é a de apresentá-lo percorrendo toda a extensão dos ossos frontal e parietal, por vezes projetando-se sobre as primeiras escamas pré-dorsais (Figs. 14 e 15: S8). 


\subsubsection{Ramos acessórios ao longo do canal infraorbital de Characiformes (Figuras 1 a}

\section{7; Figuras 12 a 17; Tabela 4).}

O canal infraorbital de Brycon nattereri apresenta onze ramos ao longo de sua extensão. Destes, dez podem ser reconhecidos em uma análise comparativa demais Characiformes, sendo apenas um único ramo tratado como supranumerário. Esses ramos foram numerados de 1 a 10 e precedidos de uma letra $\mathbf{i}$, indicando estes como ramos do canal infraorbital (i1 - i10), e o ramo supranumerário acompanhado de um sinal de asterisco (*).

Além dos dez ramos infraorbitais reconhecidos nos Characiformes, outro ramo chama a atenção por sua morfologia. Este é no trecho de canal antorbital do canal infraorbital de Hoplias aimara, e aqui denominado A1 (Fig. 12). Este ramo foi unicamente encontrado Erythrinidae, tratando-se de uma sinapomorfia para a família. Apesar de incomum dentre os Characiformes, a abertura do poro A1 foi variavelmente presente no grupo-exerno, de tal modo que descrições de ramos ao longo desse trecho são conhecidas há tempos para Actinopterygii basais (e.g. Allis, 1889), demonstrando que este trecho talvez seja uma característica primitiva retida em Ostariophysi.

Em Brycon nattereri, o primeiro ramo do canal infraorbital é encontrado na porção anterior da primeira placa infraorbital (Fig. 1: i1). Em Characiformes, este ramo é encontrado em todos os táxons apresentando o canal infraorbital, ausente apenas em Erythrinoidea sp. nov. e no exemplar troglóbio Stygichthys typhlops, táxons apresentando o canal infraorbital bastante reduzido. Variações em relação ao ramo i1 estiveram principalmente relacionadas à sua posição relativa sobre a placa infraorbital 1 , ora presente sob a margem anterior desta placa (Figs. 2 e 3: i1), ora localizado em uma posição intermediária (Fig. 6: i1). Em relação aos ramos supranumerários associados i1, o táxon Sartor sp. apresentou uma condição derivada quando comparado aos demais Characiformes. Conforme descrito por Winterbottom (1980) e Sidlauskas \& Vari (2008), exemplares da subfamília Anostominae apresentam um prolongamento da porção anterior do canal sensorial associado à primeira placa infraorbital. Este prolongamento é acompanhado de um aumento do número de ramos que se abre sobre a primeira placa infraorbital (Sidlauskas \& Vari, 2008: car. \#4 e \#5; Tab. 4). Na grande maioria dos Characiformes examinados, três ramos são encontrados ao longo da primeira placa infraorbital, sendo o mais anterior desses identificado como i1, seguidos de um ramo intermediário ao longo da primeira placa infraorbital (i2) e um terceiro ramo encontrado entre a primeira e a segunda placa infraorbital (i3). Já em Anostominae, e também em Sartor sp., o primeiro ramo associado ao canal infraorbital não é encontrado na porção mais anterior desse canal, e sim sobre a margem postero-dorsal da placa infraorbital, associado a um 
prolongamento do canal infraorbital (Sidlauskas \& Vari, 2008: figs. 12-13). Ao longo desse prolongamento de canal, outros três ramos resultam em poros, estes tratados aqui como supranumerários em Sartor sp. (Tab. 4), condição única para esta espécie dentre os Characiformes examinados.

O segundo ramo infraorbital de Brycon nattereri é visto ao longo do trecho associado à primeira placa infraorbital, projetando-se ventralmente e surgindo em um poro sobre a margem ventral da placa infraorbital 1 (Fig. 1; Weitzman, 1962: fig. 8). Este poro, aqui denominado i2, é encontrado na maioria dos caraciformes, com exceção de Pyrrhulina cf. australis e Neolebias unifasciatus (Figs. 5-6), e de táxons apresentando o canal infraorbital ausente ou reduzido em sua porção anterior (i.e. Erythrinoidea sp. nov. e Stygichthys typhlops, respectivamente). O número de ramos ao longo desse trecho de canal variou entre zero e dois (Tab. 4), com maioria dos Characiformes apresentando apenas um ramo ao longo desse trecho de canal. Ossificações da porção proximal deste ramo também foram variáveis, vistas em alguns táxons analisados (Weitzman, 1962: figs. 8 e 9; Weitzman, 1964: fig. 6; Mirande, 2010: fig. 39), enquanto outros apresentavam-no apenas como túbulo epitelial (Fig. 4; Mirande, 2010: fig.38).

O terceiro ramo do canal infraorbital de Brycon nattereri está localizado entre o limite da primeira e segunda placa infraorbital (Fig. 1: i3), partindo do canal principal e ramificandose ventralmente. Este poro é presente em praticamente todos os táxons examinados (Tab. 4), variando dentre o material analisado em relação ao ponto em que se ramifica sobre as placas infraorbitais. Por vezes esse ramo foi visto completamente sobre os limites da primeira placa infraorbital (Fig. 3). Todavia, a condição mais comum foi encontrá-lo entre o contato entre as placas infraorbitais 1 e 2 (Fig. 2). Um único táxon portou um poro supranumerário relacionado ao ramo i3, este foi Pyrrhulina cf. australis, que apresentou uma condição dos trechos de canal da primeira e segunda placa infraorbital separados entre si (Fig. 5). Isto acarretou em duas aberturas independentes de poros nessa região, uma posterior ao trecho da primeira placa infraorbital (i3), e outra na porção mais anterior do infraorbital 2 (i3*).

Em Brycon nattereri o ramo visto na porção média da segunda placa infraorbital é denominado de i4. Um ramo nesta posição está presente na grande maioria dos caraciformes (Tab. 4: i4), apresentando ramos supranumerários nos táxons Leporellus vittatus (Anostomidae), Caenotropus schizodon (Chiodontidae), Eugnatichthys sp. (Distichodontidae), Prochilodus brevis (Prochilodontidae) e Utiaritichthys esguiceroi (Serrasalmidae).

Ao final da segunda placa infraorbital, próximo à região de contato entre esta e o infraorbital 3, um novo ramo é observado, aqui tratado de i5. Este ramo foi observado em 
quase todos os Characiformes examinados, com exceção dos táxons Toracocharax stellatus, Erythrinoidea sp. nov. e Pyrrhulina cf. australis (Tab. 4). Morfologia interessante éobservada no táxon troglóbio Stygichthys typhlops, que apesar de apresentar severa redução do canal infraorbital, exibe um pequeno trecho de canal disposto sobre uma única placa infraorbital. Tal placa foi aqui identificada como infraorbital 3 (sensu Moreira et al. 2010). Utilizando-na como marcador anatômico para identificação dos poros infraorbitais, foi possível identificar os ramos presentes em Stygichthys typhlops como i5 e i6 (Tab. 4), provavelmente resultantes de apenas um único neuromasto presente ao longo desse trecho de canal. Em apenas cinco dos Characiformes examinados um ramo extra foi encontrado ao longo do trecho de canal que percorre a terceira placa infraorbital, aqui identificado como ramo supranumerário i5*, abrindo-se logo em seguida ao ramo i5. Dois deles merecem especial atenção: Prochilodus brevis (Prochilodontidae) e Citharinus latus (Citharinidae). Nestes, não apenas um, mas três ramos supranumerários surgem ao longo desse trecho de canal $\left(15^{* *}\right.$ e $\left.15^{* * *}\right)$. Castro \& Vari (2004) discorreram brevemente sobre essa condição nos Prochilodontidae, considerando o padrão ramificado sobre o infraorbital 3 em Prochilodus uma sinapomorfia para o gênero (Castro \& Vari, 2004: fig. 18 A; car. \#68). No presente trabalho, tal condição é considerada uma característica derivada desses táxons, surgindo homoplasticamente em cada um deles.

O trecho de canal entre a terceira e quarta placa infraorbital apresenta outro ramo do canal sensorial infraorbital em Brycon nattereri, este resultando na abertura do poro i6 (Fig. 1). Tal ramo é visto na grande maioria dos Characiformes, ausente apenas em Erythrinoidea sp. nov., Pyrrhulina cf. australis e Toracocharax stellatus. Os táxons Serrasalmus spilopleura, Eugnatichthys sp. e Toracocharax stellatus exibem apenas cinco placas infraorbitais, apresentando uma aparente fusão entre as placas 4 e 5. Nestes, o ramo i6 é encontrado ao longo da placa resultante da fusão entre infraorbitais 4 e 5, reforçando a hipótese de que a fusões de placas infraorbitais ocorrem justamente entre estas placas. A frequência do poro i6 em Characiformes pode ser consultada na Tabela 4.

Sobre a quarta placa infraorbital de Brycon nattereri, próximo ao contato desta com o infraorbital 5, outra abertura de poro é observada ramificando-se do canal infraorbital e prolongando-se em direção ao limite posterior das placas infraorbitais. Este longo ramo é denominado de i7, presente na maior parte dos táxons examinados (Tab. 4; Fig. 1: i7). Variações em sua morfologia são notadas em relação ao seu local de ramificação, se sobre a quarta ou quinta placa infraorbital. Na maior parte dos caraciformes, o ramo i7 é visto totalmente incluido pela quarta placa infraorbital (Figs. 1, 2 e 3; Mirande, 2010: figs. 38 e 39), porém, em alguns casos, este túbulo ramifica-se do contato entre a quarta e quinta placa 
infraorbital (Fig. 6; Mirande, 2010: fig. 41). Esta condição não pode ser examinada nos táxons Characidium xanthopterum, Characidium gomesi ou Melanocharacidium cf. auroradiatum, pois estes não apresentam margens ósseas associadas aos túbulos infraorbitais mais posteriores. Por vezes o ramo i7 apresenta sua porção mais proximal ossificada, associada à placa infraorbital. As figuras 38, 39 e 41 de Mirande (2010) ilustram esta condição (Mirande, 2010: car. \#74), evidente nos táxons examinados pelo presente trabalho Serrasalmus spilopleura e Utiaritichthys esguiceroi (Serrasalmidae) Prochilodus brevis (Prochilodontidae), Acestrorhynchus cf. microlepis (Acestrorhynchidae), Sartor sp. e Leporellus vittatus (Anostomidae), e Astyanax altiparanae (Characidae).

Ainda em relação ao ramo i7, observa-se variações em relação a sua extenção tubular, podendo esta ser bastante curta, com o poro aberto imediatamente ao lado do canal infraorbital (e.g. exemplares da família Erythrinidae, Distichodontidae, Crenuchidae e Lebiasinidae; Figs. 4, 12), ser de tamanho intermediário, apresentanado um trecho tubular que se estende até o limite posterior da quarta placa infraorbital (e.g. Acestrorhynchus cf. microlepis, Brycon nattereri; Figs. 1-2), ou apresentar um longo túbulo, que atravessa toda aquarta placa infraorbital, abrindo-se em um poro próximo à porção dorsal do osso opercular (Astyanax altiparanae, Creagrutus meridionalis, Chalceus epakros; Fig. 3). A respeito desse prolongamento tubular, cabe aqui um comentário sobre essa característica, que já foi utilizada por Mirande (2010) em seu caráter de número 75. Neste trabalho, Mirande (2010) codifica a "direção do ramo posterior do canal látero-sensorial do quarto ou quinto infraorbital", que pode levar à abertura de um poro sobre o pré-opérculo, próximo à articulação deste com a hiomandíbula, ou a um poro conspicuamente ventral ao côndilo mandibular. Durante a análise dos Characiformes, observou-se que existe, de fato, uma variação no local de abertura do poro resultante do ramo i7 quando este apresenta a condição prolongada. A condição mais comum foi a do ramo i7 prolongado até próximo à extremidade dorsal do osso pré-opercular. Todavia, em alguns táxons examinados (i.e. Caenotropus schizodon, Steindachnerina inscupta, Hemiodus argenteus e Chalceus epakros), observou-se que este ramo apresentou uma forte curvatura ventral ao longo de sua extensão. Acompanhando esta característica, notou-se nestes táxons a membrana adiposa do olho bastante desenvolvida, possivelmente relacionada ao hábito vágil de algumas dessas espécies. Ao que pode ser notado, os ramos emergindo do canal infraorbital nunca se abriam sob a região coberta por tal membrana, sendo estes geralmente alongados e muitas vezes curvados. Dessa maneira, postula-se que estas duas características (i.e. deslocamento da abertura dos poros, e presença de uma membrana 
adiposa ocular desenvolvida) estejam correlacionadas, informação importante para a correta averiguação da hipótese de homologia em relação a estes caracteres.

Próximo ao contato das placas infraorbitais 4 e 5 de Brycon nattereri, observa-se a projeção de outro ramo infraorbital, aqui denominado i8. Este é visto na maioria dos táxons analisados, ausente apenas alguns táxons apresentando reduções de trechos do canal infraorbital (e.g. Crenuchus spilurus, Stygichthys typhlops e Erythrinoidea sp. nov.). Os táxons Toracocharax stellatus e Pyrrhulina cf. australis, também apresentando reduções do canal infraorbital, por sua vez, portam um poro infraorbital identificável como i8 (Fig. 5). Nesses, as interrupções do canal infraorbital se dão na porção sub-orbital, de modo que o canal é visto ressurgindo em sua porção mais posterodorsal, portando os últimos ramos infraorbitais, i8 e i9. Variações anatômicas relacionadas ao ramo is foram principalmente relacionadas à extensão de seu prolongamento posterior, sendo sua condição mais alongada vista no táxon Chalceus epakros (Fig. 15).

No táxon Brycon nattereri o canal infraorbital encontra o supraorbital próximo à porção mais dorsal da placa dermoesfenótica. Nesse ponto, observa-se a abertura de um ramo complexo entre o sétimo ramo supraorbital e o nono ramo infraorbital, i9 (Fig. 1: S7+i9). Com exceção de Stygichthys typhlops e de Erythrinoidea sp. nov. o ramo i9 foi encontrado em todos os caraciformes examinados (Tab. 4: i9), sempre partindo da extremidade posterodorsal do canal infraorbital. Variações deste ramo se relacionaram ao local de abertura do poro i9, se sobre o dermoesfenótico, frontal, ou pterótico, ou à fusão deste com ramo S7 supraorbital (Tab. 1, S7+i9), ambas já discutidas em maiores detalhes no item Canais látero-sensoriais cefálicos de Characiformes.

O último ramo infraorbital de Brycon nattereri é onservado sobre a placa dermoesfenótica, ao fim de uma ramificação do canal infraorbital que segue anterodorsalmente e se abre próximo ao contato do dermoesfentico com o osso frontal (Fig. 1). Esta ramificação, que variou bastante dentre os caraciformes, denomina-se de i10. (Tab. 4: i10). Apesar de recorrentemente listada como presente em Xenocharax spilurus (Zanata \& Vari, 2005; Sidlauskas \& Vari, 2008), tal ramificação é aqui codificada como ausente em Distichodontidae. Esta decisão se explica pelo fato de o padrão tripartido presente em $X$. spilurus ser consequência da ramificação que dá início ao canal ótico situar-se sobre o dermoesfenótico. Isto confere aos canais situados sobre esta placa (Figs. 16, 17) um padrão ramificado semelhante àquele observado em Characiformes portadores do ramo i10 (Fig. 15). Em Brycon nattereri, assim como na maioria dos Characiformes, o início do canal ótico está sobre o osso pterótico, enquanto em Distichodontidae este início ocorre na própria placa 
dermoesfenótica, sendo a porção dérmica do osso pterótico bastante reduzida (Figs 16, 17). Maiores explanações sobre essa condição são comentadas no sub-item Canal supraorbital, no item descrevendo os canais látero-sensoriais cefálicos dos Characiformes.

Uma condição excepcional relacionada à porção posterodorsal do canal infraorbital é apresentada por Prochilodus brevis (Prochilodontidae). Este táxon apresenta sobre o dermoesfenótico não apenas um, mas cinco ramos acessórios (Fig. 13). No presente trabalho, tal condição é única ao táxon P. brevis, porém considerada por Castro \& Vari (2004) como sendo sinapomórfica aos exemplares do gênero Prochilodus dentre os Prochilodontidae (Castro \& Vari, 2004: car. \#75). Dentre os Curimatidae, uma condição similar também é conhecida para a espécie Curimata cyprinoides (Vari, 1989: fig. 36 C). Estes ramos são considerados supranumerários quando comparados à morfologia comumente exibida pelos Characiformes, e provavelmente estão relacionados à presença de um maior número de neuromastos de canal na região pós-orbital desses táxons. 
2.1.3. Ramos acessórios ao longo do canal ótico em Characiformes (Figura 4; Tabela 5).

Em Brycon nattereri, o canal ótico é considerado como trecho seguinte ao encontro entre os canais infraorbital e supraorbital, iniciando-se na porção mais anterior do osso pterótico e se estendendo até a região de contato deste com o canal pré-opercular. Este trecho, em B. nattereri, não porta nenhum ramo, sendo esta a condição mais comum dentre os Characiformes examinados (Tab. 5). Todavia, um ramo ótico (O1) foi excepcionalmente encontrado em Characidium cf. xanthopterum (Fig. 4: O1), observado em ambos os lados da cabeça do exemplar incluido na análise, e também presente em indivíduos preservados em álcool da mesma espécie. Ao que parece, ramos partindo do canal ótico são bastante incomuns em Characiformes, sendo este o primeiro relato da presença de um ramo ótico para a ordem, uma autapomorfia neste táxon. 


\subsubsection{Ramos acessórios ao longo do canal pós-ótico em Characiformes (Figuras 1 a 4;}

Figuras 6 a 10; Figuras 13 a 17; Tabela 5).

Em Brycon nattereri, o canal pós-ótico é encontrado sobre a porção media do osso pterótico, iniciando após o ponto de contato entre o canal pré-opercular e ótico, e se estendendo sobre os ossos extraescapular, pós-temporal e supracleitro até atingir a linha lateral do tronco do animal. Sobre o osso extraescapular, o trecho de canal considerado como pós-ótico é aquele seguindo em direção à cintura escapular, enquanto o trecho ramificando-se medialmente compreende ao início do canal supratemporal (tratado adiante). Ao longo da extensão do canal pós-ótico, cinco ramificações resultando em poros foram encontradas. Estas são descritas abaixo e enumeradas antero-posteriormente precedidas pelas letras PO (PO1 PO5).

O primeiro ramo encontrado ao longo do canal pós-ótico em Brycon nattereri situa-se sobre a região temporal da cabeça do animal, encontrado na extremidade dorsal do canal préopercular, próximo à região de contato deste canal com o canal ótico e pós-ótico, aberto em um poro complexo denominado PO1+PR1 (Fig. 1 - PO1+PR1). A condição apresentando este ramo complexo com o primeiro ramo pré-opercular foi bastante comum dentre os Characiformes examinados (Figs. 13-15), codificada aos membros da ordem na Tabela 1. Já em caraciformes apresentando a condição desconexa dos canais pré-opercular e ótico, o ramo PO1 é encontrado partindo ventralmente da porção média do osso pterótico. Tal poro é utilizado como um landmark do fim do canal ótico e início do canal pós-ótico (Figs. 4, 6). Variações na presença do ramo PO1 foram notificadas e apresentadas na Tabela 5. Interessantemente, a ausência do ramo PO1 em Characiformes foi acompanhada pela ausência de todo o canal pós-ótico e supratemporal, levando a crer que este ramo seja um dos de surgimento mais precoce no processo de formação dos canais pós-orbitais (ótico, pós-ótico e supratemporal).

Em relação ao segundo ramo do canal pós-ótico de Brycon nattereri, este éencontrado entre os ossos pterótico e extraescapular e aqui denominado de PO2. Tal ramo é visto na grande maioria dos Characiformes (Tab. 5: PO2), e as principais variações morfológicas relacionadas ao mesmo estão ligadas à extensão de sua porção tubular, variando de bastante prolongadas em alguns táxons (Figs. 2, 15), a um discreto túbulo (Fig. 14), ou apenas à uma escavação do canal pós-ótico (e.g. Boulengerella cuvieri). Especificamente em relação a esta estrutura, é interessante ressaltar que um ramo em posição semelhante já foi considerado sinapomorfia de Siluriformes (Fink \& Fink, 1981; Schaefer \& Aquino, 2000), ou também de Clupeiformes (Di Dario \& de Pinna, 2010). A homologia deste ramo é discutida de maneira 
detalhada abaixo, no item Neuromastos temporais e homologia do ramo pterótico do canal pós-ótico.

Seguindo posteriormente ao longo do canal pós-ótico de Brycon nattereri, o terceiro ramo é encontrado entre o limite dos ossos extraescapular e pós-temporal. Este, denominado de PO3, partiu do canal principal ainda sobre a extraescapula, deixando uma impressão ossificada de sua porção proximal sobre este osso (Fig. 1: PO3). Variações dentre o material examinado, quando relacionadas a esse ramo, estiveram principalmente ligadas ao ponto de ramificação deste em relação aos ossos da cintura escapular, se totalmente embebido na extraescápula (Fig. 1, 13), ou se entre a extraescápula e o pós-temporal (Figs. 6-7). A frequência com que o ramo $\mathrm{PO}$ foi encontrado em Characiformes pode ser consultada na Tabela 5.

O quarto ramo do canal pós-ótico de Brycon nattereri é aqui denominado de PO4, encontrado sobre o osso pós-temporal. A presença desse ramo em Characiformes foi variável, ausente em boa parte do material examinado (Tab. 5: PO4). A análise dos Characiformes revelou que muitas vezes a ausência do poro PO4 acompanhava a redução da porção dérmica do osso pós-temporal. Isso pode ser certificado em Hepsetus odoe (Hepsetidae), Hoplias aimara (Erythrinidae), Lebiasina melanoguttata (Lebiasinidae) e Caenotropus schizodon (Chilodontidae). Nestes, o ramo PO4 esteve invariavelmente ausente, e o canal pós-ótico não se associou ao osso pós-temporal, ligando-se diretamente da extraescápula ao supracleitro (Fig. 14). A participação da porção dérmica pós-temporal com o canal pós-ótico esteve bastante reduzida (e.g. Hepsetus odoe), ou completamente ausente (e.g. Caenotropus schizodon). Postula-se que a redução dos neuromastos pós-temporais desssa região esteja relacionada com a redução da porçõa dérmica do osso pós-temporal, explicando tanto a redução do número de poros pós-óticos, quanto a limitação da participação deste osso com o canal pós-ótico.

O último ramo do canal pós-ótico de Brycon nattereri, aqui tratado como PO5, é encontrado sobre a porção dorso-lateral do osso supracleitro, orientado posteriormente e prolongando-se por um túbulo tegumentar sobre as primeiras escamas do tronco do indivíduo (Fig. 1: PO5). Entre os caraciformes a ocorrência do poro PO5 foi, de certo modo, inconstante (Tab. 5: PO5). Esta característica já foi explorada por Mirande (2010) em seu trabalho acerca da filogenia da família Characidae (Mirande, 2010: car. \#88), apontando para sua ausência como uma autapomorfia de Serrasalmus maculatus (Serrasalmidae), característica homoplástica de Characidium rachovii (Crenuchidae). Demais variações observadas em respeito a este ramo estiveram principalmente relacionadas ao seu ponto de ramificação sobre 
o osso supracleitro, comumente longo da margem dorsal do mesmo (Figs. 7, 13, 16), mas também encontrado emergindo entre o supracleitro e a primeira escama da linha lateral (Fig. 14). 


\subsubsection{Ramos acessórios ao longo do canal supratemporal em Characiformes (Figuras}

1 a 4; Figuras 6 a 10; Figuras 13 a 17; Tabela 6).

O canal supratemporal de Brycon nattereri é encontrado sobre os ossos extraescapular e parietal, disposto transversalmente ao longo da região posterior do crânio, e apresentando dois poros ao longo de sua extensão, identificados no presente trabalho pelas letras ST (ST1 e $\mathrm{ST2}$ ). Assim como em B. nattereri, o canal supratemporal está presente na maioria dos Characiformes, variando principalmente na formação de uma comissura supratemporal (Tab. 1: ST2+ST2).

A primeira ramificação presente ao longo do canal supratemporal de Brycon nattereri é aqui identificada como ST1, encontrada ainda sobre o trecho de canal associado à porção medial do osso extraescapular. Sempre que presente, esse ramo é observado ao longo da superfície da extraescápula, prolongando-se sobre as primeiras escamas pré-dorsais do tronco do animal (Figs. 1 e 2: ST1). Em seu trecho sobre a extraescápula, muitas vezes esse ramo apresenta a sua porção proximal ossificada, seguindo através de um túbulo epitelial apenas após o limite posterior desse osso (Figs. 13, 15, 16). Entre os Characiformes, este ramo foi variavelmente presente (Tab. 6), sendo sua ocorrência já utilizada como característica em trabalhos de cunho filogenético (e.g. Vari, 1983).

Em um trabalho acerca do monofiletismo de Anostomoidea, Vari (1983) notou diferenças entre as ossificações de canal presentes sobre o osso extraescapular de diferentes táxons de Characiformes, percebendo que tais ossificações poderiam variar entre uma condição triparatida (Fig. 4) ou quadripartida (Fig. 7) do canal impresso sobre o osso extraescapular, esta última, em suas palavras, assemelhando-se ao formato da letra grega $\pi$ (pi). Ao analisar tal característica para membros das famílias Anostomidae, Curimatidae, Chilodontidae e Prochilodontidae, Vari (1983) postulou a condição quadripartida como sendo sinapomórfica da família Anostomidae. Décadas após a publicação desse trabalho, Sidlauskas \& Vari (2008) decidiram reexaminar esta condição em um trabalho tratando das relações filogenéticas da família Anostomidae, e decidiram excluí-la de sua lista de caracteres (Sidlauskas \& Vari, 2008: car. \#U19). Os autores justificaram tal medida por avaliar este caráter como sendo bastante homoplástico dentre Characiformes, hipótese corroborada durante o andamento do presente trabalho (Tab. 6: ST1). A condição quadripartida do canal sobre a extraescápula, ou seja, a da presença do ramo ST1 é uma característica amplamente distribuída dentre as diferentes famílias da ordem (Figs. 1, 2, 3, 7, 13, 15, 16), levando a crer a presença deste ramo seja uma característica primitiva de Characiformes. Variações do local de ramificação do poro ST1, quando encontrados fora dos limites do osso extraescapular, foram 
interpretadas como uma condição derivada, estando presente unicamente em Caenotropus schizodon (Chilodontidae), táxon que apresentou a abertura do ramo ST1 deslocada medialmente ao longo do canal supratemporal, abrindo-se sobre o osso parietal (Fig. 14: ST1). Outra condição também interpretada como derivada para Characiformes foi a perda do poro ST1 (Figs. 4, 6, 9). Nestes casos, o único ramo encontrado sobre a extraescápula foi aquele oriundo da ramificação pós-ótica $\mathrm{PO}$, de modo que o trecho de canal supratemporal sobre a extraescápula estivesse livre de abertura de poros. Esta condição foi o padrão encontrado para os táxons examinados da família Crenuchidae, Erythrinidae, Hepsetidae, Lebiasinidae, Gasteropelecidae e Parodontidae, e interessantemente, pareceu implicar em uma redução da porção dérmica do osso extraescapular, muitas vezes apresentando-a como apenas as ossificações tubulares dos canais pós-ótico e supratempral. Uma morfologia similar a esta, dentre os Characiformes, foi vista na extraescápula do táxon Caenotropus schizodon (Fig. 14), justamente aquele que apresentou um deslocamento medial do ramo ST1. Ao que parece, a presença de ambos os ramos (PO3 e ST1) sobre a extraescápula implica na formação de uma lâmina óssea desenvolvida, ao passo que a redução de um desses ramos acarreta em uma diminuição de sua ossificação dérmica. Já a redução total dos canais e poros temporais e supratemporais sempre acompanharam a ausência do osso extraescápula, fato também encontrado nas análises resultantes dos estudos de Buckup (1998) e Moreira (2007).

Em relação ao segundo ramo supratemporal de Brycon nattereri, indicado pela sigla ST2 (Fig. 1), este é encontrado deslocado medialmente no canal supratemporal, disposto sobre a fontanela craniana sobre seu limite mais posterior. Em B. nattereri, o ramo ST2 foi observado compartilhando uma abertura única à superfície com o ramo ST2 contralateral, formando uma abertura de poro complexa denominada de ST2+ST2. Esta condição foi comumente encontrada em Characiformes (Tab. 1), ausente apenas em Boulengerella cuvieri (Ctenoluciidae), Alestes longipinnis (Alestidae), Iguanodectes variatus (Characidae) e nas duas espécies examinadas da família Serrasalmidae, Serrasalmus spilopleura e Utiaritichthys esguiceroi (Serrasalmidae). 


\subsubsection{Ramos acessórios ao longo do canal pré-opercular de Characiformes (Figuras 1}

a 7; Tabela 7).

O canal pré-opercular de Brycon nattereri é encontrado principalmente ao longo do osso homônimo, iniciando-se imediatamente abaixo da porção mediana do osso pterótico, seguindo ventral e anteriormente ao longo do pré-opérculo até o limite anterior deste osso, próximo à região da articulação mandibular (Fig. 1). Pelo fato deste canal ser conectado dorsamente com o canal ótico e pós-ótico, e anteriormente com o canal mandibular, seus limites foram estimados pela presença de ramos tubulares, sendo o ramo PR1 o marcador do limite dorsal do canal pré-opercular, e o ramo PR7 marcador do seu limite anterior, ambos fundidos e exibindo uma abertura complexa (Fig. 1; Tab. 1: PO1+PR1, PR7+PM5). Sete principais ramos são encontrados ao longo do canal pré-opercular de B. nattereri (PR1-PR7). Somado a estes há a presença de um oitavo ramo (PR6*), aqui interpretado como supranumerário, sucedido pelo símbolo de um asterisco quando referido ao longo do texto.

O primeiro ramo pré-opercular de Brycon nattereri é encontrado no limite dorsal do canal pré-opercular deste peixe. Tal ramo, aqui denominado de PR1, apresenta-se compartilhado com o primeiro ramodo canal pós-ótico, formando o ramo complexo PR1+PO1 (Fig. 1). Este ramo é encontrado na grande maioria dos caraciformes, ausente apenas em Stygichthys typhlops e Erythrinoidea sp. nov., táxons apresentando reduções drásticas dos canais sensoriais cefálicos (Tab. 7: in.). Variações observadas em relação a esse ramo dentre os Characiformes estão relacionadas à sua associação com o primeiro ramo pós-ótico, formando um ramo complexo (Tab. 1: PO1+PR1), ou em sua abertura independente sobre o pré-opérculo. Em táxons apresentando contato entre os canais pré-opercular e ótico, o ramo complexo PR1+PO1 é observado ramificando-se dorsalmente a uma ossificação da porção dorsal do canal (i.e. supra-pré-opérculo sensu Mirande, 2010; Figs. 3, 7, 13, 14 e 15). Por outro lado, táxons cujo contato é ausente, o ramo PR1 encontra-se mais ventralizado, partindo da porção dorsal do osso pré-opercular (Figs. 4-6).

Ao longo do canal pré-opercular outros cinco ramos são observados em Brycon nattereri, estes variavelmente presente nos caraciformes incluidos no presente estudo (Tab. 7: PR2-PR6). O ramo PR2, quando presente, é visto ramificando-se do eixo vertical do osso préopérculo, próximo à sobreposição deste com o opérculo (Figs. 1-2). Adiante, outros três ramos foram encontrados no canal pré-opercular, caracteristicamente dispostos ao longo da curvatura do canal pré-opercular e acompanhando a flexão do osso homônimo (Figs. 1-7) . Tais ramos foram denominados de PR3, PR4 e PR5, vistos mesmo no táxon troglóbio Stygichtys typhlops, indicando surgimento bastante precoce destes ao longo do desenvolvimento do 
canal pré-opercular. Em seguida, outro ramo foi encontrado projetando-se do eixo ventral do canal pré-opercular de B. nattereri, próximo à porção anterior do osso pré-opercular. Este ramo foi denominado de PR6, sendo neste táxon precedido por um poro supranumerário S6*. A frequência do ramo PR6 nos Characiformes, e de ramos supranumerários em relação este, podem ser conferidas na Tabela 7.

O último ramo associado ao canal pré-opercular de Brycon nattereri é encontrado na porção mais anterior do osso pré-opérculo. Este ramo, aqui denominado de PR7, é visto no trecho de canal conectando o osso pré-opercular com o canal mandibular, disposto entre a extremidade mais anterior do osso pré-opérculo e a porção posterior do osso anguloarticular. Em Brycon nattereri, a abertura desse poro é compartilhada com o último ramo mandibular, justificando deniminá-lo de ramo complexo PR7+M5. Entre os Characiformes, o compartilhamento entre estes poros é recorrentemente observado, ausente apenas em táxons apresentando truncamento do desenvolvimento do canal mandibular. Ramos supranumerários relacionados ao PR7 ocorreram em cinco táxons examinados: Leporellus vittatus e Sartor sp. (Anostomidae), Triportheus flavus (Characidae), Hoplias aimara (Erythrinidae), e Prochilodus brevis (Prochilodontidae). Estes táxons apresentaram duas aberturas de poros no trecho de contato entre canais pré-opercular e mandibular, uma ramificando-se da porção mais anterior do pré-opérculo e outra partindo da porção posterior do anguloarticular, justificando deniminá-los de PR7 e PR7*.

Acerca do canal pré-opercular, notou-se que em Characiformes que este foi um dos que apresentaram maior variabilidade morfológica. A começar pela presença frequência de ramos acessórios do canal látero-sensorial, que variaram de ausentes a presentes e apresentando ramos supranumerários (Tab. 7). Exemplo disso vê-se principalmente dentre os ramos 3 a 5 do pré-opérculo: o número de três poros nesta região foi considerado condição primitiva por ser a contagem mais comum dentre caraciformes. Entretanto, apenas no trecho de canal acompanhando curvatura do osso pré-opercular, o número de ramos variou de 2 a 6 , (Stygichthys typhlops Toracocharax stellatus, respectivamente). Ramos supranumerários também foram encontrados em outros trechos do canal pré-opercular (e.g. PR2, PR6 e PR7), demonstrando grande variabilidade de neuromastos nessa região em uma análise abrangendo toda a ordem Characiformes. Isto indica que o número de neuromastos pré-operculares seja possivelmente informativo em análises mais exclusivas. 


\subsubsection{Ramos acessórios ao longo do canal mandibular de Characiformes (Figuras 1 a}

\section{4; Figura 6; Tabela 8).}

O canal mandibular de Brycon nattereri é encontrado ao longo dos ossos dentário e anguloarticular, emitindo ao longo de sua extensão cinco ramos, identificados aqui pela letra $\mathbf{M}$ e enumerados de um a cinco (M1-M5). O número de ramos mandibulares variou consideravelmente em Characiformes, desde sua completa ausência (e.g. Pyrrhulina australis, Stygichthys typhlops, Sartor sp.; Fig. 5) até a presença de mais de uma dezena de ramos associados a este canal (e.g. 13 em Galeocharax knerii, 14 em Boulengerella cuvieri, 19 em Hydrolycus tatauaia; Tab. 8). Ao considerar que o número de ramos está correlacionado ao número de neuromastos presentes ao longo de determinado canal, postula-se que o número de neuromastos ao longo do canal mandibular seja bastante variável dentre as diferentes famílias de Characiformes, podendo esta ser uma característica informativa em análises em um nível taxonômico mais exclusivo (i.e. genérico ou específico). Entretanto, estes casos são aqui considerados como exceções de um padrão básico, sendo cinco o número de ramos mandibulares utilizados para a identificação dos túbulos emergindo desse canal. O táxon Brycon nattereri, com sete ramos ao longo do canal mandibular, apresentou portanto dois ramos supranumerários (Fig. 1: M2* e M3*).

O número de ramos mandibulares já foi utilizado como caráter em um ensaio filogenético da família Characidae por Mirande (2010), autor que discutiu brevemente variações desse número nos diferentes Characiformes. Na descrição do caráter, o autor citou que a maioria dos táxons analisados apresentaram cinco ramificações ao longo do canal mandibular, quatro sobre o dentário e outra sobre o anguloarticular (Mirande 2010: fig. 43), e que o aumento de cinco para seis ou sete poros (Mirande 2010: fig. 44) seria característico de um pequeno agrupamento de espécies em Characiformes (i.e. autapomórfico de Raphiodon vulpinus; sinapomórfico de Characinae, clado 211; sinapomórfico de algumas espécies de Oligosarchus, clado 299, sensu Mirande 2010). O presente estudo corrobora a hipótese apresentada por Mirande, na qual o número de cinco ramos mandibulares é o padrão basal dentre os Characiformes (Tab. 8), e também reporta um aumento de ramos para os táxons Hydrolychus tatauaia (Cynodontidae), Galeocharax knerii (Characidae) e Boulengerella cuvieri (Ctenoluciidae).

Em relação ao primeiro ramo mandibular de Brycon nattereri, este é encontrado partindo da extremidade anterior do mento desse animal, ramificando-se do canal mandibular através de um túbulo epitelial e abrindo-se na porção frontal do dentário. Tal poro é aqui identificado como M1, e foi de presença variável entre os Characiformes examinados (Tab. 8). 
Reduções do número de ramos mandibulares ao longo do trecho do dentário foram interpretadas ocorrendo antero-posteriormente, acarretando perdas do ramo M1 nos Characiformes apresentando números inferiores a cinco ramos mandibulares, o que possivelmente pode ter ocorrido de maneira independente em diferentes famílias da ordem (e.g. Distichodontidae, Alestidae, Anostomidae, Prochilodontidae, Crenuchidae). Entretanto, mesmo ocorrendo de maneira homoplástica nesses táxons, tais reduções se mostraram bastantes consistentes em algumas famílias (e.g. Anostomidae, Crenuchidae), indicando ser possivelmente sinapomórfica desses grupos.

Adiante, outros dois ramos são vistos associados ao canal mandibular, observados ao longo do dentário de Brycon nattereri, tratados aqui como M2 e M3, seguidos de outros dois ramos supranumerários presentes neste táxon ( $2_{2} *$ e $\left.\mathrm{M}^{*}\right)$. Em Characiformes, os ramos $\mathrm{M} 2$ e M3 foram comuns na maioria dos táxons examinados, observados ao longo do canal mandibular, dispostos ao longo do osso dentário. Estes ramos apresentaram também uma morfologia bastante simples, sendo bastante semelhantes entre o material comparativo, de tal modo que as principais variações encontradas estiveram relacionadas ao número de ramos mandibulares (Tab. 8).

Os dois últimos ramos vistos ao longo do canal mandibular de Brycon nattereri são aqui denominados de M4 e M5. Tais ramos são observados abrindo-se anterior e posteriormente ao osso anguloarticular, e considerados oriundos de um único neuromasto disposto sobre este osso (Lekander, 1949). Em Characiformes, o ramo M5 foi geralmente encontrado fundido ao último ramo pré-opercular (PR7), formando o ramo complexo PR7+M5 (Figs. 1, 2, 3 e 6). Os únicos táxon a apresentar ramos supranumerários em relação aos ramos M4 e M5 foram Citharinus latus (Citharinidae) e Galeocharax knerii (Characidae). Nestes táxons, foram vistos ramos não apenas anteriormente e posteriormente ao osso anguloarticular, mas também observou-se dois poros ao longo da extensão deste osso. Esta característica, exclusivas desses dois táxons, foi considerada uma condição apomórfica, e homoplástica entre ambos. 
2.2. Demais considerações acerca dos ramos acessórios e poros ao longo dos canais sensoriais cefálicos - comparações com o grupo-externo (Figuras 1 a 26; Tabelas 1 a 14).

O número de poros presentes ao longo dos canais da linha lateral cefálica se mostrou bastante consistente dentre os Characiformes examinados, e, quando comparados a outros Ostariophysi ou mesmo com outros Teleostei, variou dentro de um padrão geral básico, tornando possível em muitos casos resgatar a homologia individual de cada uma dessas estruturas. Além da identificação desses poros individualmente, o número total de ramos ao longo de determinado canal também foi uma alternativa comparativa viável dentre os representantes do grupo externo, já que um número semelhante de poros ao longo de determinado canal em grupos filogeneticamente mais relacionados refletiria também em um mesmo número de neuromastos, sendo este um indicativo de que estas estruturas possivelmente fossem homólogas.

Os comentários acerca dos poros da linha lateral cefálica dos representantes incluidos como grupo-exerno foram apresentados acompanharam o mesmo modelo utilizado nas descrições apresentadas para Characiformes, porém dessa vez utilizando o padrão descrito para tal ordem como base para discussões das variações observadas. A nomenclatura utilizada para referir-se aos poros da linha lateral cefálica se manteva a mesma da empregada aos Characiformes, entretanto, por muitas vezes a identificação de dado poro em específico foi dificultada, seja pela ausência de ossos dérmicos como marcadores topológicos, seja pelo número de poros demasiadamente distintos daquele apresentado por Characiformes. Nesses casos a codificação de cada um desses poros nas tabelas apresentadas abaixo (Tabs. 9 a 14) considerou apenas o número de poros ao longo da linha lateral, identificando-os anteroposteriormente, sem pretensões de criar uma hipótese de homologia individual para cada um destes poros. Um número de poros excendo aquele observado em Characiformes, portanto, levou à identificação dos mesmos como supranumerários, identificado pelo símbolo de asterisco $(*)$. 
2.2.1. Ramos acessórios ao longo do canal supraorbital em grupo-externo (Figuras 18 e 19; Tabela 9).

O padrão básico de Characiformes é apresentar o canal supraorbital contendo oito ramos, estes dispostos ao longo dos ossos nasal, frontal e parietal. Dentre os Siluriformes, este mesmo número de ramos foi observado em Diplomystes mesembrinus, um exemplar da família Diplomystidae, família considerada pertencente a uma linhagem basal da ordem Siluriformes. Arratia \& Huaquín, em um trabalho acerca da linha lateral cefálica dos Loricarioidei e Diplomystidae publicado em 1995, apresentaram informações acerca do número de ramos supraorbitais para as famílias Nematogenyidae e Trichomycteridae, que novamente apresentaram em torno de oito ramos supraorbitais, levando a crer este número seja o padrão primitivamente encontrado em Siluriformes. Como apresentado na Tabela 9, dentre os demais Ostariophysi examinados o número de ramos supraorbitais variaram de seis a oito dentre os Gymnotiformes (Figs. 18-19), de sete a dez ramos em Cypriniformes, e de seis a dez em Gonorynchiformes (Tab. 9). Ao que parece, oito ramos supraorbitais parece ter sido o padrão fixado ao menos dentre os Characiphysi e Siluriphysi (Characiformes, Siluriformes e Gymnotiformes sensu Fink \& Fink, 1981, 1996). Apesar de quaisquer conclusões mais seguras necessitarem amostras com maior representatividade em Ostariophysi, cabe ressaltar que ao menos em Characiphysi e Siluriphysi, raramente observa-se mais que oito ramos supraorbitais, sendo esta característica uma uma possível sinapomorfia do clado.

Três ramos ao longo do trecho nasal do canal supraorbital foram comuns não só à maioria dos Characiformes, mas também para a maior parte dos exemplares incluidos no grupo-externo. Reduções de ramos nesse trecho se deram geralmente na porção média do osso nasal, e foram interpretadas de modo a se assumir a perda do ramo S2, e foram encontradas em diferentes táxons examinados como grupo-externo (e.g. Kneria sp., Esox americanus, Fundulus heteroclitus). Como apresentado acima, no subitem Ramos acessórios do canal supraorbital de Characiformes, identificações alternativas dos ramos presentes ao longo do nasal também seriam possíveis para estes táxons. Entretanto, preferiu-se manter o mesmo critério adotado para Characiformes às identificações dos ramos ao longo do trecho nasal dos táxons incluidos no grupo-externo (Fig. 24 A). Este critério aparentemente foi o mesmo utilizado por Bockmann \& Sazima (2004: figs. 4,5) ou Datovo (2014: fig. 2). Todavia, cabe reconhecer que identificações apresentadas por Arratia \& Huaquín (1995: fig. 8 D, fig. 9 D, F), também seriam compatíveis com a morfologia observada (Fig. 24 B,C).

Excepcionalmente em alguns exemplares da família Gymnotiformes, quatro ramos foram vistos ao longo da porção nasal do canal supraorbital. Esta condição foi observada em 
representantes da família Sternopygidae e Hypopomidae, que, diferentemente de quaisquer outros táxons analisados, apresentaram o primeiro ramo supraorbital (S1) em uma posição frontal em relação à cabeça do animal, abrindo-se na ponta do focinho. Os três ramos seguintes (S2, S3 e S4), por sua vez, pareciam deslocados anteriormente, de modo que o quarto ramo estivesse disposto ao lado do ramo antorbital. A parentemente, estes táxons apresentavam um deslocamento anterior dos quatro primeiros ramos supraorbitais. A contagem do número total de poros ao longo do canal supraorbital desses táxons não revelou qualquer ramo supranumerário, de modo que estes mantivessem um máximo de oito ramos. Tal condição, incomum a qualquer outro táxon examinado no presente trabalho, pareceu ser exclusiva de determinados grupos dentro da ordem Gymnotiformes.

Dos demais Teleostei examinados, o canal supraorbital variou tanto em extensão quanto no número de ramos apresentados. Enquanto alguns táxons apresentaram apenas a porção mais anterior do canal supraorbital completamente formada, resultando em apenas um pequeno número de ramos supraorbitais (e.g. Osteoglossum bicirrhosum, Osteoglossiformes, Osteoglossidae), outros apresentaram-no completamente formado, e com um número extremamente alto de ramos supraorbitais (e.g. Elops saurus, Elopiformes, Elopidae). Nesses casos, a identificação de cada um dos ramos individualmente foi impossibilitada dado o número bastante distindo daquele observado nos Characiformes ou demais Ostariophysi. Tais ramos foram incluidos na Tabela 9, seguidos da somatória de ramos acessórios ao longo desse canal. 
2.2.2. Ramos acessórios ao longo do canal infraorbital de grupo-externo (Figuras 18 a 22; Tabela 10).

O canal infraorbital dos Characiformes apresenta um número máximo de dez ramos resultantes em poros. Este número é ainda acrescido do ramo $\mathbf{A 1}$, encontrado associado ao trecho antorbital, que, nos Characiformes foi encontrado exclusivamente em Erythrinidae. Ramos infraorbitais variaram bastante em número dentre o material comparativo examinado (Ostariophysi e demais Teleostei). Em Ostariophysi, este número foi constante em grupos filogeneticamente mais próximos. Certa estabilidade foi notada em relação ao número total de ramificações ao longo do canal infraorbital de Siluriformes e Gymnotiformes, ordens que formam um clado juntamente com Characiformes (sensu Fink \& Fink, 1981; 1996). Dos exemplares examinados da ordem Siluriformes, Clarias submarginatus e Diplomystes mesembrinus apresentam sete e oito ramos ao redor da órbita, respectivamente. Arratia \& Huaquín (1995) apontaram que o número de ramos ao redor da órbita alcançaria dez ramos infraorbitais para o gênero Nematogenys (Arratia \& Huaquín, 1995: tabela 3, i1-i11). 0 presente trabalho encontrou os mesmos onze ramos apontados por Arratia \& Huaquín (1995), considerando, entretanto, o ramo antorbital (A1) como sendo independente do restante de ramos infraorbitais. Este, quando somado aos outros 10 ramos infraorbitais, atingem os mesmos números de ramos encontrados em Diplomystes ou Nematogenys (Arratia \& Huaquín, 1995). Dessa maneira, o número de poros encontrados em Siluriformes basais seria o mesmo observado dentre os Characiformes apresentando o canal infraorbital completo. Em Gymnotiformes também se observa números semelhantes de ramos ao redor da órbita. Com exceção do táxon Gymnotus cf. carapo (Fig. 18), os demais Gymnotiformes utilizandos na análise apresentaram todos por volta de nove ramos infraorbitais (Fig. 19), valor semelhante ao padrão considerado primitivo em Siluriformes (Arratia \& Huaquín, 1995) e Characiformes (presente análise).

Dentre os demais Ostariophysi examinados, o número de ramos encontrado ao longo do canal sensorial infraorbital foi elevado. Nestes, notou-se o aumento de ramos principalmente sobre a porção mais anterior do canal infraorbital dispostos sobre a placa denominada lacrimal dos Cypriniformes (i.e. infraorbital 1), e primeira placa infraorbital de Gonorynchiformes. Quando comparados com Characiformes, o número de ramos observados na porção anterior do canal infraorbital desses táxons foi superior a qualquer outro exemplar de Characiformes examinado (exceto Sartor sp.). O padrão observado em Characiforme se consistiu na presença de três (i1, i2 e i3) ou quatro ramos (com acréscimo de i2*) sobre a primeira placa infraorbital. Todavia, apenas na região anterior do canal infraorbital de 
Cypriniformes e Gonorynchiformes, observou-se até oito ramos associados à primeira placa infraorbial. Os táxons da família Cyprinidae Opsariichthys uncirostris, Campostoma anomalum (Fig. 21) e Barbus khudree apresentaram quatro, cinco e oito ramos entre a primeira e segunda placa infraorbital, respectivamente. Cinco ramos também foi a condição apresentada por Chanos chanos (Gonorynchiformes, Chanidae). Ao comparar a morfologia do canal infraorbital presente nesses táxons com aquela presente nos demais Ostariophysi, nota-se uma redução do número ramos na região mais anterior do canal infraorbital, esta que parece ser uma condição derivada presente em Characiphysi e Siluriphysi (sensu Fink \& Fink, 1981, 1996). Esta divergência no número de ramos na porção mais anterior do canal infraorbital parece implicar a divergência do número total de ramos ao longo do canal infraorbital. Enquanto o total de ramos infraorbitais raramente ultrapassa o onze em Characiformes, Siluriformes ou Gymnotiformes, esta quantia atinge valores de 19 ramos em Chanos chanos (Gonorynchiformes, Chanidae), 15 em Campostoma anomalum (Cypriniformes, Cyprinidae)ou 17 em Barbus khudree (Cypriniformes, Cyprinidae) (Tab. 10).

Outros táxons apresentando números elevados de poros infraorbitais foram Salmo trutta (Salmoniformes, Salmonidae) e Elops saurus (Elopiformes, Elopidae) (Fig. 22; Tab. 10), táxons que exibiram números de dezesseis a trinta poros infraorbitais, respectivamente. Condição semelhante foi reportada também para os Clupeiformes, ilustrada em Dorosoma cepedianum (Stephens, 1985: fig. 1). Reduções do número de ramos infraorbitais, portanto, parecem ser uma condição derivada, possivelmente refletindo a diminuição do número de neuromastos associados ao canal infraorbital. Dos táxons examinados, aqueles com o menor número de poros infraorbitais foram Galaxias vulgaris (Osmeriformes, Galaxiidae) apresentando quatro ramos acessórios, Osteoglossum bicirrhosum (Osteoglossiformes, Osteoglossidae) apresentando seis ramos, e Fundulus heteroclitus (Cyprinodontiformes, Fundulidae) também com seis ramos.

Dos ramos ao longo do canal infraorbital, dois deles mereceram especial atenção em relação a sua homologia: o ramo A1, resultante da presença do trecho antorbital (Fig. 12, 18, 19), e a ramificação i10, presente na região pós-orbital (Figs. 13-15). Em relação ao ramo antorbital, a decisão de se considerá-lo independente do restante do canal infraorbital já foi apresentada no tópico Demais considerações acerca dos canais látero-sensoriais cefálicos comparaç̃̃es com o grupo-externo, e a mesma justificativa sustenta a decisão de identificá-lo como poro A1 também nos táxons integrantes do grupo-externo. Dentre o material analisado como grupo-externo, o trecho antorbital esteve presente em todos os Siluriformes e Gymnotiformes analisados (Figs. 18-19), entretanto ausente nos demais Ostariophysi. A 
presença desse ramo poderia ser interpretada como uma sinapomorfia de Siluriformes e Gymnotiformes, adquirida independentemente nos Erythrinidae.

Em relação ao ramo i10, a identificação deste considerou apenas a ramificação presente sobre o dermoesfenótico (i.e. sexta placa infraorbital) seguindo em direção à extremidade anterodorsal deste osso (Figs. 13 a 15: i10). Apenas dois táxons incluidos no grupo-externo, Elops saurus (Elopiformes, Elopidae) e Chanos chanos (Gonorynchiformes, Chanidae) apresentaram uma ramificação sobre o dermoesfenótico comparável ao i10 (Tab. 10: i10; Nelson, 1969: fig. 5A). Dentre o material suplementar, tal ramo foi observado em Hiodon tergisus (Hiodontiformes, Hiodontidae) (ilustrada para Hiodon alosoides em Nelson, 1969: fig. 11). A identificação deste ramo, por sua vez, acarretou em em algumas consequências em relação à identificação dos ramos infraorbitais. Ambos os táxons que exibiram o ramo e poro i10 apresentaram um número elevado de ramos ao redor da órbita (19 em C. chanos, 30 em E. saurus) de tal forma que a identificação do ramo presente sobre o dermoesfenótico à ramificação número 19 emergindo do canal infraorbital em $C$. chanos, e aos ramos de número 27 a 30 surgindo do canal infraorbital em E. saurus. Se, de fato, tais ramificações são homólogas àqueles presentes nos Characiformes, o ganho de ramos infraorbitais nesses táxons ocorreu ao longo do trecho anterior e médio do canal ao redor da órbita ocular. 


\subsubsection{Ramos acessórios ao longo do canal ótico de grupo-externo (Figuras 20 a 22;}

Figura 26; Tabela 11).

O canal ótico de Characiformes inicia no ponto de contato dos canais supraorbital e infraorbital, se estendendo até o contato com o canal pré-opercular. Os Characiformes, com exceção da espécie Characidium cf. xanthopterum (Fig. 4: 01), não apresentaram qualquer ramo partindo do canal ótico. Também foram poucos os registros desses ramos para exemplares de Siluriformes ou Gymnotiformes. A única referência de um poro do canal ótico em Siluriformes foi feita por Arratia \& Menu-Marques (1984), reportando esta condição para três espécies do gênero Trichomycterus (T. boylei, T. duellmani, \& T. roigi). Tal condição foi ilustrada pelos autores (Arratia \& Menu-Marques, 1984: fig. 3A, fig. 12 A-B), e reanalisada por Arratia \& Huaquín (1995). Neste estudo, Arratia \& Huaquín (1995) afirmaram que ramificações do canal ótico são bastante raras em Siluriformes, encontradas somente nessas poucas espécies de Trichomycteridae. De fato, esta característica foi também bastante incomum em Characiformes, e inexistente em Gymnotiformes. Todavia, nos demais Ostariophysi, ramos ao longo do canal ótico foram frequentemente encontrados, presentes em todos os exemplares examinados de Cypriniformes (Fig. 21 e 26), e nos Gonorynchiformes Chanos chanos e Kneria sp. (Fig. 20; Tab. 11). Ao que parece, um ramo ótico seria uma condição plesiomórfica de Ostariophysi, sendo sua perda possivelmente sinapomórfica de Characiphysi + Siluriphysi (sensu Fink \& Fink, 1981, 1996). Nos demais Teleostei examinados, o poro ótico foi variavelmente presente (Fig. 22), sendo sua presença examinada na Tabela 11. 


\subsubsection{Ramos acessórios ao longo do canal pós-ótico de grupo-externo (Figura 26;}

Tabela 11).

Cinco ramos são frequentemente encontrados ao longo do canal pós-ótico de Characiformes, geralmente dispostos entre o contato dos ossos pterótico, extraescápula, póstemporal e supracleitro. Estes mesmos cinco ramos foram encontrados durante a análise do grupo-externo, resultando na proposição de uma hipótese de homologia semelhante àquela apresentada aos Characiformes.

Quando comparados com Characiformes, os Siluriformes e os Gymnotiformes apresentaram uma redução do número de ramos ao longo do canal pós-ótico, estando ausentes os ramos acessórios associados à porção dorsal da cintura escapular (e.g. ramos PO4 e PO5: Fig. 18-19). Em Gymnotiformes, três ramos foram recorrentemente encontrados ao longo do canal pós-ótico (Tab. 11), de modo que apenas a espécie Brachyhypopomus pinnicaudatus (Hypopomidae) exibisse somente os dois primeiros ramos pós-óticos (PO1-PO2). Entre os Siluriformes examinados, Diplomystes mesembrinus e Clarias submarginatus apresentaram três ramos associados ao canal pós-ótico, sendo esta aparentemente a condição comum também às demais famílias de Siluriformes (Schaefer \& Aquino,2000: tab. 1). Entre os demais Ostariophysi analisados, Cypriniformes e Gonorynchiformes apresentaram quatro ou cinco ramos partindo do canal pós-ótico, número semelhante ao observado em Characiformes, fator facilitador à identificação dos mesmos (Fig. 25). A condição de cinco ramos póstemporais pareceu, portanto, ser a condição primitiva em Ostariophysi, de modo que a redução apresentada por Siluriformes e Gymnotiformes (Siluriphysi, sensu Fink \& Fink, 1981, 1996) fosse interpretada como uma sinapomorfia ao clado.

De maneira similar, cinco ramos foram o número máximo observado em outros Teleostei examinados (Tab. 11). Reduções completas da formação do canal pós-ótico foram vistas nos táxons, Fundulus heteroclitus (Cyprinodontiformes, Fundulidae) (Gosline, 1949: figs. 1 a 5; Van Bergeijk \& Alexander, 1962: fig. 1), Esox americanus (Esociformes, Esocidae) (Nelson, 1972: fig. 1C), e Galaxias vulgaris. O táxon Anguilla rostrata apresentou modificações estruturais dos ramos dos canais ótico e pós-ótico, impossibilitando a identificação de tais estruturas. Tais modificações, por sua vez, pareceram ser comuns à família Anguillidae (Zacchei \& Tavolaro, 1988: figs. 1 a 3).

Em relação à morfologia dos ossos associados ao canal pós-ótico, o táxon Esox americanus merece especial atenção. Neste, nota-se o canal pós-ótico interrompido, com a porção associada ao osso pterótico separada do trecho disposto sobre supracleitro (Nelson, 1972: fig. 1C). Interessantemente, esta condição desconexa dos canais temporais acompanha 
modificações anatômicas relacionadas ao esqueleto craniano desse indivíduo. Em $E$. americanus observa-se que tanto a extraescápula quanto a porção exposta (dérmica) do osso pós-temporal estão ausentes, de tal maneira que a porção disposta entre a extremidade posterior do osso pterótico e a porção dorsal do supracleitro estejam completamente desprovidas de ossificações dérmicas, coberta apenas por escamas. Em relação aos ramos do canal pós-ótico, os ramos PO1 e PO2 foram encontrados ao longo do osso pterótico. Posteriormente, sobre o supracleitro, outros dois ramos foram observados, um anterior e outro posterior ao trecho de canal disposto sobre este osso (PO4 e PO5, respectivamente). Conclusões interessantes puderam ser obtidas ao comparar a morfologia dos canais e ossos dérmicos da região temporal de Esox americanus com outra espécie do mesmo gênero, Esox masquinongy. De acordo com as descrições de Nelson (1972), enquanto E. americanus apresentou interrupções da formação de canal ao longo do pós-ótico (consequentemente apresentando o ramo PO3 ausente), E. masquinongy apresentou-os contínuos ao longo do canal ótico e pós-ótico. Isso pareceu implicar diretamente na presença das ossificações dos ossos pós-temporal e da extraescápula nesse táxon. Enquanto a condição observada em $E$. americanus foi a de apresentar estes os ossos dérmicos ausentes, E. masquinongy apresentouos completamente desenvolvidos (Gregory, 1933: fig. 95, A-B). Esta configuração permite afirmar, portanto, que há correlação entre a presença de neuromastos (e consequentemente ramos do canal pós-ótico) com as ossificações dos osso extraescapular e pós-temporal nesses peixes.

Relações entre a presença de ramos do sistema látero-sensorial e ossos dérmicos da região posterior do crânio já foram feitas, de certo modo, por Lundberg (1975). Em seu trabalho, o autor traçou homologia entre o ramo PO2 de Characiformes e Siluriformes, utilizando-se dessa característica (dentre outros detalhes anatômicos relacionados à osteologia da cintura escapular) para argumentar a favor da homologia entre o osso póstemporal desses dois táxons. Todavia, sua hipótese de homologia foi posteriormente rejeitada por Fink \& Fink (1981), autores que consideraram os ramos do canal sensorial cefálico extremamente variável dentre os Ostariophysi, afirmando que o ramo PO2 de Siluriformes fosse distinto de qualquer outro poro presente nos Ostariophysi (Fink \& Fink, 1981: car. \#95). Esta afirmação de Fink \& Fink (1981)parece ter aberto precedentes para considerar o ramo PO2 dos Siluriformes uma sinapomorfia para o grupo, hipótese apresentada por Arratia \& Huaquín (1995) e Arratia \& Gayet (1995). Schaefer \& Aquino (2000) ainda dedicaram um trabalho integralmente ao assunto, propondo hipóteses de homologia robustas para a identificação do ramo PO2, além de reportá-lo para dezenas de diferentes famílias de 
Siluriformes. Esses autores mantiveram o ramo e poro PO2 como uma sinapomorfia para os bagres, memso não testando a mesma hipótese de homologia em um grupo-externo mais amplo. Este fato perpetuou a informação de que o ramo pterótico do canal pós-ótico (=ramo PO2) como uma sinapomorfia de Siluriformes mesmo este ramo e poro estando amplamente distribuido em Ostariophysi. Uma discussão mais específica em respeito a este tema é apresentada abaixo, no item Neuromastos temporais e homologia do ramo pterótico do canal pós-ótico. 
2.2.5. Ramos acessórios ao longo do canal supratemporal de grupo-externo (Figuras 18, 19, 23 e 26; Tabela 12).

Em Characiformes, o canal supratemporal é encontrado ao longo dos ossos extraescapular e parietal, disposto transversalmente à da região posterior do crânio, e apresentando dois ramos ao longo de sua extensão, identificados no presente trabalho por ST1 e ST2. Em análise comparativa com os demais Ostariophysi e também outros Teleostei, notou-se variações em relação a esse canal, principalmente relacionadas à presença e distribuição dos ramos supratemporais, bem como à formação de uma comissura entre os ramos dispostos na porção medial do crânio.

Dentre os Ostariophysi incluidos no grupo-externo, o canal supratemporal foi recorrentemente ausente em Siluriformes, característica já conhecida ao grupo (Herrick, 1901; Arratia \& Gayet, 1995) e corroborada pelo presente trabalho. Já os Gymnotiformes exibiram um canal supratemporal completamente formado em todos os indivíduos examinados. Variações notadas em Gymnotiformes estiveram relacionadas principalmente à ausência de algum dos ramos supratemporais (Tab. 12; Figs. 18-19). Quando presente, o ramo ST1 esteve localizado entre a extraescápula e o osso parietal dos Gymnotiformes, enquanto o ST2 sempre apareceu compartilhado ao ramo ST2 contralateral (Tab. 2). Em relação aos demais Ostariophysi, dois ramos supratemporais estiveram presentes nos Cypriniformes e Gonorynchiformes examinados (Fig. 25). Excepcionalmente em Campostoma anomalum (Cypriniformes, Cyprinidae), foram observados quatro ramos ao longo do canal supratemporal, número superior ao observado em qualquer outro Ostariophysi.

Nos demais Teleostei examinados, um número elevado de ramos supratemporais foi observado em Elops saurus (Elopiformes, Elopidae) (seis poros) e em Salmo trutta (Salmoniformes, Salmonidae) (sete poros). O táxon $S$. trutta se distinguiu também pela morfologia do canal supratemporal. Enquanto outros táxons apresentaram o canal supratemporal associado aos ossos extraescapular e parietal, este táxon apresentou tal canal independente de ossificações dérmicas subjacentes, exibindo-o totalmente ossificado e disposto em uma sequência de fragmentos tubulares sem qualquer associação aos ossos parietal ou extraescapular, assemelhando-se em muito à morfologia exibida pelos Siluriformes e Gymnotiformes ao longo do canal infraorbital.

O número de ramos supratemporais e o local de projeção destes ao longo do canal principal se mostraram de bastante importancia para a compreensão da morfologia expressa pelos ossos em associação ao canal supratemporal. Conforme expresso acima, no item Ramos acessórios ao longo do canal supratemporal em Characiformes, o ramo ST1, quando presente, 
foi geralmente encontrado sobre os limites da placa óssea extraescapular dos Characiformes, dando a esta um aspecto quadripartido dos canais ossificados sobre a mesma (Fig. 7). Comparações com os demais Ostariophysi revelaram que essa morfologia sobre a extraescápula foi encontrada exclusivamente em Characiformes, demonstrando ser uma característica sinapomórfica à ordem. Demais Ostariophysi examinados, ou não apresentaram tal ramo (e.g. Siluriformes), ou apresentaram-no entre os ossos extraescapular e parietal (e.g. Gymnotiformes e Cypriniformes). A morfologia apresentada pelos Cypriniformes (Fig. 25), inclusive, foi bastante semelhante àquela apresentada pelos Characiformes em que o ramo ST1 foi ausente (Fig. 4) ou em que este ramo encontrou-se deslocado medialmente (Fig. 14), reforçando a ideia de que a morfologia da extraescápula dos Characiformes seja consequente da incorporação do ramo ST1 dentro de seus limites dérmicos.

No que diz respeito aos Gonorynchiformes, a morfologia do canal supratemporal se mostrou bastante variável. Exclusivamente em Chanos chanos (Gonorynchiformes, Chanidae), o ramo ST1 apresentou-se fundido ao ramo ST8 do canal supraorbital (Fink \& Fink, 1996), formando o poro complexo S8+ST1 (Tab. 2). Ao que parece essa condição foi exclusiva ao gênero, já que não foi vista em qualquer outro táxon examinado. Por sua vez, o exemplar de Kneria sp. (Gonorynchiformes, Kneriidae) exibiu uma modificação bastante interessante em relação ao ponto de início do canal supratemporal. Conforme citado acima, no item Demais considerações acerca dos canais látero-sensoriais cefálicos - comparações com o grupoexterno, o canal supratemporal teve seu início ainda sobre o osso pterótico de Kneria sp., o que implicou em uma condição peculiar do arranjo dos ossos cranianos, em que a extraescápula se dispunha medialmente ao pterótico, e não posteriormente a este como observado nos demais táxons examinados (Fig. 23). Não surpreendente foi a observação do ramo ST1 partindo do ponto entre o pterótico a extraescápula de Kneria sp., demonstrando uma estreita relação entre os neuromastos dessa região temporal e a presença da placa dérmica extraescapular. 


\subsubsection{Ramos acessórios ao longo do canal pré-opercular de grupo-externo (Figura 19;}

Tabela 13).

O canal pré-opercular, dentre os táxons compreendendo o grupo-externo, foi encontrado associado ao osso homônimo, percorrendo sua margem póstero-ventral e prolongando-se desde sua extremidade dorsal até sua porção mais ântero-ventral, onde geralmente conectou-se com o canal mandibular. O número de ramos ao longo do canal préopercular foi bastante variável no grupo-externo (Tab. 13). Entre os Ostariophysi, este número foi relativamente constante entre os Siluriformes e os Gymnotiformes, ambos apresentando por volta de seis ramos pré-operculares (Fig. 19). Entretanto, este número passou a ser variável ao incluir as ordens Cypriniformes e Gonorynchiformes, chegando a apresentar até onze ramos pré-operculares em Chanos chanos (Gonorynchiformes, Chanidae). Comparações com os Teleostei também apontou para um número variável de ramos ao longo do préopérculo, estes atingindo até dezessete unidades em Elops saurus (Elopiformes, Elopidae).

Na maior parte dos exemplares examinados o canal pré-opercular foi contínuo ao canal mandibular, sendo o contato entre os dois definido pela emissão do ramo complexo PR7+M5 (Tab. 2). Entretanto, em Kneria sp. (Gonorynchiformes, Kneriidae) estes canais não estiveram conectados, resultado da ausência da formação de um canal mandibular. Por outro lado, em Galaxias vulgaris (Osmeriformes, Galaxiidae) e em Esox americanus (Esociformes, Esocidae) (este último ilustrado por Nelson, 1972: fig. 1C) ambos os canais estiveram presentes, porém não conectados um ao outro, interrompidos na porção do osso anguloarticular. De acordo com Lekander (1949), ao longo do desenvolvimento dos canais sensoriais cefálicos a conexão dos canais pré-opercular e mandibular seria consequência da formação de um tubo sobre o osso anguloarticular, este resultante da presença de um único neuromasto que ligaria a extremidade posterior do canal mandibular à anterior do canal préopercular. Excepcionalmente nesses dois táxons, o osso anguloarticular não apresentou qualquer porção de canal ossificado, de modo que este fosse o ponto de interrupção entre os dois canais. 
2.2.7. Ramos acessórios ao longo do canal mandibular de grupo-externo (Figura. 19; Tabela 14).

O canal mandibular dos Characiformes é encontrado sobre os ossos dentário e anguloarticular, disposto látero-ventralmente ao longo da mandíbula, e apresentando um total de cinco ramos ao longo de sua extensão. Em uma análise comparativa com outros Ostariophysi e Teleostei, o canal mandibular foi um dos que mais sofreu variações no que se diz respeito ao número de ramos. Enquanto o número de quatro ou cinco ramos foi relativamente consistente entre os caraciformes, em Siluriformes e Gymnotiformes esse número foi invariavelmente de seis ramos mandibulares, possivelmente uma característica compartilhada entre os Siluriphysi (sensu Fink \& Fink, 1981) (Fig. 19). Em relação aos demais Ostariophysi examinados, Cypriniformes apresentaram entre quatro e dez ramos mandibulares, e Gonorynchiformes apresentaram tanto o canal mandibular ausente (e.g. Kneria sp., Kneriidae), ou contendo seis ramos ao longo de sua extensão (e.g. Chanos chanos, Chanidae). Em relação à homologia dos poros do canal mandibular, muitas vezes a identificação individual destas estruturas se tornou um exercício bastante difícil devido a sua grande variação em número. Dentre os demais Teleostei examinados, o número de ramos variou de apenas dois (e.g. Galaxias vulgaris, Galaxiidae, Osmeriformes) a até vinte ramos (e.g. Elops saurus, Elopidae, Elopiformes). Perda ou aquisição de ramos, quando ocorridas ao longo da extensão do canal sobre o dentário só puderam ser notadas através da contagem do número total de ramos mandibulares. Os únicos ramos com identificação mais precisa foram aqueles partindo do osso anguloarticular, projetados anterior e posteriormente, homólogos aos ramos M4 e M5 de Characiformes, oriundos de um único neuromasto disposto ao longo do trecho de canal percorrendo este osso (Lekander, 1949). 


\section{Demais considerações.}

\section{Homologia dos ossos dérmicos portadores de canais látero-sensoriais cefálicos.}

A relação de causa e consequência entre canais sensoriais, ossos dérmicos e neuromastos de canal no desenvolvimento craniano dos peixes há mais de um século vem sendo discutida na literatura anatômica. A falta de consenso acarretou na formação de diversas hipóteses, sendo sugerido tanto que o neuromasto de canal funcionasse como um indutor para a formação dos ossos dérmicos (Pehrson, 1944), que os neuromastos induzissem apenas a ossificação dos canais sensoriais, e que a formação das placas dérmicas se rataria de um evento independente (de Beer, 1937; Lekander, 1949), ou até mesmo uma teoria "conciliadora", na qual ambos os panoramas pudessem explicar a ossificação presente em diferentes locais do crânio (Graham-Smith, 1979: fig. 1).

De fato, diferentes complexos morfológicos necessitaram hipóteses distintas para explicar a anatomia expressa pelos mesmos. Enquanto uma independência entre canais e placas dérmicas dispostas ao longo dos infraorbitais, ou ao longo da região dorsal do préopérculo parecia ser o panorama observado (sensu de Beer, 1937), uma correlação entre os elementos da linha lateral cefálica e os ossos da região pós-craniana (extraescápula) e cintura escapular (pós-temporal) foi recorrentemente a condição expressa pelos táxons analisados (e.g. Esox americanus), indicando que os neuromastos pudessem estar, de fato, induzindo ossificações dérmicas dos ossos extraescapular e pós-temporal. Ao que parece, processos de ossificação dérmica e de elementos do canal sensorial são mais variáveis do que até então especulado, carecendo ainda de estudos comparativos envolvendo uma maior representatividade taxonômica. De modo a ilustrar essa variabilidade de interações entre linha lateral cefálica e ossificações dérmicas, elegeram-se três casos em específico para uma descrição mais aprofundada. Estas são apresentadas abaixo acompanhadas de um histórico acerca de suas hipóteses de homologia, e de comentários de como o conhecimento do desenvolvimento da linha lateral cefálica puderam auxiliar na interpretação desses complexos morfológicos. 


\subsection{Homologia dos ossos infraorbitais de Ostariophysi.}

A série de placas ósseas de origem dérmica presente ao redor da órbita ocular dos peixes são comumente denominados de ossos (ou placas) infraorbitais, composta de um osso lacrimal, ou infraorbital 1, e uma série de cinco ou seis ossos infraorbitais, sendo o sexto alternativamente referido como dermoesfenótico, disposto sobre o osso esfenótico (Nelson, 1969). Dentre os Ostariophysi, os Characiformes apresentam geralmente seis ossos infraorbitais ao redor da órbita (Figs. 1 a 7; Fig. 12), enquanto Cypriniformes e Gonorynchiformes apresentam geralmente cinco ossificações infraorbitais (Figs. 20 a 22). Siluriformes e Gymnotiformes, salvo poucas exceções, apresentam ambos uma condição em que as placas dérmicas infraorbitais estão ausentes, sendo as estruturas dispostas ao redor da órbita geralmente resultantes da ossificação do canal infraorbital, formando uma série de até sete túbulos, somados a uma oitava ossificação compreendendo a porção antorbital (Fig. 18; Fink \& Fink, 1981; 1996; Arratia \& Huaquín, 1995: fig. 4B).

Apesar de também denominados infraorbitais, a série de ossículos tubulares que circundam a órbita ocular dos Siluriformes e Gymnotiformes se difere das placas dérmicas dos Characiformes tanto em morfologia quanto em número (Bockmann, 1998). De acordo com Arratia \& Huaquín (1995), os infraorbitais de Siluriformes geralmente estão presentes em números que variam de três a sete (Arratia \& Huaquín, 1995), somados anteriormente a um ossículo antorbital encontrado na porção dorsal do canal infraorbital, disposto obliquamente entre a abertura nasal posterior e a porção anterior da órbita. Um padrão muito semelhante a este é apresentado pelos Gymnotiformes (Fig. 18), cujos táxons apresentam apenas os elementos associados à linha lateral cefálica, dispostos ao redor da órbita ocular. A principal diferença observada entre estes infraorbitais com aqueles presentes nos demais Ostariophysi está na ausência de uma margem laminar óssea bem desenvolvida cobrindo a porção lateral da cabeça desses animais. De acordo com as descrições de Kindred (1919) e Lekander (1949), os canais sensoriais cefálicos surgem bastante cedo no desenvolvimento dos peixes, guardando estrita relação com o número e disposição dos neuromastos de canal. Já as placas dérmicas possuem desenvolvimento espacial e temporalmente distinto dos canais sensoriais, podendo inclusive ossificar-se sem que haja qualquer relação a um trecho de canal sensorial (Fig. 5).

Durante a presente análise, observou-se em diversos Characiformes a existência de placas infraorbitais sem que o canal infraorbital estivesse presente. Estas observações argumentaram justamente em favor da interpretação de que ambas as estruturas (i.e. canais ossificados e placas dérmicas) sejam complexos morfológicos distintos. Dentre os táxons 
examinados, esta condição foi presente em Toracocharax stellatus, Pyrrhulina cf. australis e Erythrocharax altipinnis, todos com interrupção da porção suborbital do canal infraorbital, justamente a porção de canal apresentando desenvolvimento mais tardio em Characiformes. Apesar de esse trecho do canal estar ausente nesses táxons, os mesmos apresentaram desenvolvimento completo das placas intraorbitais (Fig. 5), demonstrando independência entre ambos os complexos morfológicos. Exemplos desassociando as placas infraorbitais dos canais homônimos puderam ser encontrados na literatura anatômica sobre Characiformes. De acordo com Vari (1995), dentre os Ctenoluciidae, o gênero Boulengerella seria caracterizado por apresentar uma redução do número de placas infraorbitais (Vari, 1995: fig. 1) quando comparado a Ctenolucius ou aos demais caraciformes analisados como grupo-externo. Entretanto, mesmo apresentando número reduzido de placas infraorbitais, todos os exemplares de Boulengerella apresentaram os canais infraorbitais completos, assim como o número de ramos (e poros) infraorbitais comparável ao padrão encontrado em Characiformes, demonstrando que variações no número ou no arranjo das placas infraorbitais em nada influenciam na morfologia ou número de ramos ou poros do canal infraorbital. Esta mesma conclusão foi obtida por Bockman (1998) em sua tese de doutoramento. Na ocasião, Bockmann (1998) argumentou a favor da desassociação das placas e dos canais infraorbiais dos Ostariophysi, nomeando os elementos ossificados ao redor da órbita dos Siluriformes de ossos sub-orbitais (termo aplicado também às ossificações presentes nos Gymnotiformes), diferenciando-os das placas observadas nos demais Ostariophysi.

A utilização de hipóteses de homologia distintas para a observação de variações nos elementos da linha lateral cefálica e das placas dérmicas infraorbitais pode ser bastante interessante quando, por exemplo, se analisa a morfologia das espécies da subfamília Characidiinae (Crenuchidae). Buckup (1993), em um trabalho acerca do monofiletismo dessa subfamília, identificou como uma sinapomorfia da mesma o desenvolvimento truncado do que ele chamava de porção óssea lamelar dos ossos infraorbitais 3 a 6 (Fig. 4). Esse estado de caráter era, segundo o autor, compartilhado somente com o grupo externo utilizado em seu trabalho, os Siluriformes. Pelo que pode ser observado, uma redução das placas dérmicas infraorbitais dos Characidiinae não implica em qualquer perda dos elementos da linha lateral cefálica desses bichos, demonstrando novamente que variações de um desses sistemas não afeta na morfologia expressa pelo outro (i.e. perda da porção dérmica das placas infraorbitais não resultou em supressão da formação do canal infraorbital). Outro caráter utilizado na análise cladística de Buckup (1993), e encontrado exclusivamente em Characidiinae dentre os Characiformes, esteve relacionado com a "porção do canal látero-sensorial atravessando o 
osso esfenótico" desses táxons (Figs. 4 e 9), característica que novamente homoplástica apenas em Siluriformes. Nos demais Characiformes, este trecho de canal esteve associado ao osso dermoesfenótico (Figs. 6, 16-17), ou pterótico (Fig. 1), mas nunca encontrado sobre o esfenótico.

De acordo com Buckup (1993), a redução das placas 3 a 6, e associação do canal ótico com o osso pterótico compuseram dois eventos evolutivos distintos dentro de Characidiinae, já que foram codificados como diferentes caracteres (Buckup, 1993: car. \#6 e \#8). Entretanto, ambos os caracteres foram encontrados em todos os Characidiinae examinados, indicando uma possível relação de dependência entre os mesmos. Partindo do pressuposto de que o desenvolvimento dos elementos do canal sensorial cefálico e das placas dérmicas cranianas tratam-se de eventos distintos, é possível interpretar tais caracteres tratados por Buckup (1993) como sinapomorfia de Characidiinae de uma maneira alternativa: nesses peixes teria ocorrido o truncamento do desenvolvimento das placas infraorbitais, ou seja, da porção laminar dos ossos infraorbitais, inclusive do dermoesfenótico, de tal maneira que o canal ótico acaba por se associar ao (auto)esfenótico, osso disposto sobre a camada craniana imediatamente ventral às placas infraorbitais. Trata-se de uma mais parcimoniosa de se interpretar essas modificações listadas por Buckup (1993), evitando assim o inflacionamento artificial do suporte do referido clado. Enquanto o autor as separou em dois eventos distintos (redução da porção laminar dos infraorbitais 3 a 6; aquisição de canal no osso esfenótico), a simples ausência das placas infraorbitais já seriam capazes de explicar tal morfologia. Não é surpreendente que estas características sejam compartilhadas homoplasticamente com os siluriformes, táxons cujas placas infraorbitais (inclusive a placa dermoesfenótica) também não são desenvolvidas, permitindo a associação do canal ótico com o osso esfenótico.

Ainda discorrendo sobre a morfologia apresentada pelos ossos infraorbitais de Characidiinae, cabe um comentário acerca da homologia de sua primeira placa infraorbital, uma das únicas a serem conservadas da série infraorbital desses peixes. Nestes táxons, e também nos demais membros de Ostariophysi que apresentaram redução das placas infraorbitais (Figs. 20-21), uma única placa sempre se manteve presente, esta associada à porção mais anterior do canal infraorbital. Ao que parece, a retenção da primeira placa ao redor da órbita é bastante comum em Ostariophysi, o que levanta certo questionamento acerca da homologia da primeira placa infraorbital dos Characiformes com o osso lacrimal dos Cypriniformes e Gonorynchiformes (sensu Grande \& Poyato-Ariza, 1998; Britz \& Moritz, 2007) e antorbital dos Siluriformes (Bockmann, 1998). De acordo com Bockmann (1998), sua opção de nomear a primeira placa ao longo do infraorbital dos Siluriformes como antorbital se 
baseou na posição deste osso, na presença do ramo antorbital e infraorbital dos canais sensoriais sobre o mesmo, e na precoce ossificação deste durante a ontogenia. Com exceção do fato dos membros de Cypriniformes e Characiformes que foram examinados não apresentarem o trecho de canal antorbital, todos os Ostariophysi atenderiam aos outros criterios acima listados, sugerindo a homologia entre a placa infraorbital 1 dos Characiformes, com o lacrimal de Cypriniformes e Gonorynchiformes e antorbital dos Siluriformes. 


\subsection{Homologia do supra-pré-opérculo em Ostariophysi.}

O termo supra-pré-opérculo tem sido comumente utilizado para se referir à ossificação encontrada dorsalmente ao osso pré-opercular, na região temporal do crânio dos peixes. Tal osso pode ou não estar em associação à porção terminal do canal látero-sensorial préopercular (Gregory, 1933: figs. 44 e 59, sbtm.; Roberts, 1969: figs. 1 e 3, supraopercle), e varia morfologicamente desde uma ampla placa dérmica (Fig. 12; Roberts, 1969, Fig. 1), a apenas um túbulo ossificado disposto verticalmente nessa região (Figs. 3, 7, 13, 14 e 15). Apesar de variar bastante em morfologia, o termo supra-pré-opérculo tem sido utilizado para designar tanto o canal pré-opercular ossificado (Mirande, 2010; Mattox \& Toledo-Piza, 2012), quanto a placa dérmica disposta dorsalmente ao pré-opérculo (Vari, 1995; Oyakawa, 1998), fato que acarretou em dúvidas acerca da homologia das estruturas para qual se aplica o termo. Até a presente data, nenhum trabalho objetivou especificamente lidar com tal problema, sendo que o termo supra-pré-opérculo permanece indistintamente aplicável a ambas as estruturas.

Com base na análise morfológica dos táxons incluídos tanto no grupo de interesse (Characiformes) quanto no grupo-externo, combinada com as informações levantadas acerca do desenvolvimento da linha lateral cefálica (Kindred, 1919; Lekander, 1949; Webb, 1989), a proposta aqui apresentada é de que as diferentes morfologias expressas pelo que se tem designado supra-pré-opérculo são resultados de variações de dois caracteres distintos. 0 primeiro caráter corresponde ao segmento ossificado do canal látero-sensorial que deixa a região dorsal do pré-opérculo. Em Characiformes, a porção terminal do canal pré-opercular pode ou não ser ligada ao canal pós-ótico (PO1+PR1; Tab. 1). Quando ambos os canais se apresentam conectados, a porção terminal do canal pré-opercular pode se apresentar ossificada, formando um osso tubular que é geralmente denominado de supra-pré-opérculo. Esta ossificação (supra-pré-opérculo sensu Mirande, 2010; Mattox \& Toledo-Piza, 2012) é diferente tanto em forma quanto em origem ontogenética da placa dérmica supra-préopercular (sensu Vari, 1995; Oyakawa, 1998), que pode estar presente na mesma região e causar confusões em relação à sua identificação. A ossificação do canal pré-opercular em tal região foi variavelmente presente em Characiformes, sendo mais comum em exemplares em estágio de desenvolvimento mais avançado. Por outro lado, uma placa dérmica supra-préopercular foi incomum dentre os Characiformes, sendo encontrada apenas em exemplares da família Erythrinidae e Hepsetidae. Exemplares dessa família apresentaram uma ampla placa localizada dorsalmente ao osso pré-opérculo, cobrindo a região temporal craniana e se esendendo até a região imediatamente ventral ao osso pterótico. Erythrinidae e Hepsetidae, 
esta placa variou em apresentar associação com o canal pré-opercular da linha lateral cefálica, característica comum à primeira família, porém nunca presente em exemplares da segunda.

A ausência de contato entre o canal pré-opercular e ótico é uma característica já conhecida de algumas famílias de Characiformes (e.g. Erythrinidae, Ctenoluciidae, Crenuchidae e Lebiasinidae), de modo que nesses táxons o canal pré-opercular se estende dorsalmente apenas até a extremidade do osso homônimo, porém nunca alcançando o osso pterótico (PO1+PR1; Figs. 4 a 6; Tab. 1). Todavia, a ausência de canal percorrendo essa região não implicou necessariamente na ausência de uma placa dérmica supra-pré-opercular. Exemplares da família Eryrthrinidae, apesar de apresentarem a condição desconexa entre canal préopercular e ótico, apresentaram uma placa supra-pré-opercular bem desenvolvida (sensu Vari, 1995; Oyakawa, 1998). Já representantes das famílias Ctenoluciidae, Crenuchidae e Lebiasinidae, não apresentam conexão entre os canais e tampouco a placa dérmica nessa região, apresentando a região temporal do crânio desprovida de ossificações dérmicas. $O$ fato de o supra-pré-opérculo dérmico variar independentemente da presença do canal préopercular sobre a região temporal é aqui interpretado como uma forte evidência de que ambas as características sejam distintas, i.e. o termo supra-pré-opérculo, em Characiformes, tem sido aplicado a estruturas não homólogas.

Demais observações desassociando o canal supra-pré-opercular ossificado da placa dérmica disposta na mesma região foram tomadas em Eugnatichthys sp. (Distichodontidae), Paradistichodus sp. (Distichodontidae) e Abramytes hypselonotus (Anostomidae). Estes apresentaram uma morfologia bastante peculiar em relação ao osso dermoesfenótico, que é expandido posteriormente de forma que a porção terminal do canal do canal pré-opercular é incorporada a sua superfície (Fig. 16; Vari, 1979: figs. 22 e 26; Sidlauskas \& Vari, 2008: fig. 15). A associação do canal pré-opercular com uma placa dérmica infraorbital (e não com a placa supra-pré-opercular) demonstra que associações desse trecho do canal látero-sensorial não são especificamente ligadas à existência de uma placa dérmica supra-pré-opercular, podendo ocorrer em associação com diferentes ossos dérmicos, e indicando que ambos os caracteres se tratam de estruturas distintas.

A placa dérmica supra-pré-opércular não é exclusividade de Characiformes. Uma placa de forma e localização similar é conhecida de diferentes táxons, muitos desses incluidos no grupo-externo. Tal placa dérmica foi encontrada em Clarias submarginatus (Siluriformes, Clariidae), Chanos chanos (Gonorynchiformes, Chanidae) e Kneria sp. (Gonorynchiformes, Kneriidae), além de ser bastante evidente em Arapaima gigas (Osteoglossiformes, Arapaimidae). Estudos de desenvolvimento indicam que essa placa é uma das últimas 
estruturas a se ossificarem no crânio de Chanos chanos (Arratia \& Bagarinao, 2010). Uma possível maneira de interpretar essa informação é admitir que a ossificação do tegumento disposto sobre a região dorsal ao pré-operculo seja uma característica peramórfica expressa por esses táxons (i.e. representa, nesses táxons, um grau avançado de ossificação dérmica craniana). Esta mesma característica parece estar presente em Hoplias aimara (Characiformes, Erythrinidae) ou Arapaima gigas (Osteoglossiformes, Arapaimidae), táxons que apresentam não só a ossificação da região dérmica correspondente ao supra-pré-opérculo, mas também desenvolvimento completo de todos os demais ossos elementos dérmicos cranianos. Por fim, cabe ressaltar que uma análise mais inclusiva dos Teleostei resultaria na presença homoplástica do supra-pré-opérculo nas diferentes linhagens de peixes, conclusão que já havia sido expressa por Poyato-Ariza et al. (2010), que comentaram que "este caráter pode representar um caso de evolução em mosaico, com o supra-pré-opérculo se desenvolvendo mais de uma vez entre os membros de Ostariophysi". 


\subsection{Homologia dos neuromastos temporais em Ostariophysi.}

No início do século XX, em um trabalho intitulado "The Latero-Sensory Canals and Related Bones in Fishes", Allis (1904) apresentou descrições bastante completas da linha lateral cefálica de diversos Teleostei, entre eles, de três exemplares da ordem Characiformes: Macrodon trahira (=Hoplias malabaricus); Brycinus nurse e Hydrocyon brevis (=Hydrocynus brevis). Em relação aos canais látero-sensoriais da região temporal (ótico e pós-ótico e supratemporal) dos dois Alestidae (B. nurse e H. brevis), Allis (1904) descreveu dois neuromastos ao longo do esquamosal (=pterótico), seguidos de outro sobre a extraescápula, um neuromasto sobre o supraescapular (=pós-temporal), e mais um sobre o supraclavicular (=supracleitro). Ao longo do canal supratemporal desses dois táxons, um neuromasto era encontrado no início deste canal, ainda sobre a extraescápula, e outro já no parietal, deslocado medialmente. Sobre Hoplias malabaricus, Allis (1904) chamou atenção da ausência do neuromasto sobre o supraescapular (=pós-temporal) e a presença apenas do neuromasto parietal ao longo do canal supratemporal.

Um exercício bastante interessante foi o de comparar as descrições dos neuromastos da região temporal e supratemporal dos Characiformes com aquelas descritas para Siluriformes (Herrick, 1901; Allis, 1904). Logo de início nota-se uma modificação relacionada ao número de neuromastos ao longo dos canais ótico e pós-ótico do osso pterótico desses táxons. Enquanto os membros de Characiformes apresentaram apenas dois neuromastos ao longo canal do pós-ótico, que são separados pelo canal pré-opercular (Fig. 26 A), siluriformes possuem três neuromastos ao longo desse trecho de canal, com a conexão com o canal préopercular ocorrendo entre os dois primeiros neuromastos (Fig. 27, A-B). Estes três neuromastos de Siluriformes, de acordo com as descrições de Allis (1904), seriam homólogos aos três primeiros neuromastos encontrados em Characiformes, ou seja, aos dois ao longo do pterótico, mais o terceiro que é encontrado sobre o canal pós-ótico associado à extraescápula. Outra diferença observada entre as duas ordens foi o número de neuromastos ao longo do canal temporal (ótico e pós-ótico). Enquanto em Characiformes foram encontrados cinco neuromastos temporais, um deles ao longo do canal ótico (anterior à fusão entre os canais ótico e pré-opercular) e quatro ao longo do pós-ótico (NT1-NT5; Fig. 26 A), Siluriformes apresenta apenas quatro neuromastos ao longo desses canais, um no canal ótico e três no canal pós-ótico (NT1-NT4; Fig. 27 A-B). Por fim, siluriformes não portam qualquer resquício do canal supratemporal, e, de acordo com Allis (1904) sequer possuem neuromastos de canal ao longo dessa região, restando apenas pitlines de neuromastos . Characiformes, por outro lado, foram descritos como apresentando tipicamente dois neuromastos no canal supratemporal, 
um sobre a extraescápula e outro ao longo do trecho de canal que percorre o osso parietal (Allis, 1904).

A partir da descrição dos neuromastos temporais desses táxons fornecida por Allis (1904), foi possível associar cada um dos ramos acessórios localizados nos canais pós-ótico e supratemporal dos Characiformes ao seu respectivo neuromasto temporal. Ao longo do canal pós-ótico, Allis (1904) apontou para existência de dois neuromastos ao longo do pterótico de Brycinus nurse (NT1 e NT2), estes separados entre si pela fusão com o canal pré-opercular, compartilhando com este a abertura do poro PO1+PR1. Adiante, entre o pterótico e a extraescápula existe outro ramo (PO2), que origina-se entre o último neuromasto pterótico (NT2) e primeiro neuromasto extraescapular (NT3). Três neuromastos seguem pelo canal pósótico: um na extraescápula (NT3), um no pós-temporal (NT4) e outro no supracleitro (NT5), os quais são, provavelmente, relacionados à formação dos ramos PO3, PO4 e PO5 do canal pósótico. Ao longo do canal supratemporal, existem dois neuromastos em Brycinus nurse, um sobre a extraescápula e outro no parietal (NST1 e NST2, respecitvamente). Estes neuromastos são possivelmente responsáveis pela formação do ramo ST1, na extraescapula, e o ST2, na comissura supratemporal (Fig. 27 A).

Além de prover as descrições dos neuromastos temporais de Characiformes e de Slluriformes, Allis (1904) forneceu também informações suficientes para se traçar a homologia tais neuromastos, e consequentemente entre os ramos acessórios presentes nesses dois táxons. Os dois primeiros ramos (poros) temporais (PO1 e PO2) estão intercalados entre os três primeiros neuromastos do canal pós-ótico (NT1, NT2 e NT3), os quais estão localizados ao Iongo do pterótico dos Siluriformes (Fig. 28: A-B), e pterótico e extraescápula de Characiformes (Fig. 26 A). Em ambos os casos, o primeiro e segundo neuromasto são separados pelo sítio de contato entre o canal ótico e o canal pré-opercular e origem e abertura do ramo PO1. Uma diferença notável entre as duas ordens está na localização dos dois neuromastos seguintes: em Characiformes, um está situado no pterótico e outro na extraescápula, enquanto em Siluriformes ambos ocorrem ao longo do pterótico. De qualquer maneira, estes neuromastos seriam separados pela abertura de um ramo PO2 (ramo pterótico do canal pós-ótico sensu Arratia \& Huaquín, 1995; Schaefer \& Aquino, 2000). Em material analisado de Siluriformes da família Ictaluridae (e.g. Ameiurus catus), o terceiro neuromasto do canal pós-ótico seria deslocado posteriormente, localizado fora da ossificação do pterótico (Fig. 27-B). Nesses exemplares, a origem do ramo PO2 localiza-se entre o osso pterótico e uma ossificação membranosa portando um trecho de canal (extraescápula sensu Herrick, 1901; Allis, 1904). 
As informações apresentadas por Allis (1904) e expressas acima contribuíram bastante para discussões acerca da homologia das ossificações e dos ramos acessórios encontrados na região temporal dos Characiformes. Derivações dessa descrição, unidas às informações obtidas no presente trabalho, acarretaram no levantamento de hipóteses acerca da homologia de duas estruturas em específico, que são apresentadas abaixo. Uma delas refere-se à extraescapula de Characiformes, comparando-a também com a ossificação de mesmo nome observada nos demais Ostariophysi e Teleostei. Outra discussão é relacionada à homologia dos ramos pós-temporais dos Characiformes, comparando-os com ramo pterótico do canal pósótico de Siluriformes e ao ramo posterior do recessus lateralis (ptrc sensu Di Dario \& de Pinna, 2006) de Clupeomorpha. 


\subsubsection{Neuromastos temporais e suas implicações na morfologia e homologia do osso}

extraescapular.

Distintinguindo-se de todos os outros ossos dérmicos associados aos canais sensoriais analisados no presente trabalho, a extraescápula foi a única placa óssea a acompanhar a presença dos canais temporais (ótico e pós-ótico) e supratemporais. Observações tomadas nos diferentes táxons examinados no presente trabalho argumentaram em favor de uma desassociação entre os canais sensoriais e ossos dérmicos. O osso nasal, por exemplo, foi registrado apenas como uma placa apesar da ausência do canal nasal em alguns representantes da família Lebiasinidae (e.g. Copella arnoldi sensu Marinho, 2014); o osso frontal esteve presente independentemente da formação do canal supraorbital, tanto em Erythrinoidea fam. nov. quanto no Cypriniformes Cobitis taenia; o parietal foi encontrado independentemente da presença de um ramo parietal extendendo-se sobre este osso (S8) em diversos táxons da ordem Characiformes (e.g. Lebiasina melanoguttata; Iguanodectes variatus); ossos infraorbitais completamente desenvolvidos foram encontrados em táxons carecendo de segmentos desse canal (Fig. 5; Toracocharax stellatus); a placa dérmica suprapré-opercular foi presente mesmo sem associação com o trecho mais póstero-dorsal do canal pré-opercular (Fig. 10); e mesmo ossos pré-opercular e/ou dentário continuaram presentes apesar do truncamento de canais apresentados por alguns táxons (e.g. Erythrinoidea fam. nov.; Stygichthys typhlops; Cobitis taenia).

Todavia, ao longo do presente trabalho todas as observações falharam em desassociar a presença da extraescápula dos canais pós-ótico e supratemporal. Sempre que presente, a extraescápula apresentou estes canais associados à sua porção membranosa. Em alguns casos, a extraescápula é representadas apenas como um túbulo envolvendo partes do canal pósótico e supratemporal, sem qualquer expansão dérmica, casos de Osteoglossum bicirrhosum (Osteoglossiformes, Osteoglossidae) (Gregory, 1933: fig. 53) e Cyanogaster noctivaga (Mattox et al., 2013: fig. 3B). Tais observações apontaram para uma co-dependência entre a presença dos canais temporais e uma parte laminar, condição que pareceu concordar com as previsões de Graham-Smith (1979). Em seu trabalho, o autor disse que apesar de não haver uma relação direta entre linha lateral e formação de ossos dérmicos, há ao menos uma influência destes elementos na ossificação local do epitélio local. Nas palavras do autor "the laterosensory structures thus merely determine the precise positions, and perhaps also influence the timing, of membranogenic ossifications that would in any case develop". Uma relação de dependência entre os canais sensoriais temporais com a presença de uma extraescápula, portanto, implicaria em afirmar que o surgimento da extraescápula seria dependente da presença dos 
neuromastos da região temporal do crânio, já que os neuromastos são os precursores da formação dos canais sensoriais (Pehrson 1944; Lekander, 1949). Desdobramentos desse argumento conduzem à hipóteses de homologia da extraescápula em diferentes Ostariophysi.

Os Siluriformes sabidamente não apresentam canal supratemporal (Herrick, 1901; Arratia \& Gayet, 1995). O canal pós-ótico deste grupo é encontrado ao longo do osso pterótico e do póstemporo-supracleitro (sensu Arratia \& Huaquín, 1995). Em relação à extraescápula, a identificação desta é controversa na literatura anatômica dos Siluriformes, sendo por vezes identificada como uma placa óssea disposta na porção póstero-lateral do crânio (sensu Arratia \& Huaquín, 1995), placa que, alternativamente, recebe o nome de pós-temporal (sensu Lundberg, 1975). Conforme descrito por Allis (1904), em Characiformes a extraescápula porta dois neuromastos, um do canal pós-ótico e outro do canal supratemporal. Contudo, de acordo com Herrick (1901) e Allis (1904) em Siluriformes, o neuromasto pós-ótico primitivamente sob a extraescápula (i.e. terceiro neuromasto temporal; NT3, Fig. 27 A) estaria localizado ao longo do osso pterótico. Esta condição, comum à grande maioria dos Siluriformes, parece ter sido modificada em algumas famílias de Siluriformes, tais como os Ictaluridae. Táxons dessa família apresentaram uma ossificação membranosa localizada na porção posterior do crânio, que, de acordo com Allis (1904), está associada ao terceiro neuromasto temporal (NT3, Fig. 27 B). Este autor não teve dúvida quanto a propor a homologia dessa membrana óssea dos Ictaluridae com a extraescápula dos Characiformes, comentando que nos exemplares de Ictaluridae examinados por Herrick (1901) o terceiro neuromasto do canal pós-ótico teria sido deslocado posteriormente, fora da ossificação do pterótico e associado uma placa que seria uma extraescápula. De acordo com Allis (1904) os demais Siluriformes apresentariam, portanto, um osso composto na região do pterótico, um pterótico-extraescapular. Nas palavras do autor "the extrascapular bone is not found as an independent bone, it is because it has fused with the hind end of the squamosal (=pterotic), thus producing a squamoso-extrascapular".

Apesar de os argumentos de Allis (1904) soarem bastantes convincentes, estes não evitaram réplicas subsequentes. Acerca da identificação dessa mesma placa pós-craniana presente nos Ictaluridae, Lundberg (1975) apresentou uma opinião distinta. Este autor argumentou que a extraescápula estaria fundida à porção lamelar do osso pterótico mesmo nos Ictaluridae, de modo que a placa óssea disposta posteriormente a este osso seria, na verdade, um pós-temporal. Lundberg, todavia, parece ter dado pouca atenção às identificações dos neuromastos apresentadas por Allis (1904). Sugerir que tal osso fosse um pós-temporal implicaria em afirmar que o terceiro neuromasto pterótico desses indivíduos teria sido perdido e outro neuromasto pós-temporal readquirido (dois eventos evolutivos), ao passo que identificá-lo como uma extraescápula necessitaria em assumir apenas um 
deslocamento posterior desse neuromasto (um único evento evolutivo). Esta hipótese de Lundberg (1975) foi refutada por Fink \& Fink (1981), Arratia \& Huaquín (1995) e Arratia \& Gayet (1995). Estes autores mantiveram a identificação de tal osso, quando presente, como uma extraescápula (sensu Allis, 1904), porém sem aceitar a homologia dos ramos temporais de Siluriformes com os demais Ostariophysi que foi proposta por Lundberg (1975), sustentando que o ramo pterótico do canal pós-ótico fosse sinapomórfico dos Siluriformes.

Demais evidências ligando a ocorrência de uma extraescápula aos neuromastos temporais são encontradas na morfologia desta ossificação nos Characiformes. As consequências anatômicas resultantes da presença de um ramo ST1 sobre a extraescápula dos Characiformes já foi discutida acima, nos itens Ramos acessórios ao longo do canal supratemporal em Characiformes, e Ramos acessórios ao longo do canal supratemporal do grupo-externo. Ao que parece, a localização do ramo ST1 inteiramente sobre a extraescápula parece ser uma característica exclusiva dos Characiformes (ex: Figs. 1, 2, 3 e 7). Este ramo e poro estão atrelados à presença de um neuromasto supratemporal, que, em neste grupo, parece ser deslocado lateralmente de modo que o poro ST1 esteja completamente incorporado pela porção dérmica extraescapular (Fig. 26 A). Em outros membros de Ostariophysi que foram examinados, o neuromasto responsável pela formação do ramo ST1 parece estar localizado na porção mais medial da extraescápula, de tal forma que o ramo ST1 origina-se na fronteira entre extraescápula e parietal (Figs. 25 e 26 B), enquanto a extraescápula fica limitada apenas aos túbulos dos canais pós-ótico e supratemporal.

Uma morfologia bastante interessante foi observada em Kneria sp. (Kneriidae, Gonorynchiformes), comentada também nos itens Demais considerações acerca dos canais sensoriais cefálicos - comparações com o grupo-externo, e Ramos acessórios ao longo do canal supratemporal do grupo-externo. Nesse táxon, uma ossificação extraescapular foi observada medialmente ao osso pterótico (Fig. 23; Britz \& Moritz, 2007: fig. 20 C-D), e não lateralmente onde tal ossificação é costumeiramente encontrada, parecendo acompanhar a disposição do canal supratemporal, que se ramifica ainda sobre o pterótico. $O$ fato de a extraescápula desses indivíduos acompanhar o deslocamento do canal supratemporal é aqui entendido como mais uma evidência de que esta é dependente dos neuromastos temporais e/ou supratemporais. Ao que parece, a extraescápula de Kneria sp. parece ser consequência da presença do primeiro neuromasto supratemporal desses táxons, homóloga apenas à porção óssea gerada pelo primeiro neuromasto supratemporal dos Characiformes.

Por fim, uma última evidência da correlação entre a extraescápula e os canais temporais, ligando esta à presença dos neuromastos de canal, foi encontrada em descrições da anatomia de grupos de peixes filogeneticamente mais distantes dos Ostariophysi. Em um 
trabalho acerca das relações filogenéticas entre os Teleostei basais, Johnson \& Patterson (1996) utilizaram da morfologia da extraescápula como fonte de caracteres. Os autores descreveram como uma extraescápula típica um osso triangular que carrega os canais pósótico e supratemporal, mas que sofre variações principalmente em relação à sua presença ou fragmentações de seus canais componentes nos diferentes grupos de Teleostei. Estes autores citaram que a extraescápula está ausente em alguns táxons, enquanto em outros haveria mais de um osso extraescapular (i.e. extraescápula lateral e medial). Não seria surpreendente se esta variabilidade morfológica fosse reflexo da ausência de neuromastos de canal no primeiro caso, ou na separação desses neuromastos (separação espacial do NT3 do NST1) no segundo, formando duas ossificações extraescapulares. É sabido por análises de diferentes grupos que ambos os neuromastos, independentemente, formam uma ossificação extraescapular (NT3 em Ictaluridae, NST1 em Kneria). Em Characiformes ambos os neuromastos se apresentam muito próximos, de modo que a membrana extraescapular incorpora ambos os neuromastos em uma placa única. Entretanto, em apenas um táxon analisado, Citharinus latus (Citharinidae, Characiformes), duas placas dérmicas foram observadas, cada uma portando uma ramificação do canal látero-sensorial. Esta condição, todavia, foi presente apenas um dos lados desse indivíduo, possivelmente uma anomalia do padrão que parece ser comum aos caraciformes. 


\subsubsection{Neuromastos temporais e homologia do ramo pterótico do canal pós-ótico.}

Siluriformes são um dos táxons mais estudados em relação ao sistema látero-sensorial cefálico. Detalhes desse complexo anatômico já foram recentemente utilizados como fonte de informação filogenética em uma série de trabalhos a respeito das relações de subgrupos dessa ordem (e.g. Arratia \& Huaquin, 1995; Arratia \& Gayet, 1995; Schaefer \& Aquino, 2000; Bockmann \& Miquelarena, 2008), ou desta com os demais membros de Ostariophysi (Fink \& Fink, 1981, 1996). Caracteres desse complexo morfológico são, por exemplo, utilizados para suportar o monofiletismo dos Siluriformes (e.g. ausência do canal supratemporal, presença de um ramo pterótico no canal pós-ótico sensu Fink \& Fink, 1981; Arratia \& Gayet, 1995). Com relações aos ramos temporais, por exemplo, a presença de um ramo do canal pós-ótico que se situa sobre o pterótico foi proposta por Fink \& Fink (1981) como uma sinapomorfia de Siluriformes, hipótese posteriormente corroborada por Arratia \& Gayet (1995), Arratia \& Huaquín (1995) e Schaefer \& Aquino (2000). Dentre os Siluriformes, a ausência deste mesmo ramo, ou seja, sua reversão, já foi utilizada para suportar o monofiletismo de Loricarioidei (Arratia \& Huaquín, 1995; Arratia \& Gayet, 1995), porém subsequentemente rejeitada por Schaefer \& Aquino (2000), que encontraram ral ramo na porção pós-craniana desses táxons.

Especificamente em relação à homologia do ramo pterótico do canal pós-ótico, este tem sido objeto de um longo debate envolvendo as identificações deste ramo com outro similar encontrado na extraescápula de Characiformes (Lundberg, 1975). Em siluriformes, este ramo tem sido frequentemente reportado como presente em representantes de diferentes famílias (e.g. Schaefer \& Aquino, 2000; Apone, 2008; Bockmann \& Miquelarena, 2008). Todavia, até a presente data, nenhum estudo comparativo mais detalhado foi feito de maneira a se avaliar a real distribuição desse caráter dentre os demais Ostariophysi.

Controvérsias a respeito da identificação deste ramo datam de 1975, quando Lundberg identificou um ramo póstero-lateral situado entre o pterótico e a extraescápula em um exemplar do gênero Brycon, denominado pelo autor como ramo de número 4, ao qual foi sugerido ser homólogo a um ramo originando do osso pterótico dos Siluriformes (Lundberg, 1975: fig. 1 A-B). Alguns anos depois, Fink \& Fink (1981), em um trabalho acerca das relações filogenéticas dentre os Ostariophysi, rejeitou a hipótese de homologia de Lundberg (1975), argumentando que "the small branches and pores in sensory canals are not invariant" e que não haveria razão em crer que os pequenos ramos e poros ao longo do pterótico dos Siluriformes não pudessem ser considerados uma cararcterística distinta, única do grupo. Publicações subsequentes a respeito dos canais látero-sensoriais da cabeça dos Siluriformes 
todas concordam com a hipótese de Fink \& Fink (Arratia \& Huaquin, 1995; Arratia \& Gayet, 1995; Schaefer \& Aquino, 2000), mantendo tal ramo como sinapomórfico da ordem.

No presente trabalho, tais hipóteses sobre a homologia dos referidos ramos acessórios do canal pós-ótico em Ostariophysi foram revisadas, levando-se em conta o número de ramos, local de suas origens e o número, a posição e a seqüência dos neuromastos temporais. Como resultado, a hipótese aqui defendida é aquela proposta de Lundberg (1975), que assume que o ramo pterótico do canal pós-ótico de Siluriformes é homólogo ao ramo localizado entre o pterótico e a extraescápula dos Characiformes, aqui identificados como PO2. De modo a sustentar tal hipótese, abaixo é apresentada uma análise comparativa abragente sobre o referido ramo do canal pós-mais ampla, englobando todos os Ostariophysi, bem como demais Teleostei basais, na tentativa de mapear o surgimento desse caráter, bem como uma revisão bibliográfica completa acerca do tema.

A mais antiga identificação de um ramo pterótico aparece no trabalho de Wright (1884), que ao descrever os poros sensoriais de um exemplar de Amiurus catus (=Ameiurus catus, Ictaluridae, Siluriformes), identificou e ilustrou uma sequência ramos (e poros) na porção dorsal da fenda branquial (upper angle of the gill-cover, sensu Wright, 1884: pr. 1, figs. 4-6). Nessas ilustrações, o ramo pterótico seria identificado como o primeiro poro da sequência de poros dorsais à fenda branquial. Após pouco mais de uma década, Collinge (1895) apresentou descrições mais detalhadas do padrão de ramificação dos canais sensoriais de certos teleósteos incluidos em um grupo artificial na época denominado Physostomi. Em seu trabalho, o autor descreveu os canais sensoriais do bagre Clarias nieuhofii (Clariidae), identificando um ramo presente ao longo do osso esquamosal (=pterótico), direcionado póstero-ventralmente e terminando em um fundo cego, característica que, nas palavras do autor, eram comuns a todos os Physostomi. Este mesmo poro foi ilustrado de táxons Amiurus catus (=Ameiurus catus) e de Callichthys littoralis (Callichthyidae, Siluriformes), os quais Collinge utilizou para uma descrição mais completa da linha látero-sensorial cefálica. Collinge (1895) não indicou em seu trabalho quais grupos de peixes formariam Physostomi, porém estes poderiam ser os mesmos considerados por Günther $(1864 ; 1866 ; 1868)$, compreendendo um agrupamento de vinte e cinco famílias de peixes inclusas nos atuais clados Osteoglossomorpha, Elopomorpha, Clupeomorpha, Ostariophysi, e Protacanthopterygii (Esociformes e Salmoniformes). Posteriormente, Herrick (1901) publicou uma extensa e detalhada contribuição sobre a morfologia do sistema nervoso e órgãos da linha lateral (denominados, à época, como sense organs) dos Siluriformes da América do Norte. Neste trabalho, Herrick identificou e descreveu a morfologia de um ramo ao longo do pterótico de 
Amiurus catus (=Ameiurus catus), listando-o como o segundo poro ao longo do canal principal que atravessa o osso esquamosal (=pterótico). Este ramo foi ilustrado por Allis (1904: figs. 810), Kindred (1919: pr. 5, fig. 11), Lekander (1949: figs. 39-40) e Kapoor (1961: fig. 2) de membros de Siluriformes. Até a década de 60 do século $X X$, o ramo pterótico (PO2) foi descrito, ou ao menos ilustrado, em uma série de trabalhos de anatomia do sistema sensorial cefálico, a grande maioria também se utilizando de Siluriformes como modelo, com exceção de Herrick (1889), Collinge (1895), Allis (1904) e Lekander (1949), que expandiram suas análises para outros membros de Ostariophysi e/ou Teleostei.

A primeira menção ao ramo pterótico do canal pós-ótico como sinapomorfia de Siluriformes foi feita por Fink \& Fink (1981). A decisão dos autores pautou-se principalmente no argumento de que ramos do canal sensorial não deveriam ser interpretados como invariáveis dentre os Ostariophysi (Fink \& Fink, 1981: pg. 333). O propósito de Fink \& Fink (1981) era rejeitar a proposta de identificação dos elementos ósseos dorsais da nadadeira peitoral dos Siluriformes feita por Lundberg (1985). Nesse trabalho, Lundberg (1975) apresentou um estudo bastante detalhado da osteologia dos elementos da nadadeira peitoral dos Siluriformes, baseando seus argumentos também em caraterísticas específicas presentes na linha lateral cefálica da região pós-ótica. Lundberg (1975) propôs a homologia entre um ramo presente no osso pterótico dos Siluriformes e na extraescápula dos Characiformes (Lundberg, 1975: fig. 1 e 3, ramo 4). Argumentando sobre isso, o autor propunha que em Siluriformes a extraescápula teria sido perdida, uma pequena ossificação encontrada posteriormente ao pterótico poderia ser identificada como o pós-temporal. Fink \& Fink (1981), por sua vez, discordaram das identificações de Lundberg (1975). Em um estudo acerca das relações filogenéticas da superordem Ostariophysi, os autores refutaram tanto a identificação de um pós-temporal ao longo da cintura escapular dos Siluriformes, quanto a homologia dos ramos e poros ao longo do canal temporal desses em relação aos mesmos encontrados em Characiformes. A partir da publicação de Fink \& Fink (1981), diferentes autores passaram a tratar o ramo pterótico do canal pós-ótico como sinapomorfia de Siluriformes (e.g. Arratia \& Gayet, 1995; Arratia \& Huaquín, 1995). Em um trabalho acerca dos canais sensoriais e epitélio de Loricarioidei e Diplomystidae, Arratia \& Huaquín (1995) propuseram que a ausência secundária do ramo pterótico seria uma sinapomorfia de Loricarioidei, constituindo, portanto, uma reversão do grupo. A decisão de propor tal sinapomorfia sustentou-se principalmente sobre hipótese de homologia adotada pelas autoras para a identificação de ramos e poros dos canais sensoriais. Estas identificaram como ramo pterótico apenas os ramos que emergem do osso homônimo, identificando qualquer ramo posterior a esse osso como pertencentes à linha 
lateral corporal (Arratia \& Huaquín, 1995: figs. 8 e 9). Arratia \& Huaquín (1995) e Arratia \& Gayet (1995) ainda ilustraram alguns ramos partindo do canal principal pós-ótico, entre o osso pterótico e o extraescapular, em exemplares de Characiformes e Cypriniformes (Arratia \& Huaquín, 1995: fig. 3B; Arratia \& Gayet, 1995: fig. 13, B e D), todavia sem apresentar qualquer identificação aos mesmos.

A hipótese de Arratia \& Huaquín (1995) foi rejeitada por Schaefer \& Aquino (2000), em um trabalho focalizando especificamente a identificação do ramo pterótico do canal pós-ótico dos Siluriformes, quando reidentificaram os poros posteriores ao osso pterótico dos Loricarioidei, nomeando o primeiro deles (primeiro poro da linha lateral sensu Arratia \& Huaquín, 1995) como o ramo pterótico. Para cumprir com tal objetivo, Schaefer \& Aquino (2000) propuseram um critério duplo de identificação do ramo pterótico: 1) critério topográfico -o ramo pterótico seria o primeiro poro observado após a conexão do canal ótico com o canal pré-opercular, independentemente do osso ao qual este poro estiver associado; 2) critério morfológico - apenas ramos do sistema látero-sensorial seriam identificados como ramo pterótico, desconsiderando quaisquer ranhuras ou aberturas presentes no pterótico sem relação ao canal pós-ótico (e.g. Schaefer \& Aquino, 2000: fig. 3 A, projeção entre ramos preop e pt.br). De acordo com Schaefer \& Aquino (2000), a identificação do ramo pterótico não necessariamente estaria atrelada à sua presença sobre o osso pterótico, e possivelmente a não consideração deste aspecto essencial levou Arratia \& Huaquín (1995) a não identificá-los nos Loricarioidei. Nas palavras dos autores "a failure to apply these dual criteria has led Arratia and Huaquin (1995) to mistakenly conclude that a pterotic branch is absent in loricarioid catfishes". Como demonstrado por Schaefer \& Aquino (2000), o ramo pterótico poderia ser encontrado não só ramificando-se do pterótico, mas também na junção entre pterótico e póstemporosupracleitro (Schaefer \& Aquino, 2000: fig. 3-B) ou totalmente incluido no supracleitro (Schaefer \& Aquino, 2000: fig. 3-E). O critério de homologia dos autores, que parece ter funcionado precisamente na identificação do ramo pterótico em Siluriformes, todavia foi empregado na identificação do mesmo ramo em Characiformes. Utilizando apenas Siluriformes em sua análise (inclusive como grupo-externo), os autores continuaram refutando a hipótese de Lundberg (1975), sustentando que a presença de tal ramo seria uma sinapomorfia de Siluriformes.

O presente trabalho utilizou do critério de homologia proposto por Schaefer \& Aquino (2000) para identificação do ramo pterótico do canal pós-ótico. Este foi aceito como um bom critério para identificação do ramo PO2 (=ramo pterótico do canal pós-ótico) mesmo quando utilizado para representantes de outras ordens de Ostariophysi (ex: Figs. 13-15, 19, 26). Além 
de presente em todos os Ostariophysi examinados, um ramo de morfologia semelhante, e atendendo ao mesmo critério de topologia, esteve presente mesmo em outras ordens de Teleostei, tais como Osteoglossiformes (Osteoglossum bicirrhosum), Elopiformes (Elops saurus), Salmoniformes (Salmo trutta), e Esociformes (Esox americanus). Revisões bibliográficas revelam ainda que a presença de um ramo (ou poro) atendendo a tal critério estaria presente até mesmo em Amia calva, táxon pertencente a um grupo considerado primitivo dentro de Neopterygii, grupo-irmão dos demais Teleostei (Allis, 1889: fig. 42, poro 18 - i.e. primeiro poro após PO1+PR1). Frente a tais dados, é de se considerar que um ramo e poro em tal posição seria mais parcimoniosamente interpretado como uma plesiomorfia retida na maioria do material examinado (Tab. 11).

O exame de diferentes membros de Teleostei e a identificação desse ramo e poro na grande maioria do material examinado ao longo do presente estudo gerou certa dúvida acerca da identificação de outro ramo em específico, este encontrado na região temporal da cabeça dos Clupeiformes. Antes de discorrer sobre a homologia de tal poro, cabe aqui detalhar brevemente a morfologia básica dos canais sensoriais dispostos sobre a porção temporal craniana desse grupo de peixes, os quais exibem uma série de modificações. O recessus lateralis é uma estrutura encontrada unicamente em Clupeiformes (Grande, 1985; Di Dario, 2004: figs. 2-3), se tratando de um espaço intracraniano posicionado na região ótica dos Clupeiformes, formado pela convergência dos principais canais sensoriais cefálicos desses peixes (supraorbital, infraorbital, pré-opercular e ótico). As ramificações resultantes em poros do canal sensorial pós-ótico (i.e. canal que continua posterior à formação do recessus lateralis), foram descritas por Stephens (1985) e Di Dario \& de Pinna (2006), e podem ser vistas na Figura 28, a qual ilustra o crânio de um exemplar de Denticeps clupeoides (Denticipitidae). Entre a porção posterior do recessus lateralis e a ossificação extraescapular, há um ramo terminando em poro, nomeado de túbulo posterior do recessus lateralis (ptrc sensu Di Dario \& de Pinna, 2006) ou ramo \#53 (Stephens, 1985). Tal ramo, segundo Di Dario \& de Pinna (2006), seria um dos poucos que poderiam ter sua homologia corretamente certificada dentre os Clupeiformes, pois compartilhava entre estes peixes um landmark topográfico, ou seja, se originava entre os mesmos ossos do crânio. De acordo com Di Dario \& de Pinna (2006), em uma análise compreendendo clupeiformes e diferentes táxons incluidos em um extenso grupoexterno, nenhum túbulo e poro semelhante a este foi encontrado fora de Clupeomorpha, levando os autores a concluírem que a presença do ramo posterior do recessus lateralis (ou ramo \#53) seria uma sinapomorfia de tal clado. 
Contudo, na presente análise observou-se que tal ramo se posicionava em uma região muito semelhante ao ramo pterótico (PO2) de outros Ostariophysi e demais Teleostei, levantando dúvidas quanto ao seu status de sinapomorfia de Clupeomorpha. Tal ramo compartilha a origem e orientação bastante similar àquelas observadas no material aqui examinado (entre o pterótico e o extraescapular, orientando-se posteroventralmente). Além do mais, a identificação proposta por Di Dario \& de Pinna (2006) para o ramo posterior do recessus lateralis, a qual considera seu local de origem, orientação, e projeção sobre a porção dorsal do osso opercular (sensu Di Dario \& de Pinna, 2006), se encaixa perfeitamente na descrição feita por Collinge (1895) de um ramo presente ao longo pterótico dos Siluriformes, que nas palavras do autor seria um poro "lateral and backwardly directed which ends blindly". Portanto, é sugerido aqui que o ramo posterior do recessus lateralis de Clupeiformes seja homólogo ao ramo pterótico do canal pós-ótico, poro este amplamente distribuído dentre os Teleostei, não se tratando, portanto, de uma sinapomorfia de Clupeiformes.

Apesar de considerado uma sinapomorfia para diferentes clados (Siluriformes por Fink \& Fink, 1981; Clupeiformes por Di Dario \& de Pinna, 2006), o segundo ramo do canal pós-ótico (PO2) é, na verdade, amplamente distribuído entre os Teleostei, e potencialmente presente em grupos mais derivados de peixes (i.e. Percomorpha). Ramos (e poros) presentes ao longo do canal pós-ótico de peixes são derivados da presença de neuromastos de canal ao longo dos ossos da região pós-orbital (Allis, 1889: fig. 42, poro 18 e neuromasto 18). Dessa maneira, seria de se esperar que ramos presentes nessa região, mesmo que exibindo as mais variadas modificações morfológicas (subramificações dendríticas, variações em extensão), seriam homólogos entre si, dado que são oriundos de um mesmo conjunto de neuromastos temporais, estes amplamente distribuídos em Teleostei. 


\section{Considerações finais.}

Um dos principais resultados do presente estudo foi a constatação de que a disposição dos canais do sistema látero-sensorial cefálico, e o número de poros associados a cada um destes canais foi constante para as diferentes famílias de Characiformes. As particularidades do arranjo dos canais e da distribuição de poros foram conservadas nas diferentes linhagens e, portanto, são altamente informativas em um contexto filogenético. As primeiras indicações de que esse sistema pudesse compor uma fonte de dados importantes em um contexto comparativo, para os Characiformes, foi publicada por Allis (1904). Todavia, até o momento, pouquíssimos trabalhos utilizaram, de forma correta, o sistema látero-sensorial cefálico dos Characiformes como fonte de caracteres filogenéticos (e.g. Zanata \& Vari, 2005; Sidlauskas \& Vari, 2008). Para se traçar hipóteses precisas de homologia quanto a este complexo morfológico, e mesmo com relação aos ossos démicos cranianos, é necessário compreender que os canais látero-sensoriais são, em grande medida, independentes dos ossos com os quais se associam, conforme expresso por Allis (1904), Pehrson (1944), Lekander (1949), GrahamSmith (1979), Bockmann (1998). Outro ponto relevante do presente trabalho foi apresentar uma proposta de homologia dos ramos encontrados ao longo dos canais sensoriais cefálicos de Characiformes. Os resultados indicaram que estes poros se apresentam em número e localização consistente ao longo dos canais, permitindo elaborações de hipóteses de homologia para cada um desses ramos individualmente. $O$ fato de esses ramos variarem independentemente um dos outros reforça a ideia de que cada um destes é um caráter individual, de maneira que este complexo se consitui em uma rica fonte de informações filogenéticas em vários níveis taxonômicos.

A utilização dessa fonte de caracteres seria de grande relevância em análises filogenéticas combinando-os com demais caracteres morfológicos. Assim como para a grande maioria dos estudos anatômicos de peixes, a fonte de caracteres mais dominante em análises cladísticas continua sendo proveniente do esqueleto ósseo (e.g. Vari, 1995; Zanata \& Vari, 2005; Mirande, 2010; Mattox \& Toledo-Piza, 2012). Apesar de apresentarem um grande potencial informativo (Datovo \& Bockmann, 2010; Datovo \& Castro, 2012), outros complexos anatômicos ainda continuam sendo negligenciados. Os resultados apresentados no presente trabalho, portanto, indicam que os canais e ramos (e poros) da linha látero-sensorial cefálica constituem mais uma fonte de informação cladística, que apesar de não tradicional, têm muito a contribuir para o entendimento das relações de parentesco dos peixes. 


\section{Referências Bibliográficas.}

ADRIAENS, D, VERRAES, W. \& LOOUIS, T. 1997. The cranial lateral-line system in Clarias gariepinus (Burchell, 1822) (Siluroidei: Clariidae): morphology and development of canal related bones. European Journal of Morphology, 35 (3): 181-208.

ALBERT, J. S., LANNOO, M. J., \& YURI, T. 1998. Testing hypotheses of neural evolution in gymnotiform electric fishes using phylogenetic character data. Evolution, 52(6): 1760-1780.

ALBERT, J. S. 2001. Species diversity and phylogenetic systematics of american knifefishes (Gymnotiformes, Teleostei). Miscellaneous Publications, Museum of Zoology, University of Michigan, 90: 1-140.

ALBERT, J. S. \& FINK, W. 1996. Sternopygus xingu, a new species of electric fish from South America (Teleostei: Gymnotoidei), with comments on the phylogenetic position of Sternopygus. Copeia, 1996(1): 85-102.

ALLIS, E. P. 1889. The anatomy and development of the lateral line system in Amia calva. Journal of Morphology, 2 (3): 1-102.

ALLIS, E. P. 1903. The lateral sensory system in the Muraenidae. International Monatsschrift für Anatomie und Physiologie, 20: 125-170.

ALLIS, E. P. 1904. The latero-sensory canals and related bones in fishes. Internationale Monatsschrift Für Anatomie Und Physiologie, 21:401-496.

ALLIS, E. P. 1922. The Cranial anatomy of Polypterus, with special reference to Polypterus bichir. Journal of Anatomy, V.56, pt. 3 e 4: 189-294.

ALLIS E. P. 1923. The cranial anatomy of Chlamidoselachus anguineus. Acta Zoologica, 4: $123-221$.

APONE, F. 2008. Anatomia comparada do sistema látero-sensorial cefálico da família Pimelodidae (Pisces: Siluriformes) e suas implicações filogenéticas. Ribeirão Preto, Faculdade de Filosofia, Ciências e Letras da Universidade de São Paulo, Dissertação de Mestrado. 110p.

ARRATIA, G. \& GAYET, M. 1995. Sensory canals and related bones of tertiary siluriform crania from Bolivia and North America and comparison with recent forms. Journal of Vertebrate Paleontology, 15 (3): 482-505. 
ARRATIA, G. \& BAGARINAO, T. 2010. Early ossification and development of the cranium and paired girdles of Chanos chanos (Teleostei, Gonorynchiformes). Em: Gonorynchiformes and Ostariophysan Relationships - A comprehensive Review. GRANDE, T., POYATO-ARIZA, F. J. \& DIOGO, R. (Ed.). Science Publishers, Enfield, United States of America.

ARRATIA, G. \& HUAQUÍN, L. 1995. Morphology of the lateral line system and of the skin of diplomystid and certain primitive loricarioid catfishes and systematic and ecological considerations. Bonner Zoologische Monographien, 36: 1-110.

ARRATIA, G. \& MENU-MARQUES, S. 1984. New catfishes of the genus trichomycterus from the high andes of south america (Pisces, Siluriformes) with remarks on distribution and ecology. Zoologische Jahrbücher, Abteilung für Systematik, Ökologie und Geographie der Tiere, 111:493520.

ASAOKA, R., NAKAE, M. \& SASAKI, K. 2011 Description and innervation of the lateral line system in two gobioids, Odontobutis obscura and Pterogobius elapoides (Teleostei: Perciformes). Ichthyological Research, 58: 51-61.

de BEER, G. R. 1937. The development of vertebrate skull. University of Chicago Print. $760 p$.

BOCKMANN, F. A. 1998. Análise filogenética da família Heptapteridae (Teleostei, Ostariophysi, Siluriformes) e redefinição de seus gêneros. São Paulo, Universidade de São Paulo, Tese de Doutorado. 599p.

BOCKMANN, F. A. \& MIQUELARENA, A. M. 2008. Anatomy and phylogenetic relationships of a new catfish species from northeastern Argentina with comments on the phylogenetic relationships of the genus Rhamdella Eigenmann \& Eigenmann 1888 (Siluriformes, Heptapteridae). Zootaxa, 1780: 1-54.

BOCKMANN, F. A \& SAZIMA, I. 2004. Trichomycterus maracaya, a new catfish from the upper rio Paraná, southeastern Brazil (Siluriformes: Trichomycteridae), with notes on the $T$. brasiliensis species-complex. Neotropical Ichthyology, 2(2): 61-74.

BRITZ, R. \& MORITZ, T. 2007. Reinvestigation of the osteology of the miniature african freshwater fishes Cromeria and Grasseichthys (Teleostei, Gonorynchiformes, Kneriidae), with comments on kneriid relationships. Mitteilungen aus dem Museum für Naturkunde in Berlin, Zoologie Reihe, 83(1): 3-42 
BUCKUP, P. A. 1993. The monophyly of Characidiinae, a Neotropical group of characiform fishes. Zoological Journal of the Linnean Society, 108: 225-245.

BUCKUP, P. A. 1998. Relationship of the Characidiinae and phylogeny of characiform fishes (Teleostei: Ostariophysi). Pp 123-144. In: MALABARBA, L. R., REIS, R. E., VARI, R. P., LUCENA, Z. M. S., LUCENA, C. A. S. (Eds.). Phylogeny and classification of neotropical fishes. Porto Alegre, Edipucrs. 603p.

BUCKUP, P. A., MENEZES, N. A. \& GHAZZI, M. S. 2007. Catálogo das Espécies de Peixes de Água Doce do Brasil. Rio de Janeiro, Museu Nacional. 195p.

CASTRO, R. M. C. \& CASTRO, M. M. C. 1987. Proposta de uma nomenclatura osteológica para Characiformes (Pisces: Ostariophysi). Boletim do Museu Paraense Emílio Goeldi, série Zool., 3 (1): 25-32.

CASTRO, R. M. C. \& VARI, R. P. 2004. The South American characiform family Prochilodontidae (Ostariophysi: Characiformes): a phylogenetic and revisionary study. Smithsonian Contributions to Zoology, 622: 1-190.

CLAPP, C. M. 1899. The lateral line system of Batrachus tau. Journal of Morphology, ser. 2, 15 (2): $223-264$.

COLLINGE, W. E. 1891. On the sensory canal system of fishes. Teleostei - Suborder A. Physostomi. Proceedings of the Zoological Society of London, 2: 274-298.

DAGET, J. 1960. Le genre Xenocharax (Poissons, Characiformes). Revue de Zoologie et de Botanique Africaines, 61: 35-48

DAGET, J. 1967. Le genre Ichthyborus (Poissons, Characiformes). Cahiers d'Office de la Recherche Scientifique et Technique Outre-mer, sér. Hydrobiologie, 1: 139-154.

DATOVO, A. 2014. A new species of Ituglanis from the Rio Xingu basin, Brazil, and the evolution of pelvic fin loss in trichomycterid catfishes (Teleostei: Siluriformes: Trichomycteridae). Zootaxa, 3790(3): 466-476.

DATOVO, A., \& BOCKMANN, F. A., 2010. Dorsolateral head muscles of the catfish families Nematogenyidae and Trichomycteridae (Siluriformes: Loricarioidei): comparative anatomy and phylogenetic analysis. Neotropical Ichthyology, 8(2): 193-246. 
DATOVO, A. \& CASTRO, R. M. C. C. 2012. Anatomy and evolution of the mandibular, hyopalatine, and opercular muscles in characiform fishes (Teleostei: Ostariophysi). Zoology, 115: 84-116.

DEVILLERS, C. 1947. Recherches sur le crane dermique des téléostéens. Annales de Paléontologie,I, 94p.

DI DARIO, F. 2004. Homology between the recessus lateralis and cephalic sensory canals, with the proposition of additional synapomorphies for the Clupeiformes and the Clupeoidei. Zoological Journal of the Linnean Society, 141: 257-270.

DI DARIO, F.\& DE PINNA, M. C. C. 2006. The supratemporal system and the pattern of ramification of cephalic sensory canals in Denticeps clupeoides (denticipitoidei, teleostei): additional evidence for monophyly of clupeiformes and clupeoidei. Papéis Avulsos de Zoologia, 46(10): 107-123.

DIJKGRAAF, S. 1963. The functioning and significance of the lateral-line organs. Biological Reviews, 38: 51-105.

ESCHMEYER, W. N. \& FONG, J. D. 2012. Catalog of fishes. California Academy of Sciences, San Francisco. http://research.calacademy.org/research/ichthyology/catalog/SpeciesByFamily.asp (acessado em 01 de agosto de 2014).

FINK, S. V. \& FINK, W. L. 1981. Interrelationships of the ostariophysan fishes (Teleostei). Zoological Journal of the Linnean Society, 72: 297-353.

FINK, S. V. \& FINK, W. L. 1996. Interrelationships of the ostariophysan fishes (Teleostei). Pp. 209 - 249. In: Interrelationships of fishes. STIASSNY, M. L. J., PARENTI, L. R. \& JOHNSON, G. D. (Eds.). Academic Press, San Diego.

GARDINER, B. G. 1984. The relationships of the palaeoniscid fishes, a review based on new specimens of Mimia and Moythomasia from the upper devonian of western australia. Bulletin of the British Museum, 37 (4): 173-427.

GOSLINE, W. A. 1949. The sensory canals of the head in some cyprinodont fishes, with particular reference to the genus Fundulus. Occasional papers of the Museum of Zoology, University of Michigan, 519: 1-17 
GRAHAM-SMITH, W. 1978. On the lateral lines and dermal bones in the parietal region of some crossopterigian and dipnoan fishes. Philosophical Transactions of the Royal Society of London B, 282: 41-105.

GRANDE, L. 1985. Recent and fossil clupeomorph fishes with materials for revision of the subgroups of clupeoids. Bulletin of the American Museum of Natural History, 181:231-372.

GRANDE, L. \& BEMIS, W. 1998. A comprehensive phylogenetic study of amiid fishes (Amiidae) based on comparative skeletal anatomy. An empirical search for interconnected patterns of natural history. Society of Vertebrate Paleontology, Memoir 4, iv+1-690

GRANDE, T., POYATO- ARIZA, F. J. \& DIOGO, R. 2010 (ed). Gonorynchiformes and Ostariophysan Relationships, a Comprehensive Review. Enfield, New Hapmshire, Science Publishers, 587p.

GRANDE, T. \& POYATO-ARIZA, F. J. 1998. Phylogenetic relationships of fossil and recent gonorynchiform fishes (Teleostei: Ostariophysi). Zoological Journal of the Linnean Society, 125: 197-238.

GREGORY, W. K. 1933. Fish Skulls: a study of the evolution of natural mechanisms. The American Philosophical Society, Philadelphia, Lancaster Press. V. 23: 481p.

GUITEL, F. 1891. Recherches sur la ligne latérale de la baudroie (Lophius piscatorius). Archive de Zoologie Expérimentale et générale, sér. 2, 9: 125-190.

GUNTHER, A. 1864. Catalogue of the Physostomi containing the families Siluridae, Characinidae, Haplochitonidae, Sternoptychidae, Scopelidae, Stomatidae, in the collection of the British Museum. Vol. 5. Printed by the order of the Trustees, Londres, 454p.

GUNTHER, A. 1866. Catalogue of the Physostomi containing the families Salmonidae, Percopsidae, Galaxidae, Mormyridae, Gymnarchidae, Esocidae, Umbridae, Scombresocidae, Cyprinodontidae, in the collection of the British Museum. Vol. 6. Printed by the order of the Trustees, Londres, 358p.

GUNTHER, A. 1868. Catalogue of the Physostomi containing the families Heteropygii, Cyprinidae, Gonorynchidae, Hyodontidae, Osteoglossidae, Clupeidae, Chirocentriae, Alepocephalidae, Notopteridae, Halosauridae, in the collection of the British Museum. Vol. 7. $512 p$. 
HERRICK, C. J. 1899. The cranial and first spinal nerves of Menidia. A contribution upon the nerve components of the bony fishes. Archives of Neurology and Psychopathology, 2: 1-299.

HERRICK, C. J. 1901. The cranial nerves and cutaneous sense organs of the North American siluroid fishes. Journal of Comparative Neurology, 11: 177-249.

JOHNSON, D. \& PATTERSON, C. 1997. Relationships of lower euteleostean fishes. Pp. $251-$ 332. In. Interrelationships of fishes. STIASSNY, M. L. J., PARENTI, L. R. \& JOHNSON, G. D. (Eds.). Academic Press, San Diego.

KAPOOR, A. S. 1961. Sensory canals and related dermal bones of the head in Wallago attu. BI. \& Schn. Transactions of the American Microscopical Society, 80 (3): 329-343.

KINDRED, J. E. 1919. The skull of Amiurus. Illinois Biological Monographs, 5 (1): 1-121.

LEKANDER, B. 1949. The sensory line system and the canal bones in the head of some Ostariophysi. Acta Zoologica, 30: 1-131.

LIMA, F. C. T. 2003. Subfamily Bryconinae. Em: Check List of the Freshwater Fishes of South and Central America. REIS, R. E, KULLANDER, S. O. \& FERRARIS Jr., C. J. (ed.) 2003. Porto Alegre, Edipucrs. 729p.

LUCENA, C. A. S. \& MENEZES, N. A. 2003. Subfamily Characinae. Em: Check List of the Freshwater Fishes of South and Central America. REIS, R. E, KULLANDER, S. O. \& FERRARIS Jr., C. J. (ed.) 2003. Porto Alegre, Edipucrs. 729p.

LUNDBERG, J. 1975. Homologies of the upper shoulder girdle and temporal region bones in catfishes (order Siluriformes), with comments on the skull of the Helogeneidae. Copeia, 1975:6674.

MAGO-LECCIA, F. 1978. Los peces de la família Sternopygidae de Venezuela. Acta Científica Venezolana, 29: 1-51.

MARINHO, M. M. F. 2014. Relações filogenéticas e revisão taxonômica das espécies do gênero Copella Myers, 1956 (Characiformes: Lebiasinidae). São José do Rio Preto, Universidade Estadual Paulista "Júlio de Mesquita Filho", Tese de Doutorado. 284p.

MARUSKA, K. P. 2001. Morphology of the mechanosensory lateral line system in elasmobranch fishes: ecological and behavioral considerations. Environmental Biology of Fishes, 60: 47-75. 
MATTOX, G. M. T. \& TOLEDO-PIZA, M. 2012. Phylogenetic study of the Characinae (Teleostei: Characiformes: Characidae). Zoological Journal of the Linnean Society, 165: 809-915.

MATTOX G. M. T., BRITZ, R., TOLEDO-PIZA, M. \& MARINHO, M. F. 2013. Cyanogaster noctivaga, a remarkable new genus and species of miniature fish from the Rio Negro, Amazon basin (Ostariophysi, Characidae). Ichthyological Exploration of Freshwaters, 23(4): 297-318.

McHENRY, M. J. \& VAN NETTEL, S. M. 2007. The flexural stiffness of superficial neuromasts in the zebrafish (Danio rerio) lateral line. The Journal of Experimental Biology, 210: 4244-4253.

MCMURRICH, J. P.1884. The osteology of Amiurus catus. Proceedings of the Canadian Institute. Vol 2: 270-311

MENEZES, N. A. 1969. Systematics and evolution of the tribe Acestrorhynchini (PiscesCharacidae). Arquivos de Zoologia, São Paulo, 18(1-2): 1-150.

MENEZES, N. A. 1976. On the Cynopotaminae, a new subfamily of Characidae (Osteichthyes, Ostariophysi, Characoidei). Arquivos de Zoologia, São Paulo, 28(2): 1-91.

MENEZES, N. A. \& GÉRY, J. 1983. Seven new Acestrorhynchin characid species (Osteichthyes, Ostariophysi, Characiformes) with comments on the systematics of the group. Revue Suisse de Zoologie, (90)3: 563-592.

MIRANDE, J. C. 2010. Phylogeny of the family Characidae (Teleostei: Characiformes), from characters to taxonomy. Neotropical Ichthyology, 8 (3): 385-568.

MONTGOMERY, J. C., COOMBS, S. \& BAKER, C. S. 2001. The mechanosensory lateral line system of the hypogean form of Astyanax fasciatus. Environmental Biology of Fishes, 62: 87-96.

MOREIRA, C. R. 2003. Subfamily Iguanodectinae. Em: Check list of the freshwater fishes of South and Central America. REIS, R. E, KULLANDER, S. O. \& FERRARIS Jr., C. J. (ed.) 2003. Porto Alegre, Edipucrs. 729p.

MOREIRA, C. R. 2005. Xenurobrycon coracoralinae, a new glandulocaudine fish (Ostariophysi: Characiformes: Characidae) from central Brazil. Proceedings of the Biological Society of Washington, 118(4):855-862

MOREIRA, C. R. 2007. Relações filogenéticas na ordem Characiformes (Teleostei, Ostariophysi). São Paulo, Universidade de São Paulo, Tese de Doutorado. 468p. 
MOREIRA, C. R., BICHUETTE, M. E., OYAKAWA, O. T., de PINNA, M. C. C. \& TRAJANO, E. 2010. Rediscovery and redescription of the unusual subterranean characiform Stygichthys typhlops, with noteson its life history. Journal of Fish Biology, 76: 1815-1824.

NELSON, G. J. 1969. Infraorbital bones and their bearing on the phylogeny and geography of osteoglossomorph fishes. American Museum Novitates, 2394: 1-37.

NELSON, G. J. 1972. Cephalic sensory canals, pitlines, and the classification of esocoid fishes, with notes on galaxiids and other teleosts. American Museum of National History, 2492: $1-49$.

NELSON, J. S. 2006. Fishes of the World. Hoboken, New Jersey, John Wiley \& Sons print, $601 \mathrm{p}$.

NETTO-FERREIRA, A. L., BIRINDELLI, J. L. O., SOUSA, L. M., MARIGUELA, T. C. \& OLIVEIRA, C. 2013. A New Miniature Characid (Ostariophysi: Characiformes: Characidae), with Phylogenetic Position Inferred from Morphological and Molecular Data. PLoS ONE, 8(1): e52098. doi:10.1371/journal.pone.0052098

NORTHCUTT, G. 1989. The phylogenetic distribution and innervation of craniate mechanoreceptive lateral line: neurobiology and evolution. Pp. 17-78. In: COOMBS, S. P., P. GÖRNER \& H. MÜNZ (Eds.). The Mechanosensory Lateral Line. New York, Springer Verlag. 724p.

NORTHCUTT, R. G., HOLMES, P. H. \& ALBERTS, J. S. 2000. Distribution and innervation of lateral line organ in the channel catfish. The Journal of Comparative Neurology, 421: 570-592.

OLIVEIRA, C., AVELINO, G. S., ABE, K. T., MARIGUELA, T. C., BENINE, R. C., ORTI, G., VARI, R. P. \& CASTRO, R. M. C. C. 2011. Phylogenetic relationships within the speciose family Characidae (Teleostei: Ostariophysi: Characiformes) based on multilocus analysis and extensive ingroup sampling. BMC Evolutionary Biology, 11: 1-25.

ORTí, G., SIVASUNDAR, A., DIETZ, K. \& JÉGU, M. 2008. Phyologeny of the family Serrasalmidae (Characiformes) based on mitochondrial DNA sequences. Genetics and Molecular Biology, 31(1): 343-351.

OYAKAWA, O. T. 1998. Relações filogenéticas das famílias Pyrrhulinidae, Lebiasinidae e Erythrinidae (Osteichthyes: Characiformes). São Paulo, Universidade de São Paulo, Tese de Doutorado. 200p. 
PARIN, N. V. \& ASTAKHOV, D. A. 1982. Studies on the Acoustico-Lateralis System of Beloniform Fishes in Connection with Their Systematics. Copeia, 1982 (2): 276-291.

PASTANA, M. N. L. 2012. Descrição osteológica de uma espécie de Sartor MYERS \& CARVALHO 1959 (Characiformes; Anostomidae). Ribeirão Preto, Faculdade de Filosofia, Ciências e Letras da Universidade de São Paulo, Monografia de Bacharelado. 68p.

PEHRSON, T. 1922. Some points in the cranial development of the teleostomian fishes. Acta Zoologica, 3: 1-63.

PEHRSON, T. 1940. The development of dermal bones in the skull of Amia calva. Acta Zoologica, 21: 1-50.

PEHRSON, T. 1944. The development of latero-sensory canal bones in the skull of Esox lucius. Acta Zoologica, 25: 1-23.

de PINNA, M. C. C. 1992. A new subfamily of Trichomycteridae (Teleostei, Siluriformes), lower loricarioid relationships and a discussion on the impact of additional taxa for phylogenetic analysis. Zoological Journal of the Linnean Society, 106: 175-229.

de PINNA, M. C. C. 1993. Higher-level phylogeny of Siluriformes, with a new classification of the order (Teleostei, Ostariophysi). New York, The City University of New York, Tese de Doutorado. 482p.

POLLARD, H. B. 1892. The lateral system in siluroids. Zoologischen Jahrbüchern, 5: 525-551.

POYATO-ARIZA, F. J., GRANDE, T. \& DIOGO, R. 2010. Gonorynchiform Interrelationships: Historic overview, analysis, and revised systematic of the group. Em: Gonorynchiformes and Ostariophysan Relationships - A comprehensive Review. GRANDE, T., POYATO-ARIZA, F. J. \& DIOGO, R. (Eds.). Science Publishers, Enfield, United States of America.

REIS, R. E, KULLANDER, S. O. \& FERRARIS JR., C. J. (ed.) 2003. Check List of the Freshwater Fishes of South and Central America. Porto Alegre, Edipucrs. 729p.

RISTOVSKA, B. K., VERRAES, W. \& ADRIAENS, D. 2004. Development of the cranial lateralline system and canal related bones in Salmo letnica Kar. (Teleostei: Salmonidae). In: Proceedings of the Congress of the Balkan Water Observation and Information System for Decision Support. Ohrid, Republic of Macedonia. 
ROBERTS, T. 1969. Osteology and relationships of characoid fishes, particularly the genera Hepsetus, Salminus, Hoplias, Ctenolucius, and Acestrorhynchus. Proceedings of the California Academy of Sciences, 36(15): 391-500.

ROBERTS, T. 1973. Osteology and Relationships of the Prochilodontidae, a South American Family of Characoid Fishes. Bulletin of the Museum of Comparative Zoology, Harvard University, 145(4): 213-235.

SAGEMEHL M. 1885. Beiträge zur vergleichenden Anatomie der Fische. III. Das Cranium der Characiniden nebst allgemeinen Bemerkungen über die mit einem Weber'schen Apparat versehenen Physostomenfamilien. Morphologisches Jahrbuch, 10: 1-119.

de SANTANA, C. D. \& VARI, R. P. 2009. The South America electric fish genus Platyurosternarchus (Gymnotiformes: Apteronotidae). Copeia, 2009: 233-244.

SAXENA, P. K. 1966. Cranial nerves of the common catfish Clarias batrachus. Japanese Journal of Ichthyology, 14: 91-98.

SCHAEFER, S. A. 1990. Anatomy and relationships of the scoloplacid catfishes. Proceedings of the Academy of Natural Sciences of Philadelphia, 142: 167-210

SCHAEFER, S. A. \& AQUINO, A. E. 2000. Postotic laterosensory canal and pterotic branch homology in catfishes. Journal of Morphology, 246: 212-227.

SHARMA, M. S. 1964. The Cephalic Lateral-Line System in Notopterus chitala (Ham.). Copeia, 1964(3): 530-533.

SIDLAUSKAS, B. L. \& VARI, R. P. 2008. Phylogenetic relationships within the South American fish family Anostomidae (Teleostei, Ostariophysi, Characiformes). Zoological Journal of the Linnean Society, 154: 70-210.

STEPHENS, R. R. 1985. The lateral line system of the gizzard shad, Dorosoma cepedianum Lesueur (Pisces: Clupeidae). Copeia, 1985:540-556.

STEPHENS, R. R. 2010 A description of the cephalic lateralis system of Anchoa mitchilli (Valenciennes) (Clupeomorpha: Engraulidae) with identification of synapomorphies for the Engraulidae. Proceedings of the Biological Society of Washington, 23 (1): 8-16.

TAYLOR, W. R. \& VAN DYKE, G. C. 1985. Revised procedures for staining and clearing small fishes and other vertebrates for bone and cartilage study. Cybium, 9 (2): 107-119. 
TEYKE, T. 1990. Morphological differences in neuromasts of the blind cave fish Astyanax hubbsi and the sighted river fish Astyanax mexicanus. Brain, Behavior and Evolution, 35: 23-30.

TOLEDO-PIZA, M. \& MENEZES, N. A. 1996. Taxonomic Redefinition of the Species of Acestrorhynchus of the microlepis Group with the Description of Acestrorhynchus apurensis, a New Species from Venezuela (Ostariophysi: Characiformes: Characidae). American Museum Novitates, 3160: 1-23.

TOLEDO-PIZA, M. 2007. Phylogenetic relationships among Acestrorhynchus species (Ostariophysi: Characiformes: Acestrorhynchidae). Zoological Journal of the Linnean Society, 151: 691-757.

TOLEDO-PIZA, M., MATTOX, G. M. T., BRITZ, R. 2014. Priocharax nanus, a new miniature characid from the rio Negro, Amazon basin (Ostariophysi: Characiformes), with an updated list of miniature Neotropical freshwater fishes. Neotropical Ichthyology, 12(2): 229-246.

VAN-BERGEIJK, W. A. \& ALEXANDER, S. 1962. Lateral line canal organs on the head of Fundulus heteroclitus.Journal of Morphology, 110(3): 333-346.

VARI, R. P. 1979. Anatomy, relationships and classification of the families Citharinidae and Distichodontidae (Pisces, Characoidea). Bulletin of the British Museum (Natural History), Zoology, 36(5): 261-344.

VARI, R. P. 1983. Phylogenetic relationships of the families Curimatidae, Prochilodontidae, Anostomidae, and Chilodontidae (Pisces: Characiformes). Smithsonian Contributions to Zoology, 378: iii+1-60.

VARI, R. P. 1989. A phylogenetic study of the Neotropical characiform family Curimatidae (Pisces: Ostariophysi). Smithsonian Contributions to Zoology, 471: 1-71.

VARI, R. P. 1995. The neotropical fish family Ctenoluciidae (Teleostei: Ostariophysi: Characiformes): Supra and intrafamilial phylogenetic relationships, with a revisionary study. Smithsonian Contributions to Zoology, 564: 1-97.

VARI, R. P., CASTRO, R. M. C. C. \& RAREDOM, S. J. 1995. The Neotropical fish family Chilodontidae (Teleostei: Characiformes): a phylogenetic study and a revision of Caenotropus Günther. Smithsonian Contributions to Zoology, 577: 1-32.

VROLIK. A. J. 1873. Studien über die Verknöcherung und die Knochen des Schädels der Teleostier. Niederländisches Archiv fur Zoologie, 1: 219-318. 
WALTHER, J. 1882. Die Entwicklung der Deckknochen am kopfskelett des Heches (Esox Lucius). Jenaische Zeitschrift für Naturwissenschaft, 16: 59-84.

WEBB, J. F. 1989. Gross morphology and evolution of the mechanosensory lateral line system in teleost fishes. Brain Behavior and Evolution, 33: 34-53.

WEBB, J. F. 1990. Comparative Morphology and Evolution of the Lateral Line System in the Labridae (Perciformes: Labroidei). Copeia, 1990(1): 137-146.

WEBB J. F. \& NORTHCUTT, R. G. 1997. Morphology and distribution of pit organs and canal neuromasts in non-teleost bony fishes. Brain Behavior and Evolution, 50: 139-151.

WEBB J. F., BIRD, N. C., CARTER, L. \& DICKSON, J. 2014. Comparative Development and Evolution of Two Lateral Line Phenotypes in Lake Malawi Cichlids. Journal of Morphology, 275: 678-692.

WEBB, S. A., 1998. A phylogenetic analysis of the Goodeidae (Teleostei: Cyprinodontiformes). Ann Harbor, University of Michigan, Ph.D. Dissertation. 280p.

WEITZMAN, S. H. 1962. The osteology of Brycon meeki, a generalized characid fish, with an osteological definition of the family. Stanford Ichthyological Bulletin, 8: 1-77.

WEITZMAN, S. H. 1964. Osteology and relationships of South American characid fishes of subfamilies Lebiasininae and Erythrininae with special reference to subtribe Nannostomina. Proceedings of the United States National Museum, 116: 127- 169.

WEITZMAN, S. H, \& FINK, W. L. 1983. Relationships of the neon tetras, a group of South American freshwater fishes (Teleostei, Characidae), with comments on the phylogeny of New World characiforms. Bulletin of the Museum of Comparative Zoology, 150(6): 339-395.

WEITZMAN, S. H., \& FINK, S. V. 1985. Xenurobryconin phylogeny and putative pheromone pumps on glandulocaudine fishes (Teleostei: Characidae). Smithsonian Contributions to Zoology, 421: 1-121.

WEITZMAN, S. H., \& MALABARBA, L R. 1999. Systematics of Spintherobolus (Teleostei: Characidae: Cheirodontinae) from eastern Brazil. Ichthyological Exploration of Freshwaters, 10(1): 1-43. 
WEITZMAN, S. H. \& VARI, R. P. 1987. Two new species and a new genus of miniature characid fish (Teleostei, Characiformes) from northern South America. Proceedings of the Biological Society of Washington, 100: 640-652.

WEITZMAN, S. H., \& VARI, R P. (1988). Miniaturization in South American freshwater fishes; an overview and discussion. Proceedings of the Biological Society of Washington, 101(2): 444465.

WINTERBOTTOM, R. 1980. Systematics, osteology and phylogenetic relationships of fishes of the ostariophysan subfamily Anostominae (Characoidei, Anostomidae). Life Sciences Contributions: Royal Ontario Museum, 123: 1-112.

WRIGHT, R. R. 1884. On the skin and cutaneous sense organs of Amiurus. Proceedings of the Canadian Institute. Vol 2: 252-270

ZACCHEI, A. M. \& TAVOLARO, P. 1998. Lateral line system during the life cycle of Anguilla anguilla (L.). Bolletino di zoologia, 3: 145-153.

ZANATA, A. M. \& VARI. R. P. (2005). The family Alestidae (Ostariophysi, Characiformes): a phylogenetic analysis of a trans- Atlantic clade. Zoological Journal of the Linnean Society, 145 (1): 1-14. 
Figuras. 


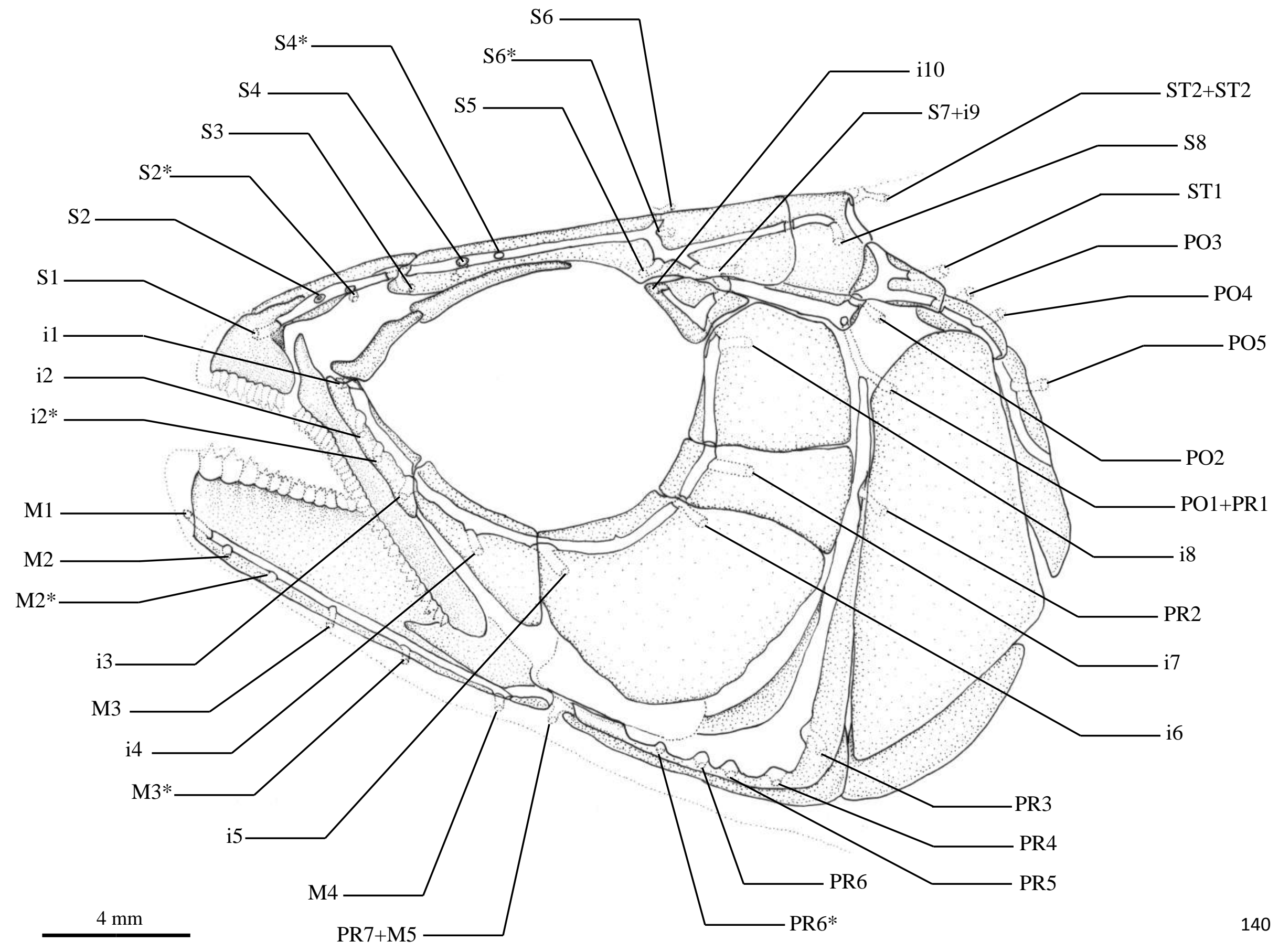




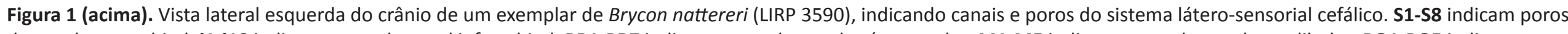

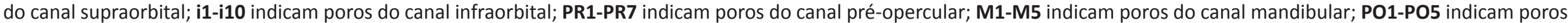
do canal pós-ótico; ST1 e ST2 indicam poros do canal supratemporal. Asteriscos representam poros supranumerários. 


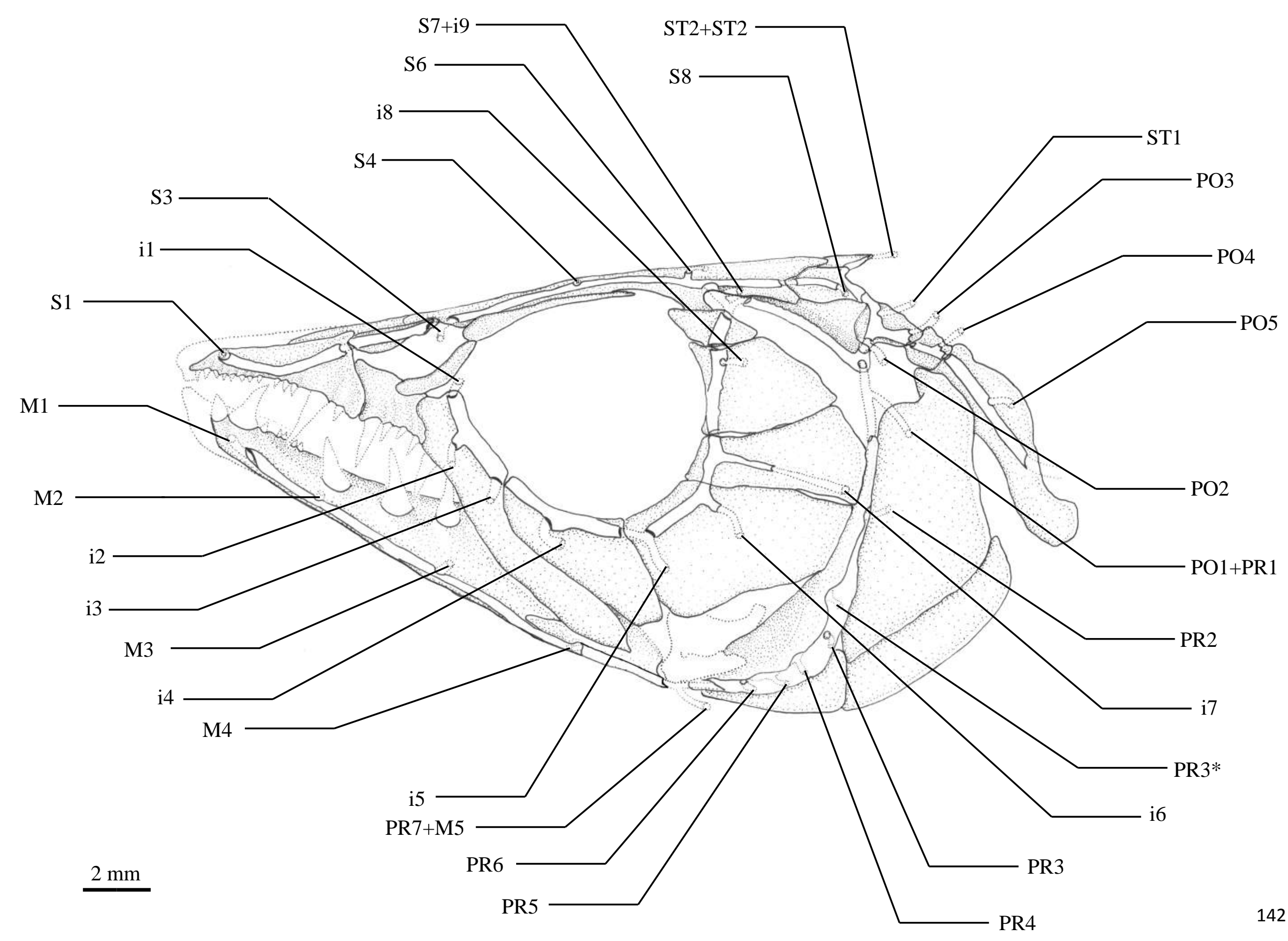




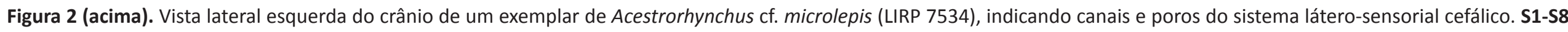

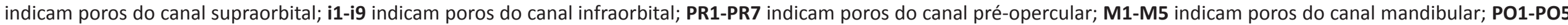
indicam poros do canal pós-ótico; ST1 e ST2 indicam poros do canal supratemporal. Asteriscos representam poros supranumerários. 


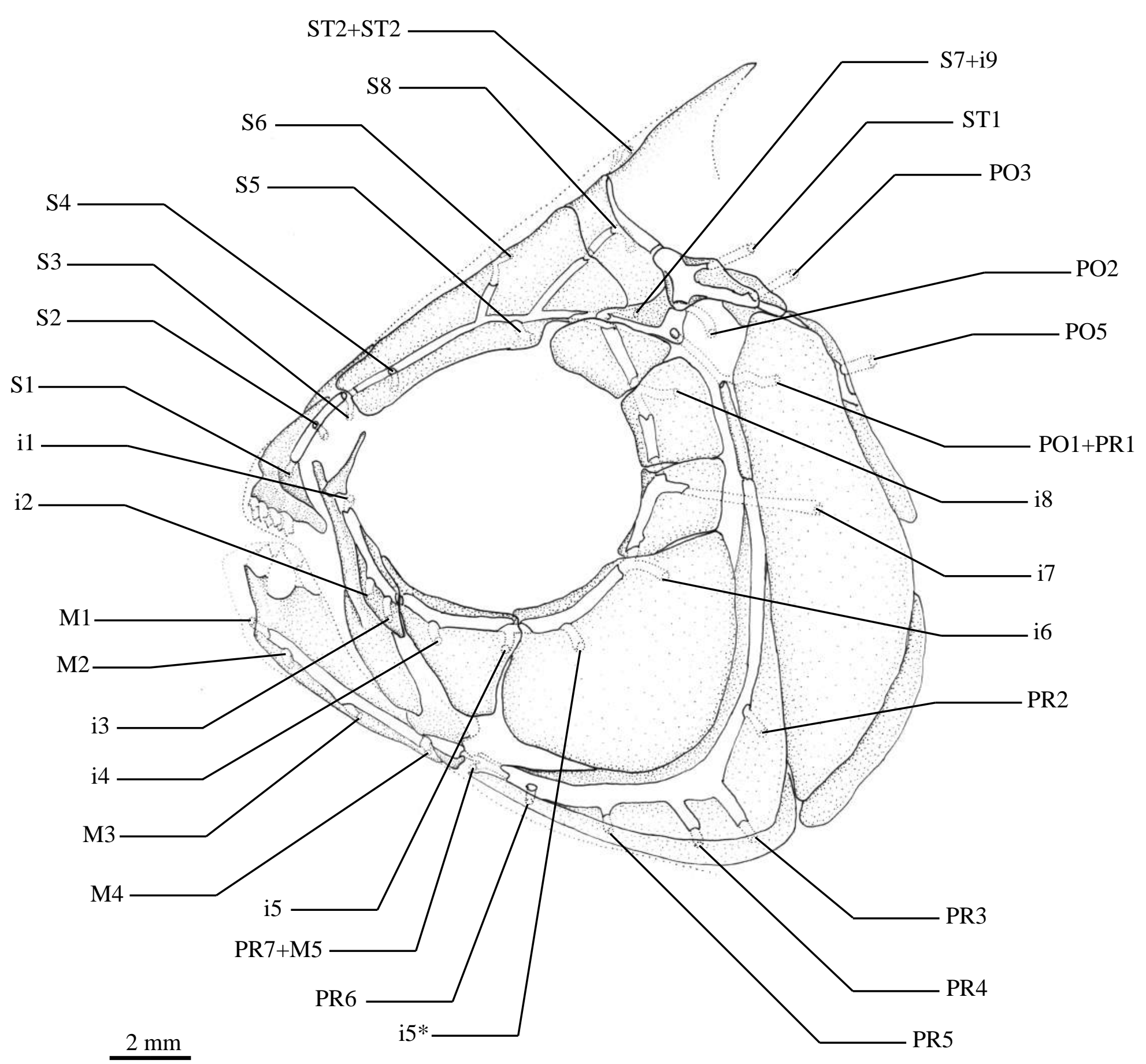




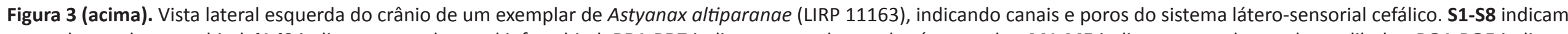

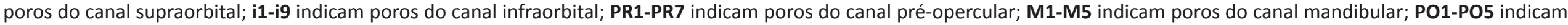
poros do canal pós-ótico; ST1 e ST2 indicam poros do canal supratemporal. Asteriscos representam poros supranumerários. 


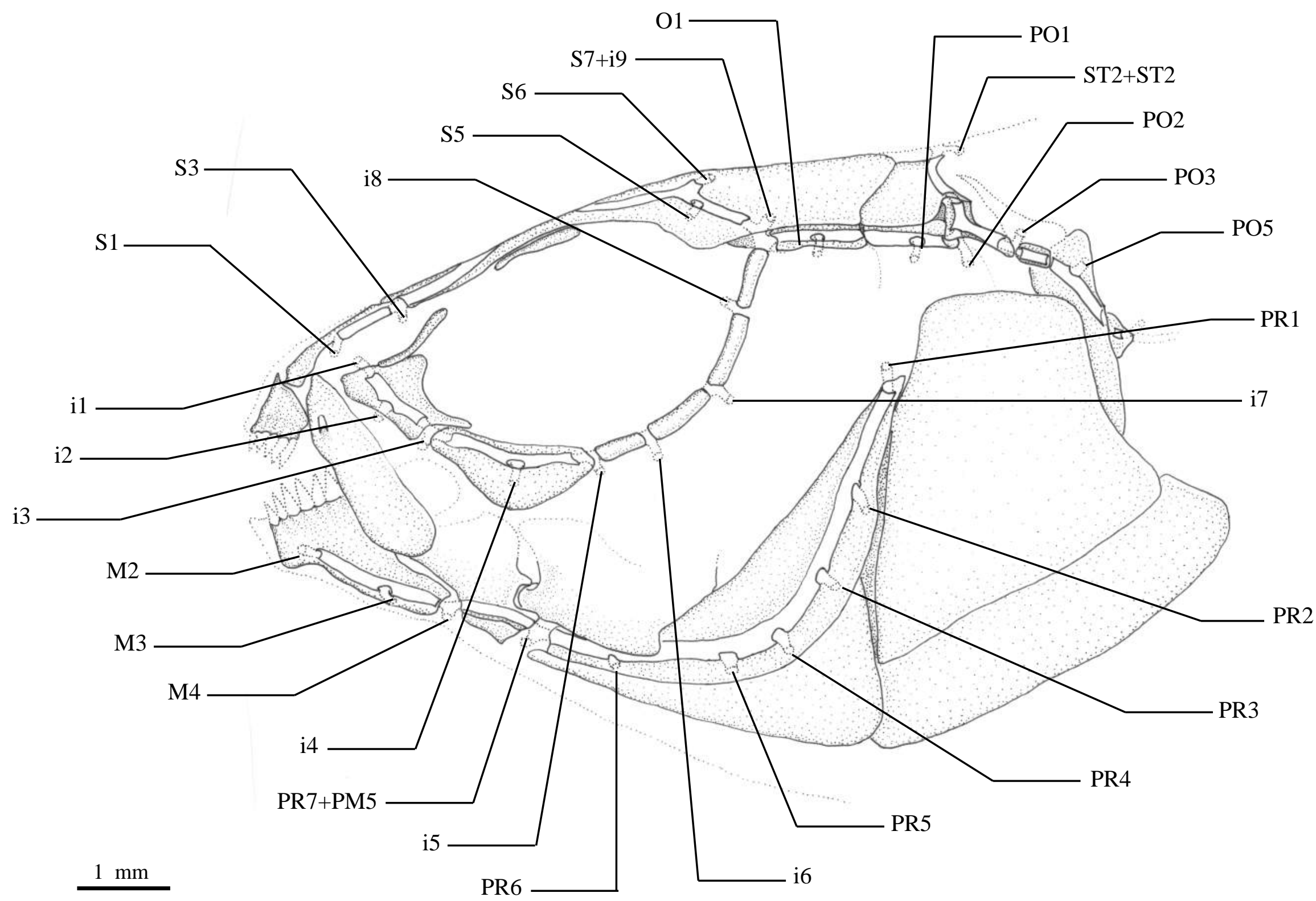

Figura 4. Vista lateral esquerda do crânio de um exemplar de Characidium cf. xanthopterum (LIRP 4470), indicando canais e poros do sistema látero-sensorial cefálico. S1-S7 indicam poros do canal supraorbital; i1-i9 indicam poros do canal infraorbital; PR1-PR7 indicam poros do canal pré-opercular; M2-M5 indicam poros do canal mandibular; $\mathbf{0 1}$ indica poro do canal ótico; PO1-PO5 indicam poros do canal pós-ótico; ST2 indica poro do canal supratemporal. 


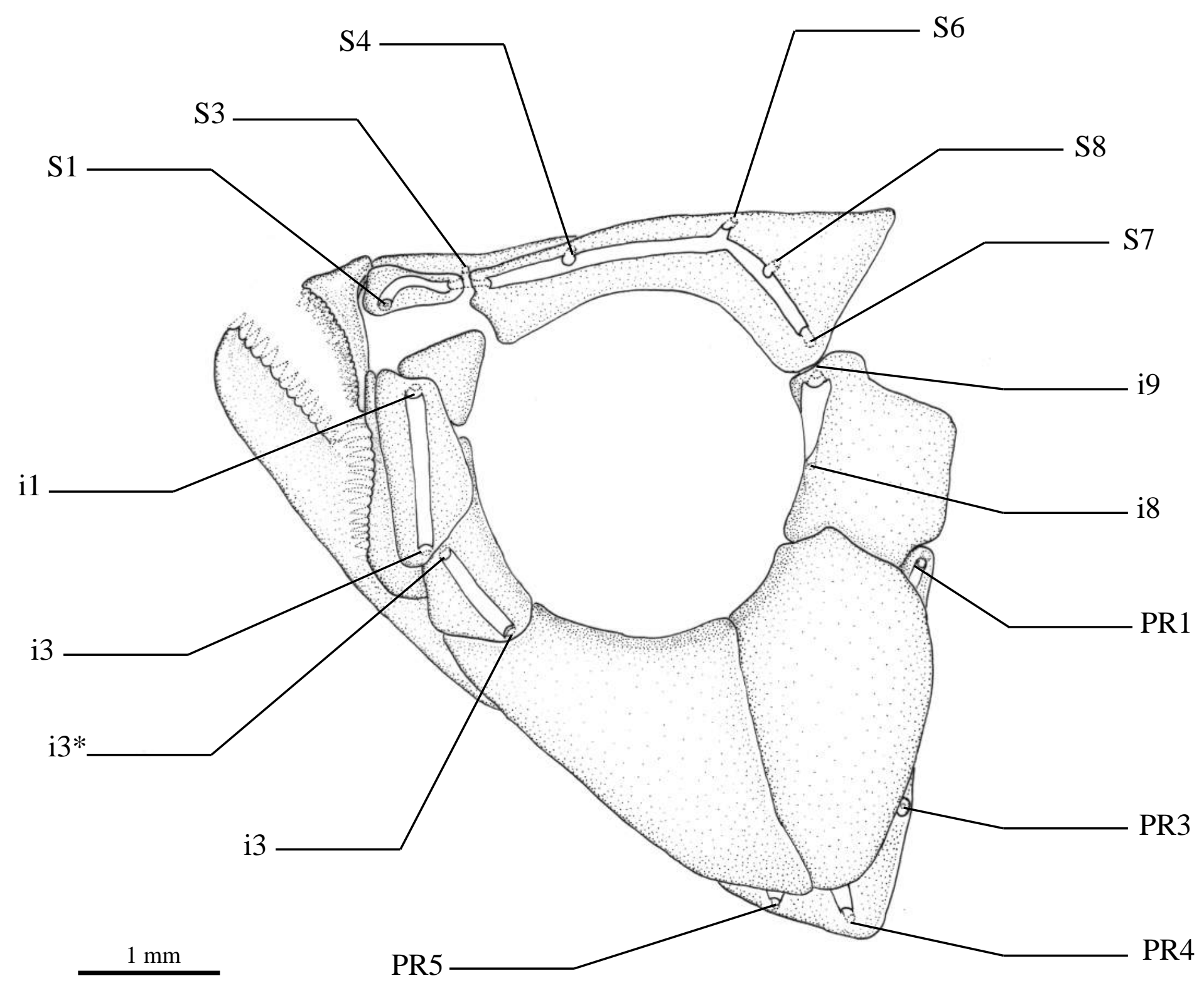

Figura 5. Vista lateral esquerda do crânio de um exemplar de Pyrrhulina cf. australis (LIRP 8590), indicando canais e poros do sistema látero-sensorial cefálico. S1-S8 indicam poros do canal supraorbital; i1-i9 indicam poros do canal infraorbital; PR1-PR7 indicam poros do canal pré-opercular. Canais mandibular, pós-ótico e supratemporal estão ausentes nesse táxon. 


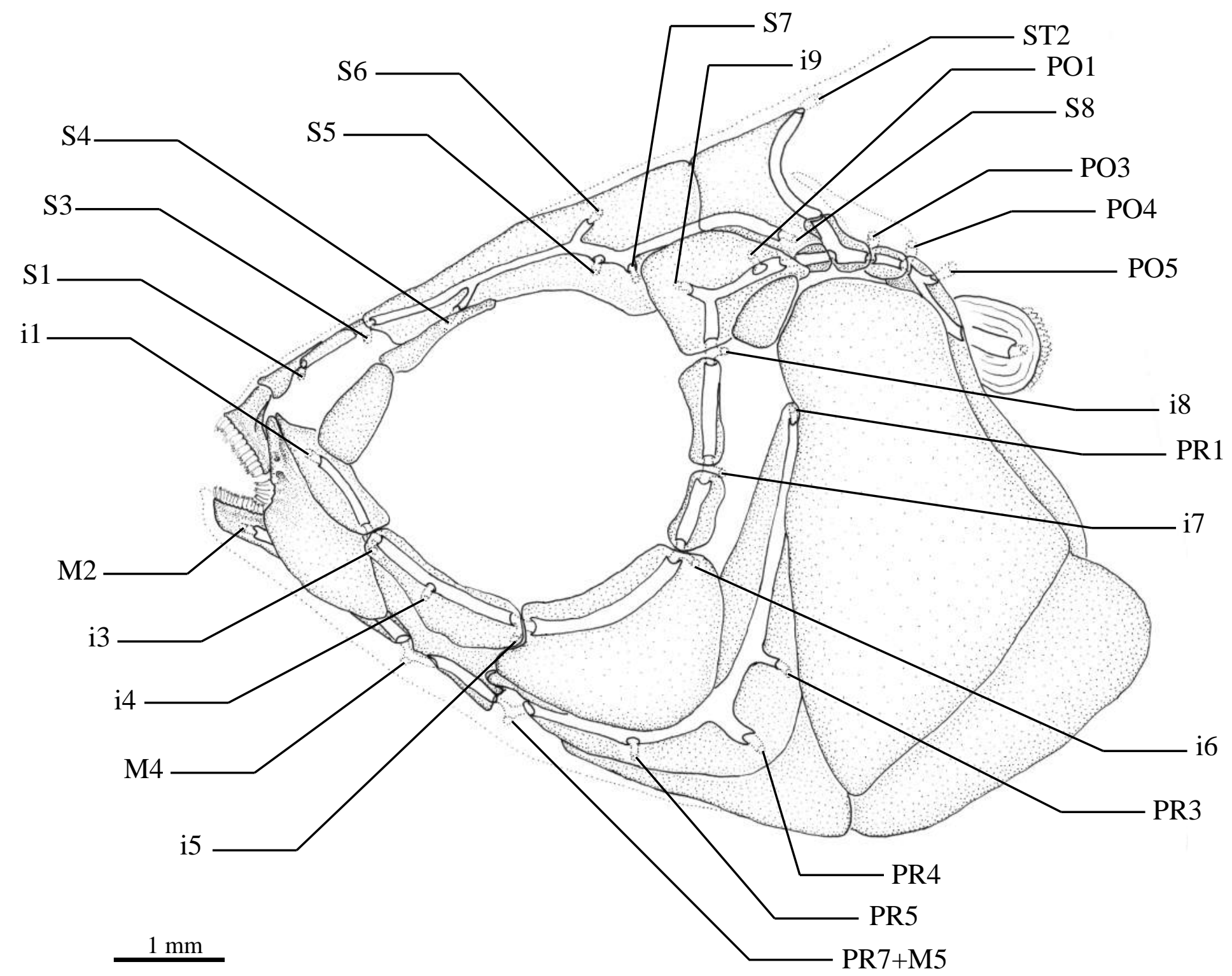

Figura 6. Vista lateral esquerda do crânio de um exemplar de Neolebias unifasciatus (MZUSP 84531), indicando canais e poros do sistema látero-sensorial cefálico. S1-S8 indicam poros do canal supraorbital; i1-i9 indicam poros do canal infraorbital; PR1-PR7 indicam poros do canal pré-opercular; M2-M5 indicam poros do canal mandibular; PO1-PO5 indicam poros do canal pós-ótico; ST2 indica poro do canal supratemporal. 


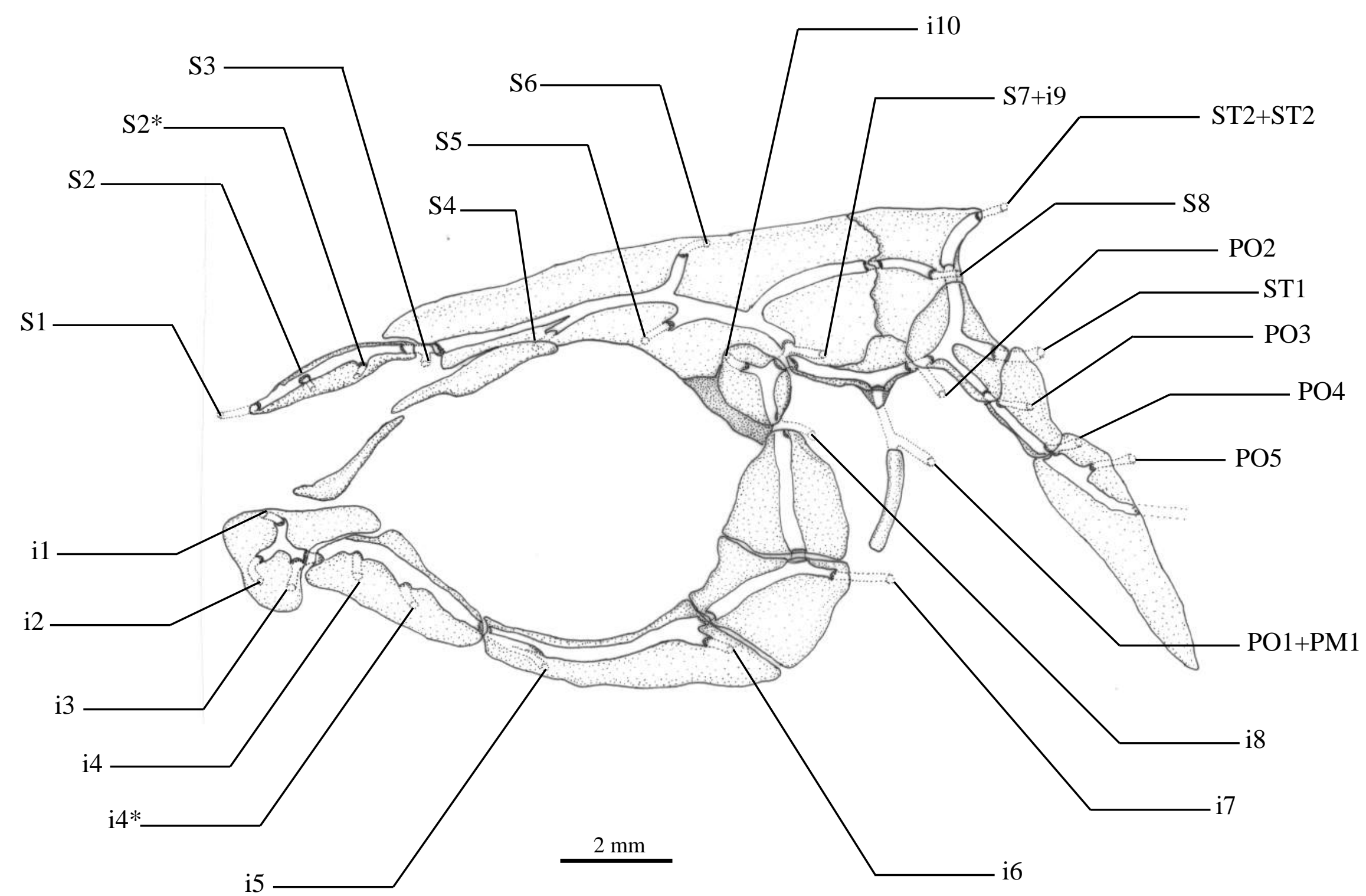

Figura 7. Vista lateral esquerda ilustrando ossos dérmicos cranianos em associação com canais e poros do sistema látero-sensorial cefálico de um exemplar de Leporellus vittatus (LIRP 8857). S1-S8 indicam poros do canal supraorbital; i1-i10 indicam poros do canal infraorbital; PR1 indica primeiro poro pré-opercular; P01-PO5 indicam poros do canal pós-ótico; ST1 e ST2 indicam poros do canal supratemporal. Demais poros pré-operculares, bem como poros do canal mandibular não foram ilustrados. Asteriscos representam poros supranumerários. 


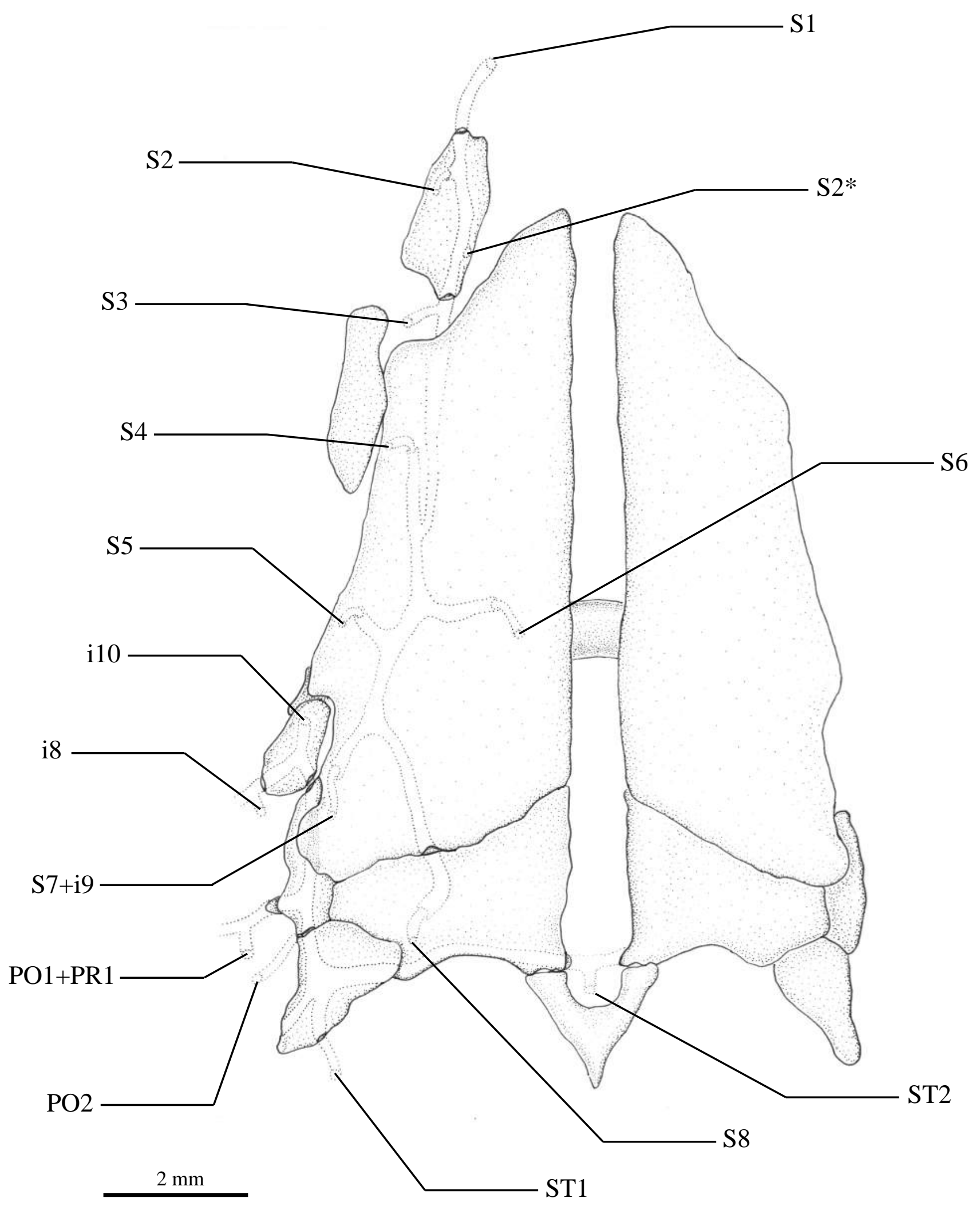

Figura 8. Vista dorsal do crânio de um exemplar de Leporellus vittatus (LIRP 8857), indicando canais e poros do sistema látero-sensorial cefálico. S1-S8 indicam poros do canal supraorbital; PO1 e PO2 indicam poros do canal pós-ótico; ST1 e ST2 indicam poros do canal supratemporal. Poros do canal infraorbital, pré-opercular e mandibular, bem como demais poros do canal pós-ótico e supratemporal não observados em vista dorsal. Asteriscos representam poros supranumerários. 


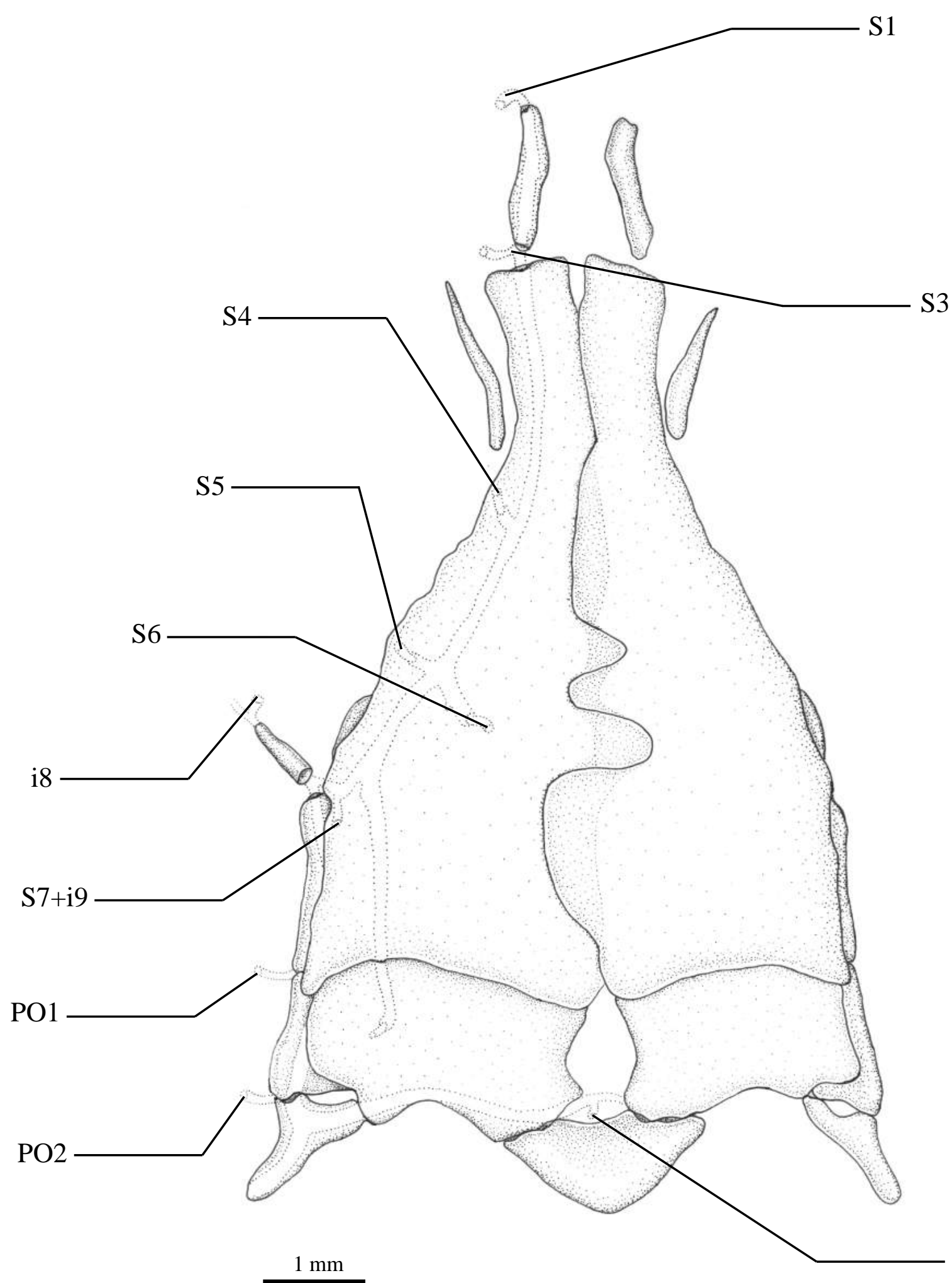

Figura 9. Vista dorsal do crânio de um exemplar de Characidium gomesi (LIRP 8239), indicando canais e poros do sistema látero-sensorial cefálico. S1-S8 indicam poros do canal supraorbital; i9 indica último poro do canal infraorbital; PO1 e PO2 indicam os dois primeiros poros do canal pós-ótico; ST2 indica poro do canal supratemporal. Demais poros infraorbitais e pré-operculares, bem como poros mandibulares não observados em vista dorsal. Demais poros do canal pós-ótico não ilustrados. 


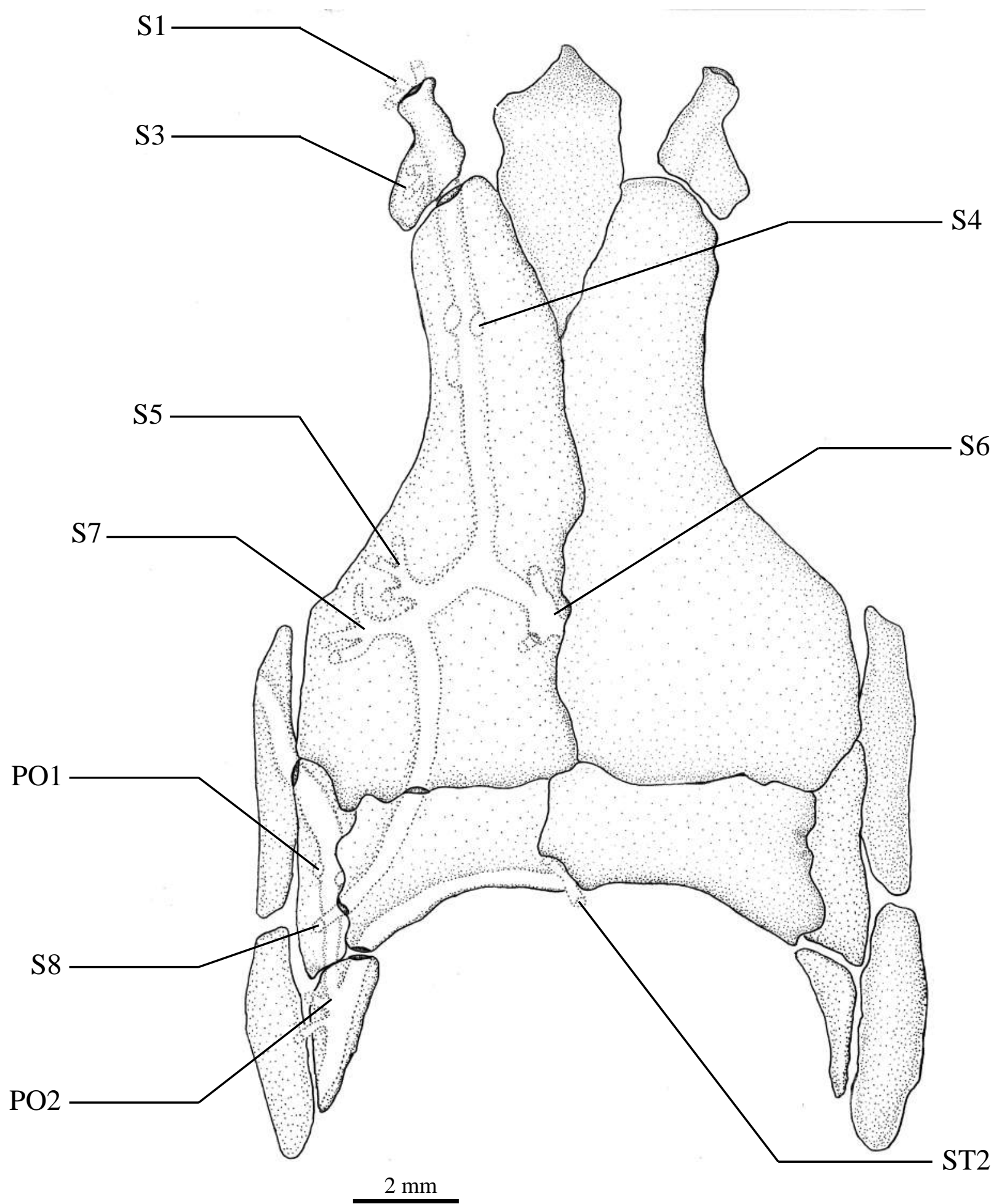

Figura 10. Vista dorsal do crânio de um exemplar de Hoplias aimara (LIRP 9108), indicando canais e poros do sistema látero-sensorial cefálico. S1-S8 indicam poros do canal supraorbital; PO1 e PO2 indicam os dois primeiros poros do canal pós-ótico; ST2 indica poro do canal supratemporal. Poros pré-operculares, infraorbitais e mandibulares não observados em vista dorsal. Demais poros do canal pós-ótico não ilustrados. 


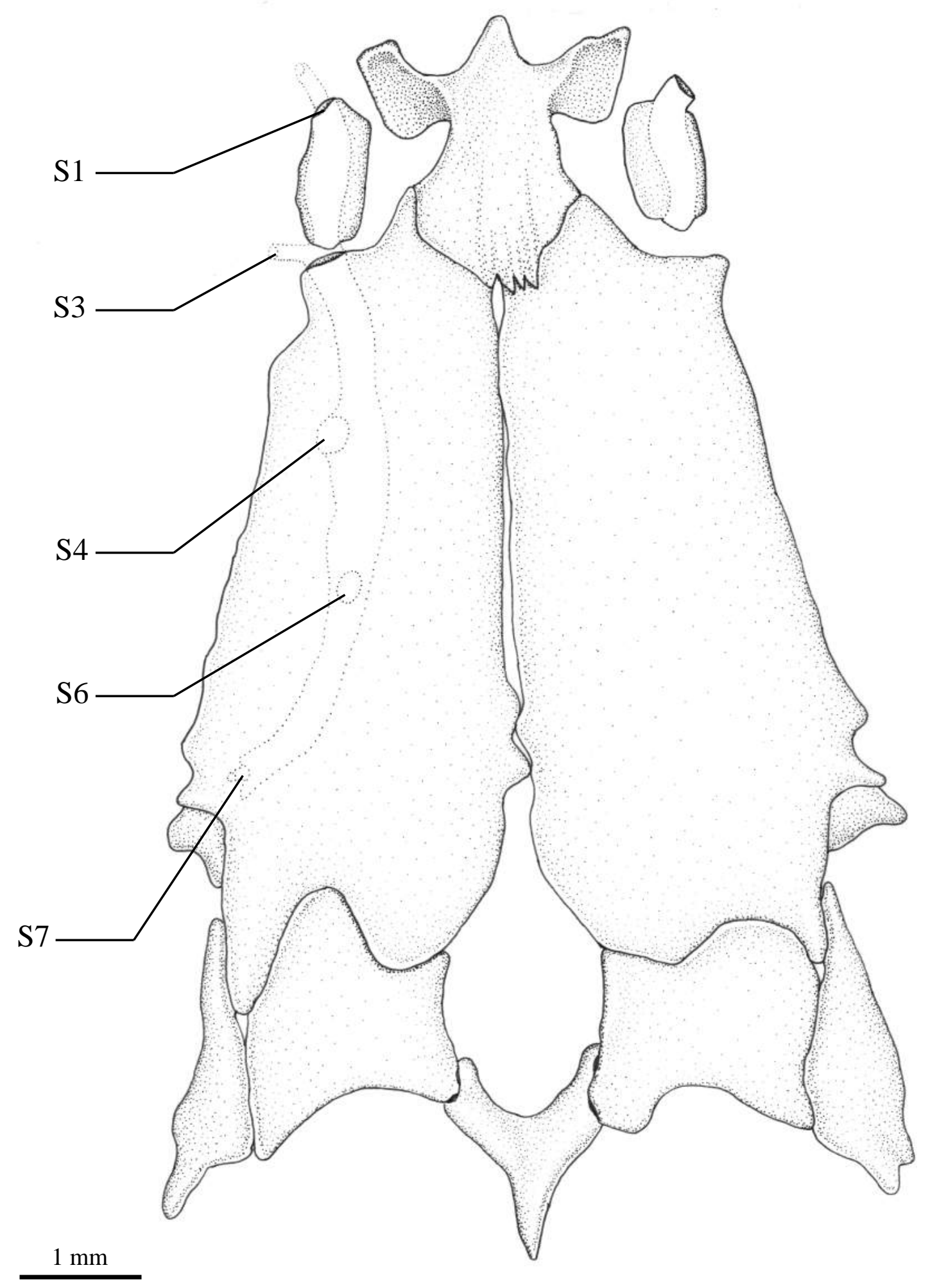

Figura 11. Vista dorsal do crânio de um exemplar de Stygichthys typhlops (LESCI 000230/ 002), indicando canais e poros do sistema látero-sensorial cefálico. S1-S7 indicam poros do canal supraorbital. Canais mandibular, pós-ótico e supratemporal ausentes nesse táxon. Demais canais não observados em vista dorsal. 


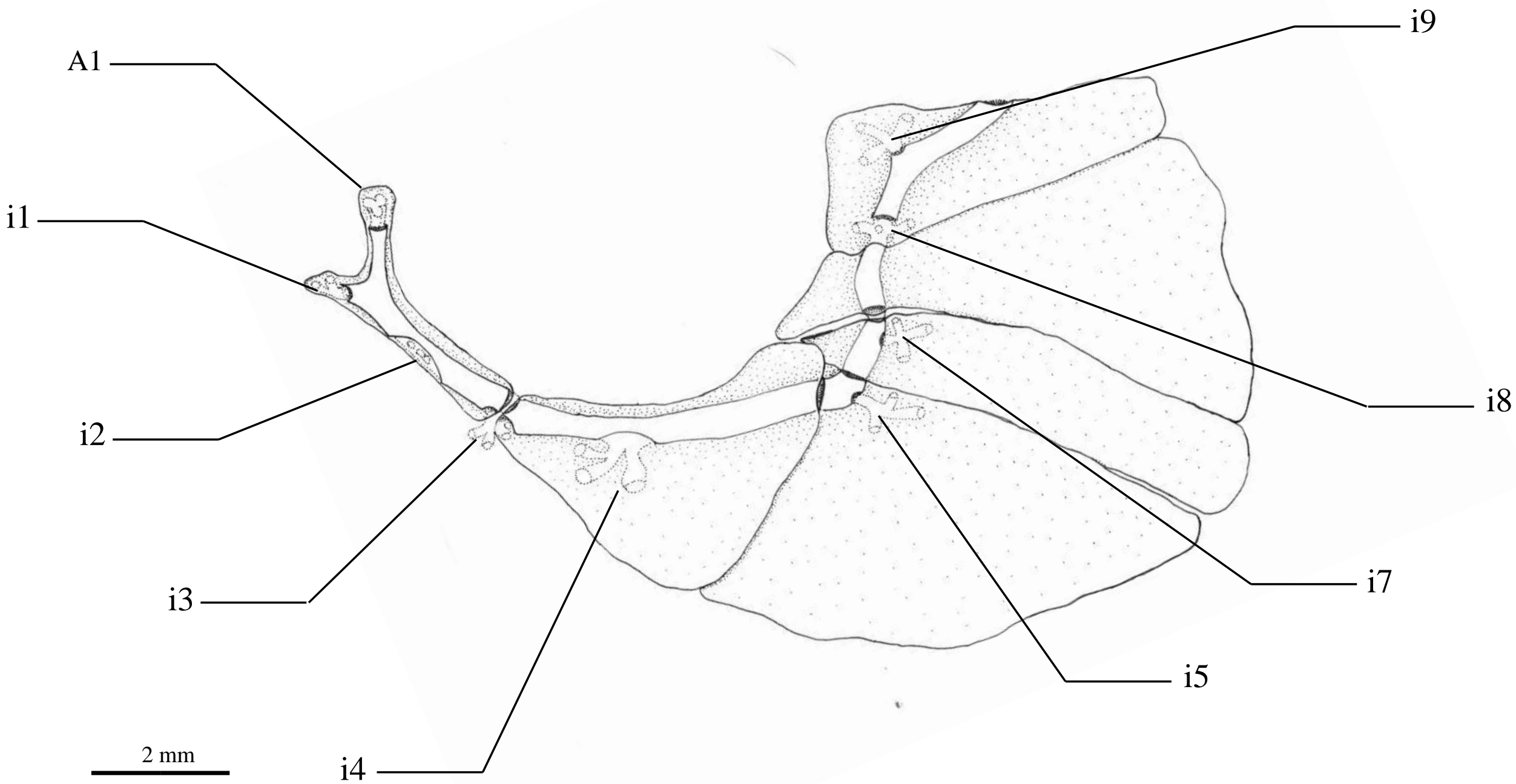

Figura 12. Poros do canal infraorbital e ossos dérmicos associados de um exemplar de Hoplias aimara (LIRP 9108) em vista lateral esquerda. A1 indica poro do trecho antorbital do canal infraorbital; i1-i9 indicam poros ao longo do canal infraorbital. 


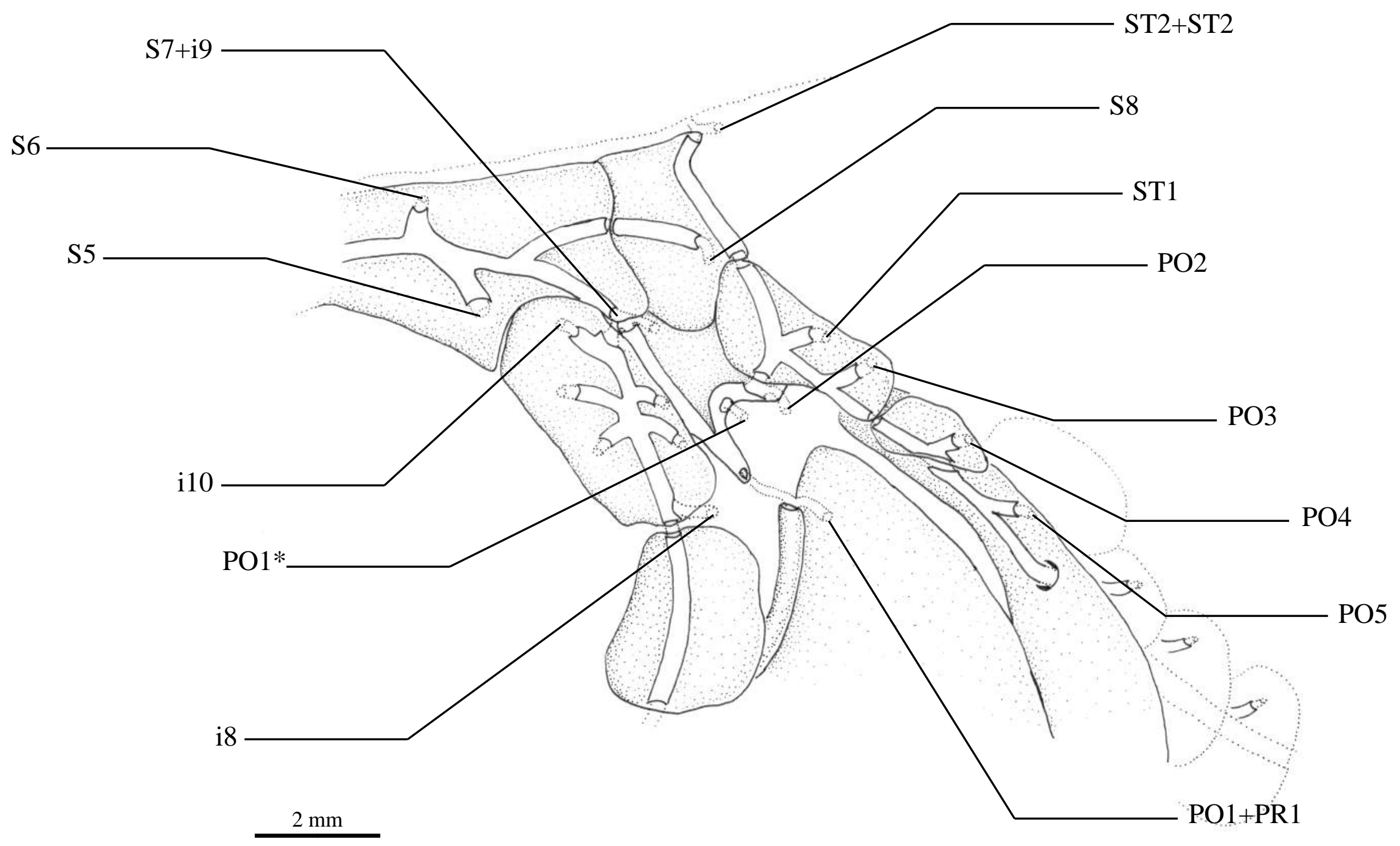

Figura 13. Região temporal do crânio de um exemplar de Prochilodus brevis (LIRP 3781) ilustrado em vista lateral esquerda, indicando canais e poros do sistema látero-sensorial cefálico. S5-S8 indicam poros do canal supraorbital; i8-i10 indicam poros do canal infraorbital; PR1+PO1 indica anastomose entre o primeiro poro pós-ótico com o primeiro poro do canal pré-opercular; PO2-PO5 indicam poros do canal pós-ótico; ST1 e ST2 indicam poros do canal supratemporal. Asteriscos indicam poros supranumerários. Detalhe para as ramificações sobre a placa dermoesfenótica, característica sinapomórfica para espécies do gênero Prochilodus (sensu Castro \& Vari, 2004). Asteriscos representam poros supranumerários. 


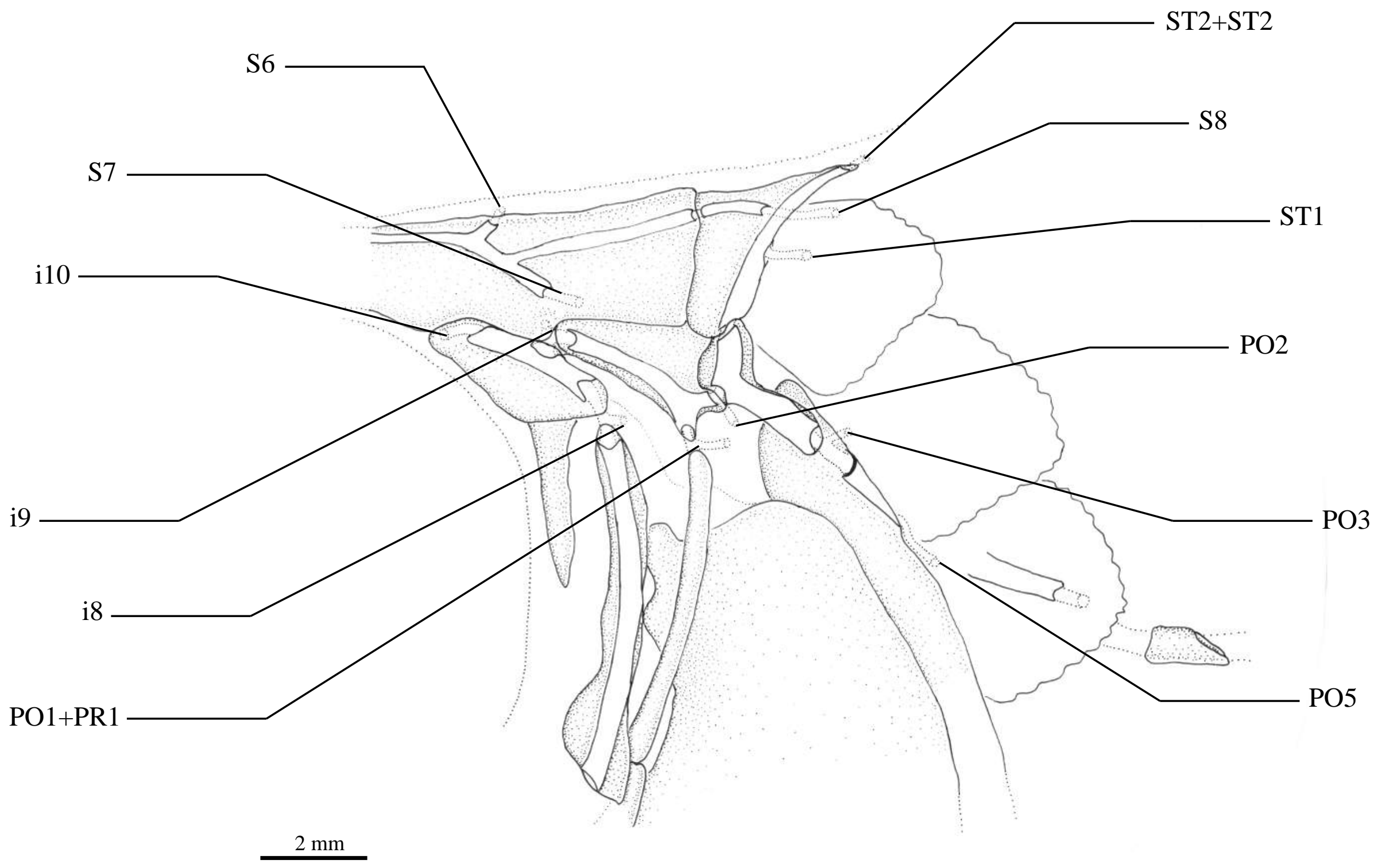

Figura 14. Região temporal do crânio de um exemplar de Caenotropus schizodon (LIRP 8333) ilustrado em vista lateral esquerda, indicando canais e poros do sistema látero-sensorial cefálico. S6-S8 indicam poros do canal supraorbital; i8-i10 indicam poros do canal infraorbital; PR1+PO1 indica anastomose entre o primeiro poro pós-ótico com o primeiro poro do canal pré-opercular; PO2-PO5 indicam poros do canal pós-ótico; ST1 e ST2 indicam poros do canal supratemporal. 


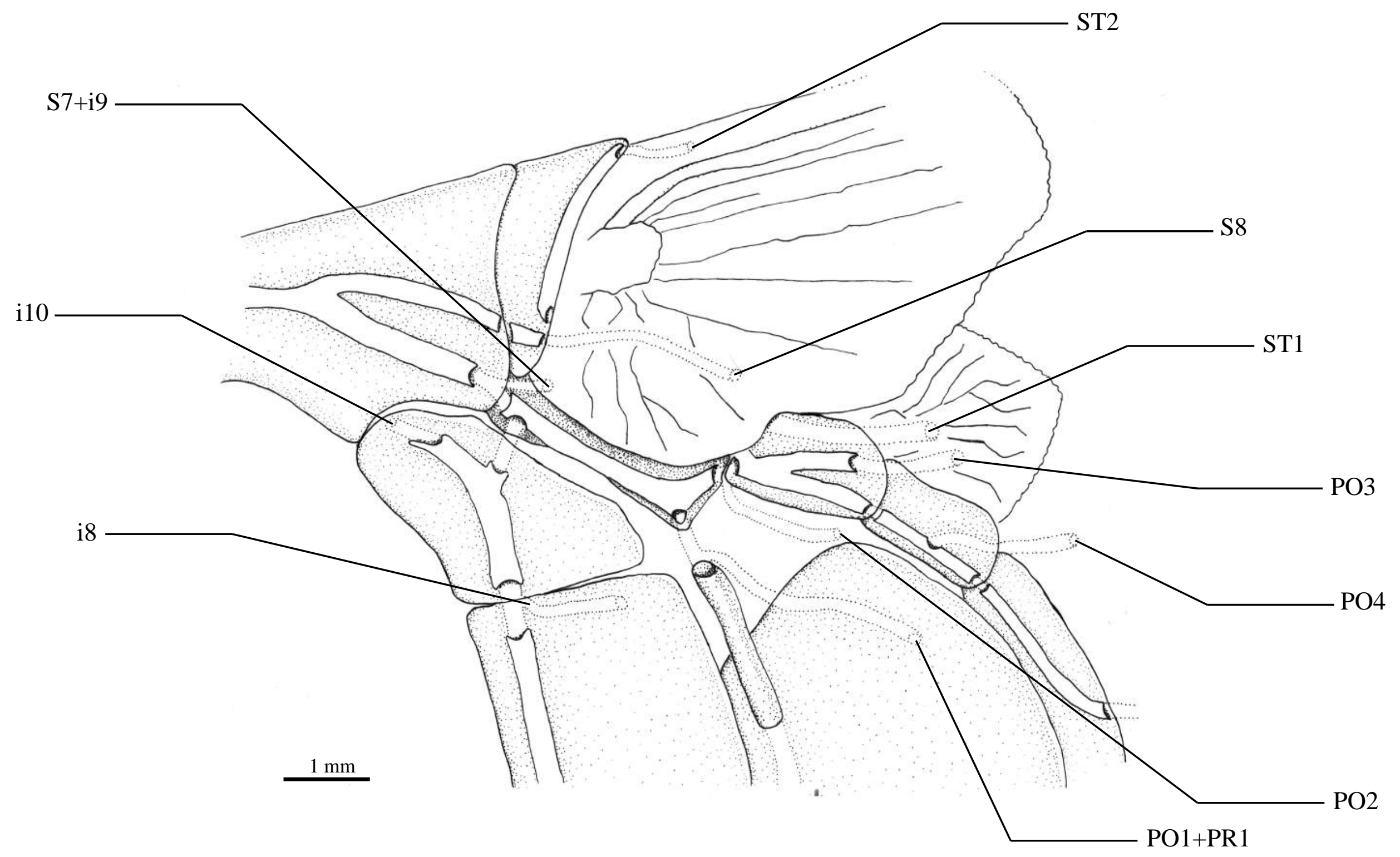

Figura 15. Região temporal do crânio de um exemplar de Chalceus epakros (LIRP 7538) ilustrado em vista lateral esquerda, indicando canais e poros do sistema látero-sensorial cefálico. $\mathbf{S 7}$ e $\mathbf{S 8}$ indicam poros do canal supraorbital; i8-i10 indicam poros do canal infraorbital; PR1+PO1 indica anastomose entre o primeiro poro pós-ótico com o primeiro poro do canal pré-opercular; PO2-PO4 indicam poros do canal pós-ótico; ST1 e ST2 indicam poros do canal supratemporal. 


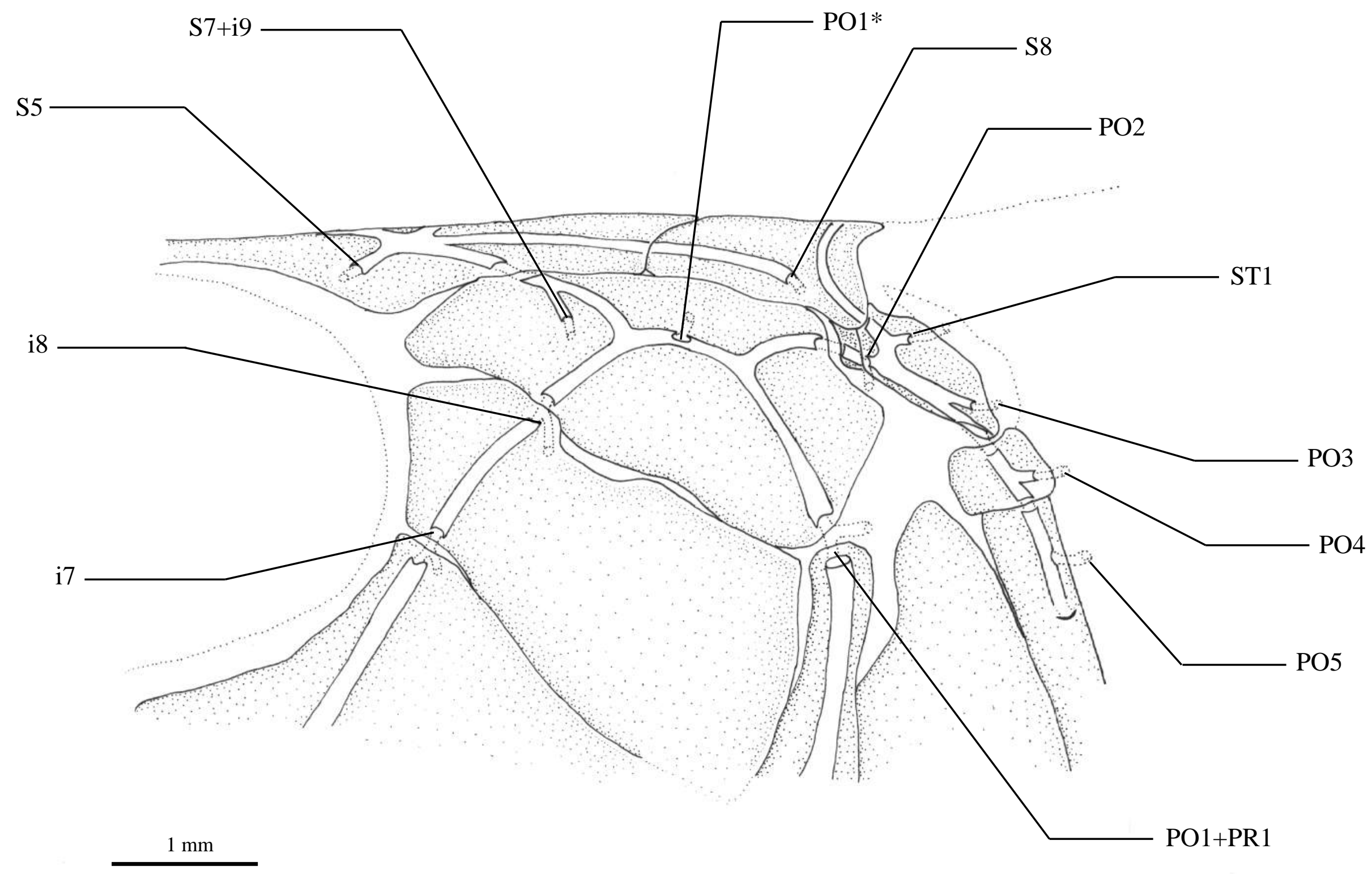

Figura 16. Região temporal do crânio de um exemplar de Eugnatichthys sp. (USNM 326206) ilustrado em vista lateral esquerda, indicando canais e poros do sistema látero-sensorial cefálico. S5-S8 indicam poros do canal supraorbital; i7-i9 indicam poros do canal infraorbital; PR1+PO1 indica anastomose entre o primeiro poro pós-ótico com o primeiro poro do canal pré-opercular; PO2-PO5 indicam poros do canal pós-ótico; ST1 indica primeiro poro supratemporal. Asteriscos representam poros supranumerários. 


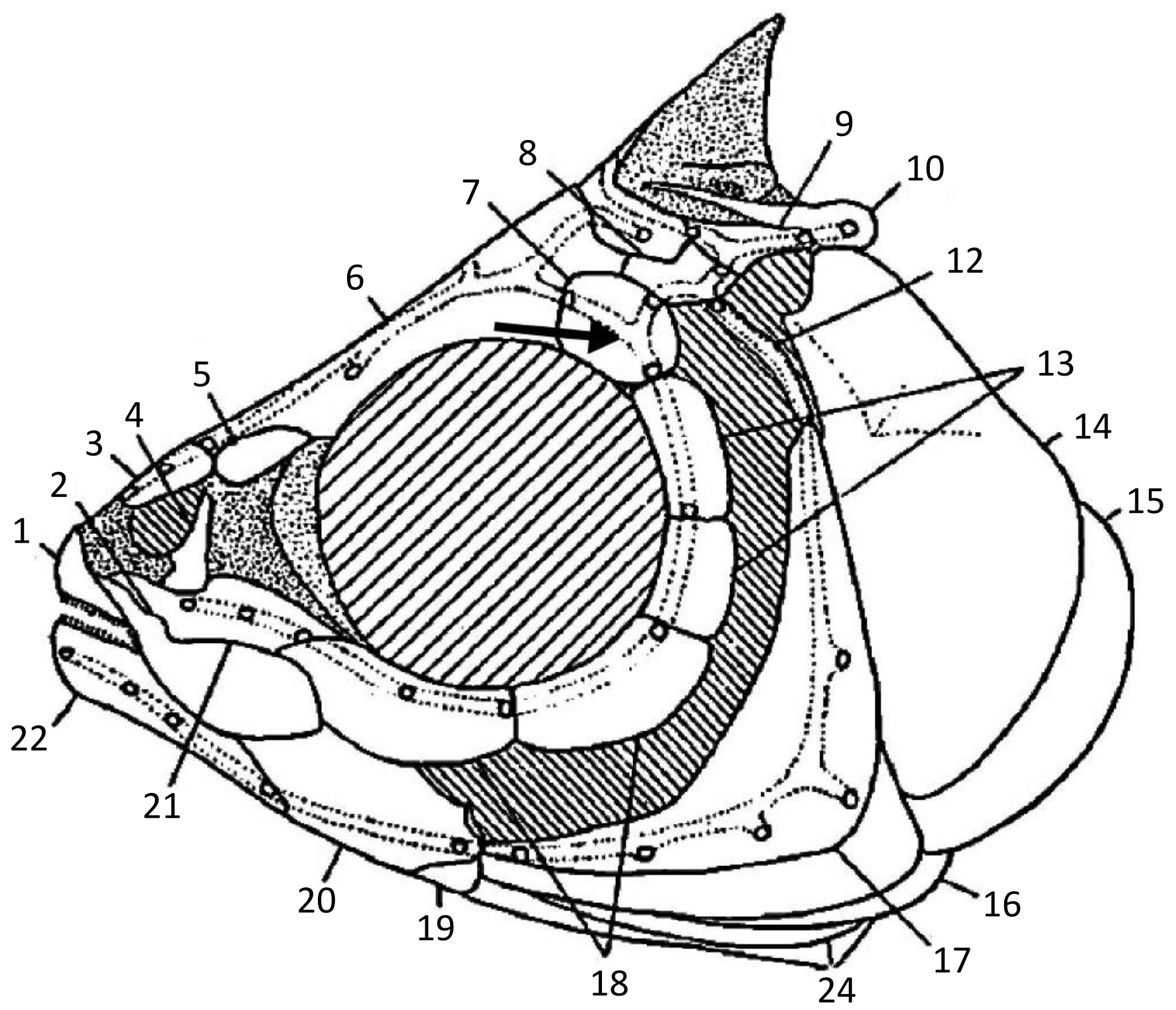

Figura 17. Crânio de Xenocharax spilurus em vista lateral esquerda. Linha pontilhada representa o sistema látero-sensorial cefálico, circulos brancos indicam poros associados a esse sistema, e números apontam ossos superficiais do crânio. Detalhe para a seta sobre o osso de número 7, indicando o início do canal ótico, que nos Distichodontidae parte de uma ramificação lateral sobre o dermoesfenótico. Imagem adaptada de Daget (1960). 


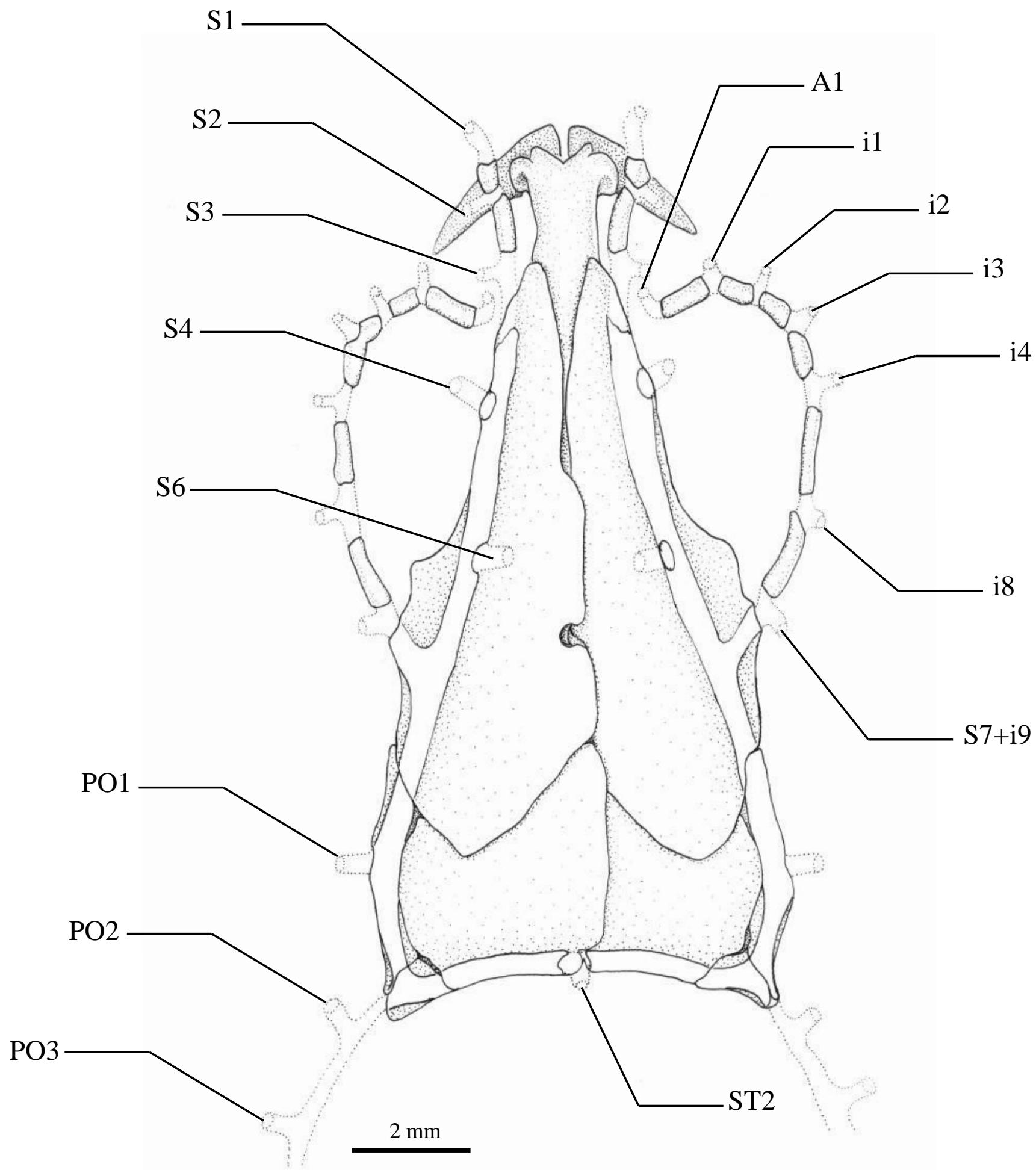

Figura 18. Vista dorsal do crânio de um exemplar de Gymnotus cf. carapo (LIRP 10129), indicando canais e poros do sistema látero-sensorial cefálico. S1-S7 indicam poros do canal supraorbital; A1 indica poro do trecho antorbital do canal infraorbital; i1-i9 indicam poros do canal infraorbital; P01-PO3 indicam poros do canal pós-ótico; ST2 indica poro do canal supratemporal. Poros do canal pré-opercular e mandibular não observados em vista dorsal. 


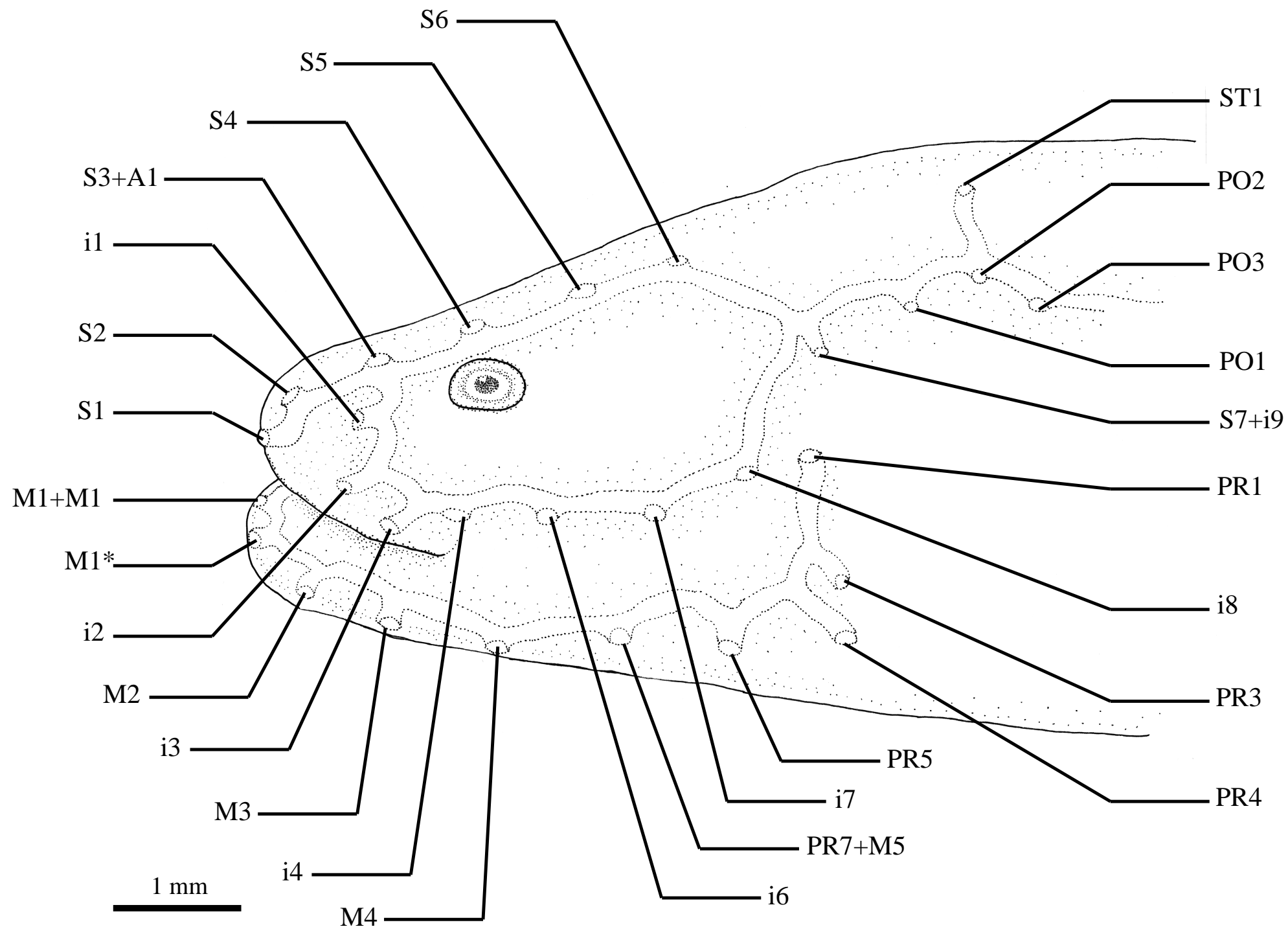

Figura 19. Vista lateral esquerda da cabeça de um exemplar de Electrophorus sp. (MPEG 25442), indicando canais e poros do sistema látero-sensorial cefálico. S1-S8 indicam poros do canal supraorbital; A1 indica poro associado à porção antorbital do canal infraorbital; i1-i9 indicam poros do canal infraorbital; PR1-PR7 indicam poros do canal pré-opercular; M1-M5 indicam poros do canal mandibular; PO1-PO5 indicam poros do canal pós-ótico; ST1 indica primeiro poro do canal supratemporal. Asteriscos, quando presentes, indicam poro supranumerário. 


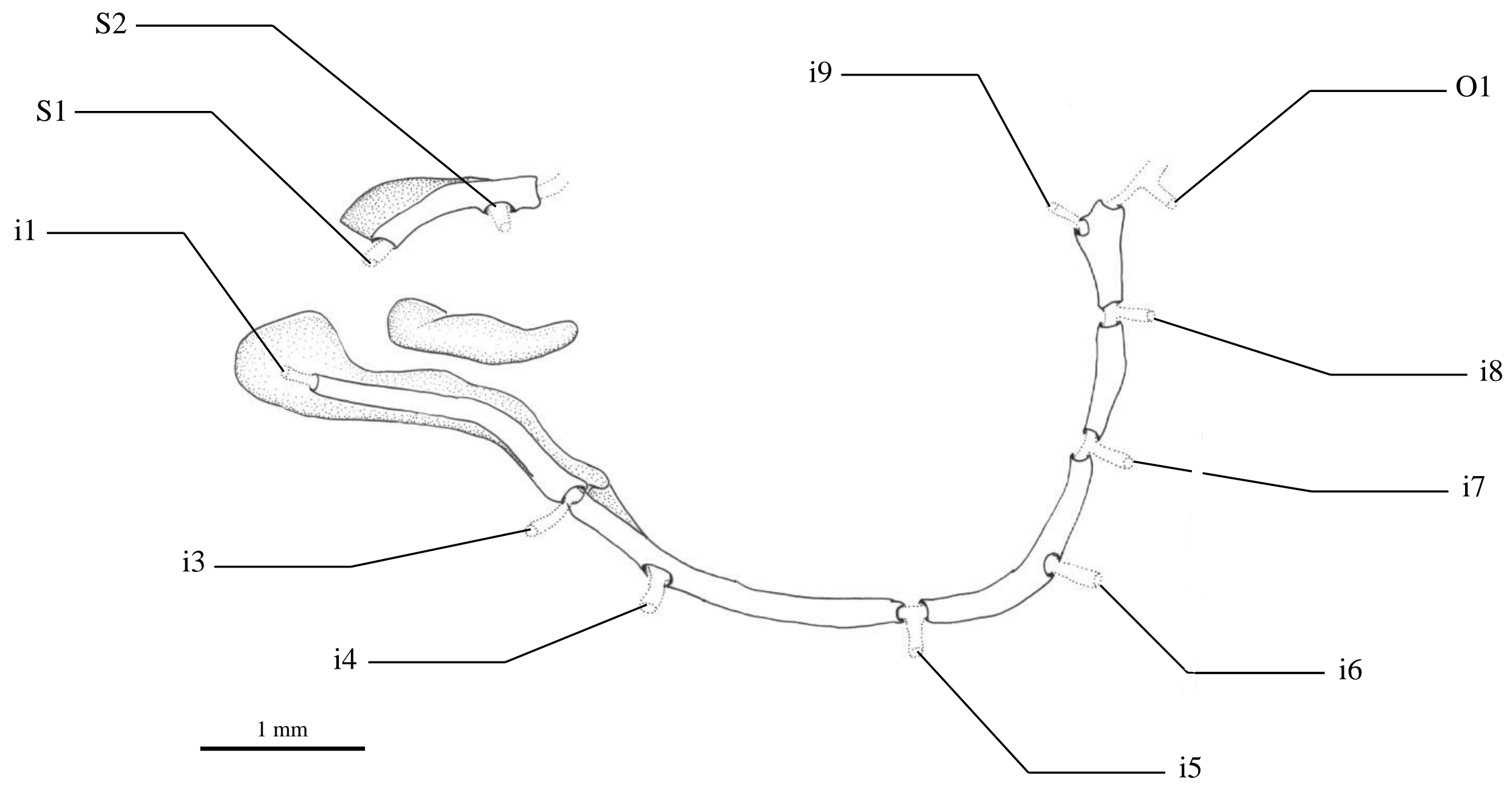

Figura 20. Poros do canal infraorbital e ossos dérmicos associados de um exemplar de Kneria sp. (USNM 290762) em vista lateral esquerda. i1-i9 indicam poros ao longo do canal infraorbital, $\mathbf{0 1}$ indica poro ao longo do canal ótico. 


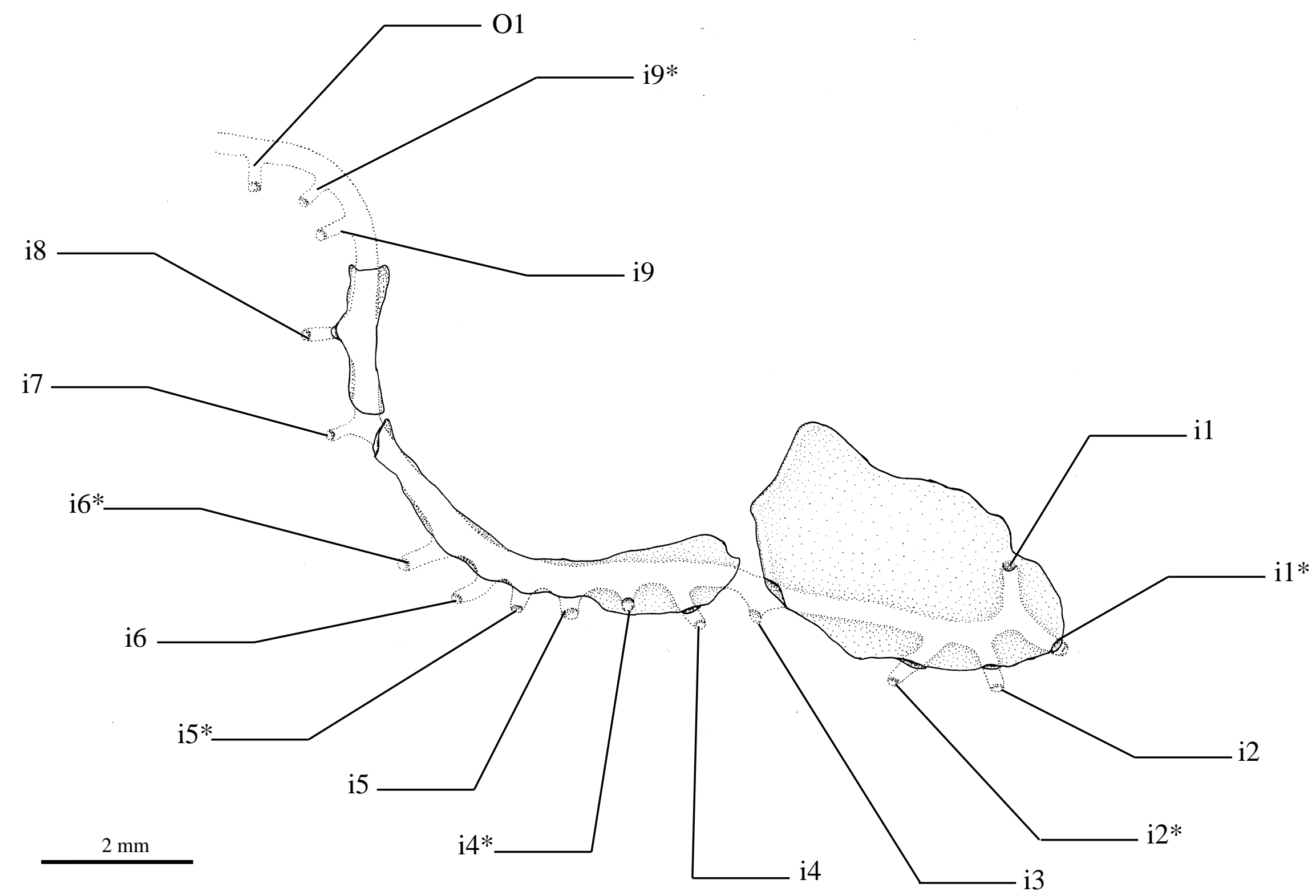

Figura 21. Vista lateral direita dos poros do canal infraorbital e ossos dérmicos associados de um exemplar de Campostoma anomalum (USNM 200731). i1-i9 indicam poros ao longo do canal infraorbital, $\mathbf{O 1}$ indica poro ao longo do canal ótico, asteriscos indicam poros supranumerários em relação ao canal infraorbital dos Characiformes. 


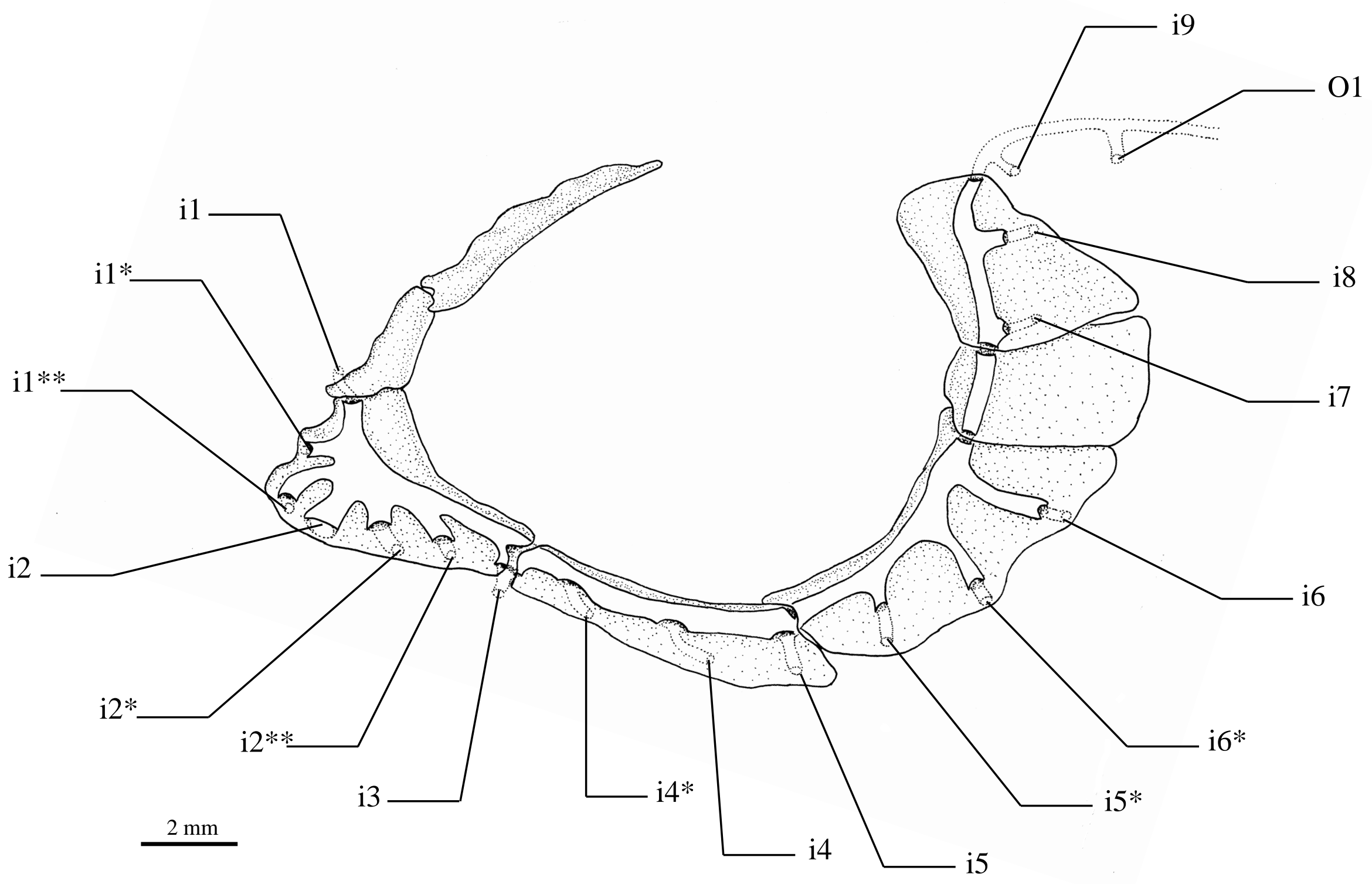

Figura 22. Poros do canal infraorbital e ossos dérmicos associados de um exemplar de Salmo trutta (USNM 373790 ) em vista lateral esquerda. i1-i9 indicam poros ao longo do canal infraorbital; $\mathbf{O 1}$ indica poro ao longo do canal ótico, asteriscos indicam poros supranumerários em relação ao canal infraorbital dos Characiformes. 


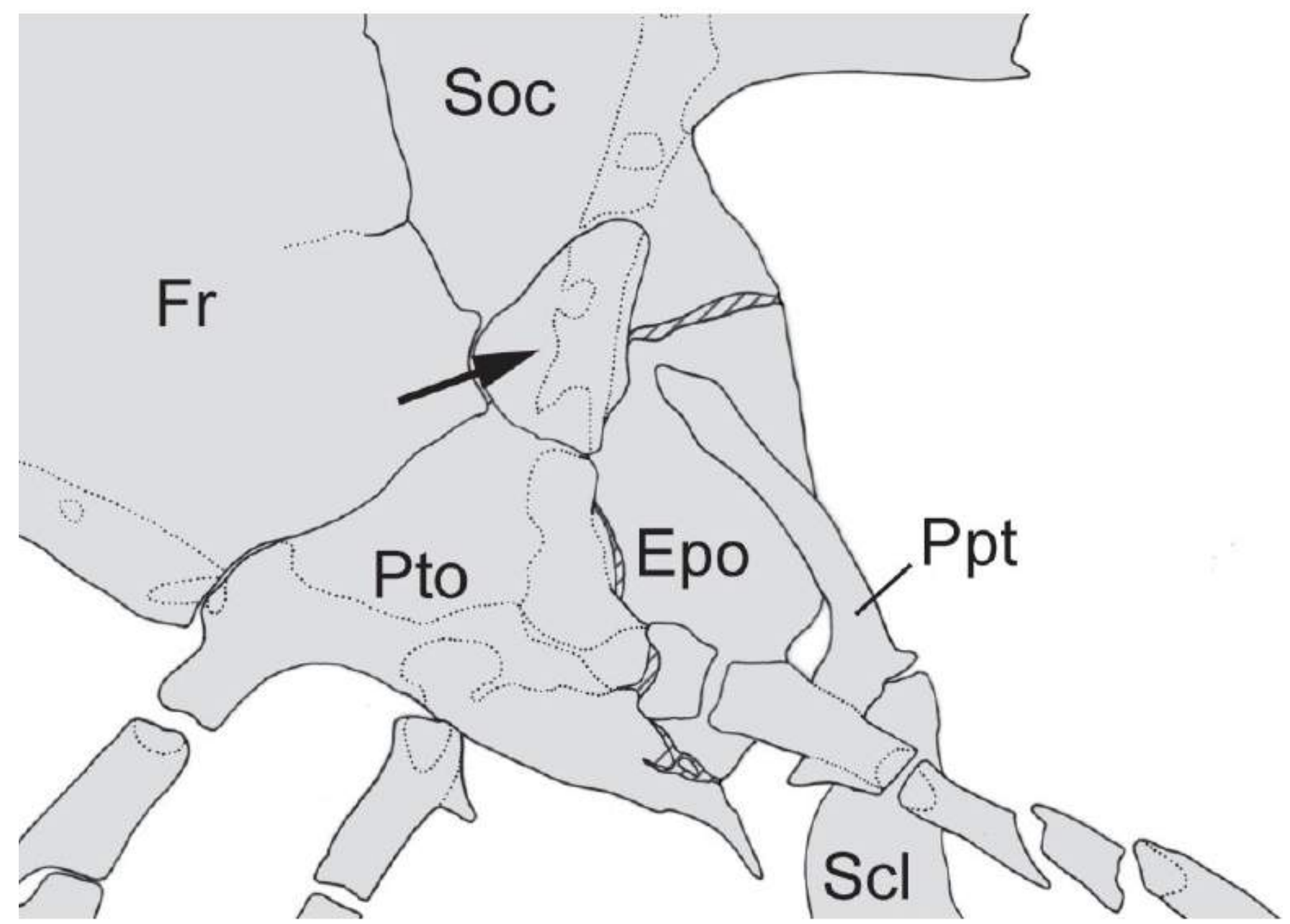

$1 \mathrm{~mm}$

Figura 23. Região temporal do crânio de um exemplar de Kneria auriculata (BMNH 1976.10.20.142-160) ilustrado em vista lateral esquerda. Fr indica osso frontal; Pto indica o osso pterótico; Epo indica o osso epioccipital; Soc indica o osso supraoccipital; Ppt indica o osso pós-temporal; Scl indica o osso supracleitro. Detalhe para a seta indicando um elemento ósseo dérmico associado à porção lateral do canal supratemporal, aqui identificado como porção medial extraescapular associada ao neuromasto formador do poro ST1. Imagem adaptada de Britz \& Moritz (2007). 


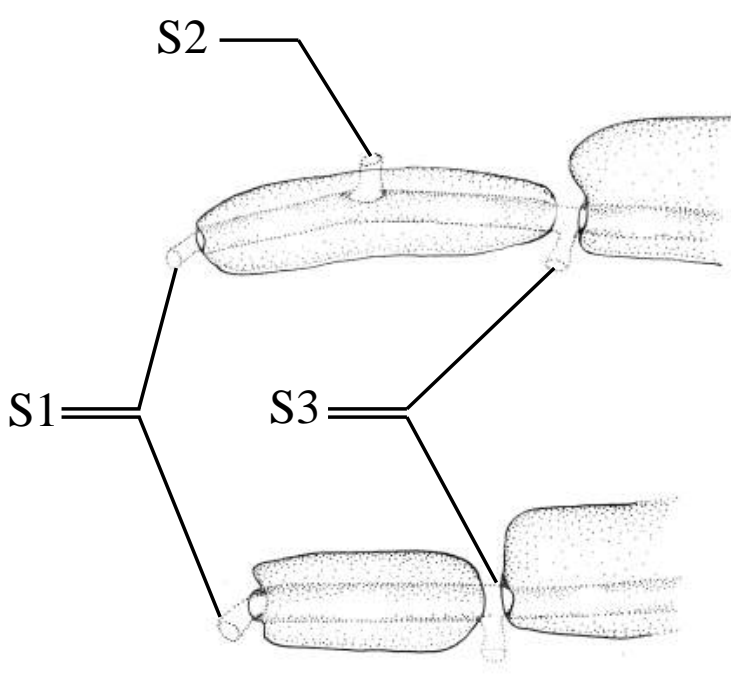

A

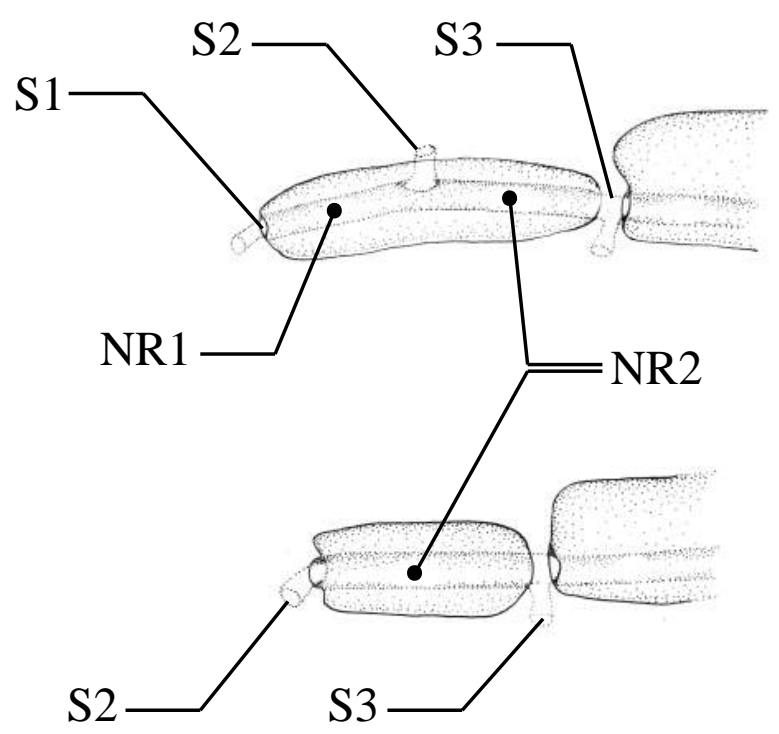

B

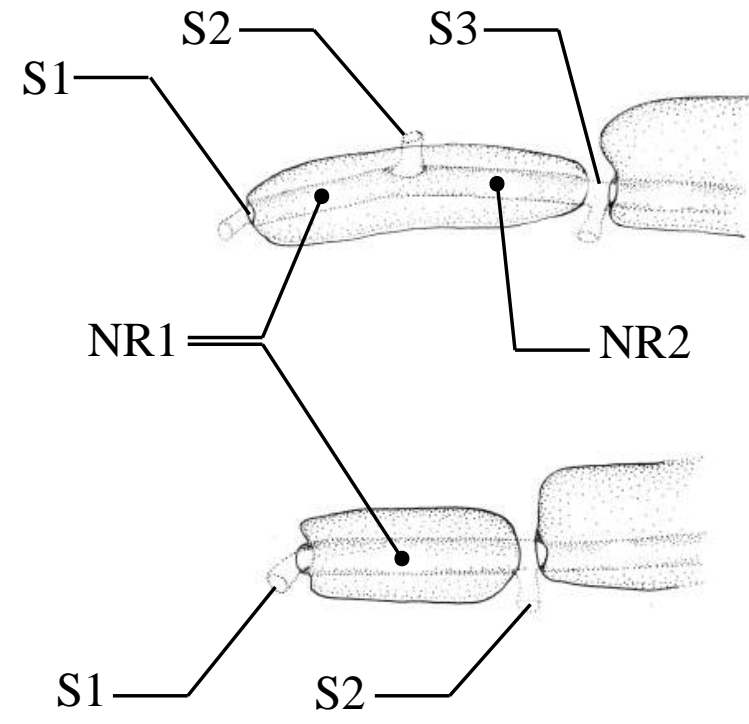

C

Figura 24. Diagramas representando variações morfológicas apresentadas por Characiformes ao longo do trecho nasal do canal supraorbital. O padrão com três poros látero-sensoriais, apresentados nas ilustrações de cima, foi considerado primitivo em Characiformes, apresentando um poro anterior (S1), um poro ao longo (S2), e outro poro posterior (S3) ao osso nasal, este último localizado entre o nasal e o osso frontal. Redução para uma condição com apenas dois poros sensoriais, (ilustrações de baixo), foi considerada derivada para a ordem Characiformes, apresentando três possíveis identificações dos poros tubulares explicando esta condição. A hipótese apresentada em A considera a perda do poro intermediário ao osso nasal (S2), preservando os poros anterior (S1) e posterior (S3) a este osso. Esta proposta leva em conta a localização dos poros S1 e S3 no estado primitivo (superior), mantendo a identificação destes mesmos poros em uma condição derivada (inferior). Os esquemas B e C apresentam identificações alternativas dos poros tubulares ao longo do trecho nasal do canal supraorbital, considerando reduções de neuromastos de canal na identificação dos poros em um estado derivado. Em uma condição primitiva há dois neuromastos de canal (indicados como NR1 e NR2) entre três poros tubulares (S1, S2 e S3). Uma perda do neuromasto NR1, apresentada na hipótese B, acarreta na supressão da formação do primeiro poro tubular, bem como de toda a metade anterior do osso nasal, conservando apenas os poros S2 e S3 e a porção do osso nasal. Já a condição C considera a perda do segundo neuromasto do canal supraorbital (NR2), refletindo na supressão da formação metade posterior do osso nasal e na formação do terceiro poro supraorbital (S3). 


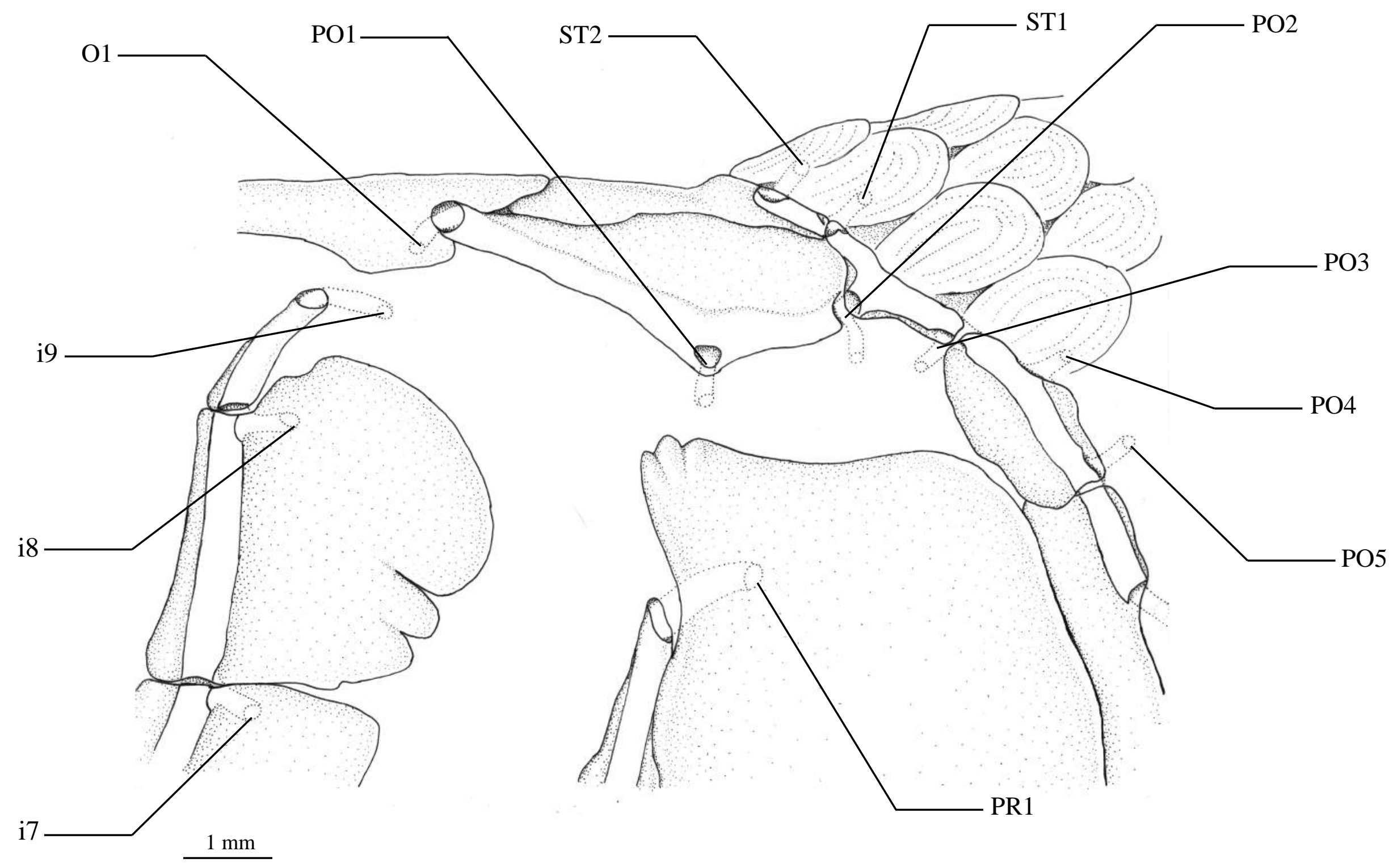

Figura 25. Região temporal do crânio de um exemplar de Opsariichthys uncirostris (USNM 86470) ilustrado em vista lateral esquerda, indicando canais e poros do sistema látero-sensorial cefálico. i7-i9 indicam poros do canal infraorbital; PR1 indica primeiro poro do canal pré-opercular; P01-PO5 indicam poros do canal pós-ótico; ST1 e ST2 indicam poros do canal supratemporal. 

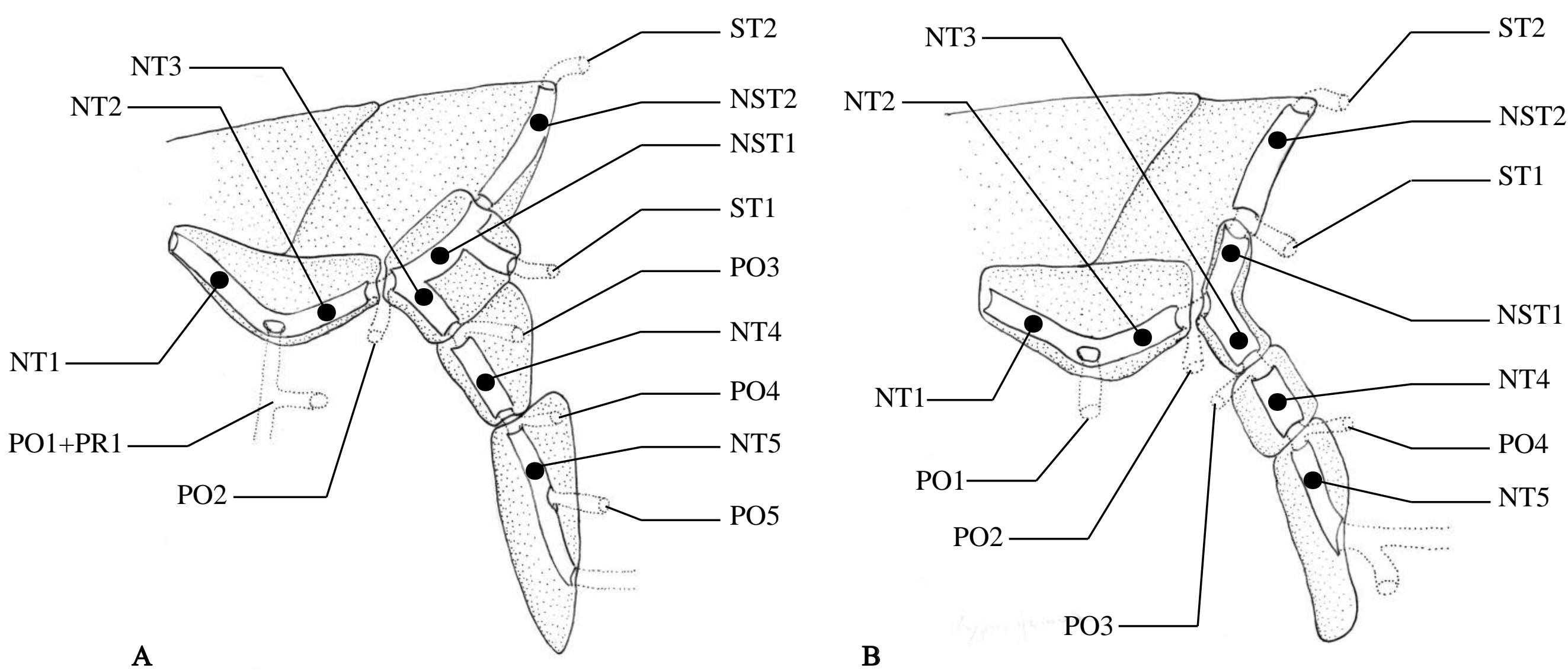

Figura 26. Diagramas representando a morfologia dos canais, poros, neuromastos e ossos dérmicos encontrados na região temporal de diferentes Ostariophysi. A indica a condição típica de um exemplar da ordem Characiformes, ilustrada em vista lateral esquerda. Neste, o pterótico possui dois neuromastos temporais (NT1 e NT2), ao longo dos canais ótico e pós-ótico, separados entre si pela confluência do canal pré-opercular com o canal ótico (PO1+PR1). Entre o pterótico e a extraescápula surge um poro tubular, aqui identificado como segundo poro do canal pós-ótico (PO2). Um terceiro neuromasto temporal (NT3) é encontrado sobre a extraescápula, osso que também porta o primeiro neuromasto do canal supratemporal (NST1). Mais adiante, outros dois neuromastos são encontrados ao longo da cintura escapular (NT4 e NT5), dispostos sobre o pós-temporal e o supracleitro, respectivamente. Ao longo do canal ótico associado à extraescápula, pós-temporal e supracleitro, outros três poros são encontrados, identificados por PO3, PO4 e PO5. Já ao longo do canal supratemporal, poros estão presentes sobre a extraescápula (ST1) e na margem medial do osso parietal (ST2), porção que também porta o segundo neuromasto supratemporal (NST2). Em B é ilustrada a condição típica de um Cypriniformes. Esta difere-se de Characiformes principalmente por apresentar o poro ST1 entre a extraescápula e o parietal, consequência do deslocamento medial do neuromasto NST1. Isto parece refletir na morfologia da extraescápula, reduzida apenas aos trechos dos canais pós-ótico e supratemporal nesses táxons. 


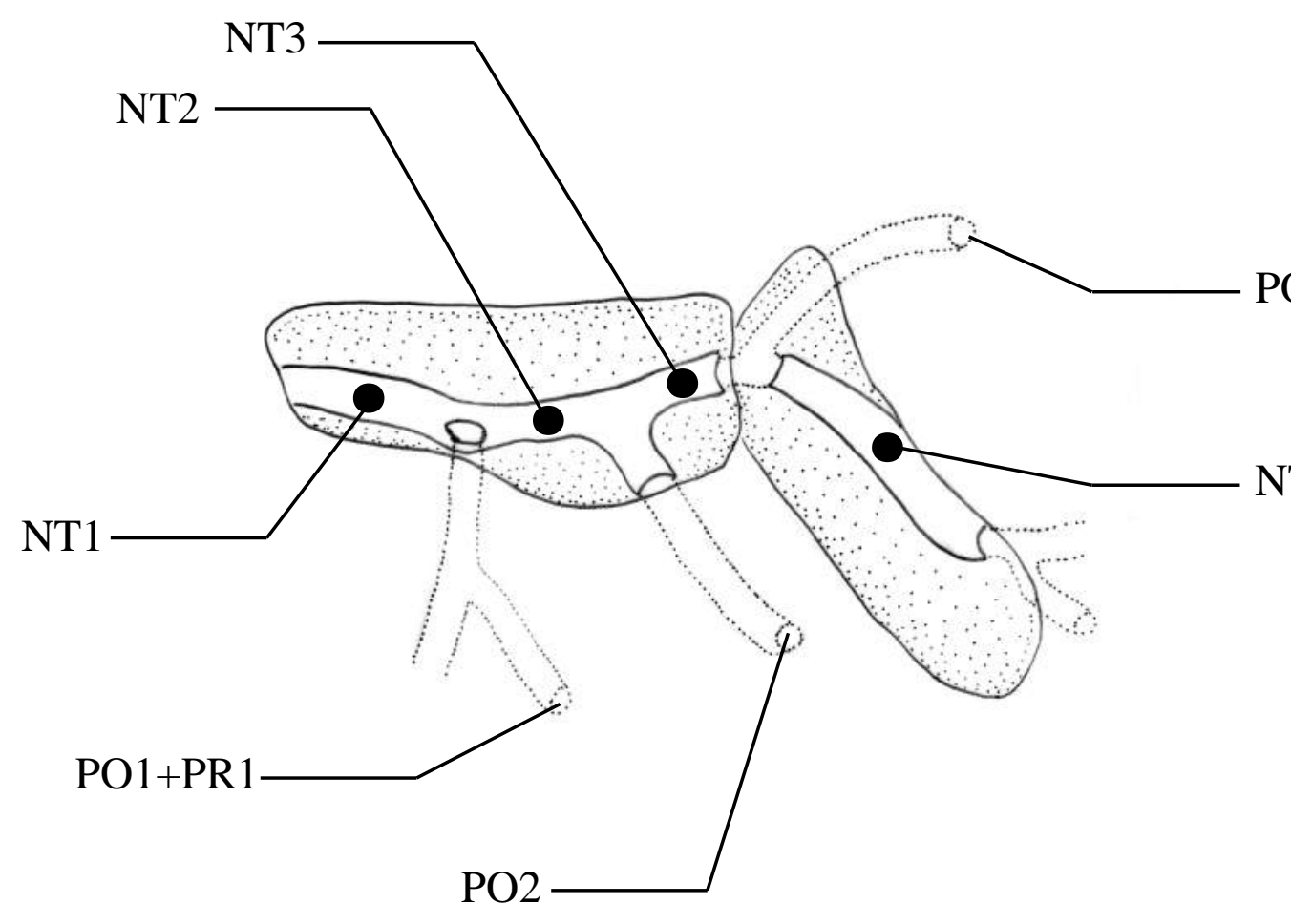

A

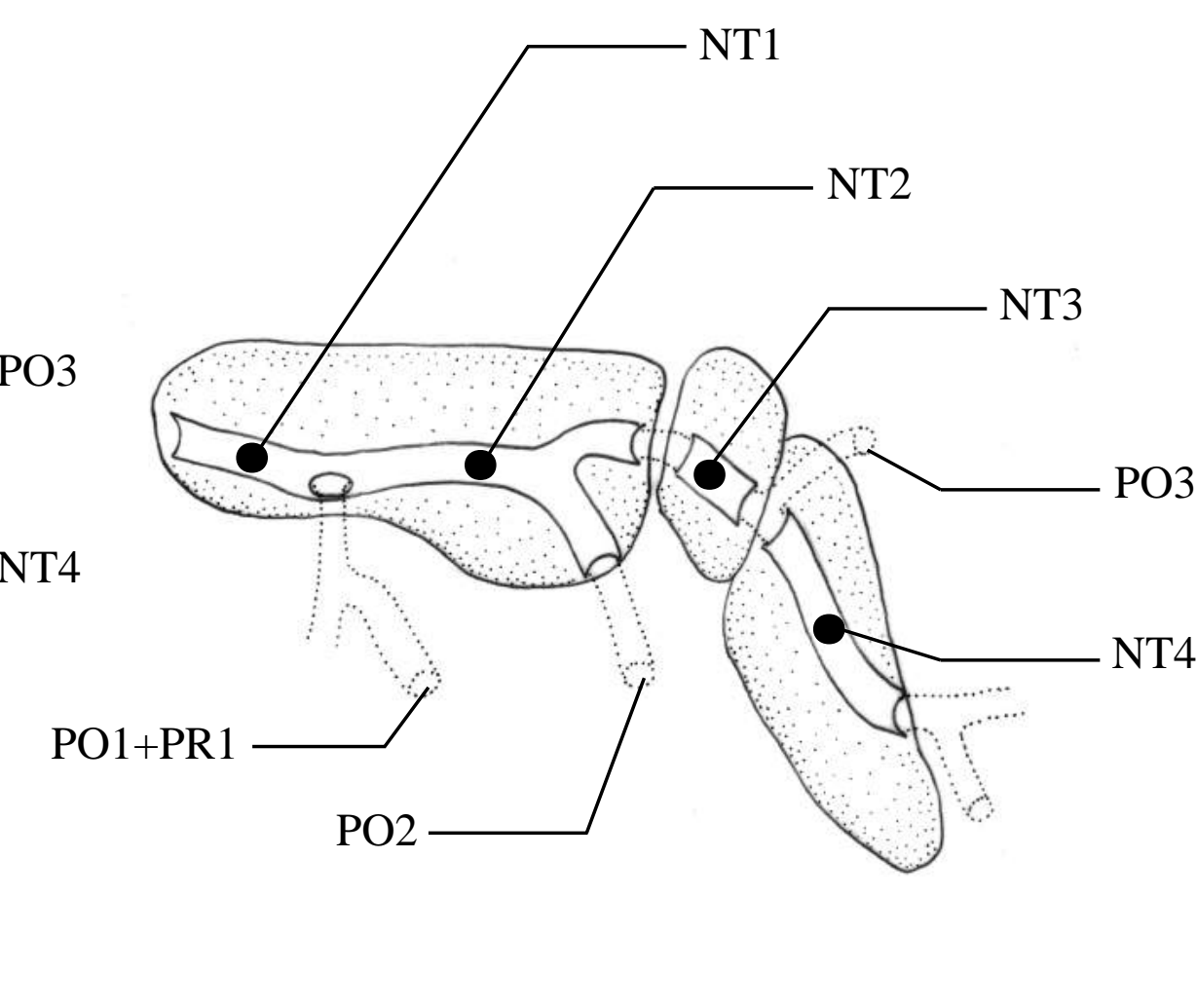

B

Figura 27. Diagramas representando a morfologia dos canais, poros, neuromastos e ossos dérmicos encontrados na região temporal de Siluriformes. A condição apresentada em A ilustra a morfologia temporal de um representante Siluriformes típico em vista lateral esquerda. Esta se difere dos Characiformes e Cypriniformes (Figura 26, A e B) principalmente por não possuir um canal supratemporal e possuir três neuromastos temporais sobre o osso pterótico (NT1, NT2 e NT3). Aparentemente esta disposição de neuromastos acarreta na presença do ramo PO2 ainda sobre o osso pterótico, além da supressão da formação de um osso extraescapular. Entretanto, nos Siluriformes apresentando extraescápula (B), o terceiro neuromasto temporal (NT3) encontra-se posterior aos limites do osso pterótico, o que parece resultar na reaquisição de uma ossificação extraescapular em Siluriformes de maneira homoplástica aos demais Teleostei. 


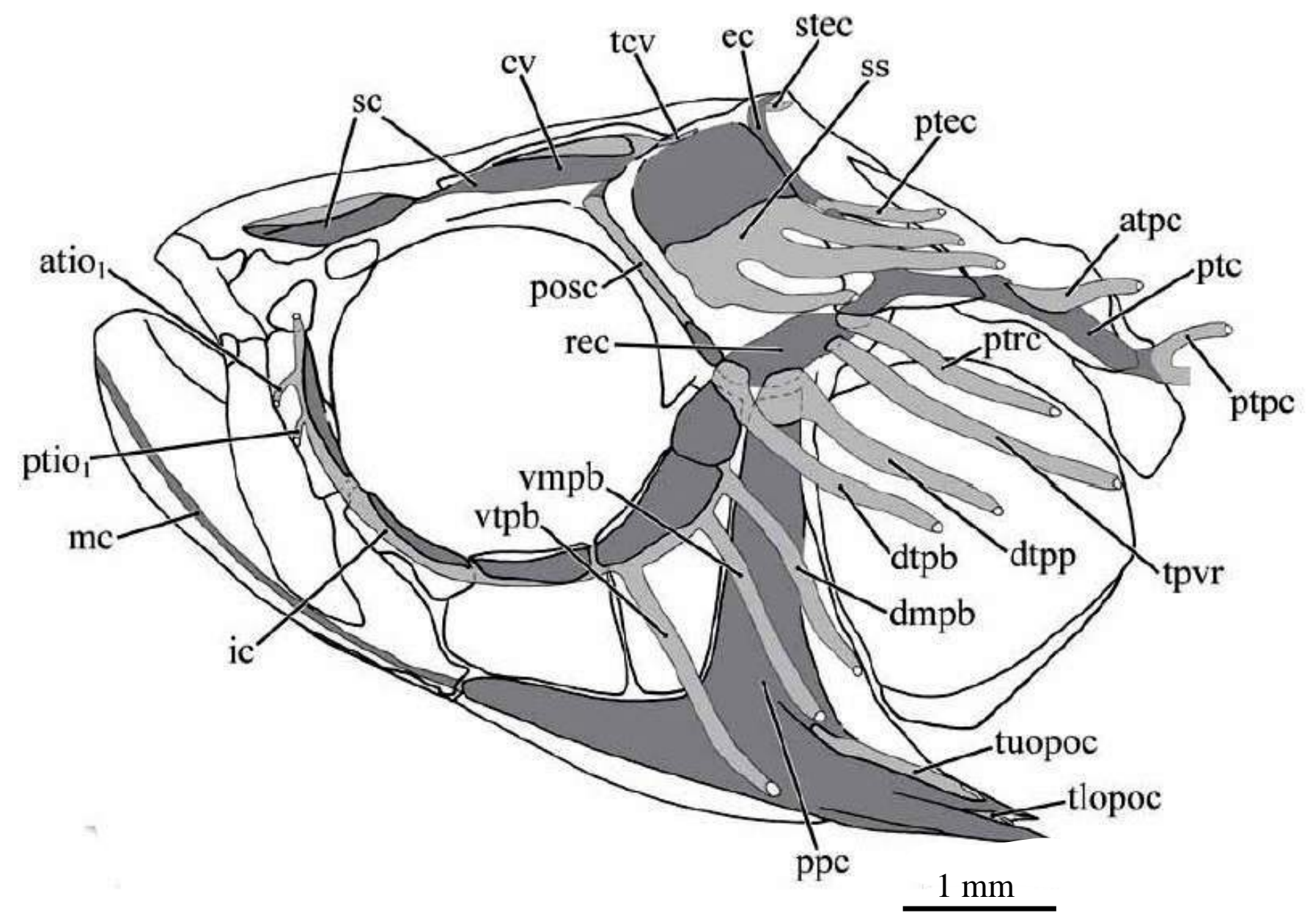

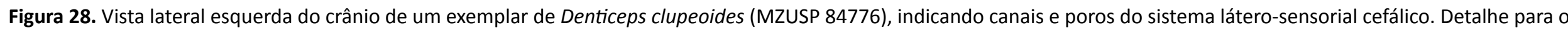

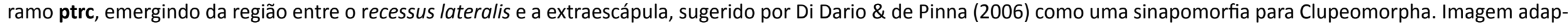
tada de Di Dario \& de Pinna (2006). 
Tabelas. 
Tabela 1. Poros compartilhados entre canais sensoriais da linha lateral cefálica de Characiformes. Números indicam a abertura individual (zero) ou o compartilhamento de uma única abertura (um) entre poros de diferentes canais. A condição expressa por "in." indica que a característica foi inaplicável para determinado táxon, que no caso de Characiformes, foi relacionada à ausência da formação de canais.

\begin{tabular}{|c|c|c|c|c|c|c|c|c|c|}
\hline Compartilhamento de poros & ntre canais sensor & & & & & & & & \\
\hline & № САT. & S3+A1 & $56+56$ & $57+19$ & P01+PR1 & PR7+M5 & M1+M1 & ST1+S8 & $\mathrm{ST2+ST2}$ \\
\hline \multicolumn{10}{|c|}{ 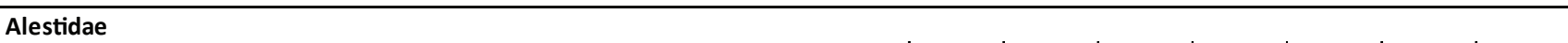 } \\
\hline Brycinus imberi & MZUSP 84537 & in. & 0 & 1 & 1 & 1 & 0 & 0 & 1 \\
\hline Alestes longipinnis & USNM 285665 & in. & 0 & 1 & 1 & 1 & 0 & 0 & 0 \\
\hline Chalceus epakros & LIRP 7538 & in. & 0 & 1 & 1 & 1 & 0 & 0 & 1 \\
\hline \multicolumn{10}{|l|}{ Anostomidae } \\
\hline Leporellus vittatus & LIRP 8857 & in. & 0 & 1 & 1 & 1 & 0 & 0 & 1 \\
\hline Sartor sp. (Anostominae) & LIRP 8176 & in. & 0 & 1 & 1 & 1 & 0 & 0 & 1 \\
\hline \multicolumn{10}{|l|}{ Acestrorhynchidae } \\
\hline Acestrorhynchus cf. microlepis & LIRP 7534 & in. & 0 & 1 & 1 & 1 & 0 & 0 & 1 \\
\hline \multicolumn{10}{|l|}{ Chilodontidae } \\
\hline Caenotropus schizodon & LIRP 8333 & in. & 0 & 0 & 1 & 1 & 0 & 0 & 1 \\
\hline \multicolumn{10}{|l|}{ Citharinidae } \\
\hline Citharinus latus & MZUSP 84480 & in. & 0 & 1 & 1 & 1 & 0 & 0 & 1 \\
\hline \multicolumn{10}{|l|}{ Curimatidae } \\
\hline Steindachnerina insculpta & LIRP 8257 & in. & 0 & 1 & 1 & 1 & 0 & 0 & 1 \\
\hline \multicolumn{10}{|l|}{ Crenuchidae } \\
\hline Crenuchus spilurus (Crenuchinae) & MZUSP 93343 & in. & 0 & 1 & 0 & 1 & 0 & 0 & 1 \\
\hline Characidium cf. xanthopterum (Characidiinae) & LIRP 4470 & in. & 0 & 1 & 0 & 1 & 0 & 0 & 1 \\
\hline Melanocharacidium cf. auroradiatum (Characidiinae) & LIRP 10257 & in. & 0 & 1 & 0 & 1 & 0 & 0 & 1 \\
\hline Characidium gomesi (Characidiinae) & LIRP 8239 & in. & 0 & 1 & 0 & 1 & 0 & 0 & 1 \\
\hline \multicolumn{10}{|l|}{ Ctenoluciidae } \\
\hline Boulengerella cuvieri & LIRP 10888 & in. & 0 & 0 & 0 & 1 & 0 & 0 & 0 \\
\hline \multicolumn{10}{|l|}{ Cynodontidae } \\
\hline Hydrolycus tatauaia & LIRP 10527 & in. & 0 & 1 & 1 & 1 & 0 & 0 & 1 \\
\hline \multicolumn{10}{|l|}{ Characidae } \\
\hline Galeocharax knerii (Characinae) & LIRP 11165 & in. & 1 & 1 & 1 & 1 & 0 & 0 & 1 \\
\hline Brycon nattereri (Bryconinae) & LIRP 3590 & in. & 0 & 1 & 1 & 1 & 0 & 0 & 1 \\
\hline Triportheus angulatus (Triportheinae) & LIRP 4560 & in. & 0 & 1 & 1 & 1 & 0 & 0 & 1 \\
\hline Creagrutus meridionalis (Incertae sedis) & LIRP 5467 & in. & 0 & 1 & 1 & 1 & 0 & 0 & 1 \\
\hline Astyanax altiparanae (Incertae sedis) & LIRP 11163 & in. & 0 & 1 & 1 & 1 & 0 & 0 & 1 \\
\hline Iguanodectes variatus (Incertae sedis) & LIRP 10745 & in. & 0 & 1 & 1 & 1 & 0 & 0 & 0 \\
\hline Stygichthys thyphops (Incertae sedis) & $\mathrm{ESCl} 000230$ / 002 & in. & in. & in. & in. & in. & in. & in. & in. \\
\hline \multicolumn{10}{|c|}{ Distichodontidae } \\
\hline Neolebias unifasciatus & MZUSP 84531 & in. & 0 & 0 & 0 & 1 & 0 & 0 & 0 \\
\hline Eugnatichthys sp. & USNM 326206 & in. & 0 & 1 & 1 & 1 & 0 & 0 & 1 \\
\hline Xenocharax spilurus & USNM 227693 & in. & 0 & 1 & 1 & 1 & 0 & 0 & 1 \\
\hline \multicolumn{10}{|l|}{ Erythrinidae } \\
\hline Hoplias aimara & LIRP 9108 & 0 & 1 & 0 & 0 & 1 & 0 & 0 & 1 \\
\hline \multicolumn{10}{|l|}{ Gasteropelecidae } \\
\hline Thoracocharax stellatus & MZUSP 105502 & in. & in. & in. & 0 & 1 & 0 & 0 & in. \\
\hline \multicolumn{10}{|l|}{ Hemiodontidae } \\
\hline Hemiodus argenteus & LIRP 8305 & in. & 0 & 1 & 1 & 1 & 0 & 0 & 1 \\
\hline \multicolumn{10}{|l|}{ Hepsetidae } \\
\hline Hepsetus odoe & MZUSP 84469 & in. & 0 & 0 & 1 & 1 & 0 & 0 & 1 \\
\hline Lebiasinidae & & & & & & & & & \\
\hline Pyrrhulina cf. australis & LIRP 8590 & in. & in. & 0 & in. & in. & in. & in. & in. \\
\hline Lebiasina melanoguttata & MZUSP 99610 & in. & 0 & 0 & 0 & 1 & 0 & 0 & 1 \\
\hline Parodontidae & & & & & & & & & \\
\hline Apaeirodon affinis & LIRP 8232 & in. & 0 & 1 & 1 & 1 & 0 & 0 & 1 \\
\hline Prochilodontidae & & & & & & & & & \\
\hline Prochilodus brevis & LIRP 3781 & in. & 0 & 1 & 1 & 1 & 0 & 0 & 1 \\
\hline Serrasalmidae & & & & & & & & & \\
\hline Serrasalmus spilopleura & LIRP 1941 & in. & 1 & 1 & 1 & 1 & 0 & 0 & 0 \\
\hline Utiaritichthys esguiceroi & LIRP 9045 & in. & 1 & 1 & 1 & 1 & 0 & 0 & 0 \\
\hline Erythrinoidea fam. nov. & & & & & & & & & \\
\hline Erythrinoidea sp. nov. & INPA 26241 & in. & in. & in. & in. & in. & in. & in. & in. \\
\hline
\end{tabular}


Tabela 2. Poros compartilhados entre canais sensoriais da linha lateral cefálica dos grupos externos à ordem Characiformes. Números indicam a abertura individual (zero) ou o compartilhamento de uma única abertura (um) entre poros de diferentes canais. A condição expressa por "in." indica que a característica foi inaplicável para determinado táxon, esta relacionada à ausência da formação de canais ou modificações estruturais dos mesmos.

\begin{tabular}{|c|c|c|c|c|c|c|c|c|c|}
\hline \multicolumn{10}{|c|}{ Compartilhamento de poros entre canais sensoriais } \\
\hline Grupos-externo & № САT. & S3+A1 & $56+56$ & $S 7+19$ & $\mathrm{PO1+PF}$ & $\mathrm{R} 7+\mathrm{M}$ & $\mathrm{M} 1+\mathrm{M} 1$ & $\mathrm{ST} 1+\mathrm{S} 8$ & $\mathrm{ST} 2+\mathrm{ST} 2$ \\
\hline \multicolumn{10}{|l|}{ Gymnotidae } \\
\hline Gymnotus cf. carapo & LIRP 10129 & 0 & 0 & 1 & 0 & 1 & 1 & 0 & 1 \\
\hline Electrophorus sp. & MPEG 25442 & 1 & 0 & 1 & 0 & 1 & 1 & 0 & 0 \\
\hline $\begin{array}{l}\text { Brachyhypopomus pinnicaudatus } \\
\text { Sternopygidae }\end{array}$ & LIRP 6055 & 0 & 0 & 1 & 0 & 1 & 1 & 0 & 0 \\
\hline Sternopygus macrurus & LIRP 10209 & 0 & 0 & 1 & 0 & 1 & 1 & 0 & 1 \\
\hline Platyurosternarchus macrostoma & ANSP 192794 & 0 & 0 & 1 & 0 & 1 & 1 & 0 & 0 \\
\hline $\begin{array}{l}\text { Sternarchorhynchus oxyrhynchus } \\
\text { Diplomystidae }\end{array}$ & ANSP 193959 & 0 & 0 & 1 & 0 & 1 & 1 & 0 & 0 \\
\hline Diplomystes mesembrinus & LBP 449 & 0 & 1 & 1 & 1 & 1 & 0 & in. & in. \\
\hline Clarias submarginatus & ANSP 67182 & 0 & 0 & 1 & 1 & 1 & 0 & in. & in. \\
\hline Barbus khudree & USNM 238933 & in. & 0 & 1 & 1 & 1 & 0 & 0 & 1 \\
\hline Opsariichthys uncirostris & USNM 86470 & in. & 0 & 0 & 0 & 1 & 0 & 0 & 0 \\
\hline Campostoma anomalum & USNM 200731 & in. & 0 & 0 & 0 & 1 & 0 & 0 & 1 \\
\hline Chanos chanos & USNM 232325 & 0 & 0 & 1 & 1 & 1 & 0 & 1 & 1 \\
\hline Osteoglossidae & USNM 290762 & in. & 0 & 0 & 1 & 1 & 0 & 0 & 1 \\
\hline Osteoglossum bicirrhosum & USNM 198123 & 1 & in. & in. & 1 & 1 & 0 & 0 & 0 \\
\hline Salmonidae & USNM 128294 & 0 & 0 & 1 & 1 & 1 & 0 & 0 & 1 \\
\hline Galaxiidae & USNM 373790 & in. & 0 & 1 & 1 & 1 & 0 & 0 & 1 \\
\hline Galaxias vulgaris & USNM 399149 & 0 & 0 & 0 & in. & 0 & 0 & in. & in. \\
\hline Esox americanus & ANSP 176232 & in. & 0 & 1 & 0 & 0 & 0 & in. & in. \\
\hline Cyprinodontidae & ANSP 115537 & 0 & 0 & 1 & 1 & 1 & 0 & 0 & 1 \\
\hline Fundulus heteroclitus & ANSP 151931 & 0 & 0 & 1 & in. & in. & 0 & in. & in. \\
\hline
\end{tabular}


Tabela 3. Poros do canal supraorbital da linha lateral cefálica de Characiformes. S1 a S8 indicam poros ao longo do canal supraorbital. Números indicam a ausência (zero) ou presença (um) de determinado poro ao longo do canal. Asteriscos (*) indicam poros supranumerários, de modo que cada asterisco represente um poro extra relacionado a determinada posição. A condição expressa por "in." demonstra característica inaplicável para determinado táxon, que no caso de Characiformes esteve relacionada à ausência da formação de canais.

\begin{tabular}{|c|c|c|c|c|c|c|c|c|c|}
\hline \multicolumn{10}{|c|}{ Poros ao longo do canal supraorbital de Characiformes } \\
\hline & № САT. & S1 & S2 & S3 & S4 & S5 & S6 & S7 & 58 \\
\hline \multicolumn{10}{|l|}{ Alestidae } \\
\hline Brycinus imberi & MZUSP 84537 & 1 & 1 & 1 & 1 & 1 & 1 & 1 & 1 \\
\hline Alestes longipinnis & USNM 285665 & 1 & 1 & 1 & 1 & 1 & 1 & 1 & 1 \\
\hline Chalceus epakros & LIRP 7538 & 1 & 1 & 1 & 1 & 1 & 1 & 1 & 1 \\
\hline \multicolumn{10}{|l|}{ Anostomidae } \\
\hline Leporellus vittatus & LIRP 8857 & 1 & $1^{*}$ & 1 & 1 & 1 & 1 & 1 & 1 \\
\hline Sartor sp. (Anostominae) & LIRP 8176 & 1 & $1^{*}$ & 1 & 1 & 1 & 1 & 1 & 1 \\
\hline \multicolumn{10}{|l|}{ Acestrorhynchidae } \\
\hline Acestrorhynchus cf. microlepis & LIRP 7534 & 1 & 0 & 1 & 1 & 0 & 1 & 1 & 1 \\
\hline \multicolumn{10}{|l|}{ Chilodontidae } \\
\hline Caenotropus schizodon & LIRP 8333 & 1 & $1^{*}$ & 1 & 1 & 0 & 1 & 1 & 1 \\
\hline \multicolumn{10}{|l|}{ Citharinidae } \\
\hline Citharinus latus & MZUSP 84480 & 1 & $1^{*}$ & 1 & 1 & 1 & 1 & 1 & 1 \\
\hline \multicolumn{10}{|l|}{ Curimatidae } \\
\hline Steindachnerina insculpta & LIRP 8257 & 1 & 1 & 1 & 1 & 0 & 1 & 1 & 1 \\
\hline \multicolumn{10}{|l|}{ Crenuchidae } \\
\hline Crenuchus spilurus (Crenuchinae) & MZUSP 93343 & 1 & 0 & 1 & 1 & 0 & 1 & 1 & 1 \\
\hline Characidium cf. xanthopterum (Characidiinae) & LIRP 4470 & 1 & 0 & 1 & 1 & 1 & 1 & 1 & 0 \\
\hline Melanocharacidium cf. auroradiatum (Characidiinae) & LIRP 10257 & 1 & 0 & 1 & 1 & 1 & 1 & 1 & 1 \\
\hline Characidium gomesi (Characidiinae) & LIRP 8239 & 1 & 0 & 1 & 1 & 1 & 1 & 1 & 1 \\
\hline \multicolumn{10}{|l|}{ Ctenoluciidae } \\
\hline Boulengerella cuvieri & LIRP 10888 & 1 & $1 *$ & 1 & 1 & 1 & 1 & 1 & 1 \\
\hline \multicolumn{10}{|l|}{ Cynodontidae } \\
\hline Hydrolycus tatauaia & LIRP 10527 & 1 & 1 & 1 & 1 & 1 & 1 & 1 & 1 \\
\hline \multicolumn{10}{|l|}{ Characidae } \\
\hline Galeocharax knerii (Characinae) & LIRP 11165 & 1 & 0 & 1 & 1 & 1 & 1 & 1 & 1 \\
\hline Brycon nattereri (Bryconinae) & LIRP 3590 & 1 & $1^{*}$ & 1 & $1^{*}$ & 1 & $1^{*}$ & 1 & 1 \\
\hline Triportheus angulatus (Triportheinae) & LIRP 4560 & 1 & 1 & 1 & 1 & 1 & 1 & 1 & 1 \\
\hline Creagrutus meridionalis (Incertae sedis) & LIRP 5467 & 1 & 1 & 1 & 1 & 1 & 1 & 1 & 1 \\
\hline Astyanax altiparanae (Incertae sedis) & LIRP 11163 & 1 & 1 & 1 & 1 & 1 & 1 & 1 & 1 \\
\hline Iguanodectes variatus (Iguanodectinae) & LIRP 10745 & 1 & 0 & 1 & 1 & 0 & 1 & 1 & 1 \\
\hline Stygichthys typhlops (Incertae sedis) & LESCI 000230 / 002 & 1 & 0 & 1 & 1 & 0 & 1 & 1 & 0 \\
\hline \multicolumn{10}{|l|}{ Distichodontidae } \\
\hline Neolebias unifasciatus & MZUSP 84531 & 1 & 0 & 1 & 1 & 1 & 1 & 1 & 1 \\
\hline Eugnatichthys eetveldii & USNM 326206 & 1 & $1^{* *}$ & 1 & 1 & 1 & 1 & 1 & 1 \\
\hline Xenocharax spilurus & USNM 227693 & 1 & 1 & 1 & 1 & 1 & 1 & 1 & 1 \\
\hline \multicolumn{10}{|l|}{ Erythrinidae } \\
\hline Hoplias aimara & LIRP 9108 & 1 & 0 & 1 & 1 & 1 & 1 & 1 & 1 \\
\hline \multicolumn{10}{|l|}{ Gasteropelecidae } \\
\hline Thoracocharax stellatus & MZUSP 105502 & 1 & 0 & 1 & in. & in. & in. & in. & in. \\
\hline \multicolumn{10}{|l|}{ Hemiodontidae } \\
\hline Hemiodus argenteus & LIRP 8305 & 1 & 1 & 1 & 0 & 1 & 1 & 1 & 1 \\
\hline Hepsetidae & & & & & & & & & \\
\hline Hepsetus odoe & MZUSP 84469 & 1 & 1 & 1 & 1 & 1 & 1 & 1 & 1 \\
\hline Lebiasinidae & & & & & & & & & \\
\hline Pyrrhulina cf. australis & LIRP 8590 & 1 & 0 & 1 & 1 & 0 & 1 & 1 & 1 \\
\hline Lebiasina melanoguttata & MZUSP 99610 & 1 & 0 & 1 & 1 & 1 & 1 & 1 & 1 \\
\hline Parodontidae & & & & & & & & & \\
\hline Apaeirodon affinis & LIRP 8232 & 1 & 0 & 1 & 1 & 1 & 1 & 1 & 1 \\
\hline Prochilodontidae & & & & & & & & & \\
\hline Prochilodus brevis & LIRP 3781 & 1 & $1^{* *}$ & 1 & 1 & 1 & 1 & 1 & 1 \\
\hline Serrasalmidae & & & & & & & & & \\
\hline Serrasalmus spilopleura (Serrasalminae) & LIRP 1941 & 1 & 1 & 1 & 1 & 0 & 1 & 1 & 1 \\
\hline Utiaritichthys sp. nov. (Serrasalminae) & LIRP 9045 & 1 & 1 & 1 & 1 & 0 & 1 & 1 & 1 \\
\hline Erythrinoidea fam. nov. & & & & & & & & & \\
\hline Erythrinoidea sp. nov. & INPA 26241 & 1 & 0 & 1 & 1 & in. & in. & in. & in. \\
\hline
\end{tabular}


Tabela 4. Poros do canal infraorbital da linha lateral cefálica do material examinado de Characiformes. i1 a i10 indicam poros ao longo do canal infraorbital, A1 indica poro abrindo-se sobre o trecho antorbital do canal infraorbital. Números indicam a ausência (zero) ou presença (um) de determinado poro ao longo do canal. Asteriscos (*) indicam poros supranumerários, de modo que cada asterisco represente um poro extra relacionado a determinada posição. A condição expressa por "in." demonstra característica inaplicável para determinado táxon, que no caso de Characiformes esteve relacionada à ausência da formação de canais.

\begin{tabular}{|c|c|c|c|c|c|c|c|c|c|c|c|c|}
\hline \multicolumn{12}{|c|}{ Poros ao longo do canal infraorbital de Characiformes } & \\
\hline & № CAT. & A1 & i1 & $\mathrm{i2}$ & i3 & i4 & i5 & i6 & i7 & i8 & i9 & $\mathbf{i 1 0}$ \\
\hline \multicolumn{13}{|l|}{ Alestidae } \\
\hline Brycinus imberi & MZUSP 84537 & 0 & 1 & 1 & 1 & 1 & 1 & 1 & 1 & 1 & 1 & 1 \\
\hline Alestes longipinnis & USNM 285665 & 0 & 1 & 1 & 1 & 1 & 1 & 1 & 1 & 1 & 1 & 1 \\
\hline Chalceus epakros & LIRP 7538 & 0 & 1 & 1 & 1 & 1 & 1 & 1 & 1 & 1 & 1 & 1 \\
\hline \multicolumn{13}{|l|}{ Anostomidae } \\
\hline Leporellus vittatus & LIRP 8857 & 0 & 1 & 1 & 1 & $1^{*}$ & 1 & 1 & 1 & 1 & 1 & 1 \\
\hline Sartor sp. (Anostominae) & LIRP 8176 & 0 & $1 * *$ & $1^{*}$ & 1 & 1 & $1^{*}$ & 1 & 1 & 1 & 1 & 0 \\
\hline \multicolumn{13}{|l|}{ Acestrorhynchidae } \\
\hline Acestrorhynchus cf. microlepis & LIRP 7534 & 0 & 1 & 1 & 1 & 1 & 1 & 1 & 1 & 1 & 1 & 0 \\
\hline \multicolumn{13}{|l|}{ Chilodontidae } \\
\hline Caenotropus schizodon & LIRP 8333 & 0 & 1 & 1 & 1 & $1^{*}$ & 1 & 1 & 1 & 1 & 1 & 1 \\
\hline \multicolumn{13}{|l|}{ Citharinidae } \\
\hline Citharinus latus & MZUSP 84480 & 0 & 1 & 1 & 1 & 1 & $1^{* * *}$ & 1 & 1 & 1 & 1 & 1 \\
\hline \multicolumn{13}{|l|}{ Curimatidae } \\
\hline Steindachnerina insculpta & LIRP 8257 & 0 & 1 & 0 & 1 & 1 & 1 & 1 & 1 & 1 & 1 & 0 \\
\hline \multicolumn{13}{|l|}{ Crenuchidae } \\
\hline Crenuchus spilurus (Crenuchinae) & MZUSP 93343 & 0 & 1 & 1 & 1 & 1 & 1 & 0 & 0 & 1 & 1 & 0 \\
\hline Characidium cf. xanthopterum (Characidiinae) & LIRP 4470 & 0 & 1 & 1 & 1 & 1 & 1 & 1 & 1 & 1 & 1 & 0 \\
\hline Melanocharacidium cf. auroradiatum (Characidiinae) & LIRP 10257 & 0 & 1 & 1 & 1 & 1 & 1 & 1 & 1 & 1 & 1 & 0 \\
\hline Characidium gomesi (Characidiinae) & LIRP 8239 & 0 & 1 & 1 & 1 & 1 & 1 & 1 & 1 & 1 & 1 & 0 \\
\hline \multicolumn{13}{|l|}{ Ctenoluciidae } \\
\hline Boulengerella cuvieri & LIRP 10888 & 0 & 1 & $1^{*}$ & 1 & 1 & 1 & 1 & 1 & 1 & 1 & 1 \\
\hline \multicolumn{13}{|l|}{ Cynodontidae } \\
\hline Hydrolycus tatauaia & LIRP 10527 & 0 & 1 & $1^{*}$ & 1 & 1 & 1 & 1 & 1 & 1 & 1 & 1 \\
\hline \multicolumn{13}{|l|}{ Characidae } \\
\hline Galeocharax knerii (Characinae) & LIRP 11165 & 0 & 1 & 1 & 1 & 1 & $1^{*}$ & 1 & 1 & 1 & 1 & 1 \\
\hline Brycon nattereri (Bryconinae) & LIRP 3590 & 0 & 1 & $1^{*}$ & 1 & 1 & 1 & 1 & 1 & 1 & 1 & 1 \\
\hline Triportheus angulatus (Triportheinae) & LIRP 4560 & 0 & 1 & 1 & 1 & 1 & 1 & 1 & 1 & 1 & 1 & 1 \\
\hline Creagrutus meridionalis (Incertae sedis) & LIRP 5467 & 0 & 1 & in. & 1 & 1 & 1 & 1 & 1 & 1 & 1 & 0 \\
\hline Astyanax altiparanae (Incertae sedis) & LIRP 11163 & 0 & 1 & 1 & 1 & 1 & $1^{*}$ & 1 & 1 & 1 & 1 & 0 \\
\hline Iguanodectes variatus (Iguanodectinae) & LIRP 10745 & 0 & 1 & 1 & 1 & 1 & 1 & 1 & 1 & 1 & 1 & 0 \\
\hline Stygichthys thyphops (Incertae sedis) & LESCI 000230 / 002 & in. & in. & in. & in. & in. & 1 & 1 & in. & in. & in. & in. \\
\hline \multicolumn{13}{|c|}{ Distichodontidae } \\
\hline Neolebias unifasciatus & MZUSP 84531 & 0 & 1 & 0 & 1 & 1 & 1 & 1 & 1 & 1 & 1 & 0 \\
\hline Eugnatichthys eetveldii & USNM 326206 & 0 & 1 & $1^{\prime}$ & 1 & $1^{*}$ & 1 & 1 & 1 & 1 & 1 & 0 \\
\hline Xenocharax spilurus & USNM 227693 & 0 & 1 & 1 & 1 & 1 & 1 & 1 & 1 & 1 & 1 & 0 \\
\hline \multicolumn{13}{|l|}{ Erythrinidae } \\
\hline Hoplias aimara & LIRP 9108 & 1 & 1 & 1 & 1 & 1 & 1 & 0 & 1 & 1 & 1 & 0 \\
\hline \multicolumn{13}{|l|}{ Gasteropelecidae } \\
\hline Thoracocharax stellatus & MZUSP 105502 & 0 & 1 & 1 & 1 & 1 & in. & in. & in. & 1 & 1 & 0 \\
\hline Hemiodontidae & & & & & & & & & & & & \\
\hline Hemiodus argenteus & LIRP 8305 & 0 & 1 & 1 & 1 & 1 & 1 & 1 & 1 & 1 & 1 & 1 \\
\hline Hepsetidae & & & & & & & & & & & & \\
\hline Hepsetus odoe & MZUSP 84469 & 0 & 1 & 1 & 1 & 1 & 1 & 1 & 1 & 1 & 1 & 1 \\
\hline Lebiasinidae & & & & & & & & & & & & \\
\hline Pyrrhulina cf. australis & LIRP 8590 & 0 & 1 & 0 & $1^{*}$ & 0 & 1 & in. & in. & 1 & 1 & 0 \\
\hline Lebiasina melanoguttata & MZUSP 99610 & 0 & 1 & 1 & 1 & 1 & 1 & 1 & 1 & 1 & 1 & 0 \\
\hline Parodontidae & & & & & & & & & & & & \\
\hline Apaeirodon affinis & LIRP 8232 & 0 & 1 & 1 & 1 & 1 & 1 & 1 & 1 & 1 & 1 & 0 \\
\hline Prochilodontidae & & & & & & & & & & & & \\
\hline Prochilodus brevis & LIRP 3781 & 0 & 1 & $1^{*}$ & 1 & $1^{*}$ & $1 * * *$ & 1 & 1 & 1 & 1 & 1 \\
\hline Serrasalmidae & & & & & & & & & & & & \\
\hline Serrasalmus spilopleura & LIRP 1941 & 0 & 1 & 1 & 1 & 1 & 1 & 1 & 1 & 1 & 1 & 0 \\
\hline Utiaritichthys esguiceroi & LIRP 9045 & 0 & 1 & 1 & 1 & $1^{*}$ & $1^{*}$ & 1 & 1 & 1 & 1 & 1 \\
\hline Erythrinoidea fam. nov. & & & & & & & & & & & & \\
\hline Erythrinoidea sp. nov. & INPA 26241 & in. & in. & in. & in. & in. & in. & in. & in. & in. & in. & in. \\
\hline
\end{tabular}


Tabela 5. Poros do canal temporal (ótico e pós-ótico) da linha lateral cefálica do material examinado de Characiformes. P01 a PO5 indicam poros ao longo do canal pós-ótico, 01 indica poro abrindo-se ainda sobre o trecho ótico do canal temporal, LL1 indica o primeiro poro da linha lateral corporal. Números indicam a ausência (zero) ou presença (um) de determinado poro ao longo do canal. Asteriscos $(*)$ indicam poros supranumerários, de modo que cada asterisco represente um poro extra relacionado a determinada posição. A condição expressa por "in." demonstra característica inaplicável para determinado táxon, que no caso de Characiformes esteve relacionada à ausência da formação de canais.

\begin{tabular}{|c|c|c|c|c|c|c|c|c|}
\hline \multicolumn{9}{|c|}{ Poros ao longo do canal temporal de Characiformes } \\
\hline & № CAT. & 01 & P01 & $\mathrm{PO2}$ & PO3 & PO4 & P05 & LL1 \\
\hline \multicolumn{9}{|l|}{ Alestidae } \\
\hline Brycinus imberi & MZUSP 84537 & 0 & 1 & 1 & 1 & 1 & Ind. & 1 \\
\hline Alestes longipinnis & USNM 285665 & 0 & 1 & 0 & 1 & 1 & 0 & 1 \\
\hline Chalceus epakros & LIRP 7538 & 0 & 1 & 1 & 1 & 1 & 0 & 1 \\
\hline \multicolumn{9}{|l|}{ Anostomidae } \\
\hline Leporellus vittatus & LIRP 8857 & 0 & 1 & 1 & 1 & 1 & 1 & 1 \\
\hline Sartor sp. (Anostominae) & LIRP 8176 & 0 & 1 & 1 & 1 & 1 & 1 & 1 \\
\hline \multicolumn{9}{|l|}{ Acestrorhynchidae } \\
\hline Acestrorhynchus cf. microlepis & LIRP 7534 & 0 & 1 & 1 & 1 & 1 & 1 & 1 \\
\hline \multicolumn{9}{|l|}{ Chilodontidae } \\
\hline Caenotropus schizodon & LIRP 8333 & 0 & 1 & 1 & 1 & 0 & 1 & 1 \\
\hline \multicolumn{9}{|l|}{ Citharinidae } \\
\hline Citharinus latus & MZUSP 84480 & 0 & 1 & 1 & 1 & 1 & 1 & 1 \\
\hline \multicolumn{9}{|l|}{ Curimatidae } \\
\hline Steindachnerina insculpta & LIRP 8257 & 0 & 1 & 1 & 1 & 1 & 1 & 1 \\
\hline \multicolumn{9}{|l|}{ Crenuchidae } \\
\hline Crenuchus spilurus (Crenuchinae) & MZUSP 93343 & 0 & 1 & 0 & 1 & 0 & 0 & 1 \\
\hline Characidium cf. xanthopterum (Characidiinae) & LIRP 4470 & 1 & 1 & 1 & 1 & 0 & 1 & 1 \\
\hline Melanocharacidium cf. auroradiatum (Characidiinae) & LIRP 10257 & 0 & 1 & 1 & 1 & 1 & 1 & 1 \\
\hline Characidium gomesi (Characidiinae) & LIRP 8239 & 0 & 1 & 1 & 1 & 1 & 0 & 1 \\
\hline \multicolumn{9}{|l|}{ Ctenoluciidae } \\
\hline Boulengerella cuvieri & LIRP 10888 & 0 & 1 & 1 & 1 & 0 & 1 & 1 \\
\hline \multicolumn{9}{|l|}{ Cynodontidae } \\
\hline Hydrolycus tatauaia & LIRP 10527 & 0 & 1 & 1 & 1 & 1 & 1 & 1 \\
\hline \multicolumn{9}{|l|}{ Characidae } \\
\hline Galeocharax knerii(Characinae) & LIRP 11165 & 0 & 1 & 1 & 1 & 1 & 1 & 1 \\
\hline Brycon nattereri (Bryconinae) & LIRP 3590 & 0 & 1 & 1 & 1 & 1 & 1 & 1 \\
\hline Triportheus angulatus (Triportheinae) & LIRP 4560 & 0 & 1 & 1 & 1 & 1 & 1 & 1 \\
\hline Creagrutus meridionalis (Incertae sedis) & LIRP 5467 & 0 & 1 & 0 & 1 & 0 & 0 & 1 \\
\hline Astyanax altiparanae(Incertae sedis) & LIRP 11163 & 0 & 1 & 1 & 1 & 0 & 1 & 1 \\
\hline Iguanodectes variatus (Incertae sedis) & LIRP 10745 & 0 & 1 & 1 & 1 & 1 & 1 & 1 \\
\hline Stygichthys thyphops (Incertae sedis) & LESCI 000230 / 002 & in. & in. & in. & in. & in. & in. & in. \\
\hline \multicolumn{9}{|c|}{ Distichodontidae } \\
\hline Neolebias unifasciatus & MZUSP 84531 & 0 & 1 & 0 & 1 & 1 & 1 & 1 \\
\hline Eugnatichthys eetveldii & USNM 326206 & 0 & $1^{*}$ & 1 & 1 & 1 & 1 & 1 \\
\hline Xenocharax spilurus & USNM 227693 & 0 & 1 & 1 & 1 & 1 & 1 & 1 \\
\hline \multicolumn{9}{|l|}{ Erythrinidae } \\
\hline Hoplias aimara & LIRP 9108 & 0 & 1 & 1 & 1 & 0 & 1 & 1 \\
\hline \multicolumn{9}{|l|}{ Gasteropelecidae } \\
\hline Thoracocharax stellatus & MZUSP 105502 & 0 & 1 & 1 & 1 & 0 & 0 & 1 \\
\hline \multicolumn{9}{|l|}{ Hemiodontidae } \\
\hline Hemiodus argenteus & LIRP 8305 & 0 & 1 & 1 & 1 & 1 & 1 & 1 \\
\hline \multicolumn{9}{|l|}{ Hepsetidae } \\
\hline Hepsetus odoe & MZUSP 84469 & 0 & 1 & 0 & 1 & 0 & 1 & 1 \\
\hline Lebiasinidae & & & & & & & & \\
\hline Pyrrhulina cf. australis & LIRP 8590 & in. & in. & in. & in. & in. & in. & 1 \\
\hline Lebiasina melanoguttata & MZUSP 99610 & 0 & 1 & 0 & 1 & 0 & 1 & 1 \\
\hline Parodontidae & & & & & & & & \\
\hline Apaeirodon affinis & LIRP 8232 & 0 & 1 & 1 & 0 & 1 & 1 & 1 \\
\hline Prochilodontidae & & & & & & & & \\
\hline Prochilodus brevis & LIRP 3781 & 0 & $1^{*}$ & 1 & 1 & 1 & 1 & 1 \\
\hline Serrasalmidae & & & & & & & & \\
\hline Serrasalmus spilopleura & LIRP 1941 & 0 & 1 & 1 & 1 & 1 & 1 & 1 \\
\hline Utiaritichthys esguiceroi & LIRP 9045 & 0 & 1 & 1 & $1^{*}$ & 1 & 1 & 1 \\
\hline Erythrinoidea fam. nov. & & & & & & & & \\
\hline Erythrinoidea sp. nov. & INPA 26241 & in. & in. & in. & in. & in. & in. & in. \\
\hline
\end{tabular}


Tabela 6. Poros do canal supratemporal da linha lateral cefálica do material examinado de Characiformes. ST1 e ST2 indicam poros ao longo do canal supratemporal. Números indicam a ausência (zero) ou presença (um) de determinado poro ao longo do canal. Asteriscos $(*)$ indicam poros supranumerários, de modo que cada asterisco represente um poro extra relacionado a determinada posição. A condição expressa por "in." demonstra característica inaplicável para determinado táxon, que no caso de Characiformes esteve relacionada à ausência da formação de canais.

\begin{tabular}{|c|c|c|c|}
\hline \multicolumn{4}{|c|}{ Poros ao longo do canal supratemporal de Characiformes } \\
\hline & № САT. & ST1 & ST2 \\
\hline \multicolumn{4}{|l|}{ Alestidae } \\
\hline Brycinus imberi & MZUSP 84537 & 1 & 1 \\
\hline Alestes longipinnis & USNM 285665 & 1 & 1 \\
\hline Chalceus epakros & LIRP 7538 & 1 & 1 \\
\hline \multicolumn{4}{|l|}{ Anostomidae } \\
\hline Leporellus vittatus & LIRP 8857 & 1 & 1 \\
\hline Sartor sp. (Anostominae) & LIRP 8176 & 1 & 1 \\
\hline \multicolumn{4}{|l|}{ Acestrorhynchidae } \\
\hline Acestrorhynchus cf. microlepis & LIRP 7534 & 1 & 1 \\
\hline \multicolumn{4}{|l|}{ Chilodontidae } \\
\hline Caenotropus schizodon & LIRP 8333 & 1 & 1 \\
\hline \multicolumn{4}{|l|}{ Citharinidae } \\
\hline Citharinus latus & MZUSP 84480 & 1 & 1 \\
\hline \multicolumn{4}{|l|}{ Curimatidae } \\
\hline Steindachnerina insculpta & LIRP 8257 & 0 & 1 \\
\hline \multicolumn{4}{|l|}{ Crenuchidae } \\
\hline Crenuchus spilurus (Crenuchinae) & MZUSP 93343 & 0 & 1 \\
\hline Characidium cf. xanthopterum (Characidiinae) & LIRP 4470 & 0 & 1 \\
\hline Melanocharacidium cf. auroradiatum (Characidiinae) & LIRP 10257 & 0 & 1 \\
\hline Characidium gomesi (Characidiinae) & LIRP 8239 & 0 & 1 \\
\hline \multicolumn{4}{|l|}{ Ctenoluciidae } \\
\hline Boulengerella cuvieri & LIRP 10888 & 1 & 1 \\
\hline \multicolumn{4}{|l|}{ Cynodontidae } \\
\hline Hydrolycus tatauaia & LIRP 10527 & 1 & 1 \\
\hline \multicolumn{4}{|l|}{ Characidae } \\
\hline Galeocharax knerii (Characinae) & LIRP 11165 & 1 & 1 \\
\hline Brycon nattereri (Bryconinae) & LIRP 3590 & 1 & 1 \\
\hline Triportheus angulatus (Triportheinae) & LIRP 4560 & 1 & 1 \\
\hline Creagrutus meridionalis (Incertae sedis) & LIRP 5467 & 1 & 1 \\
\hline Astyanax altiparanae(Incertae sedis) & LIRP 11163 & 1 & 1 \\
\hline Iguanodectes variatus (Iguanodectinae) & LIRP 10745 & 1 & 1 \\
\hline Stygichthys thyphops (Incertae sedis) & LESCI 000230 / 002 & in. & in. \\
\hline \multicolumn{4}{|c|}{ Distichodontidae } \\
\hline Neolebias unifasciatus & MZUSP 84530 & 1 & 1 \\
\hline Eugnatichthys eetveldii & USNM 326206 & 1 & 1 \\
\hline Xenocharax spilurus & USNM 227693 & 1 & 1 \\
\hline \multicolumn{4}{|l|}{ Erythrinidae } \\
\hline Hoplias aimara & LIRP 9108 & 0 & 1 \\
\hline \multicolumn{4}{|l|}{ Gasteropelecidae } \\
\hline Thoracocharax stellatus & MZUSP 105502 & 0 & in. \\
\hline \multicolumn{4}{|l|}{ Hemiodontidae } \\
\hline Hemiodus argenteus & LIRP 8305 & 1 & 1 \\
\hline \multicolumn{4}{|l|}{ Hepsetidae } \\
\hline Hepsetus odoe & MZUSP 84469 & 0 & 1 \\
\hline \multicolumn{4}{|l|}{ Lebiasinidae } \\
\hline Pyrrhulina cf. australis & LIRP 8590 & in. & in. \\
\hline Lebiasina melanoguttata & MZUSP 99610 & 0 & 1 \\
\hline \multicolumn{4}{|l|}{ Parodontidae } \\
\hline Apaeirodon affinis & LIRP 8232 & 0 & 1 \\
\hline Prochilodontidae & & & \\
\hline Prochilodus brevis & LIRP 3781 & 1 & 1 \\
\hline Serrasalmidae & & & \\
\hline Serrasalmus spiropleura & LIRP 1941 & 1 & 1 \\
\hline Utiaritichthys esguiceroi & LIRP 9045 & 1 & 1 \\
\hline Erythrinoidea fam. nov. & & & \\
\hline Erythrinoidea sp. nov. & INPA 26241 & in. & in. \\
\hline
\end{tabular}


Tabela 7. Poros do canal pré-opercular da linha lateral cefálica do material examinado de Characiformes. PR1 a PR7 indicam poros ao longo do canal pré-opercular. Números indicam a ausência (zero) ou presença (um) de determinado poro ao longo do canal. Asteriscos $\left({ }^{*}\right)$ indicam poros supranumerários, de modo que cada asterisco represente um poro extra relacionado a determinada posição. A condição expressa por "in." demonstra característica inaplicável para determinado táxon, que no caso de Characiformes esteve relacionada à ausência da formação de canais.

\begin{tabular}{|c|c|c|c|c|c|c|c|c|}
\hline \multicolumn{9}{|c|}{ Poros ao longo do canal pré-opercular de Characiformes } \\
\hline & № САT. & PR1 & PR2 & PR3 & PR4 & PR5 & PR6 & PR7 \\
\hline \multicolumn{9}{|l|}{ Alestidae } \\
\hline Brycinus imberi & MZUSP 84537 & 1 & 0 & 1 & 1 & 1 & $1^{*}$ & 1 \\
\hline Alestes longipinnis & USNM 285665 & 1 & 1 & 1 & 1 & 1 & $1^{*}$ & 1 \\
\hline Chalceus epakros & LIRP 7538 & 1 & 0 & 1 & 1 & 1 & 1 & 1 \\
\hline \multicolumn{9}{|l|}{ Anostomidae } \\
\hline Leporellus vittatus & LIRP 8857 & 1 & 1 & 1 & 1 & 1 & 1 & $1^{*}$ \\
\hline Sartor sp. (Anostominae) & LIRP 8176 & 1 & 0 & 1 & 1 & 1 & 0 & $1^{*}$ \\
\hline \multicolumn{9}{|l|}{ Acestrorhynchidae } \\
\hline Acestrorhynchus cf. microlepis & LIRP 7534 & 1 & 1 & $1^{*}$ & 1 & 1 & 1 & 1 \\
\hline \multicolumn{9}{|l|}{ Chilodontidae } \\
\hline Caenotropus schizodon & LIRP 8333 & 1 & 0 & 1 & 1 & 1 & 1 & 1 \\
\hline \multicolumn{9}{|l|}{ Citharinidae } \\
\hline Citharinus latus & MZUSP 84480 & 1 & 1 & 1 & 1 & 1 & $1^{*}$ & 1 \\
\hline \multicolumn{9}{|l|}{ Curimatidae } \\
\hline Steindachnerina insculpta & LIRP 8257 & 1 & 0 & $1^{*}$ & 1 & 1 & 1 & 1 \\
\hline \multicolumn{9}{|l|}{ Crenuchidae } \\
\hline Crenuchus spilurus (Crenuchinae) & MZUSP 93343 & 1 & 0 & 1 & 1 & 1 & 0 & 1 \\
\hline Characidium cf. xanthopterum (Characidiinae) & LIRP 4470 & 1 & 1 & 0 & 1 & 1 & 1 & 1 \\
\hline Melanocharacidium cf. auroradiatum (Characidiinae) & LIRP 10257 & 1 & 1 & 1 & 1 & 1 & 1 & 1 \\
\hline Characidium gomesi (Characidiinae) & LIRP 8239 & 1 & 1 & 1 & 1 & 1 & 1 & 1 \\
\hline \multicolumn{9}{|l|}{ Ctenoluciidae } \\
\hline Boulengerella cuvieri & LIRP 10888 & 1 & 1 & 1 & 1 & 1 & $1^{*}$ & 1 \\
\hline \multicolumn{9}{|l|}{ Cynodontidae } \\
\hline Hydrolycus tatauaia & LIRP 10527 & 1 & 1 & 1 & 1 & 1 & 1 & 1 \\
\hline \multicolumn{9}{|l|}{ Characidae } \\
\hline Galeocharax knerii (Characinae) & LIRP 11165 & 1 & $1^{*}$ & $1^{*}$ & $1^{*}$ & 1 & 1 & 1 \\
\hline Brycon nattereri (Bryconinae) & LIRP 3590 & 1 & 1 & 1 & 1 & 1 & $1^{*}$ & 1 \\
\hline Triportheus angulatus (Triportheinae) & LIRP 4560 & 1 & 1 & 1 & 1 & 1 & $1^{*}$ & $1^{*}$ \\
\hline Creagrutus meridionalis (Incertae sedis) & LIRP 5467 & 1 & 1 & 1 & 1 & 1 & 1 & 1 \\
\hline Astyanax altiparanae (Incertae sedis) & LIRP 11163 & 1 & 1 & 1 & 1 & 1 & 1 & 1 \\
\hline Iguanodectes variatus (Incertae sedis) & LIRP 10745 & 1 & 0 & 1 & 1 & 1 & 1 & 1 \\
\hline Stygichthys thyphops (Incertae sedis) & LESCI 000230 / 002 & 0 & 0 & 1 & 1 & 1 & 1 & 0 \\
\hline \multicolumn{9}{|c|}{ Distichodontidae } \\
\hline Neolebias unifasciatus & MZUSP 84531 & 1 & 0 & 1 & 1 & 1 & 0 & 1 \\
\hline Eugnatichthys sp. & USNM 326206 & 1 & 1 & 1 & 1 & 1 & 1 & 1 \\
\hline Xenocharax spilurus & USNM 227693 & $1^{*}$ & $1^{*}$ & $1^{*}$ & $1^{*}$ & 1 & 1 & 1 \\
\hline \multicolumn{9}{|l|}{ Erythrinidae } \\
\hline Hoplias aimara & LIRP 9108 & $1^{*}$ & $1^{*}$ & $1^{*}$ & $1^{*}$ & $1^{*}$ & 0 & $1^{*}$ \\
\hline \multicolumn{9}{|l|}{ Gasteropelecidae } \\
\hline Thoracocharax stellatus & MZUSP 105502 & 1 & 1 & $1^{*}$ & $1^{*}$ & $1^{*}$ & 1 & 1 \\
\hline \multicolumn{9}{|l|}{ Hemiodontidae } \\
\hline Hemiodus argenteus & LIRP 8305 & 1 & 1 & 1 & 1 & 1 & 1 & 1 \\
\hline \multicolumn{9}{|l|}{ Hepsetidae } \\
\hline Hepsetus odoe & MZUSP 84469 & 1 & 1 & 1 & 1 & 1 & 1 & 1 \\
\hline Lebiasinidae & & & & & & & & \\
\hline Pyrrhulina cf. australis & LIRP 8590 & 1 & 0 & 1 & 1 & 1 & 0 & 1 \\
\hline Lebiasina melanoguttata & MZUSP 99610 & 1 & 1 & 1 & 1 & 1 & 1 & 1 \\
\hline Parodontidae & & & & & & & & \\
\hline Apaeirodon affinis & LIRP 8232 & 1 & 1 & 1 & 1 & 1 & 0 & 1 \\
\hline Prochilodontidae & & & & & & & & \\
\hline Prochilodus brevis & LIRP 3781 & 1 & 1 & 1 & 1 & 1 & 1 & $1^{*}$ \\
\hline Serrasalmidae & & & & & & & & \\
\hline Serrasalmus spilopleura & LIRP 1941 & 1 & 0 & 1 & 1 & 1 & 1 & 1 \\
\hline Utiaritichthys esguiceroi & LIRP 9045 & 1 & 1 & 1 & 1 & 1 & 1 & 1 \\
\hline Erythrinoidea fam. nov. & & & & & & & & \\
\hline Erythrinoidea sp. nov. & INPA 26241 & in. & in. & in. & in. & in. & in. & in. \\
\hline
\end{tabular}


Tabela 8. Poros do canal mandibular da linha lateral cefálica do material examinado de Characiformes. M1 a M5 indicam poros ao longo do canal mandibular. Números indicam a ausência (zero) ou presença (um) de determinado poro ao longo do canal. Asteriscos $\left({ }^{*}\right)$ indicam poros supranumerários, Total indica o número total de poros encontrados ao longo do canal mandibular. A condição expressa por "in." demonstra característica inaplicável para determinado táxon, que pode estar relacionada à ausência do canal ou a modificações estruturais do mesmo.

\begin{tabular}{|c|c|c|c|c|c|c|c|}
\hline \multicolumn{8}{|c|}{ Poros ao longo do canal mandibular de Characiformes } \\
\hline & № CAT. & M1 & M2 & M3 & M4 & M5 & Total \\
\hline \multicolumn{8}{|l|}{ Alestidae } \\
\hline Brycinus imberi & MZUSP 84537 & 0 & 1 & 1 & 1 & 1 & 4 \\
\hline Alestes longipinnis & USNM 285665 & 1 & 1 & 1 & 1 & 1 & 5 \\
\hline Chalceus epakros & LIRP 7538 & 1 & 1 & 1 & 1 & 1 & 5 \\
\hline \multicolumn{8}{|l|}{ Anostomidae } \\
\hline Leporellus vittatus & LIRP 8857 & 0 & 0 & 0 & 1 & 1 & 2 \\
\hline Sartor sp. (Anostominae) & LIRP 8176 & in. & in. & in. & in. & in. & 0 \\
\hline \multicolumn{8}{|l|}{ Acestrorhynchidae } \\
\hline Acestrorhynchus cf. microlepis & LIRP 7534 & 1 & 1 & 1 & 1 & 1 & 5 \\
\hline \multicolumn{8}{|l|}{ Chilodontidae } \\
\hline Caenotropus schizodon & LIRP 8333 & 1 & 1 & 1 & 1 & 1 & 5 \\
\hline \multicolumn{8}{|l|}{ Citharinidae } \\
\hline Citharinus latus & MZUSP 84480 & 1 & 1 & $1^{*}$ & $1^{*}$ & $1^{*}$ & 8 \\
\hline \multicolumn{8}{|l|}{ Curimatidae } \\
\hline Steindachnerina insculpta & LIRP 8257 & 1 & 1 & 1 & 1 & 1 & 5 \\
\hline \multicolumn{8}{|l|}{ Crenuchidae } \\
\hline Crenuchus spilurus (Crenuchinae) & MZUSP 93343 & 0 & 1 & 1 & 1 & 1 & 4 \\
\hline Characidium cf. xanthopterum (Characidiinae) & LIRP 4470 & 0 & 1 & 1 & 1 & 1 & 4 \\
\hline Melanocharacidium cf. auroradiatum (Characidiinae) & LIRP 10257 & 0 & 1 & 1 & 1 & 1 & 4 \\
\hline Characidium gomesi (Characidiinae) & LIRP 8239 & 0 & 1 & 1 & 1 & 1 & 4 \\
\hline \multicolumn{8}{|l|}{ Ctenoluciidae } \\
\hline Boulengerella cuvieri & LIRP 10888 & 1 & 1 & 1 & 1 & 1 & 14 \\
\hline \multicolumn{8}{|l|}{ Cynodontidae } \\
\hline Hydrolycus tatauaia & LIRP 10527 & 1 & 1 & 1 & 1 & 1 & 19 \\
\hline \multicolumn{8}{|l|}{ Characidae } \\
\hline Galeocharax knerii (Characinae) & LIRP 11165 & 1 & 1 & 1 & $1^{*}$ & $1^{*}$ & 15 \\
\hline Brycon nattereri (Bryconinae) & LIRP 3590 & 1 & $1^{*}$ & $1^{*}$ & 1 & 1 & 7 \\
\hline Triportheus angulatus (Triportheinae) & LIRP 4560 & 1 & 1 & $1^{*}$ & 1 & 1 & 6 \\
\hline Creagrutus meridionalis (Incertae sedis) & LIRP 5467 & 1 & 1 & 1 & 1 & 1 & 5 \\
\hline Astyanax altiparanae (Incertae sedis) & LIRP 11163 & 1 & 1 & 1 & 1 & 1 & 5 \\
\hline Iguanodectes variatus (Incertae sedis) & LIRP 10745 & 1 & 1 & 1 & 1 & 1 & 5 \\
\hline Stygichthys thyphops (Incertae sedis) & LESCI 000230 / 002 & in. & in. & in. & in. & in. & 0 \\
\hline \multicolumn{8}{|c|}{ Distichodontidae } \\
\hline Neolebias unifasciatus & MZUSP 84531 & 0 & 1 & 1 & 1 & 1 & 4 \\
\hline Eugnatichthys sp. & USNM 326206 & 1 & 1 & 1 & 1 & 1 & 5 \\
\hline Xenocharax spilurus & USNM 227693 & 1 & 1 & 1 & 1 & 1 & 5 \\
\hline \multicolumn{8}{|l|}{ Erythrinidae } \\
\hline Hoplias aimara & LIRP 9108 & 1 & 1 & 1 & 1 & 1 & 5 \\
\hline \multicolumn{8}{|l|}{ Gasteropelecidae } \\
\hline Thoracocharax stellatus & MZUSP 105502 & 1 & $1^{*}$ & $1^{*}$ & 1 & 1 & 7 \\
\hline \multicolumn{8}{|l|}{ Hemiodontidae } \\
\hline Hemiodus argenteus & LIRP 8305 & 1 & 1 & $1^{*}$ & 1 & 1 & 6 \\
\hline \multicolumn{8}{|l|}{ Hepsetidae } \\
\hline Hepsetus odoe & MZUSP 84469 & 1 & 1 & 1 & 1 & 1 & 5 \\
\hline Lebiasinidae & & & & & & & \\
\hline Pyrrhulina cf. australis & LIRP 8590 & in. & in. & in. & in. & in. & 0 \\
\hline Lebiasina melanoguttata & MZUSP 99610 & 1 & 1 & 1 & 1 & 1 & 5 \\
\hline Parodontidae & & & & & & & \\
\hline Apaeirodon affinis & LIRP 8232 & 0 & 1 & 1 & 1 & 1 & 4 \\
\hline Prochilodontidae & & & & & & & \\
\hline Prochilodus brevis & LIRP 3781 & 0 & 0 & 0 & 1 & 1 & 2 \\
\hline Serrasalmidae & & & & & & & \\
\hline Serrasalmus spilopleura & LIRP 1941 & 1 & 1 & 1 & 1 & 1 & 5 \\
\hline Utiaritichthys esguiceroi & LIRP 9045 & 1 & 1 & $1^{*}$ & 1 & 1 & 6 \\
\hline Erythrinoidea fam. nov. & & & & & & & \\
\hline Erythrinoidea sp. nov. & INPA 26241 & in. & in. & in. & in. & in. & 0 \\
\hline
\end{tabular}


Tabela 9. Poros do canal supraorbital da linha lateral cefálica dos grupos externos à ordem Characiformes. $\mathbf{S 1}$ a $\mathbf{S 8}$ indicam poros ao longo do canal supraorbital. Números indicam a ausência (zero) ou presença (um) de determinado poro ao longo do canal. Total indica a somatória de poros ao longo do canal. Asteriscos $\left({ }^{*}\right)$ indicam poros supranumerários, de modo que cada asterisco represente um poro extra relacionado a determinada posição. A condição expressa por "in." demonstra característica inaplicável para determinado táxon, que pode estar relacionada à ausência do canal ou a modificações estruturais do mesmo.

\begin{tabular}{|c|c|c|c|c|c|c|c|c|c|c|}
\hline \multicolumn{11}{|c|}{ Poros ao longo do canal supraorbital do grupo externo à Characiformes } \\
\hline & № САT. & S1 & S2 & S3 & S4 & S5 & s6 & S7 & S8 & Total \\
\hline \multicolumn{11}{|l|}{ Gymnotidae } \\
\hline Gymnotus cf. carapo & LIRP 10129 & 1 & 1 & 1 & 1 & 0 & 1 & 1 & 0 & 6 \\
\hline \multicolumn{11}{|l|}{ Electrophoridae } \\
\hline Electrophorus sp. & MPEG 25442 & 1 & 1 & 1 & 1 & 1 & 1 & 1 & 0 & 7 \\
\hline \multicolumn{11}{|l|}{ Hypopomidae } \\
\hline Brachyhypopomus pinnicaudatus & LIRP 6055 & 1 & 1 & 1 & 1 & 0 & 1 & 1 & $1 *$ & 8 \\
\hline \multicolumn{11}{|l|}{ Sternopygidae } \\
\hline Sternopygus macrurus & LIRP 10209 & 1 & 1 & 1 & 1 & 1 & 1 & 1 & 1 & 8 \\
\hline \multicolumn{11}{|l|}{ Apteronotidae } \\
\hline Platyurosternarchus macrostoma & ANSP 192794 & 1 & 1 & 1 & $1^{*}$ & 1 & 1 & 1 & 1 & 9 \\
\hline Sternarchorhynchus oxyrhynchus & ANSP 193959 & 1 & 1 & 1 & 0 & 0 & 1 & 1 & 1 & 6 \\
\hline \multicolumn{11}{|l|}{ Diplomystidae } \\
\hline Diplomystes mesembrinus & LBP 449 & 1 & 1 & 1 & 1 & 1 & 1 & 1 & 1 & 8 \\
\hline \multicolumn{11}{|l|}{ Clariidae } \\
\hline Clarias submarginatus & ANSP 67182 & 1 & 1 & 1 & 0 & 0 & 1 & 1 & 0 & 5 \\
\hline \multicolumn{11}{|l|}{ Cyprinidae } \\
\hline Barbus khudree & USNM 238933 & 1 & 1 & 1 & $1^{*}$ & $1 *$ & 1 & 1 & 1 & 10 \\
\hline Opsariichthys uncirostris & USNM 86470 & 1 & 1 & 1 & 1 & 1 & 1 & 1 & 0 & 7 \\
\hline Campostoma anomalum & USNM 200731 & 1 & 1 & 1 & $1 *$ & $1 *$ & 1 & 1 & 1 & 10 \\
\hline \multicolumn{11}{|l|}{ Chanidae } \\
\hline Chanos chanos & USNM 232325 & 1 & $1 *$ & $1^{*}$ & 1 & 1 & 1 & 1 & 1 & 10 \\
\hline \multicolumn{11}{|l|}{ Kneriidae } \\
\hline Kneria sp. & USNM 290762 & 1 & 0 & 1 & 1 & 1 & 1 & 1 & 0 & 6 \\
\hline \multicolumn{11}{|l|}{ Osteoglossidae } \\
\hline Osteoglossum bicirrhosum & USNM 198123 & 1 & 1 & 1 & 1 & 0 & 0 & 0 & 0 & 4 \\
\hline \multicolumn{11}{|l|}{ Elopidae } \\
\hline Elops saurus & USNM 128294 & $1 *$ & $1 *$ & $1 *$ & $1 *$ & $1 *$ & $1^{*}$ & $1 *$ & $1^{*}$ & 26 \\
\hline \multicolumn{11}{|l|}{ Galaxiidae } \\
\hline Galaxias vulgaris & USNM 399149 & 1 & 1 & 1 & 0 & 0 & 1 & 1 & 0 & 5 \\
\hline \multicolumn{11}{|l|}{ Salmonidae } \\
\hline Salmo trutta & USNM 373790 & 1 & 1 & $1 *$ & 1 & $1 *$ & 1 & 1 & 0 & 9 \\
\hline \multicolumn{11}{|l|}{ Esocidae } \\
\hline Esox americanus & ANSP 176232 & 1 & 0 & 1 & 1 & 0 & 1 & 1 & 1 & 6 \\
\hline \multicolumn{11}{|l|}{ Anguillidae } \\
\hline Anguilla rostrata & ANSP 115537 & 1 & 1 & 1 & in. & in. & in. & in. & in. & 3 \\
\hline \multicolumn{11}{|l|}{ Cyprinodontidae } \\
\hline Fundulus heteroclitus & ANSP 151931 & 1 & 0 & 1 & 1 & 1 & 1 & 1 & 0 & 6 \\
\hline
\end{tabular}


Tabela 10. Poros do canal infraorbital da linha lateral cefálica do material examinado como grupo externo à ordem Characiformes. i1 a i10 indicam poros ao longo do canal infraorbital, A1 indica poro abrindo-se sobre o trecho antorbital do canal infraorbital. Números indicam a ausência (zero) ou presença (um) de determinado poro ao longo do canal. Total indica a somatória de poros ao longo do canal. Asteriscos $(*)$ indicam poros supranumerários, de modo que cada asterisco represente um poro extra relacionado a determinada posição. A condição expressa por "in." demonstra característica inaplicável para determinado táxon, que pode estar relacionada à ausência do canal ou a modificações estruturais do mesmo.

\begin{tabular}{|c|c|c|c|c|c|c|c|c|c|c|c|c|c|}
\hline \multicolumn{14}{|c|}{ Poros ao longo do canal infraorbital do grupo externo à Characiformes } \\
\hline & № САT. & A1 & i1 & i2 & i3 & i4 & i5 & i6 & i7 & i8 & i9 & i10 & Total \\
\hline \multicolumn{14}{|l|}{ Gymnotidae } \\
\hline Gymnotus cf. carapo & LIRP 10129 & 1 & 1 & 1 & 1 & 1 & 0 & 0 & 0 & 1 & 1 & 0 & 7 \\
\hline \multicolumn{14}{|l|}{ Electrophoridae } \\
\hline Electrophorus sp. & MPEG 25442 & 1 & 1 & 1 & 1 & 1 & 0 & 1 & 1 & 1 & 1 & 0 & 9 \\
\hline \multicolumn{14}{|l|}{ Hypopomidae } \\
\hline Brachyhypopomus pinnicaudatus & LIRP 6055 & 1 & 1 & 1 & 1 & 1 & 0 & 1 & 1 & 1 & 1 & 0 & 9 \\
\hline \multicolumn{14}{|l|}{ Sternopygidae } \\
\hline Sternopygus macrurus & LIRP 10209 & 1 & 1 & 1 & 1 & 1 & 1 & 1 & 1 & 1 & 1 & 0 & 10 \\
\hline \multicolumn{14}{|l|}{ Apteronotidae } \\
\hline Platyurosternarchus macrostoma & ANSP 192794 & $1^{*}$ & 1 & 1 & 1 & 1 & 1 & 1 & 1 & 1 & 1 & 0 & 11 \\
\hline Sternarchorhynchus oxyrhynchus & ANSP 193959 & 1 & 1 & 1 & 1 & 1 & $1 *$ & 1 & 1 & 1 & 1 & 0 & 11 \\
\hline \multicolumn{14}{|l|}{ Diplomystidae } \\
\hline Diplomystes mesembrinus & LBP 449 & 1 & 1 & 1 & 1 & 1 & 0 & 0 & 1 & 1 & 1 & 0 & 8 \\
\hline \multicolumn{14}{|l|}{ Clariidae } \\
\hline Clarias submarginatus & ANSP 67182 & 1 & 1 & 1 & 1 & 0 & 1 & 0 & 1 & 0 & 1 & 0 & 7 \\
\hline \multicolumn{14}{|l|}{ Cyprinidae } \\
\hline Barbus khudree & USNM 238933 & 0 & 1 & 1 & 1 & 1 & $1^{*}$ & 1 & 1 & 1 & 1 & 0 & 10 \\
\hline Opsariichthys uncirostris & USNM 86470 & 0 & 1 & $1^{*}$ & 1 & 0 & $1^{*}$ & 0 & 1 & 1 & 1 & 0 & 9 \\
\hline Campostoma anomalum & USNM 200731 & 0 & $1^{*}$ & $1^{*}$ & 1 & $1^{*}$ & $1^{*}$ & $1^{*}$ & 1 & 1 & $1^{*}$ & 0 & 15 \\
\hline \multicolumn{14}{|l|}{ Chanidae } \\
\hline Chanos chanos & USNM 232325 & 0 & $1^{* *}$ & $1^{* *}$ & $1^{* *}$ & $1^{*}$ & $1^{*}$ & $1^{*}$ & 1 & 1 & 1 & 1 & 19 \\
\hline \multicolumn{14}{|l|}{ Kneriidae } \\
\hline Kneria sp. & USNM 290762 & 0 & 1 & 0 & 1 & 1 & 1 & 1 & 1 & 1 & 1 & 0 & 8 \\
\hline \multicolumn{14}{|l|}{ Osteoglossidae } \\
\hline Osteoglossum bicirrhosum & USNM 198123 & 1 & 1 & 1 & 0 & 0 & 1 & 0 & 1 & 1 & 0 & 0 & 6 \\
\hline \multicolumn{14}{|l|}{ Elopidae } \\
\hline Elops saurus & USNM 128294 & $1 *$ & $1^{*}$ & $1 *$ & $1^{*}$ & $1^{*}$ & $1^{*}$ & $1^{*}$ & $1^{*}$ & $1^{*}$ & $1^{*}$ & $1^{*}$ & 30 \\
\hline \multicolumn{14}{|l|}{ Galaxiidae } \\
\hline Galaxias vulgaris & USNM 399149 & 0 & 1 & 1 & 1 & 0 & 1 & 0 & 0 & 0 & 0 & 0 & 4 \\
\hline \multicolumn{14}{|l|}{ Salmonidae } \\
\hline Salmo trutta & USNM 373790 & 0 & $1^{* *}$ & $1 * *$ & 1 & $1^{*}$ & $1 *$ & $1 *$ & 1 & 1 & 1 & 0 & 16 \\
\hline \multicolumn{14}{|l|}{ Esocidae } \\
\hline Esox americanus & ANSP 176232 & 0 & 1 & $1 *$ & 1 & 1 & 1 & 0 & 0 & 1 & 1 & 0 & 8 \\
\hline \multicolumn{14}{|l|}{ Anguillidae } \\
\hline \multirow{2}{*}{\multicolumn{14}{|c|}{ Cyprinodontidae }} \\
\hline & & & & & & & & & & & & & \\
\hline Fundulus heteroclitus & ANSP 151931 & 0 & 1 & 1 & 1 & 1 & 0 & 0 & 0 & 1 & 1 & 0 & 6 \\
\hline
\end{tabular}


Tabela 11. Poros do canal temporal (ótico e pós-ótico) da linha lateral cefálica do material examinado como grupo externo à ordem Characiformes. PO1 a PO5 indicam poros ao longo do canal pós-ótico, 01 indica poro abrindo-se ainda sobre o trecho ótico do canal temporal, LL1 indica o primeiro poro da linha lateral corporal. Números indicam a ausência (zero) ou presença (um) de determinado poro ao longo do canal. Total indica a somatória de poros ao longo do canal. Asteriscos $\left(^{*}\right)$ indicam poros supranumerários, de modo que cada asterisco represente um poro extra relacionado a determinada posição. A condição expressa por "in." demonstra característica inaplicável para determinado táxon, que pode estar relacionada à ausência do canal ou a modificações estruturais do mesmo.

\begin{tabular}{|c|c|c|c|c|c|c|c|c|c|}
\hline \multicolumn{10}{|c|}{ Poros ao longo do canal temporal do grupo externo à Characiformes } \\
\hline & № САT. & 01 & PO1 & PO2 & PO3 & PO4 & PO5 & LL1 & Total \\
\hline \multicolumn{10}{|l|}{ Gymnotidae } \\
\hline Gymnotus cf. carapo & LIRP 10129 & 0 & 1 & 1 & 1 & 0 & 0 & 1 & 3 \\
\hline \multicolumn{10}{|l|}{ Electrophoridae } \\
\hline Electrophorus sp. & MPEG 25442 & 0 & 1 & 1 & 1 & 0 & 0 & 1 & 3 \\
\hline \multicolumn{10}{|l|}{ Hypopomidae } \\
\hline Brachyhypopomus pinnicaudatus & LIRP 6055 & 0 & 1 & 1 & 0 & 0 & 0 & 1 & 2 \\
\hline \multicolumn{10}{|l|}{ Sternopygidae } \\
\hline Sternopygus macrurus & LIRP 10209 & 0 & 1 & 1 & 1 & 0 & 0 & 1 & 3 \\
\hline \multicolumn{10}{|l|}{ Apteronotidae } \\
\hline Platyurosternarchus macrostoma & ANSP 192794 & 0 & 1 & 1 & 1 & 0 & 0 & 0 & 3 \\
\hline Sternarchorhynchus oxyrhynchus & ANSP 193959 & 0 & 1 & 1 & 1 & 0 & 0 & 0 & 3 \\
\hline \multicolumn{10}{|l|}{ Diplomystidae } \\
\hline Diplomystes mesembrinus & LBP 449 & 0 & 1 & 1 & 1 & 0 & 0 & 1 & 3 \\
\hline \multicolumn{10}{|l|}{ Clariidae } \\
\hline Clarias submarginatus & ANSP 67182 & 0 & 1 & 1 & 1 & 0 & 0 & 1 & 3 \\
\hline \multicolumn{10}{|l|}{ Cyprinidae } \\
\hline Barbus khudree & USNM 238933 & 1 & 1 & 1 & 1 & 1 & 0 & 1 & 5 \\
\hline Opsariichthys uncirostris & USNM 86470 & 1 & 1 & 1 & 1 & 1 & 1 & 1 & 6 \\
\hline Campostoma anomalum & USNM 200731 & 1 & 1 & 1 & 1 & 0 & 0 & 1 & 4 \\
\hline \multicolumn{10}{|l|}{ Chanidae } \\
\hline Chanos chanos & USNM 232325 & 1 & 1 & 1 & 1 & 1 & 1 & 1 & 6 \\
\hline \multicolumn{10}{|l|}{ Kneriidae } \\
\hline Kneria sp. & USNM 290762 & 1 & 1 & 1 & 1 & 0 & 0 & 1 & 4 \\
\hline \multicolumn{10}{|l|}{ Osteoglossidae } \\
\hline Osteoglossum bicirrhosum & USNM 198123 & 1 & 1 & 1 & 1 & 0 & 0 & 1 & 4 \\
\hline \multicolumn{10}{|l|}{ Elopidae } \\
\hline Elops saurus & USNM 128294 & $1^{*}$ & 1 & 1 & 1 & 1 & 1 & 1 & 7 \\
\hline \multicolumn{10}{|l|}{ Salmonidae } \\
\hline Salmo trutta & USNM 373790 & 1 & 1 & 1 & $1^{*}$ & 1 & 0 & 1 & 6 \\
\hline \multicolumn{10}{|l|}{ Galaxiidae } \\
\hline Galaxias vulgaris & USNM 399149 & in. & in. & in. & in. & in. & in. & in. & 0 \\
\hline \multicolumn{10}{|l|}{ Esocidae } \\
\hline Esox americanus & ANSP 176232 & 0 & 1 & 1 & 0 & 1 & 1 & 1 & 4 \\
\hline \multicolumn{10}{|l|}{ Anguillidae } \\
\hline Anguilla rostrata & ANSP 115537 & in. & in. & in. & in. & in. & in. & 1 & 1 \\
\hline \multicolumn{10}{|l|}{ Cyprinodontidae } \\
\hline Fundulus heteroclitus & ANSP 151931 & in. & in. & in. & in. & in. & in. & in. & 0 \\
\hline
\end{tabular}


Tabela 12. Poros do canal supratemporal da linha lateral cefálica do material examinado como grupo externo à ordem Characiformes. ST1 e ST2 indicam poros ao longo do canal supratemporal. Números indicam a ausência (zero) ou presença (um) de determinado poro ao longo do canal. Asteriscos $\left({ }^{*}\right)$ indicam poros supranumerários, de modo que cada asterisco represente um poro extra relacionado a determinada posição. A condição expressa por "in." demonstra característica inaplicável para determinado táxon, que pode estar relacionada à ausência do canal ou a modificações estruturais do mesmo.

\begin{tabular}{|c|c|c|c|}
\hline \multicolumn{4}{|c|}{ Lista de poros ao longo do canal supratemporal do grupo externo à Characiformes } \\
\hline & № CAT. & ST1 & ST2 \\
\hline \multicolumn{4}{|l|}{ Gymnotidae } \\
\hline Gymnotus cf. carapo & LIRP 10129 & 0 & 1 \\
\hline \multicolumn{4}{|l|}{ Electrophoridae } \\
\hline Electrophorus sp. & MPEG 25442 & 1 & 0 \\
\hline \multicolumn{4}{|l|}{ Hypopomidae } \\
\hline Brachyhypopomus pinnicaudatus & LIRP 6055 & 1 & 0 \\
\hline \multicolumn{4}{|l|}{ Sternopygidae } \\
\hline Sternopygus macrurus & LIRP 10209 & 1 & 1 \\
\hline \multicolumn{4}{|l|}{ Apteronotidae } \\
\hline Platyurosternarchus macrostoma & ANSP 192794 & 1 & 0 \\
\hline Sternarchorhynchus oxyrhynchus & ANSP 193959 & 1 & 0 \\
\hline \multicolumn{4}{|l|}{ Diplomystidae } \\
\hline Diplomystes mesembrinus & LBP 449 & in. & in. \\
\hline \multicolumn{4}{|l|}{ Clariidae } \\
\hline Clarias submarginatus & ANSP 67182 & in. & in. \\
\hline \multicolumn{4}{|l|}{ Cyprinidae } \\
\hline Barbus khudree & USNM 238933 & 1 & 1 \\
\hline Opsariichthys uncirostris & USNM 86470 & 1 & 1 \\
\hline Campostoma anomalum & USNM 200731 & $1^{*}$ & $1^{*}$ \\
\hline \multicolumn{4}{|l|}{ Chanidae } \\
\hline Chanos chanos & USNM 232325 & 1 & 1 \\
\hline \multicolumn{4}{|l|}{ Kneriidae } \\
\hline Kneria sp. & USNM 290762 & 1 & 1 \\
\hline \multicolumn{4}{|l|}{ Osteoglossidae } \\
\hline Osteoglossum bicirrhosum & USNM 198123 & 1 & 1 \\
\hline \multicolumn{4}{|l|}{ Elopidae } \\
\hline Elops saurus & USNM 128294 & $1^{* *}$ & $1^{* *}$ \\
\hline \multicolumn{4}{|l|}{ Salmonidae } \\
\hline Salmo trutta & USNM 373790 & $1^{* *}$ & $1 * * *$ \\
\hline \multicolumn{4}{|l|}{ Galaxiidae } \\
\hline Galaxias vulgaris & USNM 399149 & in. & in. \\
\hline \multicolumn{4}{|l|}{ Esocidae } \\
\hline Esox americanus & ANSP 176232 & in. & in. \\
\hline \multicolumn{4}{|l|}{ Anguillidae } \\
\hline Anguilla rostrata & ANSP 115537 & in. & in. \\
\hline \multicolumn{4}{|l|}{ Cyprinodontidae } \\
\hline Fundulus heteroclitus & ANSP 151931 & in. & in. \\
\hline
\end{tabular}


Tabela 13. Poros do canal pré-opercular da linha lateral cefálica do material examinado como grupo externo à ordem Characiformes. PR1 a PR7 indicam poros ao longo do canal pré-opercular. Números indicam a ausência (zero) ou presença (um) de determinado poro ao longo do canal. Total indica a somatória de poros ao longo do canal. Asteriscos (*) indicam poros supranumerários, de modo que cada asterisco represente um poro extra relacionado a determinada posição. A condição expressa por "in." demonstra característica inaplicável para determinado táxon, que pode estar relacionada à ausência do canal ou a modificações estruturais do mesmo.

\begin{tabular}{|c|c|c|c|c|c|c|c|c|c|}
\hline \multicolumn{10}{|c|}{ Poros ao longo do canal pré-opercular do grupo externo à Characiformes } \\
\hline & № САT. & PR1 & PR2 & PR3 & PR4 & PR5 & PR6 & PR7 & Total \\
\hline \multicolumn{10}{|l|}{ Gymnotidae } \\
\hline Gymnotus cf. carapo & LIRP 10129 & 1 & 1 & 1 & 1 & 0 & 1 & 1 & 6 \\
\hline \multicolumn{10}{|l|}{ Electrophoridae } \\
\hline Electrophorus sp. & MPEG 25442 & 1 & 0 & 1 & 1 & 1 & 0 & 1 & 5 \\
\hline \multicolumn{10}{|l|}{ Hypopomidae } \\
\hline Brachyhypopomus pinnicaudatus & LIRP 6055 & 1 & 1 & 1 & 1 & 0 & 1 & 1 & 6 \\
\hline \multicolumn{10}{|l|}{ Sternopygidae } \\
\hline Sternopygus macrurus & LIRP 10209 & 1 & 1 & 1 & 1 & 1 & 0 & 1 & 6 \\
\hline \multicolumn{10}{|l|}{ Apteronotidae } \\
\hline Platyurosternarchus macrostoma & ANSP 192794 & 1 & 1 & 1 & 0 & 0 & 0 & 1 & 4 \\
\hline Sternarchorhynchus oxyrhynchus & ANSP 193959 & 1 & 1 & 1 & 0 & 0 & 0 & 1 & 4 \\
\hline \multicolumn{10}{|l|}{ Diplomystidae } \\
\hline Diplomystes mesembrinus & LBP 449 & 1 & 0 & 1 & 1 & 1 & 0 & 1 & 5 \\
\hline \multicolumn{10}{|l|}{ Clariidae } \\
\hline Clarias submarginatus & ANSP 67182 & 1 & 0 & 1 & 1 & 0 & 0 & 1 & 4 \\
\hline \multicolumn{10}{|l|}{ Cyprinidae } \\
\hline Barbus khudree & USNM 238933 & 1 & 1 & 1 & 1 & 1 & 1 & 1 & 7 \\
\hline Opsariichthys uncirostris & USNM 86470 & 1 & $1^{* *}$ & 1 & 1 & 1 & 1 & 1 & 9 \\
\hline Campostoma anomalum & USNM 200731 & 1 & 0 & 1 & 1 & 1 & 1 & 1 & 6 \\
\hline \multicolumn{10}{|l|}{ Chanidae } \\
\hline Chanos chanos & USNM 232325 & 1 & $1^{*}$ & $1^{*}$ & $1^{*}$ & $1^{*}$ & 1 & 1 & 11 \\
\hline \multicolumn{10}{|l|}{ Kneriidae } \\
\hline Kneria sp. & USNM 290762 & 1 & 1 & 1 & 1 & 1 & 0 & 1 & 6 \\
\hline \multicolumn{10}{|l|}{ Osteoglossidae } \\
\hline Osteoglossum bicirrhosum & USNM 198123 & 1 & 1 & 1 & 1 & 1 & 1 & 1 & 7 \\
\hline \multicolumn{10}{|l|}{ Elopidae } \\
\hline Elops saurus & USNM 128294 & $1^{*}$ & $1^{*}$ & $1^{*}$ & $1^{*}$ & $1^{*}$ & $1^{*}$ & $1^{*}$ & 17 \\
\hline \multicolumn{10}{|l|}{ Salmonidae } \\
\hline Salmo trutta & USNM 373790 & $1^{*}$ & 1 & 1 & 1 & 1 & 1 & 1 & 8 \\
\hline \multicolumn{10}{|l|}{ Galaxiidae } \\
\hline Galaxias vulgaris & USNM 399149 & 1 & 1 & 1 & 1 & 1 & 1 & 0 & 6 \\
\hline \multicolumn{10}{|l|}{ Esocidae } \\
\hline Esox americanus & ANSP 176232 & 1 & 1 & 1 & 1 & 1 & 1 & 0 & 6 \\
\hline \multicolumn{10}{|l|}{ Anguillidae } \\
\hline Anguilla rostrata & ANSP 115537 & in. & in. & in. & in. & 0 & 0 & 1 & 1 \\
\hline \multicolumn{10}{|l|}{ Cyprinodontidae } \\
\hline Fundulus heteroclitus & ANSP 151931 & 1 & 1 & 1 & 1 & 1 & 1 & 1 & 7 \\
\hline
\end{tabular}


Tabela 14. Poros ao longo do canal mandibular do material examinado como grupo externo à ordem Characiformes. M1 a M5 indicam poros ao longo do canal mandibular. Números indicam a ausência (zero) ou presença (um) de determinado poro ao longo do canal. Total indica a somatória de poros ao longo do canal. Asteriscos (*) indicam poros supranumerários, de modo que cada asterisco represente um poro extra relacionado a determinada posição. A condição expressa por "in." demonstra característica inaplicável para determinado táxon, que pode estar relacionada à ausência do canal ou a modificações estruturais do mesmo.

\begin{tabular}{|c|c|c|c|c|c|c|c|}
\hline \multicolumn{8}{|c|}{ Poros ao longo do canal mandibular dos grupos externos à Characiformes } \\
\hline & № CAT. & M1 & M2 & M3 & M4 & M5 & Total \\
\hline \multicolumn{8}{|l|}{ Gymnotidae } \\
\hline Gymnotus cf. carapo & LIRP 10129 & $1^{*}$ & 1 & 1 & 1 & 1 & 6 \\
\hline \multicolumn{8}{|l|}{ Electrophoridae } \\
\hline Electrophorus sp. & MPEG 25442 & $1^{*}$ & 1 & 1 & 1 & 1 & 6 \\
\hline \multicolumn{8}{|l|}{ Hypopomidae } \\
\hline Brachyhypopomus pinnicaudatus & LIRP 6055 & $1^{*}$ & 1 & 1 & 1 & 1 & 6 \\
\hline \multicolumn{8}{|l|}{ Sternopygidae } \\
\hline Sternopygus macrurus & LIRP 10209 & $1^{*}$ & 1 & 1 & 1 & 1 & 6 \\
\hline \multicolumn{8}{|l|}{ Apteronotidae } \\
\hline Platyurosternarchus macrostoma & ANSP 192794 & $1^{*}$ & 1 & 1 & 1 & 1 & 6 \\
\hline Sternarchorhynchus oxyrhynchus & ANSP 193959 & 1 & 1 & 1 & 1 & 1 & 5 \\
\hline \multicolumn{8}{|l|}{ Diplomystidae } \\
\hline Diplomystes mesembrinus & LBP 449 & 1 & 1 & 1 & 1 & 1 & 5 \\
\hline \multicolumn{8}{|l|}{ Clariidae } \\
\hline Clarias submarginatus & ANSP 67182 & $1^{*}$ & 1 & 1 & 1 & 1 & 6 \\
\hline \multicolumn{8}{|l|}{ Cyprinidae } \\
\hline Barbus khudree & USNM 238933 & $1^{*}$ & $1^{*}$ & $1^{*}$ & $1^{*}$ & $1^{*}$ & 10 \\
\hline Opsariichthys uncirostris & USNM 86470 & 1 & $1^{*}$ & $1^{*}$ & 1 & 1 & 7 \\
\hline Campostoma anomalum & USNM 200731 & 0 & 1 & 1 & 1 & 1 & 4 \\
\hline \multicolumn{8}{|l|}{ Chanidae } \\
\hline Chanos chanos & USNM 232325 & 1 & 1 & 1 & 1 & 1 & 6 \\
\hline \multicolumn{8}{|l|}{ Kneriidae } \\
\hline Kneria sp. & USNM 290762 & 0 & 0 & 0 & 0 & 0 & 0 \\
\hline \multicolumn{8}{|l|}{ Osteoglossidae } \\
\hline Osteoglossum bicirrhosum & USNM 198123 & 1 & 1 & 1 & 1 & 1 & 6 \\
\hline \multicolumn{8}{|l|}{ Elopidae } \\
\hline Elops saurus & USNM 128294 & 1 & 1 & 1 & 1 & 1 & 20 \\
\hline \multicolumn{8}{|l|}{ Salmonidae } \\
\hline Salmo trutta & USNM 373790 & 1 & 1 & 1 & 1 & 1 & 9 \\
\hline \multicolumn{8}{|l|}{ Galaxiidae } \\
\hline Galaxias vulgaris & USNM 399149 & 0 & 0 & 1 & 1 & 0 & 2 \\
\hline \multicolumn{8}{|l|}{ Esocidae } \\
\hline Esox americanus & ANSP 176232 & 1 & 1 & 1 & 1 & 0 & 4 \\
\hline \multicolumn{8}{|l|}{ Anguillidae } \\
\hline Anguilla rostrata & ANSP 115537 & $1^{*}$ & 1 & 1 & 1 & 1 & 6 \\
\hline \multicolumn{8}{|l|}{ Cyprinodontidae } \\
\hline Fundulus heteroclitus & ANSP 151931 & 1 & 1 & 1 & 1 & 0 & 4 \\
\hline
\end{tabular}


Anexo - Material Examinado 


\section{Material incluido na análise: Characiformes}

ALESTIDAE: Brycinus imberi; MZUSP 84537; 80 ind., 1 C\&S (45,5 mm CP). África, Benin, Kouffo, Rio Mono nos arredores de Kpoba, próximo à fronteira entre Benin e Togo. Alestes longipinnis; USNM 285665, 20 ind., 3 C\&S (47,04 - 55,81 mm CP). África, Togo, cidade de Togbe Kope. Chalceus epakros; LIRP 7538; 4 ind., 1 musc., 2 C\&S (69,13 mm CP). Brasil, estado de Roraima, município de Bonfim, Rio Arraias, afluente do rio Tacutu, drenagem do Rio Branco.

ANOSTOMIDAE : Anostominae: Sartor sp.; LIRP 8176; 9 ind., 2 C\&S (70,6 - 76,7 mm CP). Brasil, Mato Grosso, Sapezal, Rio Juruena, PCH Telegráfica. Leporellus vittatus; LIRP 8857; 2 ind., 1 C\&S (74,03 mm CP). Brasil, Mato Grosso, Tangará da Serra, Córrego do Dimba, drenagem Paraná-Paraguai.

ACESTRORHYNCHIDAE: Acestrorhynchus cf. microlepis; LIRP 7534; 10 ind., 1 musc., 1 C\&S (90,1 mm CP). Brasil, Roraima, Caracaraí, Igarapé Água Boa, drenagem do Rio Branco.

CHILODONTIDAE: Caenotropus schizodon; LIRP 8333; 6 ind., 1 C\&S (90,6 mm CP). Brasil, Mato Grosso, Sapezal, Rio Juruena, drenagem do Rio Tapajós.

CITHARINIDAE: Citharinus latus; MZUSP 84480; 17 ind., 1 C\&S (99,3 mm CP). África, Benin, Ouémé, Azowlissé, Rio Ouémé.

CURIMATIDAE: Steindachnerina insculpta; LIRP 8257; 7 ind., 1 C\&S (73,8 mm CP). Brasil, São Paulo, Luiz Antônio, Lagoa do Diogo, Estação Ecológica de Jataí, drenagem do Rio Mogi.

CRENUCHIDAE: Crenuchinae: Crenuchus spilurus; MZUSP 93343; 56 ind., 1 C\&S (39,1 mm CP). Brasil, Amazonas, Igarapé no Rio Tiquié, comunidade da Serra do Mucura. Characidiinae: Characidium cf. xanthopterum; LIRP 4470; 45 ind., 1 C\&S (39,5 mm CP). Brasil, Mato Grosso, Alto Araguaia, Córrego Carneiro, drenagem do Rio Araguaia. Melanocharacidium cf. auroradiatum; LIRP 10257; 4 ind., 1 C\&S (48,2 mm CP). Brasil, Mato Grosso, Sapezal, Rio Juruena, Drenagem do Rio Tapajós. Characidium gomesi; LIRP 8239; 9 ind., 1 C\&S (57,5 mm CP). Brasil, São Paulo, Ribeirão Corrente, Córrego do Japão, drenagem do Rio Grande.

CTENOLUCIIDAE: Boulengerella cuvieri; LIRP 10888; 2 ind., 1 C\&S (128,1 mm CP). Brasil, estado de Rondônia, Município de Machadinho D’Oeste, Rio São João, drenagem do Rio Madeira.

CYNODONTIDAE: Hydrolycus tatauaia; LIRP 10527; 2ind., 1 C\&S (129,7 mm CP). Brasil, Rondônia, Machadinho D'Oeste, canal principal do Rio Machado, drenagem do Rio Madeira.

CHARACIDAE: Characinae: Galeocharax knerii; LIRP 11165; 1 C\&S (90,1 mm CP). Brasil, Minas Gerais, Ituiutaba, Rio Tijuco, afluente do Rio Paranaíba, Drenagem do Alto Paraná. Bryconinae: Brycon nattereri; LIRP 3590; 1 C\&S (75,4 mm CP). Brasil, Minas Gerais, Paracatu, Ribeirão da Batalha, drenagem do Paranaíba. Triportheinae: Triportheus angulatus; LIRP 4560; 14 ind., 3 C\&S (77,7 mm CP). Brasil, Amazonas, Manaus, Paraná do 
Janauacá, entrada do Lago do Castanho, drenagem do Rio Amazonas. Iguanodectinae: Iguanodectes variatus; LIRP 10745; 6 ind., 1 C\&S (61,8 mm CP). Brasil, Rondônia, Machadinho D'Oeste, Igarapé Preto, drenagem do Rio Madeira. Incertae sedis: Creagrutus meridionalis; LIRP 5467; 20 ind., 2 C\&S (40,8 - 45,4 mm CP). Brasil, Mato Grosso do Sul, Bonito, Córrego Mutum, fazenda Fortaleza. Astyanax altiparanae; LIRP 11163; 2 ind. C\&S (61,5 - 61,6 mm CP). Brasil, São Paulo, Marília, açude dentro da propriedade particular Sítio São Judas Tadeu, drenagem do Rio do Peixe. Stygichthys thyphops; LESCI 000230 / 002; 1 exemplar C\&S (38,9 mm CP). Brasil, Minas Gerais, Jaíba, poço Mandioqueu, drenagem do Rio São Francisco.

DISTICHODONTIDAE: Neolebias unifasciatus; MZUSP 84531; 221 ind., 1 C\&S (31,5 mm CP). África, Benin, Ahoyéye, rio margeando a rodovia RN3, entre Pobe e Ketou. Eugnatichthys sp.; USNM 326206; 1 C\&S (91,1 mm CP). África, sem dados de coleta ou localidade. Xenocharax spilurus; USNM 227693; 1 C\&S (101,6 mm CP). África. Gabão, cidade de Alomba, Lago Ezanga.

ERYTHRINIDAE: Hoplias aimara; LIRP 9108; 5 ind., 1 C\&S (77,2 mm CP). Brasil, Mato Grosso, Sapezal, PCH Cidezal, Rio Juruena, drenagem do Rio Tapajós.

GASTEROPELECIDAE: Thoracocharax stellatus; MZUSP 105502; 38 ind., 1 C\&S (48,1 mm CP). Brasil, Pará, Marabá, Rio Tapirapé, acampamento Tatuzão, montante da base Bacaba da REBIO Tapirapé.

HEMIODONTIDAE: Hemiodus argenteus; LIRP 8305; 1 C\&S (94,3 mm CP). Brasil, Mato Grosso, Sapezal, Rio Juruena, drenagem do Rio Tapajós.

HEPSETIDAE; Hepsetus odoe; MZUSP 84469; 6 ind., 1 C\&S (116,7 mm CP). África, Benin, Ouémé, Azowlissé, Rio Ouémé.

LEBIASINIDAE: Pyrrhulina cf. australis; LIRP 8590; 11 ind., 1 C\&S (36,2 mm CP). Brasil, Mato Grosso, Sapezal, Rio Juruena, Drenagem do Rio Tapajós. Parátipos de Lebiasina melanoguttata; MZUSP 99610; 3 ind., 1 C\&S (72,1 mm CP). Brasil, Pará, Altamira, tributário do Rio Curuá, drenagem do Rio Iriri.

PARODONTIDAE: Apaeirodon affinis; LIRP 8232; 8 ind., 1 C\&S (76,7 mm CP). Brasil, estado de São Paulo, Ribeirão Corrente, Córrego do Japão na fazenda Solapão, drenagem do Rio Grande.

PROCHILODONTIDAE: Prochilodus brevis; LIRP 3781; 1 C\&S (77,5 mm CP). Brasil, Pernambuco, poça em trecho praticamente seco do riacho do Gentio, drenagem do São Francisco.

SERRASALMIDAE: Serrasalmus spilopleura; LIRP 1941; 4 ind., 1 C\&S (69,3 mm CP). Brasil, São Paulo, entre os municípios de Cerqueira Cesar e Piraju, rio Paranapanema, abaixo da UHE de Jurumirim, drenagem do Alto Paraná. Utiaritichthys esguiceroi; LIRP 9045; 13 ind., 1 C\&S (60,3 mm CP). Brasil, Mato Grosso, Sapezal, Rio Juruena, drenagem do Rio Tapajós.

ERYTHRINOIDEA FAM. NOV.: Parátipo de Erythrinoidea sp. nov.; INPA 26241; 1 C\&S (49,7 mm CP). Brasil, Amazonas, Manaus, Rio Amazonas. 


\section{Material incluido na análise: Grupo-externo}

\section{GYMNOTIFORMES.}

GYMNOTIDAE: Gymnotus cf. carapo; LIRP 10129; 9 ind., 1 C\&S (122,6 mm CT). Brasil, São Paulo, Gavião Peixoto, Rio Jacaré-Guaçu, drenagem do Rio Tietê.

ELECTROPHORIDAE: Electrophorus sp.; MPEG 25442; 1 C\&S (99,1 mm CT). Brasil, Pará, llha de Marajó, Rio Goiapi, drenagem do Amazonas.

HYPOPOMIDAE : Brachyhypopomus pinnicaudatus; LIRP 6055; xx ind., 1 C\&S (135,7 mm CT). Brasil, São Paulo, Cravinhos, drenagem do Rio Pardo.

STERNOPYGIDAE: Sternopygus macrurus; LIRP 10209; 17 ind., 1 C\&S (195,1 mm CT). Brasil, estado do Mato Grosso, Sapezal, Rio Juruena, drenagem do Rio tapajós.

APTERONOTIDAE: Platyurosternarchus macrostoma; ANSP 192794; 1 C\&S (149,5 mm CT). América do Sul, Brasil, Amazonas, Rio Juruá, a jusante de Pauapixuna. Sternarchorhynchus oxyrhynchus; ANSP 193959; 1 C\&S (180,1 mm CT). América do Sul, Brasil, Amazonas, Rio Negro, 21,5 km a montante de Manaus, 5,7 km a montante de Tarumã-Açú.

\section{SILURIFORMES.}

DIPLOMYSTIDAE: Diplomystes mesembrinus; LBP 449; 1 C\&S (90,1 mm CP). Argentina, Departamento Pasos de Indios, Província de Chubut, Los Altares, Rio Chubut.

CLARIIDAE: Clarias submarginatus; ANSP 67182; 2 C\&S (76,5 - 83,3 mm CP). África, Congo, província de Uele, Rio Uele.

\section{CYPRINIFORMES.}

CYPRINIDAE: Barbus khudree; USNM 238933; 5 ind., 3 C\&S (64,5 -79,5 mm CP). Ásia, SriLanka, província de Teldeniya, tributário do Rio Mahaweii Ganga, 3,8 milhas ao leste de Teldeniya. Opsariichthys uncirostris; USNM 86470; 15 ind., 1 C\&S (107,1 mm CP). Ásia, China, Hangchow Chekiang. Campostoma anomalum; USNM 200731; 71 ind., 2 C\&S (62,3$88,6 \mathrm{~mm}$ CP). América do Norte, Estados Unidos da America, estado do Tennessee, província de Sevier, Seviervillee, córrego Walden.

\section{GONORYNCHIFORMES.}

CHANIDAE: Chanos chanos; USNM 232325; 4 ind., 1 C\&S (73,8 mm CP). Oceania, Papua-Nova Guiné, província de Akib, ilha Hermit.

KNERIIDAE: Kneria sp.; USNM 290762; aprox. 40 ind., 1 C\&S (53,8 mm CP). África, Angola, Rio Coropolo. 


\section{SALMONIFORMES.}

SALMONIDAE: Salmo trutta; USNM 373790; 9 ind., 1 C\&S (95,2 mm CP). América do norte, Estados Unidos, estado de North Dakota, província de Lander, córrego Birch.

\section{OSTEOGLOSSIFORMES.}

OSTEOGLOSSIDAE: Osteoglossum bicirrhosum; USNM 198123; 160 ind., 1 C\&S (69,1 mm CP). Brasil, Roraima, Rio Xeriuni, drenagem do Rio Negro.

\section{ELOPIFORMES.}

ELOPIDAE: Elops saurus; USNM 128294; 4 ind., 2 alc. (119,82 - 166,1 mm CP). América do Norte, Estados Unidos da América, estado de Louisiana, cidade de Grande Isle.

\section{OSMERIFORMES.}

GALAXIIDAE: Galaxias vulgaris; USNM 399149; 17 ind., 1 C\&S $(80,6 \mathrm{~mm}$ CP). Oceania, Nova Zelândia, Ilha Sul, Rio Rubicon.

\section{ESOCIFORMES.}

ESOCIDAE: Esox americanus; ANSP 176232; 1 C\&S (88,1 mm CP). América do Norte, Estados Unidos da América, estado de Georgia, Rio Savannah, milha 76,5.

\section{ANGUILLIFORMES.}

ANGUILLIDAE: Angiulla rostrata; ANSP 115537; 2 C\&S (118,7 - 143,6 mm CP). América do Norte, Estados Unidos da América, estado de South Carolina, Rio Savannah.

\section{CYPRINODONTIFORMES.}

CYPRINODONTIDAE; Fundulus heteroclitus; ANSP 151931; 1 C\&S (50,9 mm CP). América do Norte, Estados Unidos da América, estado de New Jersey, córrego Woodbury entre rodovia Interstate 295 e Avenida Grove. 


\section{Material Suplementar.}

\section{CHARACIFORMES.}

ALESTIDAE: Alestes dentex; USNM 371017; 1 C\&S (137,4 mm SL). África, Egito, Rio Nilo, cidade de Aswan. Brycinus macrolepidotus: USNM 303918; 2 C\&S (122,1 - 124,9 mm CP). Africa, Camarões; província do sudeste, drenagem do Rio Munaya, Korup. Brycinus nurse: USNM 339724; 1 C\&S ( 109,2 mm CP). Nigeria, Rio Gamgam, campo Gashaka.

CHARACIDAE: Parátipos de Erythrocharax altipinnis; MZUSP 110999; 2 alc. $(22,8-26,2)$. Brasil, Pará, Altamira, ponte sobre a rodovia BR 163, Rio Curuá, bacia do Rio Iriri, drenagem do Rio Xingu.

CTENOLUCIIDAE: Boulengerella maculata; USNM 319781; 1 C\&S (59,1 mm CC). Brazil, Rondonia, Rio Machado. Parátipo de Boulengerella xyrekes; USNM 319783; 1 C\&S (57,9 mm CC). Brazil, Amazonas, Rio Negro, Marauia. Boulengerella lucius: USNM 319782; 1 C\&S (42,5 mm CC). Brasil, Pará, Oriximiná, Rio Trombetas. Material de aquário. Ctenolucius beani: USNM 293169; 1 C\&S (45,1 mm CC). Panama, província de Darien, Rio Tuira. Ctenolucius hujeta: USNM 121334; 1 C\&S (43,6 mm CC). Venezuela, Rio San Pedro, Maracaibo Basin. Boulengerella lateristriga: MZUSP 113312; 2 ind., 1 C\&S (96,1 mm CP). Brasil, Roraima, Caracaraí, Igarapé Pretinho, afluente do Igarapé Caicubi, Rio Jufari.

CYNODONTIDAE: Rhaphiodon vulpinus; LIRP 7799; 1 C\&S (165,2 mm CP). Brasil, Goiás, Paranaiguara, Córrego Mateira, afluente do rio Paranaíba, drenagem do Alto Paraná.

DISTICHODONTIDAE: Paradistichodus dimidiatus; USNM 231556; 9 ind. 1 C\&S (47,4 mm CP). África, Gana, província de Gbefi, Rio Dayi.

ERYTHRINIDAE: Hoplias malabaricus; USNM 226265; 2 C\&S (22,6 - 23,8 mm CP). Venezuela, estado de Monagas, Rio Orinoco, Laguna El Guatero.

LEBIASINIDAE: Piabucina panamensis; USNM 304211; 1 C\&S (72,5 mm CP). Panama, Rio Cardenas.

\section{ALBULIFORMES.}

ALBULIDAE: Albula vulpes: USNM 315407; 2 C\&S (120,2 - 131,2 mm CP). Território britânico do Oceano Índico.

HIODONTIFORMES.

HIODONTIDAE: Hiodon tergisus; USNM 266581; 5 ind., 2 C\&S (88,2-88,7 mm CP). América do Norte, Estados Unidos, Alabama, Stokton, Rio Tensaw.

\section{OSTEOGLOSSIFORMES.}

NOTOPTERIDAE: Notopterus notopterus; USNM 315408; 2 C\&S (141,1 - 137,5 mm CP). Ásia, Tailândia, província de Ubon Ratchathand, Mercado matinal de Ubon. 
OSTEOGLOSSIDAE: Arapaima gigas; USNM 117528; 4 ind., 1 MUSC (142,2 mm CP) e 1 C\&S (128,1 mm CP). América do Sul. Material de aquarismo, sem informações de localidade.

\section{ELOPIFORMES.}

ELOPIDAE: Elops smithi; USNM 121694; 1 C\&S (116,6 mm CP). Venezuela, Salina Rica, 5 km. de Maracaibo. Megalops atlanticus: USNM 73758; 3 ind. (58,5 - 74,3 mm CP). América Central, Fajardo, Porto Rico.

\section{CLUPEIFORMES.}

DENTICIPITIDAE: Denticeps clupeoides; MZUSP 84776; 1 C\&S (42,1 mm CP). África, Benin, Rio Iguidi próximo à antiga estação de trem de Gbokoutou.

\section{SALMONIFORMES.}

SALMONIDAE: Salmo trutta; USNM 238517; 2 ind., 1 C\&S (137,2 mm CP). Estados Unidos da América, estado de Pennsylvania, província de Fayette. Pequeno córrego próximo ao Colégio Sandy Creek.

\section{ESOCIFORMES.}

ESOCIDAE: Esox americanus; USNM 391633; 1 C\&S (123,5 mm CP). Estados Unidos da América. Sem dados de localidade.

\section{CYPRINIFORMES.}

CYPRINIDAE: Nocomis micropogon; USNM 200732; 7 ind., 2 C\&S (67,3 - 70,6 mm CP). Estados Unidos da América, estado do Tennessee, província Sevier, córrego Walden ao longo da rodovia Wear Valley.

COBITIDAE: Cobitis taenia; USNM 271746; 11 ind. 1 C\&S (70,7 mm CP). Europa, lugoslávia, Podgorica, Rio Orahovstica, Lago Skadar.

CATOSTOMIDAE: Catostomus commersonii: USNM 399375; 4 ind., 1 C\&S (67,2 mm CP). América do Norte, Estados Unidos da América, estado de Ohio, cidade de Bellville, córrego Cedar Fork.

\section{SILURIFORMES.}

ICTALURIDAE: Ameiurus catus; ANSP 151402; 1C\&S (96,2 mm CP). Estados Unidos da América, estado de South Carolina, Rio Edisto.

\section{ATHERINIFORMES.}

ATHERINIDAE: Atherina duodecimalis; ANSP 88581; 4 C\&S (53,5 - 56,5 mm CP). Oceano Índico, Tailândia, província de Rayong, cidade de Siam. 